\title{
Estado nutricional de escolares de 7 a 10 anos de idade: diagnóstico e comparação de métodos
}

\section{Claudia Regina Koga}

Dissertação apresentada ao Programa de Pós-Graduação em Saúde Pública da Faculdade de Saúde Pública da Universidade de São Paulo para obtenção do Título de Mestre em Saúde Pública.

Área de Concentração: Nutrição Orientadora: Profa Dra Denise Pimentel Bergamaschi

\section{São Paulo}

2005 
Autorizo, exclusivamente para fins acadêmicos e científicos, a reprodução total ou parcial desta dissertação. Em caso de utilização é obrigatória a citação da fonte no texto, com a respectiva referência bibliográfica.

Citação sugerida: Koga CR. Estado Nutricional de escolares de 7 a 10 anos de idade: diagnóstico e comparação de métodos. São Paulo; 2005. [Dissertação de Mestrado - Faculdade de Saúde Pública da Universidade de São Paulo/USP].

Assinatura:

Data: 


\section{DEDICATÓRIA}

Aos meus pais Antonio Koga e Alice Koga, pela dedicação, e pelo amor e carinho doados aos filhos.

Ao amor da minha vida Rogério Ogusuko, pelo companheirismo, amor, carinho e pela sua infinita paciência comigo.

Aos meus irmãos Fábio, Lígia e Marcelo, pela alegria em tê-los como irmãos. 


\section{AGRADECIMENTOS}

À Profa Dra DENISE PIMENTEL BERGAMASCHI, pela orientação cuidadosa prestada, oportunidade fornecida e pelo incentivo na realização deste trabalho acadêmico.

À JULICRISTIE MACHADO DE OLIVEIRA e THAÍS ARTHUR, pela ajuda imprescindivel na coleta de dados, leitura cuidadosa do trabalho final e sobretudo pela amizade.

À Profa Dra ANA MARIA DIANEZI GAMBARDELLA, pela "co-orientação" prestada.

À Profa Dra SUELI GODOY AGOSTINHO GIMENO e Profa Dra MARIA HELENA D`AQUINO BENÍCIO, pelas oportunas sugestões prestadas ao presente trabalho.

Ao Prof Dr WOLNEY LISBOA CONDE, Prof Dr JOSÉ MARIA PACHECO E SOUZA, à SUSANA MARIA REBELO SAMPAIO DA PAZ e ao ALEX ANTONIO FLORINDO pelas sugestões prestadas no decorrer da pesquisa.

À Profa Dra MARIA PASTOR VALERO, pela oportunidade de poder iniciar o curso de mestrado.

À Profa Dra MARIA DO ROSÁRIO DIAS DE OLIVEIRA LATORRE e YEDA NOGUEIRA pelas sugestões metodológicas e auxilio na utilização de ferramentas de microinformática.

Às diretoras, coordenadoras, aos alunos, pais, professores e funcionários das escolas pela colaboração com a pesquisa.

Ao Laboratório de Avaliação Nutricional de Populações - LANPOP, pelo empréstimo dos equipamentos utilizados na coleta dos dados.

À CAPES (Coordenação de Aperfeiçoamento de Pessoal de Nível Superior), pela bolsa de estudo concedida. 


\section{RESUMO}

Koga CR. Estado nutricional de escolares de 7 a 10 anos de idade: diagnóstico e comparação de métodos. São Paulo; 2005. [Dissertação de Mestrado - Faculdade de Saúde Pública da USP].

Objetivo. Avaliar o estado nutricional de escolares de 7 a 10 anos de idade. Métodos. Estudo de corte transversal em duas escolas públicas da região sudeste da cidade de São Paulo. Utilizou-se medidas de peso, estatura, circunferências braquial e da cintura (CC), pregas cutâneas tricipital e da panturrilha, bioimpedância elétrica (BIA), e medidas derivadas (área gordurosa do braço (AGB), percentual de gordura total (\%GT), índice de massa corporal (IMC) e índice de estatura para a idade). $O$ estado nutricional foi avaliado segundo o percentil do IMC em relação à curva CDC 2000. Os dados foram apresentados em tabelas e gráficos; para comparações foram utilizados Intervalos de Confiança de $95 \%$, valores medianos e estratégia de Bland e Altman. Foram investigados o desempenho e propostos pontos de corte para medidas de composição corporal no diagnóstico de estados nutricionais inadequados com base em curvas ROC e tgROC. Resultados. A prevalência de desnutrição, risco de sobrepeso e sobrepeso observados foram de 4,5\%, $15,3 \%$ e $11 \%$, respectivamente. As características antropométricas e de composição corporal observadas, em geral, apresentaram magnitudes maiores quando comparadas a outros estudos envolvendo outras populações. O \%GT depende do método utilizado para sua estimação. As pregas cutâneas apresentaram melhor desempenho do que a BIA para classificar excesso de peso utilizando-se o IMC como referência. A CC e a AGB apresentaram bom desempenho para identificar risco de doenças cardiovasculares. Conclusões. Escolares, na faixa de 7 a 10 anos apresentam alta reserva de gordura, indicando a necessidade de ações de saúde.

Palavras chaves: Antropometria, Composição Corporal, Crianças, Curva ROC, Estado nutricional, Impedância elétrica. 


\section{ABSTRACT}

Koga CR. Nutritional status of schoolchildren aged 7 to 10 years: diagnostic and comparison of methods. São Paulo; 2005. [MSc Dissertation - School of Public Health/University of São Paulo].

Objective. To assess the nutritional status of schoolchildren from 7 to 10 years of age. Methods. Cross-sectional study in two public schools in the southeastern region of the city of São Paulo. Weight, height, arm and waist circumference (WC), skinfold thickness (triceps and calf), bioelectrical impedance (BIA) and derived indices and measurements (upper arm fat area (AFA), percentage of body fat (\%BF), body mass index (BMI) and height to age index) were used. The nutritional status was assessed by BMI percentile using CDC 2000 curve. The data was presented in tables and graphics; comparisons were carried out by $95 \%$ confidence intervals, median values and Bland and Altman analysis. The performances of measures of body composition to identify inadequate nutritional status and cut-off values were studied based on ROC and TGROC curves. Results. The following prevalences were observed: underweight, $4.5 \%$, risk of overweight, $15.3 \%$ and overweight $11.0 \%$. The median of the anthropometric measurements and body composition were greater than in previous studies. The percentage of fat values depends on the method used for its estimation. Skinfold thickness presents better performance than BIA to identify excess of weight when BMI was taken as a reference method. WC and AFA showed good performance to identify risk of cardiovascular diseases. Conclusions. Schoolchildren from 7 to 10 years of age present high levels of body fat reserve. These conditions indicate the need for health interventions.

Key words: Anthropometry, Body Composition, ROC Curve, Nutritional Status, Children, Electric Impedance. 
1 INTRODUÇÃo

página

$1.2 \quad$ Avaliação do estado nutricional....................................................... 3

1.2.1 Antropometria: peso, estatura, pregas cutâneas e circunferências corporais. 3

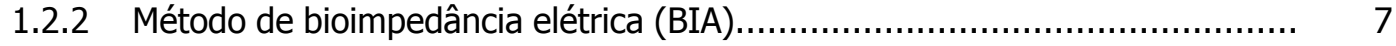

1.2.3 Critérios de diagnóstico do estado nutricional........................................ 10

1.3 Transição nutricional....................................................................... 12

1.4 Comparação de métodos de avaliação do estado nutricional......................... 13

1.5 Justificativa do presente estudo.......................................................... 15

2 OBJetIVOS

3

\section{MÉTODOS}

3.1 Local e população de estudo........................................................... 17

3.2 Tipo de amostragem..................................................................... 18

3.3 Aspectos éticos............................................................................ 18

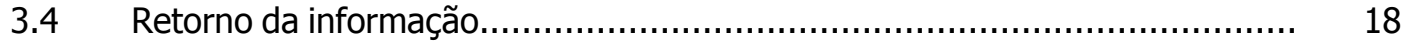

3.5 Atividades de extensão...................................................................... 19

3.6 Coleta dos dados......................................................................... 19

3.7 Medidas de composição corporal derivadas................................................. 21

3.8 Escore de atividade física.................................................................... 22

3.9 Mensuração de características sócio-econômicas........................................ 23

3.10 Padronização dos procedimentos de coleta............................................. 24

3.11 Aspectos metodológicos da realização da Bioimpedância elétrica.................. 25

3.12 Digitação dos dados.............................................................................. 25

3.13 Análise estatística............................................................................. 26

4

\section{Resultados}

$4.1 \quad$ Características da área de estudo....................................................... 30

4.2 Características da população de estudo................................................ 31

$4.3 \quad$ Características antropométricas............................................................ 33

4.4 Estado nutricional..................................................................... 45

4.5 Composição corporal........................................................................... 47

4.6 Comparação entre o percentual de gordura total estimado pela BIA e pelas pregas cutâneas tricipital e da panturrilha.

4.7 Análise de desempenho dos percentuais de gordura total estimado pela BIA e pelas pregas cutâneas tricipital e da panturrilha em relação à classificação do estado nutricional pelo percentil do IMC.

4.8 Comparação entre o percentual de gordura total estimado pela BIA e pelas pregas cutâneas tricipital e da panturrilha e a circunferência da cintura.......

4.9 Descrição da área gordurosa do braço e comparação com o percentual de gordura total estimado pela BIA......

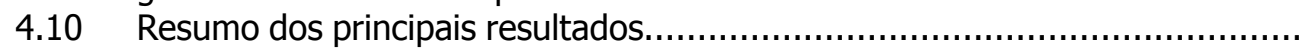
DISCUSSÃo 


\section{Índice de mapas, fotos, figuras, quadros, tabelas, gráficos}

\begin{tabular}{|c|c|c|}
\hline Tipo & Número & Título \\
\hline Mapa & 1 & 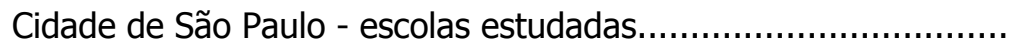 \\
\hline Foto & 1 & Escola1. \\
\hline
\end{tabular}

$\begin{array}{llll}\text { Figura } & 1 & \text { Locais de posicionamento de eletrodos para realização da BIA.... } 20\end{array}$

2 Questionário de avaliação de prática de atividade física.............. 23

Quadro $\quad 1 \quad$ Estado nutricional - classificação pelo IMC................................ 12

$2 \quad$ Critérios de categorização das variáveis quantitativas contínuas.. 27

3 Critérios de categorização do percentual de gordura total estimado pela BIA e pelas pregas cutâneas tricipital e da panturrilha.....

4 Resumo dos principais resultados encontrados.........................

Tabela 1 Construção do escore de atividade física.

2 Distribuição de escolares segundo sexo, idade, escolaridade materna, renda per capita, condições de moradia e escore de atividade física. Duas escolas públicas de São Paulo, 2004.

3 Distribuição de escolares segundo IMC, percentil de estatura/idade (E/I) e escola.

4 Peso médio, estatura média, desvio padrão (dp) e IC (95\%) segundo sexo e idade (anos). Duas escolas públicas de São Paulo, 2004...

5 Diferença relativa (\%) e absoluta de peso e estatura segundo

6 IMC médio, desvio padrão (dp) e IC (95\%) segundo sexo e

3

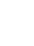
idade (anos) .......................................................................

7 Diferença relativa (\%) e absoluta de IMC segundo idade.

8 Prega cutânea média tricipital e da panturrilha, desvio padrão (dp) e IC(95\%) segundo sexo e idade (anos). Duas escolas públicas de São Paulo, 2004.

9 Diferença relativa (\%) e absoluta da prega cutânea tricipital e da panturrilha de acordo com a idade (anos)............................

10 Circunferência média braquial e da cintura, desvio padrão (dp) e IC(95\%) segundo sexo e idade (anos)....

11 Diferença relativa (\%) e absoluta (cm) da circunferência braquial e da cintura segundo idade.

12 Distribuição de escolares segundo classificação do estado nutricional com base no percentil do IMC e percentil de estatura/idade segundo sexo. Duas escolas públicas de São Paulo, 2004......

13 Distribuição de escolares segundo classificação do estado nutricional com base no percentil do IMC e percentil de estatura/idade segundo idade (anos). Duas escolas públicas de São Paulo, 2004...

14 Percentual de gordura corporal total média pela BIA e pelas pregas cutâneas tricipital e da panturrilha, desvio padrão (dp) e IC $(95 \%)$ segundo sexo e idade (anos). Duas escolas públicas de São Paulo, 2004... 
15 Distribuição de escolares segundo avaliação de gordura corporal estimado pela BIA e pelas pregas cutâneas tricipital e da panturrilha, segundo sexo. Duas escolas públicas de São Paulo, 2004.

16 Distribuição de escolares segundo avaliação de gordura corporal estimado pela BIA e pelas pregas cutâneas tricipital e da panturrilha, segundo idade. Duas escolas públicas de São Paulo, 2004.

17 Diferença relativa (\%) e absoluta do percentual de gordura corporal total calculado pela BIA e pelas pregas cutâneas tricipital e da panturrilha.

18 Limites de concordância e IC (95\%) para a diferença entre percentuais de gordura total estimados pela BIA e pelas pregas cutâneas e dos limite inferior e superior dos limites de concordância, segundo idade.

19 Limites de concordância e IC (95\%) para a diferença entre percentuais de gordura total estimados pela BIA e pelas pregas cutâneas e dos limite inferior e superior dos limites de concordância, segundo sexo.

20 Valores de pontos de corte que igualam (otimizam) a sensibilidade e especificidade, da estimativa de gordura total pela BIA e pelas pregas cutâneas, em relação ao percentil do IMC, segundo sexo, idade e método. Duas escolas públicas de São Paulo, 2004.

21 Distribuição de escolares segundo condição nutricional, método diagnóstico e sexo. Duas escolas públicas de São Paulo, 2004 ...

22 Valores de sensibilidade (\%), especificidade (\%), eficiência, índice de Youden e área sob a curva ROC para o percentual de gordura total estimado pela BIA e pelas pregas cutâneas tricipital e da panturrilha, considerando-se como referência o percentil do IMC segundo sexo para escolares de 7 a 10 anos..

23 Valores de pontos de corte que igualam (otimizam) a sensibilidade e especificidade, da circunferência da cintura, tomando-se como referência os percentuais de gordura total pela BIA e pelas pregas cutâneas, segundo sexo.

24 Valores de sensibilidade (\%), especificidade (\%), eficiência, índice de Youden e área sob a curva ROC para a circunferência da cintura considerando-se como referências o percentual de gordura total estimado pela BIA e pelas pregas cutâneas tricipital e da panturrilha, segundo sexo para escolares de 7 a 10 anos.

25 Área gordurosa do braço média, desvio padrão (dp) e IC(95\%) segundo sexo e idade (anos). Duas escolas públicas de São Paulo, 2004..... Diferença relativa (\%) e absoluta $\left(\mathrm{mm}^{2}\right)$ da área gordurosa do braço segundo idade.....

27 Valores de pontos de corte que igualam (otimizam) a sensibilidade e especificidade, da área gordurosa do braço, tomando-se como referência os percentuais de gordura total pela BIA, segundo sexo. 
28 Valores de sensibilidade (\%), especificidade (\%), eficiência, índice de Youden e área sob a curva ROC para a área gordurosa do braço considerando-se como referências o percentual de gordura total estimado pela BIA, segundo sexo para escolares de 7 a 10 anos. Duas escolas públicas de São Paulo, 2004.

Gráfico 1 Distribuição acumulada de escolares segundo peso $(\mathrm{kg})$ e idade. Duas escolas públicas de São Paulo, 2004.

2 Distribuição acumulada de escolares segundo estatura $(\mathrm{cm})$ e idade. Duas escolas públicas de São Paulo, 2004

$3 a$ e $3 b$ Medianas de peso $(\mathrm{kg})$ em relação à idade de escolares de duas escolas públicas de São Paulo em 2004 e de crianças americanas

$4 a$ e $4 b$ Medianas de estatura $(\mathrm{cm})$ em relação à idade de escolares de duas escolas públicas de São Paulo em 2004 e de crianças americanas

Distribuição acumulada de escolares segundo IMC $\left(\mathrm{kg} / \mathrm{m}^{2}\right)$ e idade. Duas escolas públicas de São Paulo, 2004.

6a e 6b Medianas de IMC $\left(\mathrm{kg} / \mathrm{m}^{2}\right)$ em relação à idade de escolares de duas escolas públicas de São Paulo em 2004 e de crianças americanas

7 Distribuição acumulada de escolares segundo prega cutânea tricipital $(\mathrm{mm})$ e idade. Duas escolas públicas de São Paulo, $2004 .$.

8 Distribuição acumulada de escolares segundo prega cutânea da panturrilha $(\mathrm{mm})$ e idade. Duas escolas públicas de São Paulo, 2004.

9a e 9b Medianas de prega cutânea tricipital $(\mathrm{mm})$ em relação à idade de escolares de duas escolas públicas de São Paulo em 2004 e de crianças americanas

10 Distribuição acumulada de escolares segundo circunferência braquial $(\mathrm{cm})$ e idade. Duas escolas públicas de São Paulo, 2004.

11 Distribuição acumulada de escolares segundo circunferência da cintura $(\mathrm{cm})$ e idade. Duas escolas públicas de São Paulo, $2004 .$.

12a e 12b Medianas de circunferência braquial $(\mathrm{cm})$ em relação à idade de escolares de duas escolas públicas de São Paulo em 2004 e de crianças americanas.

$13 a$ e 13b Medianas de circunferência da cintura $(\mathrm{cm})$ em relação à idade de escolares de duas escolas públicas de São Paulo em 2004 e de crianças britânicas

14 Distribuição de escolares segundo classificação do estado nutricional com base no percentil do IMC em relação à população de referência. Duas escolas públicas de São Paulo, 2004.

15 Distribuição de escolares segundo classificação do estado nutricional com base no percentil do Índice de Estatura/idade (E/I) em relação à população de referência. Duas escolas públicas de São Paulo, 2004.

Distribuição acumulada de escolares segundo percentual de gordura corporal total pela BIA e pelas pregas cutâneas tricipital e da panturrilha para ambos os sexos, segundo idade (anos). Duas escolas públicas de São Paulo, 2004. 
17a e 17b Distribuição de escolares segundo percentual de gordura total estimado pela BIA e pelas pregas cutâneas tricipital e da panturrilha, segundo sexo. Duas escolas públicas de São Paulo, 2004.

18a e 18b Diagrama de Bland e Altman - distribuição de escolares segundo valores médios e diferenças do percentual de gordura total estimado pela BIA e pelas pregas cutâneas tricipital e da panturrilha. Duas escolas públicas de São Paulo, 2004.................

19 Curva TGROC. Valores de sensibilidade e especificidade do percentual de gordura total estimado pela BIA para escolares de 10 anos do sexo feminino.

20 Área da curva ROC segundo métodos para estimar percentuais de gordura total

21a e 21b Distribuição de escolares segundo percentual de gordura corporal estimado pela BIA e circunferência da cintura, segundo sexo. Duas escolas públicas de São Paulo,

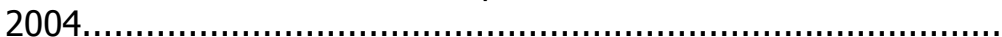

22a e 22b Distribuição de escolares segundo percentual de gordura corporal estimado pelas pregas cutâneas tricipital e da panturrilha e circunferência da cintura, segundo sexo. Duas escolas públicas de São Paulo, 2004. Freqüência acumulada de escolares segundo área gordurosa do braço e idade em anos. Duas escolas públicas de São Paulo, 2004.

24a e 24b Medianas da área gordurosa do braço $\left(\mathrm{mm}^{2}\right)$ em relação à idade de escolares de duas escolas públicas de São Paulo em 2004 e de crianças americanas

1 Autorização da escola para a realização do estudo

2 Consentimento livre e esclarecido

3 Carta enviada aos pais informando sobre resultados das medidas

4 Procedimentos para mensurações de variáveis antropométricas

5 Instrumento de coleta de dados antropométricos e da BIA

6 Avaliação da qualidade dos dados durante o estudo

7 Questionário de atividade física

8 Questionário de dados sócio-demográficos

9 Padronização dos procedimentos para tomada de medidas

10 Confiabilidade do questionário de atividade física

11 Aspectos metodológicos da realização da BIA

12 Distribuição de escolares segundo medidas antropométricas e composição corporal 
13 Variabilidade das variáveis antropométricas e da composição corporal segundo sexo e idade

14 Curvas TGROC do percentual de gordura total (BIA) e pregas, segundo sexo

15 Distribuição de escolares segundo percentual de gordura corporal e circunferência da cintura, segundo sexo e idade. Duas escolas públicas de São Paulo, 2004

16 Comparação dos valores medianos de características do estado nutricional com os valores de outras populações de referência. 
Lista de siglas e abreviaturas

$\mathrm{AB}$ - Área do braço

ACT - Água corporal total

AGB - Área gordurosa do braço

AMB - Área muscular do braço

ANOVA - Análise de variância

BIA - Bioimpedância elétrica

CB - Circunferência braquial

CC - Circunferência da cintura

CDC - Centers for Disease Control and Prevention

CV - Coeficiente de variação

DCV - Doença cardiovascular

$\mathrm{dp}$ - Desvio padrão

DXA - Dual-energy-x-ray-absorptiometry

E/I - Estatura para idade

IC(95\%) - Intervalo de confiança de $95 \%$

Icc - Intraclass corelation coeficient (coeficiente de correlação intraclasse)

IMC - Índice de massa corporal

LI - limite de confiança

MLG - Massa livre de gordura

NCHS - National Center for Health Statistics

OMS - Organização Mundial da Saúde

PCT - Prega cutânea tricipital

PP - Prega cutânea da panturrilha

$\mathrm{R}$ - Resistência

$r$ - Coeficiente de correlação de Pearson

ROC - Receiver Operating Characteristic

TGROC - Two Graph Receiver Operating Characteristic

Xc - Reactância

WHO - World Health Organization

Z - Impedância 


\section{1 - INTRODUÇÃO}

\section{1 - Considerações iniciais sobre o estado nutricional de indivíduos}

O estado nutricional assume grande importância na determinação da saúde de indivíduos. A desnutrição, o sobrepeso e a obesidade são estados nutricionais indicativos de problemas que podem afetar o adequado desenvolvimento e interferir nos processos de saúde/doença.

A desnutrição na infância constitui uma condição que pode acarretar problemas para a criança e deixar seqüelas que surgirão na idade adulta. Entre as crianças desnutridas, pode-se observar aumento de enfermidades infecciosas, retardo do desenvolvimento psicomotor, dificuldades no aproveitamento escolar, diminuição da estatura e da capacidade produtiva na idade adulta (MONTEIRO e CONDE 2000).

$\mathrm{Na}$ desnutrição ocorre a falta de gordura necessária para manutenção adequada das funções fisiológicas e, se presente, representa um risco à saúde. A gordura é necessária na formação da membrana celular, como isolante térmico, no armazenamento de energia e vitaminas lipossolúveis, no funcionamento do sistema nervoso e sistema reprodutor, bem como no crescimento e maturação durante a puberdade (HEYWARD e STOLARCZYK 2000). Entretanto, pode ocorrer o excesso de gordura que, por sua vez, aumenta o risco de desenvolvimento de doenças, tais como as cardiovasculares, hipertensão, diabetes tipo II, doença pulmonar obstrutiva, osteoartrite e certos tipos de câncer (NATIONAL INSTITUTES OF HEALTH [NIH] 1985).

No Brasil, as doenças cardiovasculares representam a principal causa de morte e, excluindo-se as doenças relacionadas à gestação e ao parto, mais da metade dos leitos hospitalares do Sistema Único de Saúde são ocupados por pacientes com enfermidades cardiovasculares, gastrointestinais, câncer e diabetes (PRATA 1992). 
Problemas de saúde relacionados à gordura corporal não afetam somente os adultos. Existe indicação que crianças com gordura corporal relativa maior do que $30 \%$ para meninas e $25 \%$ para meninos apresentam risco de moderado a alto para o desenvolvimento futuro de doenças coronarianas (LOHMAN 1992).

Segundo SOAR (2004), assim como os adultos, na presença de gordura central, as crianças também podem sofrer os efeitos da síndrome plurimetabólica: tolerância à glicose diminuída, diabetes mellitus, resistência à insulina, hipertensão arterial sistêmica, dislipidemia, obesidade visceral e albuminúria.

O risco à saúde relacionado à gordura inclui, além da quantidade, a distribuição da mesma e sua concentração, principalmente na região abdominal (gordura intra-abdominal ou visceral). Segundo BJORNTORP (1985), a gordura visceral prediz melhor doenças cardiovasculares e metabólicas do que a quantidade total de gordura.

Estudos têm alertado para $\mathrm{o}$ aumento da obesidade em crianças, apontando para a possibilidade de crianças obesas tornarem-se adultos obesos. Sendo assim, a avaliação precoce do estado nutricional assume grande importância na identificação do problema, permitindo intervenções com vistas ao controle e prevenção de doenças relacionadas ao excesso ou falta de peso (DIETZ 1998, MUST e col. 1991).

Estudos relacionados ao estado nutricional do grupo etário de 7 a 10 anos são relativamente poucos. Em buscas realizadas nas bases bibliográficas MEDLINE e LILACS e biblioteca eletrônica SCIELO, utilizando-se as palavras-chave: ("NUTRITIONAL ASSESSMENT"[MESH] OR OBESITY [MESH] OR UNDERNUTRITION [MESH] OR "NUTRITIONAL STATUS" OR ANTHROPOMETRY) AND (BRAZIL*[TW] OR BRASIL*[TW]) AND (CHILD*[MESH] OR SCHOOLCHILD* [TW]), verificou-se que de 161 artigos de estudos brasileiros identificados a partir de 1969, 76 (47\%) envolviam avaliação antropométrica em crianças menores de 6 anos de idade, 37 (23\%) envolviam escolares de primeira à quarta série (faixa etária aproximada de 7 a 10 anos) e o restante abordava faixas etárias 
maiores de 10 anos ( $n=24,15 \%)$ ou não se referiam a um grupo etário específico $(n=25,15 \%)$.

\section{2 - Avaliação do estado nutricional}

Segundo MELLO (2002), a avaliação do estado nutricional constitui etapa fundamental na qual se verifica a adequação do crescimento e das proporções corporais, de um ou de um grupo de indivíduos segundo padrões de crescimento esperados. A avaliação do estado nutricional pode ser feita pela análise de medidas e índices antropométricos, por métodos bioquímicos, exame clínico, por inquéritos de consumo alimentar e por métodos que avaliam a composição corporal: hidrodensitometria, espectrometria do potásssio, hidrometria, infravermelho próximo, bioimpedância elétrica (BIA), ultra-sonografia, ressonância nuclear magnética, tomografia computadorizada e DEXA (dual-energy-x-ray-absorptiometry) (SIGULEM e col. 2000).

A escolha do método de avaliação do estado nutricional está vinculada ao objetivo, ao custo, ao tempo disponível para realização, ao grupo populacional a ser estudado, ao nível de dificuldade e de habilidade requeridos, à receptividade por parte da população e aos possíveis riscos envolvidos (SIGULEM e col. 2000).

\subsection{1 - Antropometria: peso, estatura, pregas cutâneas e circunferências corporais.}

A antropometria tem sido utilizada na avaliação do estado nutricional por mais de um século e consiste na avaliação das dimensões físicas e da composição do corpo humano, sem necessitar de uso de exames laboratoriais. Tem sido amplamente utilizada na infância e adolescência principalmente por aspectos relacionados ao baixo custo, à facilidade de execução e à inocuidade (LUKASKI 1987, WHO 1986, HEYWARD e STOLARCZYK 2000, SIGULEM e col. 2000). 
A avaliação do estado nutricional pela antropometria envolve a coleta de dados de características corporais tais como peso, estatura, pregas cutâneas, circunferências corporais, que irão compor índices antropométricos que serão comparados com populações de referência tais como a de Cole e col. (2000) e a do Centers for Diseases Control (CDC), 2000 (http://cdc/gov/growthcharts).

\section{Peso e estatura}

O peso e a estatura (altura, comprimento) são essenciais na avaliação do estado nutricional (atual e pregresso) e na identificação de necessidades calóricas, devendo ser analisados segundo a idade e sexo (MARTINS 2001, SIGULEM 2000).

Pela aferição do peso e da estatura pode-se calcular, entre outros, o índice de massa corporal (IMC) e o índice de estatura para idade.

Índice de massa corporal (IMC)

O índice de massa corporal (IMC) definido por $\frac{\text { Peso(kg) }}{\mathrm{Altura}(\mathrm{m})^{2}}$, tem sido utilizado para a avaliação do estado nutricional e identificação de excesso de peso (risco de sobrepeso e sobrepeso) em qualquer faixa etária, sendo de utilidade na estimação da prevalência de excesso de peso em populações (DIETZ 1999, ROLLAND-CACHERA 1982). Uma característica importante deste índice é que, em nível individual, não está necessariamente associado à quantidade de tecido adiposo, já que não fornece informações sobre a composição corporal. Indivíduos com o mesmo IMC podem apresentar diferentes quantidades de gordura corporal e, conseqüentemente, diferentes riscos de morbidade. Esta característica do IMC foi relatada por DANIELS (1997) e ANJOS (2003), que encontraram valores de IMC semelhantes em crianças pré-púberes do sexo masculino e feminino, mas com maior percentual de gordura corporal entre as meninas. 
Não existe concordância na literatura sobre a utilidade do IMC como um indicador de gordura corporal em crianças (DIETZ e BELLIZZI 1999). Alguns autores afirmam que o IMC não tem relação direta com distúrbios biológicos em crianças, e não tem apresentado boa correlação estatística com gordura corporal, especialmente em crianças menores (MAYNARD e col. 2001, WILLET 1990). HIGGINS (2001) argumenta que as definições de obesidade baseadas nos valores de IMC (específicos para sexo e idade) podem superestimar (overpredict) o nível de massa gorda e, portanto, superestimar a prevalência de obesidade especialmente em crianças. Entretanto, ELLIS e col. (1999) afirmam que o IMC pode descrever adequadamente as características de adiposidade em populações de crianças, mas não em nível individual. A utilização do IMC como indicador de gordura é defendida também por outros pesquisadores que concluem que além de ser um método simples e acurado, é válido para medida de gordura em crianças e adolescentes (POSKITT 1995, DIETZ 1999, ROLLANDCACHERA 1982)

\section{Índice de estatura para idade}

$\mathrm{O}$ índice de estatura para idade reflete $\mathrm{o}$ crescimento linear obtido por crianças e seu déficit (também chamado de "stunting") e, neste caso, indica crescimento esquelético comprometido devido às inadequadas condições de vida ou de saúde, inclusive nutrição, por um longo período de tempo. No entanto, um baixo índice de estatura para idade não necessariamente indica um déficit de estatura para idade, podendo ser reflexo do baixo potencial genético de crescimento linear da criança (WHO 1995).

Segundo a Organização Mundial da Saúde - OMS (WHO 1995), a prevalência de déficit de estatura/idade, nos países menos desenvolvidos, varia de 5 a $65 \%$. MONTEIRO e col. (1984) constataram que cerca de $90 \%$ do déficit estatural das crianças de 7 anos já estava estabelecido aos 24 meses de idade. É provável que uma criança com déficit estatural aos 7 anos 
tenha sofrido grandes privações no passado devido a sua condição social (LEI e col. 1993).

Medidas de peso e estatura apesar de amplamente utilizadas, não fornecem informações sobre composição corporal. Sendo assim, informações adicionais fornecidas por pregas cutâneas ou circunferências corporais, são de utilidade (HEYWARD e STOLARCZYK 2000).

\section{Circunferências do braço e cintura e pregas cutâneas}

A circunferência do braço é uma medida antropométrica de fácil mensuração. Apesar de não requerer o uso de equipamento sofisticado, se não for coletada por avaliadores bem treinados pode apresentar grande variabilidade, comprometendo sua confiabilidade (WHO 1995). É de utilidade na identificação de crianças com risco de óbito, principalmente em situações de emergência, por exemplo em campos de refugiados. É considerada como melhor preditora de mortalidade quando comparada ao índice de peso para a altura. O estudo de MEI e col. (1998) analisou o desempenho da circunferência braquial em relação à estatura de crianças americanas de 6 meses a 9 anos dos estudos National Health and Nutrition Survey I e II (NHANES I e II) e propuseram uma forma de identificar desnutrição utilizando estas duas medidas.

A circunferência braquial, quando utilizada de modo associado à prega cutânea tricipital, é útil na determinação da área gordurosa do braço (massa gorda do braço) que reflete o estado nutricional de crianças, melhor do que a utilização de cada medida independente (JELLIFFE 1966, GURNEY e JELLIFE 1972).

A circunferência da cintura é preditora de depósito de gordura visceral e é utilizada também na composição do indicador razão entre a circunferência da cintura e a do quadril, principalmente em estudos com população adulta.

Estudos mostram que a circunferência da cintura pode ser um indicador seguro para determinar adiposidade central, inclusive em crianças. 
Mas estudos sobre a determinação da distribuição de gordura em crianças são escassos (SOAR 2004).

As pregas cutâneas são importantes para avaliar a espessura do tecido adiposo subcutâneo. São freqüentemente utilizadas na estimação da gordura corporal total em situações clínicas e em pesquisas epidemiológicas apesar de dificuldades operacionais relacionadas à sua mensuração. A coleta de dados necessita de padronização de procedimentos e leitura em duplicata para assegurar a precisão, reprodutibilidade e qualidade dos resultados (ZAMBON e col. 2003, LUKASKI 1987, HEYWARD e STOLARCZYK 2000).

$\mathrm{O}$ uso de pregas cutâneas está baseado no conceito de que a gordura subcutânea resulta do balanço energético, refletindo a quantidade de reservas calóricas (FRANÇA e col. 1988, ZAMBON e col. 2003). Várias pregas cutâneas podem ser avaliadas isoladamente ou em conjunto. Entre estas é possível citar as pregas cutâneas tricipital, bicipital e da panturrilha, indicadoras de gordura periférica, e a subescapular e suprailíaca, indicadoras de gordura central (FREEDMAN e col. 1989). A prega cutânea mais utilizada em crianças é a tricipital (ZAMBON e col. 2003).

Dados publicados por FRANÇA e col. (1988) sobre escolares de 7 a 18 anos, da rede pública de ensino da Grande São Paulo, indicaram que escolares do sexo feminino apresentavam valores médios de prega cutânea tricipital maiores do que os do sexo masculino. Os autores concluíram que no sexo feminino os valores de prega cutânea tricipital aumentam com a idade e no sexo masculino, os valores tendem à estabilização entre 7 e 8 anos, com aumento considerável nas idades de 9 e 10 anos.

\subsection{2 - Método de Bioimpedância elétrica (BIA)}

O método da bioimpedância ou impedância bioelétrica corporal (BIA) tem sido utilizado, principalmente a partir da década de 80 , com o objetivo de predizer a composição do corpo humano em quantidade total de água, massa livre de gordura, in vivo, permitindo estimar o percentual de gordura corporal total (MÂNGIA 2000). 
A BIA é baseada na suposição que o corpo humano é um condutor iônico de formato cilíndrico no qual tecidos não adiposos, extra e intracelulares, atuam como resistores e capacitores, respectivamente. Pela aplicação de uma corrente elétrica de baixa intensidade alternada $(800 \mu \mathrm{A})$ em eletrodos fixados no corpo humano (injetores e detectores), sob um sinal de radiofreqüência fixo $(50-\mathrm{KHz})$, pode-se mensurar a mobilidade ou concentração de íons determinados pelo fluxo da corrente elétrica que passa pelos compartimentos corporais condutores que estejam entre os eletrodos. Assim, observa-se maior concentração de íons, e portanto menor resistência, em tecidos magros, bons condutores por serem ricos em água e eletrólitos (KHALED e col. 1988; KOTLER e col. 1996).

A impedância (Z) é a razão entre a voltagem e a corrente aplicada. É mensurada pela combinação da resistência $(R)$ e da reactância $(X c)$, escrita matematicamente como $Z^{2}=R^{2}+X c^{2}$, onde $X c$ e $R$ representam conteúdo intracelular e extracelular, respectivamente. A partir de equações matemáticas, e adotando-se a transformação de circuito eletrofisiológico corporal em série para paralelo, pode-se estimar a água corporal total (ACT) e a massa livre de gordura (MLG) (LUKASKI e col. 1996).

A BIA quando comparada a métodos padrão, tais como a densitometria hidrostática e a diluição de isótopos, em estudos de validade (MÂNGIA 2000) apresenta resultados nem sempre favoráveis. Alguns estudos evidenciam a existência de problemas da BIA, podendo resultar em super estimação da massa livre de gordura em obesos e subestimação em magros (DEURENBERG 1996). Por outro lado, KUSHNER e col., em 1992, investigaram a validação de equações de predição de água corporal total, segundo sexo para diversas idades, utilizando a BIA e concluíram que este método permite boa predição.

Para a avaliação do estado nutricional, pela composição corporal, de crianças é necessário utilizar equações de predição de massa livre de gordura (MLG) fornecidas para cada faixa etária e sexo. As mudanças sofridas pelas crianças em relação aos componentes do corpo: água, 
minerais, gordura, e proteínas, devido ao crescimento e à maturação, influenciam na densidade da massa livre de gordura (MLG) que aumenta constantemente com a idade. É conhecida a mudança do conteúdo da água da massa livre de gordura com o crescimento (envelhecimento), com diminuição desta (e aumento da gordura) com o passar da idade. Isto explica as diferenças na composição corporal da MLG em crianças e adultos (HEYWARD e STOLARCZYK 2000).

Sabe-se também que pessoas do sexo feminino apresentam percentual de gordura maior do que pessoas do sexo masculino para qualquer idade (FOMON 1982), sendo esta uma característica fisiológica. Em relação à idade, a evolução normal do tecido gorduroso compreende distintas etapas: durante o primeiro ano de vida ocorre rápido aumento da gordura corporal devido ao crescimento do tamanho das células adiposas. A esta fase, segue-se a diminuição do crescimento de tecido adiposo (segundo ano de vida), permanecendo estável por alguns anos. Paralelamente a estatura de crianças continua a aumentar, e a partir dos 6 anos de idade (segunda etapa), o tamanho e número de células gordurosas voltam a aumentar, com evolução visível pelo desenvolvimento da gordura corporal durante este período de crescimento. Algumas crianças podem começar o segundo aumento da gordura corporal aos 3 e outras aos 8 anos de idade (ROLLAN-CACHERA 1984). Assim, a estabilidade da gordura da infância à adolescência é variável em função do sexo, idade, peso ao nascer, entre outros fatores (SCHROEDER 1999).

Para a realização da BIA, deve-se estar atento para aspectos metodológicos importantes: o paciente deve estar num lugar livre de condutividade; os braços e pernas devem estar separados; a pele onde será fixado o eletrodo deve estar íntegra e a fixação dos mesmos deve ser antecedida de limpeza da área para garantir adesão (LUKASKI 1996, SCHELL e GROSS 1987, MÂNGIA 2000). Além disto, é possível que interferências ocorram na realização do exame pela temperatura e quantidade de água corporal: exercícios intensos que aumentam a temperatura tendem a 
diminuir o valor da resistência; o frio, assim como a desidratação, tende a aumentá-la. A ingestão de refeições 2 a 4 horas antes da realização da BIA pode também diminuir a resistência, em função do aumento da quantidade de íons no organismo (DEURENBERG e WESTSTRATE 1988, LUKASKI 1996, SCHELL e GROSS 1987).

Estas demandas metodológicas podem ser satisfeitas a partir da padronização de procedimentos de mensuração em fase anterior à coleta dos dados, assegurando a boa qualidade dos mesmos.

Possivelmente, pelo custo financeiro para realização da BIA, observase relativa escassez de publicações de estudos brasileiros que utilizam esta técnica para estimar a composição corporal em crianças de 7 a 10 anos.

\subsection{3 - Critérios de classificação do estado nutricional}

Para classificação do estado nutricional de crianças, que apresentam peso acima das eutróficas, o CDC2000 propõe a denominação risco de sobrepeso quando o IMC para a idade for igual ou maior que valor do IMC no percentil 85 e menor que o do percentil 95 da curva de referência; e sobrepeso quando a criança apresentar IMC para a idade igual ou maior que o valor do IMC no percentil 95 da curva de referência. O CDC não classifica obesidade com base no IMC, uma vez que este índice é inexato para medir gordura corporal (http://cdc/gov/growthcharts).

A OMS (WHO 1995) recomenda como critério para crianças, na faixa etária abaixo de 10 anos, o uso do escore z para avaliação do estado nutricional e classifica como sobrepeso valores do escore $z$ de peso/estatura ou do IMC acima de +2 desvios padrão da mediana da população de referência. Para adolescentes (10 - 19 anos), recomenda como ponto de corte para classificar risco de sobrepeso valores de IMC iguais ou maiores que o percentil 85 da curva de referência e, este mesmo ponto de corte, associado à presença de alto nível de gordura subcutânea (valor das pregas cutâneas subescapular e tricipital maiores ou iguais ao percentil 90 da curva de referência) para classificar obesidade (WHO 1995). 
COLE e col. (2000) propuseram a classificação do estado nutricional de menores de 18 anos a partir do uso de percentis da curva de referência e apresenta valores de ponto de corte segundo idade e sexo equivalentes aos valores de IMC $25 \mathrm{~kg} / \mathrm{m}^{2}$ (sobrepeso) e $30 \mathrm{~kg} / \mathrm{m}^{2}$ (obesidade), utilizados para população adulta. A denominação sobrepeso, por exemplo, é dada para meninos de 10 anos com valores de IMC maiores ou iguais a $19,84 \mathrm{~kg} / \mathrm{m}^{2} \mathrm{e}$ obesidade, para aqueles com valores de IMC iguais ou maiores que 24 $\mathrm{kg} / \mathrm{m}^{2}$.

MUST e col. (1991) chamam a atenção para diferenças nos valores de pontos de corte do IMC segundo sexo, idade e raça (meio ambiente) para indivíduos de 6 meses a 74 anos. Utilizam as denominações obeso e super obeso, tomando como pontos de corte os percentis 85 e 95 da curva de referência construída com dados do NHANES I.

Além dos termos risco de sobrepeso, sobrepeso, obesidade e super obesidade utilizados na avaliação do estado nutricional, observa-se na literatura falta de concordância nos pontos de corte utilizados para tais definições. Por exemplo, OGDEN (2002) classifica como risco de sobrepeso, pessoas com IMC igual ou maior ao percentil 85 e menor que o percentil 95 da curva de referência. 0 mesmo autor, no mesmo artigo, classifica como sobrepeso pessoas com IMC maior ou igual ao percentil 95 da curva de referência. Já SOTELO e col (2004) utilizam, como critério para sobrepeso, IMC maior que o percentil 85 , sendo que este mesmo critério é utilizado por FAITH e col. (2001) para classificar obesidade (Quadro 1). Esta falta de padronização nos critérios (e denominações) para classificação do estado nutricional causam dificuldades, principalmente, para comparações de prevalência e incidência de categorias do estado nutricional. 
Quadro 1 - Classificação do estado nutricional com base no percentil do IMC. Levantamento bibliográfico.

\begin{tabular}{|c|c|c|c|c|}
\hline Referência & $\begin{array}{l}\text { Denominaçã } \\
0\end{array}$ & Critério & Idade & Artigos/autores \\
\hline CDC 2000 & $\begin{array}{l}\text { Risco de } \\
\text { Sobrepeso }\end{array}$ & $\geq$ P85 e $<$ P95 & $<20$ anos & $\begin{array}{r}\text { TROIANO e FLEGAL. } 1998 \\
\text { SALBE e col. } 2002 \\
\text { WANG } 2002 \\
\text { OGDEN } 2002 \\
\text { MAYNARD } 2003 \\
\text { SOARES } 2003\end{array}$ \\
\hline CDC 2000 & '"Sobrepeso & $\geq 95$ & $<20$ anos & $\begin{array}{r}\text { SALBE e col. } 2002 \\
\text { OGDEN } 2002 \\
\text { SOARES } 2003 \\
\text { MAYNARD } 2003\end{array}$ \\
\hline Must & "'sobrepeso & $>$ P85 & $<12$ anos & $\begin{array}{r}1997 \\
\text { JOHNSON-DOWN e col. } \\
\text { SOTELO e col. } 2004\end{array}$ \\
\hline Cole & '"Sobrepeso & $\begin{array}{l}\text { Percentis escolhidos para } \\
\text { igualar os pontos de corte de } \\
\text { IMC de } 25 \mathrm{~kg} / \mathrm{m}^{2} \text {, utilizados } \\
\text { para adultos }\end{array}$ & Escolares & $\begin{array}{r}\text { GIUGLIANO e CARNEIRO } \\
2004\end{array}$ \\
\hline Não menciona & "'sobrepeso & $>95$ & $<20$ anos & $\begin{array}{l}\text { OGDEN e col. } 2002 \\
\text { STEELER e col. } 2002\end{array}$ \\
\hline Não menciona & Sobrepeso & $\geq 85$ & $<10$ anos & FREEDMAN e col. 1997 \\
\hline Não menciona & Sobrepeso & Ponto de corte P80 & $<18$ anos & MAYNARD e col. 2001 \\
\hline Não menciona & "'Sobrepeso & Ponto de corte 85 & $<20$ anos & $\begin{array}{r}\text { BARLOW e col. } 1998 \\
\text { ZEFERINO } 2003\end{array}$ \\
\hline Must & Obesidade & $>$ P95 & $\begin{array}{r}\text { Crianças, } \\
\text { adolescentes, } \\
\text { escolares }\end{array}$ & $\begin{array}{r}\text { DIETZ } 1998 \\
\text { SOTELO e col. } 2004\end{array}$ \\
\hline Não menciona & "'Obesidade & Ponto de corte P85 & $<20$ anos & $\begin{array}{r}\text { MUST e col. } 1991 \\
\text { BARLOW e col. } 1998\end{array}$ \\
\hline Não menciona & Obesidade & $\geq$ P85 & $7-10$ anos & TANASCESCU e col. 2000 \\
\hline Não menciona & Obesidade & $>$ P85 & $<19$ anos & $\begin{array}{l}\text { MONTEIRO POA } 2000 \\
\text { FAITH e col. } 2001\end{array}$ \\
\hline Não menciona & Obesidade & $\geq \mathrm{P95}$ & 8-14 anos & WANG 2002 \\
\hline Não menciona & Obesidade & Ponto de corte 95 & $<18$ anos & MAYNARD e col. 2001 \\
\hline Não menciona & $\begin{array}{l}\text { Sobrepeso/ } \\
\text { Obesidade }\end{array}$ & $>$ P85 & $<10$ anos & SAWAYA e ROBERTS 2003 \\
\hline Não menciona & Super obeso & Ponto de corte 95 & $<20$ anos & MUST e col. 1991 \\
\hline
\end{tabular}

\section{3 - Transição nutricional}

A transição nutricional consiste no impacto na situação nutricional de pessoas devido a mudanças rápidas de dieta e padrão de vida resultantes da urbanização, industrialização e desenvolvimento econômico de países. Convive-se atualmente com a ocorrência simultânea de déficit e de excesso de peso, com tendência de diminuição da ocorrência da primeira e aumento da segunda (TROIANO e FLEGAL 1998, BENÍCIO e MONTEIRO 2000, AMIGO 2003).

Vários estudos apontam para o aumento do sobrepeso e obesidade em crianças brasileiras abaixo de 10 anos (ABRANTES e col. 2002, BALABAN 
e Silva 2001, MONTEIRO e col. 1995). ABRANTES e col. (2002) descrevem prevalências de sobrepeso nas regiões Sudeste e Nordeste do Brasil de $8,2 \%$ e $11,9 \%$, respectivamente, entre menores de 10 anos, a partir de dados de 1997. BALABAN e SILVA (2001), utilizando dados de 1999, apresentam prevalências de sobrepeso e obesidade em alunos de escola privada em Recife/Pernambuco, na faixa etária de 6 a 9 anos, iguais a 34,3\% e 14,2\%, respectivamente.

MONTEIRO e col. (1995) em estudo com dados de 1974 a 1989 observaram estabilidade da obesidade entre crianças menores de 5 anos de idade, com prevalência em torno de 5\%. Em contrapartida, em crianças de 6 a 10 anos, consideraram que o sobrepeso está em ascensão, com aumento de $4,9 \%$ para $17,4 \%$ no período de 1974 a 1989 . GROSS (1990) encontrou prevalência de sobrepeso de $18 \%$ em escolas particulares do Rio de Janeiro, e ANJOS e col. (2003), em estudo probabilístico de escolares da rede pública deste mesmo estado, verificaram $16 \%$ de sobrepeso e $5 \%$ de obesidade.0 problema da obesidade não afeta somente o Brasil. Aproximadamente um terço de 12 países da América Latina superam a marca de $20 \%$ na prevalência de sobrepeso e obesidade segundo AMIGO (2003).

Frente à complexidade do perfil nutricional no Brasil, pode-se considerar a avaliação nutricional de populações, em especial no espaço escolar, uma ferramenta importante para compreensão do perfil nutricional de crianças e adolescentes no sentido de fornecer subsídios para a implantação de políticas e ações mais efetivas.

\section{4 - Comparação de métodos de avaliação do estado nutricional}

A comparação de métodos de avaliação do estado nutricional é utilizada em estudos que têm como objetivo, validação, concordância, correlação, associação e calibração de métodos diagnósticos (SNEDECOR 1967, GREINER 2003, FLEISS 1986, BLAND e ALTMAN 1986). 
Para o estudo de validação, é necessário definir-se um método de referência ("gold standard") que classifica indivíduos como tendo ou não determinada característica, avaliando-se o desempenho de um segundo método na classificação destes mesmos indivíduos em relação à presença da característica. Por exemplo, é possível classificar indivíduos como apresentando ou não sobrepeso utilizando como método de referência o IMC e avaliar o desempenho da BIA para diagnosticar sobrepeso. Neste caso, é necessário encontrar valores (pontos de corte) da BIA que otimizam a sensibilidade e especificidade na identificação de indivíduos corretamente classificados pela BIA como de sobrepeso ou não. Pode-se citar o estudo de LAZARUS e col. (1996) que investigaram a sensibilidade do percentual de gordura no diagnóstico de sobrepeso e obesidade tomando como referência o IMC.

Se o interesse residir na comparação de métodos de avaliação do estado nutricional sem que um deles seja considerado referência, é indicado o estudo de concordância. Se os métodos permitirem a utilização de mensurações em escala de razões contínuas, pode-se utilizar métodos estatísticos, tais como o coeficiente de correlação intraclasse e estratégia de Bland e Altman (FLEISS 1986, BLAND e ALTMAN 1986). Pode-se citar, como exemplo, a comparação da BIA com as pregas cutâneas tricipital e da panturrilha na estimação do percentual de gordura corporal total. GUTIN e col. (1996) em estudo que envolveu a comparação dos métodos DXA, BIA e pregas cutâneas subescapular e tricipital, para estimação do percentual de gordura, utilizaram para avaliação da equivalência das técnicas, o coeficiente de correlação intraclasse e a estratégia de BLAND e ALTMAN (1986), e concluíram que os métodos não devem ser utilizados indistintamente em função da falta de concordância entre eles.

Estudos que investigam o comportamento de um método de avaliação do estado nutricional em relação a outro são mais comuns na literatura: estudo da relação entre a dobra cutânea tricipital e o IMC (ZAMBON e col. 2003, MEI e col. 2002, SCHAEFER e col. 1998); entre a circunferência da 
cintura e o IMC (TAYLOR 2000, DANIELS e col. 2000, MAFFEIS e col. 2001, SOAR e col. 2004, GIUGLIANO e CARNEIRO 2004); entre o IMC e o percentual de gordura (MAYNARD e col. 2001; COCETTI 2001).

\section{5 - Justificativa do presente estudo}

Frente à escassez de estudos de avaliação do estado nutricional de crianças na faixa etária de 7 a 10 anos e considerando-se que esta antecede a puberdade, período de grandes mudanças corporais e possui grande potencial de receptividade a ações educativas, vê-se como importante o estudo do estado nutricional de indivíduos desta faixa etária.

Uma investigação sobre avaliação do estado nutricional do grupo etário de 7 a 10 anos exige o cumprimento de aspectos metodológicos, tais como a representatividade da amostra e a seleção aleatória de indivíduos para que fique assegurada a possibilidade de inferir os resultados para todo o grupo populacional. Em função de limitações financeiras e de tempo, somente foi possível propor um desenho metodológico em escolares de primeira à quarta série de duas escolas públicas da cidade de São Paulo, selecionadas a partir de critérios operacionais. Para fornecer elementos que auxiliem no julgamento sobre a validade externa do estudo, procura-se apresentar as características da região onde as escolas se situam.

Apesar da importância de se acompanhar o estado nutricional deste grupo etário e da existência de diferentes métodos de avaliação, ainda não existe consenso na literatura sobre a forma mais adequada para sua realização. A solução desta questão envolve o conhecimento das características dos métodos (operacionais, relativas às informações fornecidas, precisão e variabilidade das informações obtidas, custo, entre outros) e a realização de estudos comparativos, buscando-se um método fácil e seguro que identifique indivíduos com problemas nutricionais para que se possa precocemente direcionar ações de saúde apropriadas. 


\section{2 - OBJETIVOS}

\section{Objetivo Geral}

Avaliar o estado nutricional de escolares de 7 a 10 anos de idade.

\section{Objetivos específicos}

1- Descrever a população de estudo segundo características sóciodemográficas e de prática de atividade física.

2- Descrever a população de estudo segundo características antropométricas: peso $(\mathrm{kg})$, estatura $(\mathrm{cm})$, pregas cutâneas tricipital e da panturrilha $(\mathrm{mm})$, circunferências da cintura e do braço $(\mathrm{cm})$.

3- Caracterizar o estado nutricional de escolares com base no índice de massa corporal (IMC).

4- Descrever a população de estudo segundo composição corporal: percentual de gordura total estimada pela BIA e pelas pregas cutâneas tricipital e da panturrilha

5- Comparar os valores do percentual de gordura corporal total calculados pela BIA e os obtidos pelas pregas cutâneas tricipital e da panturrilha.

6- Analisar o desempenho dos métodos de estimação do percentual de gordura total (BIA e pregas) no diagnóstico de excesso de peso.

7- Investigar relação entre a circunferência da cintura e o percentual de gordura corporal total estimado pela BIA e pelas pregas cutâneas e analisar o desempenho da circunferência da cintura na classificação de risco de doenças cardiovascular.

8- Analisar o desempenho da área gordurosa do braço na classificação de risco de doenças cardiovascular 


\section{3 - MÉTODOS}

\section{1 - Local e População de estudo}

Constituiu a população de estudo escolares de 7 a 10 anos de idade, matriculados nas $1^{\mathrm{a}}, 2^{\mathrm{a}}, 3^{\mathrm{a}} \mathrm{e}$ $4^{a}$ séries de duas escolas públicas localizadas na região sudeste da cidade de São Paulo, no bairro da Água Rasa, denominadas neste estudo, escola 1 e escola 2 (Mapa 1).

A escola 1 (Foto1) pertence à rede estadual de ensino do Estado de São Paulo; atendeu, em 2004, 400 escolares no ensino fundamental ( $1^{\mathrm{a}}$ a $4^{\mathrm{a}}$ série), nos turnos da manhã (7:00 às 12:00 h) e da tarde (13:00 às 18:00 h). Nesta são servidas diária e gratuitamente duas refeições em cada turno.

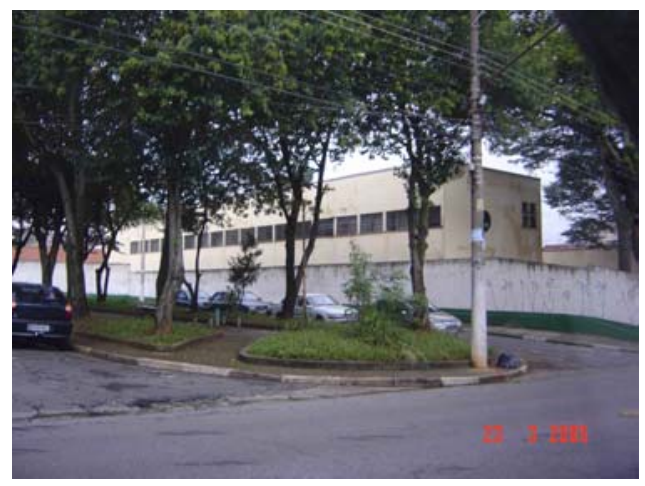

Foto 1 - Escola 1
Mapa 1 - Cidade de São Paulo - escolas estudadas

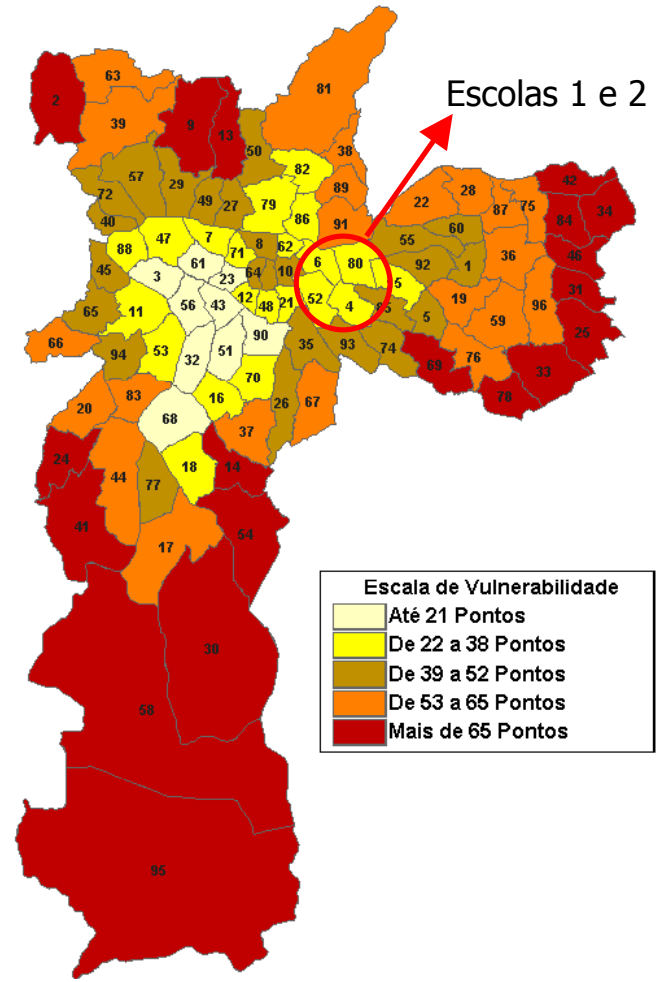

A escola 2 (Foto 2) pertence à rede municipal de ensino da cidade de São Paulo e atendeu, em 2004, 329 escolares no ensino fundamental ( $1^{\mathrm{a}}$ a $4^{\mathrm{a}}$ 
série) durante o turno da tarde (13:00 às $17: 00 \mathrm{~h}$ ), sendo o turno da manhã reservado para escolares de $5^{\mathrm{a}}$ à $8^{\mathrm{a}}$ série. É servida gratuitamente uma refeição em cada turno.

\section{2 - Tipo de Amostragem}

A amostragem de escolas não foi probabilística, tendo sido realizada por facilidade operacional e demonstração de interesse pelos diretores em participar do estudo. Em cada escola foi realizado o estudo universal de escolares de $1^{\mathrm{a}}$ à $4^{\mathrm{a}}$ séries do ensino fundamental, independente da idade, por motivos operacionais e éticos.

\section{3 - Aspectos éticos}

O projeto de pesquisa foi aprovado em 17 de novembro de 2003 pelo Comitê de Ética da Faculdade de Saúde Pública da Universidade de São Paulo/USP, seguindo as normas do Conselho Nacional de Saúde, contidas nas Resoluções números 196/96 e 251/97.

Obteve-se autorização prévia das escolas para realização do estudo (Anexo 1) e assinatura, pelos responsáveis pela criança, de termo de consentimento livre e esclarecido (Anexo 2).

\section{4 - Retorno da informação}

Após o término da coleta dos dados, os valores das medidas antropométricas, bem como um diagnóstico nutricional simplificado, foram enviados aos pais por carta (Anexo 3). Não foram feitas recomendações aos pais dos casos em que o escolar se encontrava fora da faixa de normalidade, a menos que houvesse interesse explícito pelos responsáveis. Nestes casos foram dadas orientações para buscar atendimento no Serviço de Saúde público do bairro. 


\section{5 - Atividades de extensão}

Ao final do trabalho de campo, foi realizado trabalho educativo com os escolares e professores, com participação da equipe de teatro de fantoches da Secretaria de Abastecimento e Agricultura do Estado de São Paulo.

\section{6 - Coleta de dados}

A coleta de dados foi realizada durante o período de aula, em sala própria, cedida pela direção de cada escola. O trabalho de campo foi realizado durante 22 dias na escola 1 (12/08/04 a 24/09/2004) e 16 dias na escola 2 (18/10/2004 a 11/11/2004).

Participaram da coleta de dados antropométricos quatro avaliadores treinados, com padronização dos procedimentos de coleta dos dados. 0 treinamento foi realizado no Laboratório de Avaliação Nutricional de Populações (LANPOP) do Departamento de Nutrição da Faculdade de Saúde Pública da USP.

As características antropométricas: peso, estatura, pregas cutâneas (tricipital e da panturrilha) e circunferências (cintura e braço) foram realizadas em duplicata, adotando-se os procedimentos recomendados pela OMS (WHO 1995) e HEYWARD e STOLARCZYK (2000) (Anexo 4), com o escolar sem calçado e sem agasalho. As pregas cutâneas tricipital e da panturrilha e a circunferência braquial foram medidas do lado direito. Cada avaliador mensurou todas as medidas em um primeiro momento e, em seqüência, realizou a segunda tomada após o término da primeira seqüência, evitando repetir a tomada da mesma medida imediatamente. Os avaliadores não tinham acesso aos valores das primeiras mensurações registradas. 0 instrumento para registro dos dados antropométricos e da bioimpedância é apresentado no Anexo 5.

Para a mensuração das medidas antropométricas, foram utilizados os seguintes equipamentos/instrumentos: estadiômetro ( $\mathrm{Seca}^{\circledR}$ ) para a estatura $(\mathrm{cm})$, fixado em suporte de madeira, balança digital $\left(\right.$ Tanita $\left.^{\circledR}\right)$ para o peso 
$(\mathrm{kg})$, adipômetro (Lange ${ }^{\circledR}$ ) para as pregas cutâneas tricipital e da panturrilha $(\mathrm{mm})$ e fitas métricas inextensíveis (Seca ${ }^{\circledR}$ ) para as circunferências da cintura e do braço $(\mathrm{cm})$.

Para a realização da BIA, posicionou-se o escolar em decúbito horizontal sobre uma maca construída com superfície isolante, solicitando-se aos escolares que retirassem relógios, anéis ou pulseiras metálicas. Posicionou-se a perna e o braço direitos dos escolares afastados 30 graus em relação ao corpo. Após limpeza com álcool, fixou-se quatro eletrodos, dois na mão direita e dois no pé direito conforme indica a Figura 1 , seguindo as recomendações do fabricante. Os eletrodos foram usados no máximo até quatro vezes.

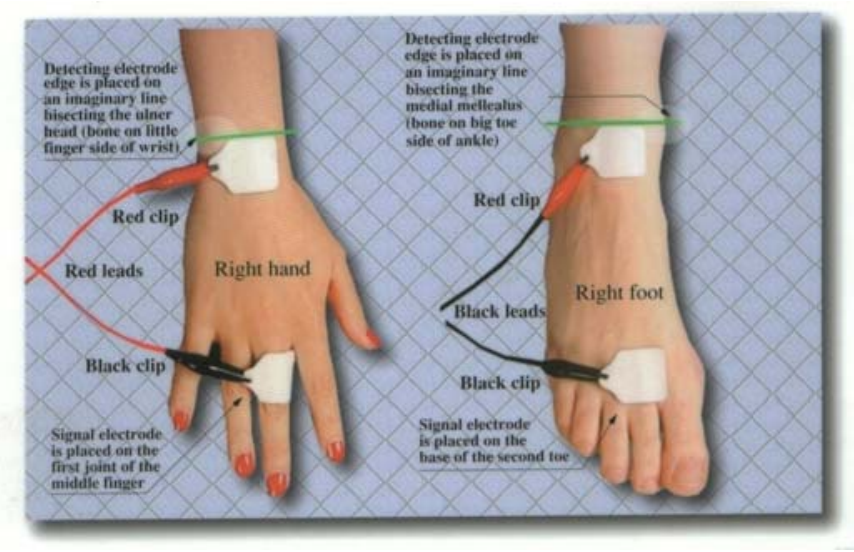

Figura 1 - Locais de posicionamento de eletrodos para a realização da BIA.

A bioimpedância foi realizada com utilização do aparelho bioimpedanciômetro (RJL systems ${ }^{\circledR}$ ) que fornece a leitura da resistência $(\Omega$ ) e reactância $(\Omega)$ como resultado da passagem da corrente elétrica.

Para o estudo da utilização de eletrodos em até 4 vezes, a cada 10 escolares, repetia-se o procedimento da BIA utilizando-se, na segunda realização, eletrodos novos. Nestes mesmos escolares, aplicou-se o questionário de atividade física em duplicata, para realização do estudo de confiabilidade do escore de atividade física (Anexo 6).

Os equipamentos/instrumentos utilizados no estudo foram cedidos pelo Laboratório de Avaliação Nutricional de Populações (LANPOP) do 
Departamento de Nutrição da Faculdade de Saúde Pública da Universidade de São Paulo/USP.

\section{7 - Medidas de composição corporal derivadas}

Para o cálculo das circunferências e áreas muscular e gordurosa do braço, foram utilizadas equações, apresentadas a seguir.

\section{Área muscular do braço (AMB) (FRISANCHO 1981)}

Sexo masculino: $A M B\left(\mathrm{~mm}^{2}\right)=\frac{(C B-(\pi x P C T))^{2}}{4 \pi}$

Sexo feminino: $A M B\left(\mathrm{~mm}^{2}\right)=\frac{P C T x C T}{2}-\frac{\pi x P C T^{2}}{4}$

onde, CB: Circunferência braquial e PCT: Prega cutânea tricipital

\section{Área gordurosa do braço (FRISANCHO 1981)}

$A G B\left(m^{2}\right): A B-A M B$, onde,

AB: Área do braço; $A B\left(\mathrm{~mm}^{2}\right)=\frac{\pi x d^{2}}{4}$, sendo $d=\frac{C B(m m)}{\pi}$

\section{Percentual de gordura corporal}

Utilizando-se dobras cutâneas (SLAUGHTER e col. 1988)

$$
\begin{aligned}
& \% \text { Gordura }_{\text {meninos }}=0,735(\Sigma \mathrm{PP}+\mathrm{PCT})+1 \\
& \% \text { Gordura }_{\text {meninas }}=0,610(\Sigma \mathrm{PP}+\mathrm{PCT})+5,1
\end{aligned}
$$

onde, PP: Prega cutânea da panturrilha; PCT: Prega cutânea tricipital Utilizando-se a BIA, meninos e meninas de 6 a 10 anos (KUSHNER 1992) Água corporal total $(\mathrm{ACT})(\mathrm{I})=\frac{0,593 \mathrm{x}(\operatorname{altura}(\mathrm{cm}))^{2}}{\operatorname{resistencia}(\Omega)}+(0,065 \mathrm{xaltura}(\mathrm{cm}))+0,04$

\begin{tabular}{ccc}
\hline & \multicolumn{2}{c}{ Massa Livre de Gordura - MLG (kg) } \\
Idade (anos) & Masculino & Feminino \\
\hline $5-6$ & $\mathrm{ACT} / 0,77$ & $\mathrm{ACT} / 0,78$ \\
$7-8$ & $\mathrm{ACT} / 0,768$ & $\mathrm{ACT} / 0,7776$ \\
$9-10$ & $\mathrm{ACT} / 0,762$ & $\mathrm{ACT} / 0,77$ \\
\hline
\end{tabular}


$\%$ Gordura corporal total $=\frac{\operatorname{Peso}(\mathrm{kg})-\mathrm{MLG}(\mathrm{kg})}{\operatorname{Peso}(\mathrm{kg})}$

\section{Índice de massa corporal (IMC)}

$$
\mathrm{IMC}=\frac{\operatorname{Peso}(\mathrm{kg})}{\operatorname{Altura}(\mathrm{m})^{2}}
$$

\section{8 - Escore de Atividade Física}

Para a mensuração da atividade física, utilizou-se o questionário proposto por BARROS e NAHAS (2003) apresentado no Anexo 7. Este instrumento é validado e apresenta bom nível de reprodutibilidade, segundo os autores.

O questionário utiliza desenhos sugestivos do tipo de atividade física em três colunas de acordo com a intensidade da atividade: devagar, rápido e muito rápido. Após uma explicação inicial sobre o que significavam as figuras desenhadas (andar, dançar, jogar bola, etc) e o que diferenciava cada coluna, solicitava-se ao escolar que escolhesse o desenho que mais se aproximava à sua prática diária (Figura 2).

Esclarecia-se, antes do preenchimento, sobre a possibilidade de circular mais de um desenho na mesma linha. Apresenta-se, para fins de exemplificação, a cópia de um questionário preenchido por um aluno.

O escore de atividade física foi construído como proposto por BARROS e NAHAS (2003), pela soma ponderada dos tipos de atividade: (devagar x 3) $+($ rápido $\times 5)+($ muito rápido $\times 9$ ), resultando em um escore mínimo de 0 e máximo de 187. Para exemplificação, indica-se a seguir, na Tabela 1, a construção do escore para o questionário apresentado na figura 2. O escore para este escolar foi igual a 69. 


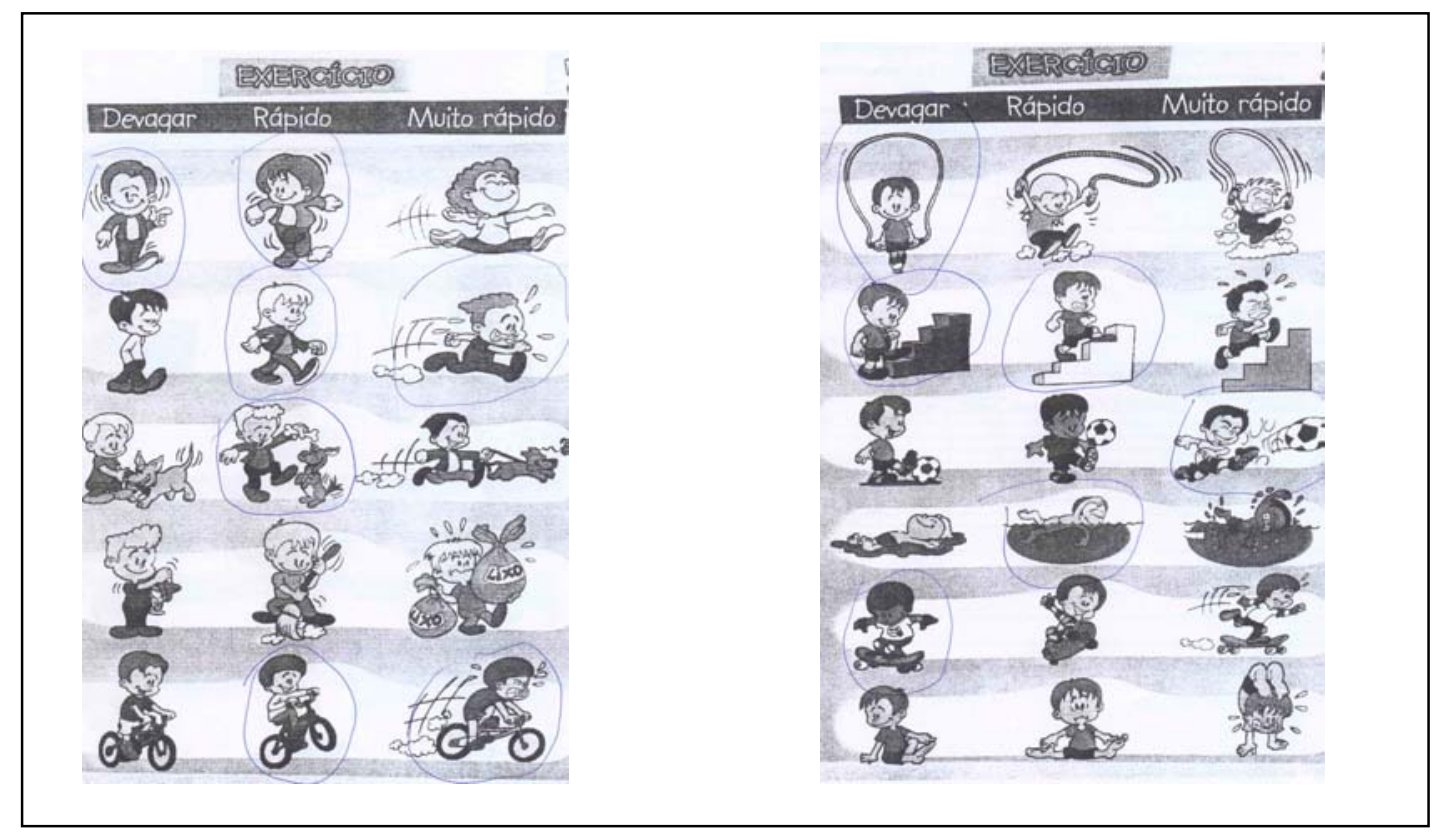

Figura 2 - Questionário de avaliação de prática de atividade física

Tabela 1 - Construção do escore de atividade física

\begin{tabular}{|c|c|c|c|c|}
\hline Atividade Física & Devagar (x3) & Rápido (x5) & Muito Rápido (x9) & Soma \\
\hline Dançar & $1 \times 3$ & $1 \times 5$ & - & 8 \\
\hline Brincar com o cão & - & $1 \times 5$ & - & 5 \\
\hline Andar de bicicleta & - & $1 \times 5$ & $1 \times 9$ & 14 \\
\hline Pular corda & $1 \times 3$ & - & - & 3 \\
\hline Subir as escadas & $1 \times 3$ & $1 \times 5$ & - & 8 \\
\hline Nadar & - & $1 \times 5$ & - & 5 \\
\hline Andar de skate & $1 \times 3$ & - & - & 3 \\
\hline Fazer ginástica & - & - & - & - \\
\hline
\end{tabular}

\section{9 - Mensuração de características sócio-econômicas}

A partir de questionário preenchido pelos pais (Anexo 8) foram mensuradas as seguintes características:

- Escolaridade materna (não alfabetizada, $1^{\mathrm{a}}$ a $4^{\mathrm{a}}$ série do ensino fundamental, $5^{\mathrm{a}}$ a $8^{\mathrm{a}}$ série do ensino fundamental, $1^{\mathrm{a}}$ a $3^{\mathrm{a}}$ série do ensino médio, curso superior incompleto, curso superior completo e curso de pós-graduação);

- Renda familiar (Menos de 1 salário mínimo, entre 1 e 3 salários mínimos, mais de 3 e até 5 salários mínimos, mais de 5 e até 10 salários mínimos, mais de 10 e até 20 salários mínimos e mais de 20 salários mínimos). Para construção da variável renda per capita, considerou-se os pontos médios dos intervalos: para menos de 1 
salário mínimo - $R \$ 130,00$; entre 1 e 3 salários mínimos - $R \$ 520,00$; mais de 3 e até 5 salários mínimos - R $\$ 1040,00$; mais de 5 e até 10 salários mínimos - $R \$ 1950,00$; mais de 10 e até 20 salários mínimos $\mathrm{R} \$ 3900,00$;

- $\quad$ Número de pessoas que vivem com a renda familiar;

- $\quad$ Número de pessoas que moram no domicílio;

- Número de quartos;

- Condição de moradia (imóvel próprio, alugado, cedido, abrigo e outros);

- $\quad$ Posse de telefone (sim ou não).

O não retorno do questionário preenchido implicou na coleta dos dados durante entrevista por telefone.

\subsection{0 - Padronização de procedimentos (Anexo 9)}

\section{Tomada de medidas antropométricas e de bioimpedância}

A padronização de procedimentos para tomada de medidas teve como objetivo assegurar a confiabilidade dos dados antropométricos e de bioimpedância. Os avaliadores que participaram da padronização não eram necessariamente os que participariam da coleta final dos dados, seguindo um modelo de efeitos aleatórios. A padronização envolveu a tomada das medidas antropométricas e realização da BIA em escolares de ambos os sexos, de 9 e 10 anos de idade, em momento anterior à coleta principal dos dados. Cada avaliador tomou cada medida duas vezes para investigação da concordância intra, realizando-se também a avaliação de variabilidade entre avaliadores. Optou-se por realizar as segundas mensurações após a primeira tomada de todo o conjunto de medidas. Por não se tratar de calibração, não foi considerada a existência de um avaliador padrão.

\section{Aplicação do questionário de atividade física (Anexo 10)}

A realização da padronização para utilização do questionário de prática de atividade física envolveu escolares de ambos os sexos, da $4^{\mathrm{a}}$ série, sendo os mesmos que participaram da investigação dos aspectos metodológicos da 
BIA, a ser descrito a seguir. O questionário de atividade física foi respondido duas vezes por avaliadores distintos, sendo que entre as aplicações, eram realizadas tomadas de medidas antropométricas, assegurando um tempo entre as duas coletas. Tanto o escolar quanto 0 avaliador não tinham acesso aos resultados da primeira aplicação.

\subsection{1 - Aspectos metodológicos na realização da BIA}

\section{Momento da tomada das medidas (antes e após o recreio) (Anexo 11)}

Investigou-se a influência do momento de realização da BIA (antes e após o recreio) nos resultados da resistência e reactância. Este estudo e a padronização dos procedimentos de tomada de medidas foram realizados em dias distintos. Foram realizadas medidas de reactância e resistência antes e após o recreio, controlando-se as variáveis: local da fixação dos eletrodos, ângulos entre o braço e a perna em relação ao corpo e avaliador.

\section{Utilização dos eletrodos em até quatro vezes (Anexo 11)}

Pela ausência de financiamento da pesquisa, foi necessário reutilizar os eletrodos. Para tanto foi investigada a influência desta reutilização, em estudo piloto, com as seguintes características experimentais: realizou-se a BIA inicialmente com eletrodos novos, e, em seguida, com eletrodos usados 1,2 e 3 vezes, em escolares de ambos os sexos entre 9 e 12 anos de idade, por um único avaliador.

\subsection{2 - Digitação e processamento dos dados}

Foi realizada dupla digitação dos dados com uso do Validate, disponível no programa Epi-Info versão 6.04b (Dean e col. 2002), com correção das discrepâncias. Para a análise estatística, utilizou-se o programa STATA versão 7 (1999). Os gráficos apresentados foram construídos na planilha eletrônica Excel, Windows $2000^{\circledR}$.

Para o cálculo dos percentis dos índices de estatura/idade e IMC/idade, foi utilizado o programa SAS versão 8 (1999) para 
microcomputador, adotando-se como referência os dados do CDC 2000 (URL:http://www.cdc.gov/ [20 dez 2004]).

\subsection{3 - Análise estatística}

\section{Padronização da tomada de medidas antropométricas}

A análise estatística da padronização (Anexo 9) incluiu a apresentação dos dados observados para todos os avaliadores, para a prega cutânea tricipital. Os dados para as demais medidas não são apresentados. Para a análise de confiabilidade, investigou-se as variabilidades intra e entre avaliadores utilizando-se o coeficiente de correlação intraclasse estimado pela Análise de variância - ANOVA, com um fator aleatório (escolar) e dois fatores (fixo/aleatório - avaliador e aleatório - escolar) e intervalo de confiança de 95\% (IC95\%).

\section{Apresentação dos dados antropométricos}

Os dados antropométricos e da composição corporal são apresentados em distribuições de freqüências simples e acumuladas, segundo sexo e idade (Anexo 12), em ogivas e em histogramas.

A avaliação antropométrica foi feita com base no percentil do IMC em relação à curva do CDC 2000. O Índice de E/I é utilizado somente para compor a descrição dos dados antropométricos.

As variáveis categóricas criadas e os critérios utilizados são apresentados no Quadro 2.

\section{Apresentação dos dados sócio-demográficos e de prática de atividade física}

O Quadro 2 contém os critérios utilizados para a apresentação das variáveis sócio-demográficos e de prática de atividade física.

\section{Análise exploratória dos dados}


Com o objetivo de apresentar os resultados para todos os escolares, agregando-se as escolas, investigou-se a existência de heterogeneidade entre estas para as variáveis antropométricas, sócio-demográficas e de atividade física, utilizando-se o teste do Q-Quadrado de Pearson.

Quadro2 - . Critérios e categorização das variáveis quantitativas contínuas.

\begin{tabular}{|lll|}
\hline Característica & Categorias & Valores de ponto de corte para as categorias \\
\hline Percentil do IMC ${ }^{(1)}$ & Baixo peso & Percentil do IMC $<5$ \\
& Peso normal & Percentil do IMC $\geq 5 \mathrm{e}<85$ \\
& Risco de sobrepeso & Percentil do IMC $\geq 85 \mathrm{e}<95$ \\
& Sobrepeso & Percentil do IMC $\geq 95$ \\
\hline Excesso de peso & Sim & Percentil do IMC $\geq 85$ \\
& Não & Percentil do IMC $<85$ \\
\hline Percentil de E/I $\mathrm{I}^{(1)}$ & Baixa estatura & Percentil escore E/I $<5$ \\
& Estatura normal & Percentil escore E/I $\geq 5$ \\
\hline Renda per capita & $0,00-130,00$ & Menos do que $1 / 2 \mathrm{SM}$ \\
(SM $=$ R $\$ 260,00)$ & $131,00-260,00$ & de $1 / 2$ a $1 \mathrm{SM}$ \\
& $261,00-390,00$ & De 1 a $1,5 \mathrm{SM}$ \\
& $391,00-1300,00$ & De 1,51 a 10 SM \\
\hline Escore de atividade & $0-47$ & quartis do escore \\
Física & $48-94$ & \\
& $95-141$ & \\
& $142-187$ & \\
\hline
\end{tabular}

${ }^{(1)}$ CDC 2000

Para o resumo e comparação dos dados antropométricos e de composição corporal foram utilizadas medidas de tendência central, média e mediana, e intervalo de confiança de $95 \%$ para as médias populacionais, segundo sexo e idade. As decisões estatísticas foram tomadas com base na sobreposição dos IC (95\%). Foram calculados coeficientes de variação de Pearson (CV) para estudo das variabilidades das medidas (Anexo 13).

Para a investigação da relação entre variáveis quantitativas contínuas utilizou-se o diagrama de dispersão e o coeficiente de correlação de Pearson ( $r$ ), estimado por $r=\frac{\sum(x-\bar{x})(y-\bar{y})}{\sqrt{\sum(x-\bar{x})^{2} \sum(y-\bar{y})^{2}}}$, onde $x$ representa, por exemplo, o percentual de gordura total estimado pela BIA e Y, o percentual de gordura total, estimado pelas pregas cutâneas (SNEDECOR e COCHRAN 1967). 
A análise de concordância entre os métodos que estimam o percentual de gordura total foi realizada pelo gráfico proposto por BLAND e ALTMAN (1986) com cálculo dos limites de concordância e IC95\% dos limites de concordância superior e inferior, estimados por: limites de concordância: $\overline{\mathrm{d}} \pm 1,96 \mathrm{~s}$, onde $\overline{\mathrm{d}}$ representa a diferença média entre os métodos e $s$ o desvio padrão das diferenças entre os métodos; IC95\% do limite inferior: $\left[(\overline{\mathrm{d}}-1,96 \mathrm{~s})-\mathrm{t}_{\mathrm{n}-1, \alpha / 2}\left(\sqrt{\frac{3 \mathrm{~s}^{2}}{\mathrm{n}}}\right)\right]$ e do limite superior: $\left[(\overline{\mathrm{d}}+1,96 \mathrm{~s})+\mathrm{t}_{\mathrm{n}-1, \alpha / 2}\left(\sqrt{\frac{3 \mathrm{~s}^{2}}{\mathrm{n}}}\right)\right]$, onde $t_{n-1, \alpha / 2}$ é o valor crítico da distribuição t de "Student", para n-1 graus de liberdade e confiança igual a 95\%.

Utilizou-se como classificação para risco de doença cardiovascular o percentual de gordura corporal $\geq 25$ para meninos e $\geq 30$ para meninas, segundo proposto por LOHMAN (1992).

Para a análise de desempenho da gordura total (estimada pela BIA e pregas cutâneas), na identificação de excesso de peso, e da circunferência da cintura e área gordurosa do braço na identificação de risco de doença cardiovascular (DCV), utilizou-se os índices de sensibilidade, especificidade, eficiência e de Youden, com determinação de pontos de corte pelo gráfico Two-Graph Receiver Operating Characteristic (TGROC) (FLETCHER e col. 1991, GREINER 2003, BRIESOFSKY 2004).

Após o cálculo dos índices de sensibilidade e especificidade, utilizandose as fórmulas apresentadas a seguir, encontrou-se, pelo gráfico TGROC, o ponto de corte para cada método, que minimizava a distância entre estas estatísticas. Os pontos de corte foram estimados segundo sexo. Os índices de eficiência e Youden são utilizados para compor a análise de desempenho dos métodos. Utilizou-se, ainda, a área sob a curva ROC para a comparação do desempenho dos métodos.

Apresenta-se a seguir as fórmulas para cálculo das estatísticas mencionadas, com base na configuração de tabela $2 \times 2$. 


\begin{tabular}{lccc}
\hline Classificação pelo & \multicolumn{2}{c}{ Referência (percentil do IMC em relação ao CDC) } \\
"teste"diagnóstico & Excesso de peso & Não excesso de peso & Total \\
\hline Excesso de peso & $\mathrm{a}$ & $\mathrm{c}$ & $\mathrm{a}+\mathrm{c}$ \\
Não excesso de peso & $\mathrm{b}$ & $\mathrm{d}$ & $\mathrm{b}+\mathrm{d}$ \\
\hline Total & $\mathrm{a}+\mathrm{b}$ & $\mathrm{c}+\mathrm{d}$ & $\mathrm{a}+\mathrm{b}+\mathrm{c}+\mathrm{d}$ \\
\hline
\end{tabular}

Considerando-se a notação Sensibilidade $=$ Se; Especificidade = Es; Eficiência = Ef; índice de Youden = J, tem-se:

$\mathrm{Se}=\frac{\mathrm{a}}{\mathrm{a}+\mathrm{b}} ; \mathrm{Es}=\frac{\mathrm{d}}{\mathrm{c}+\mathrm{d}} ; \mathrm{Ef}=\mathrm{SeP}+\mathrm{Es}(1-\mathrm{P})$, onde $\mathrm{P}$ é a prevalência do evento de interesse, por exemplo, excesso de peso e $\mathrm{J}=\mathrm{Se}+\mathrm{Es}-1$.

Para o estudo da relação da circunferência da cintura como função do percentual de gordura total, estimado pela BIA e pelas pregas cutâneas, utilizou-se o gráfico de dispersão. Não foi realizado estudo de regressão, com ajuste de curva, por se apresentar além do escopo dos objetivos do estudo. 


\section{4 - RESULTADOS}

\section{1 - Características da área de estudo}

As escolas estudadas estão localizadas na Água Rasa, distrito situado na região sudeste da cidade de São Paulo, na confluência entre o Tatuapé e a Mooca, sendo composta pelos bairros: Chácara Paraíso, Vila Cláudia, Vila Regente Feijó, Jardim Guanabara, Vila Bertioga, Vila Lúcia, Elvira, Vila Rio Branco, Vila Invernada, Vila Leme, Alto da Mooca, Vila Oratório, Jardim Itália e Quarta Parada. Em 2000, a população da Água Rasa era de 79213 habitantes, com taxa de crescimento anual igual a $-1,13 \%$ (zona Leste $=$ 1,21\%) (EMPLASA 2002); em 2000, segundo dados do IBGE (2000), a taxa anual de natalidade foi igual a 15,51 crianças por 1000 habitantes; a esperança de vida para pessoas do sexo masculino foi de 65,2 anos e para 0 sexo feminino, 74,7 anos. A mortalidade geral da região foi de 9,96 óbitos por 1000 habitantes e o coeficiente de mortalidade infantil igual a 13,86 óbitos em menores de 1 ano para cada 1000 nascidos vivos. A região possuía, em 2000, no Ensino Fundamental, 10 escolas estatuais, 4 municipais e 7 particulares.

Utilizando-se o Índice de Vulnerabilidade Juvenil (IVJ) proposto pela Fundação Sistema Estadual de Análise de Dados da Secretaria de Economia e Planejamento do Estado de São Paulo (SEADE), tem-se que a Água Rasa, em 2000 foi classificada como tendo nível 2 de vulnerabilidade, sendo o menor valor desta escala, 1 e o maior, 5 (pior situação). $O$ índice de vulnerabilidade juvenil (IVJ) considera para sua composição os níveis de crescimento populacional, a presença de jovens entre a população distrital, a freqüência à escola e ocorrência de gravidez e violência entre os jovens e adolescentes residentes no local. Do total da população deste distrito, $8,11 \%$ são jovens de 15 a 19 anos (valor 38 em uma escala de 0 a 100); a taxa de homicídios entre homens de 15 a 19 anos, por 100000 habitantes é de 38,5\% (valor 7 em uma escala de 0 a 100); do total de nascidos vivos, 4,32\% são de mães adolescentes de 14 a 17 anos (valor 29 em uma escala de 0 a 100). A renda 
nominal média em domicílios particulares era, em 2000, de $\mathrm{R} \$ 1503,34$. A proporção de escolares de 15 a 17 anos que não freqüentava a escola era de 14,89\% (valores mínimo e máximo na cidade de São Paulo: 7,52\% e $41,80 \%$, respectivamente) e a proporção de jovens com idade entre 18 e 19 anos que não concluíram o ensino fundamental era de 25,23\% (valor mínimo na cidade de São Paulo = 17,89\%; valor máximo $=66,3 \%$ ).

\section{2 - Características da população de estudo}

De 729 escolares matriculados nas duas escolas, não participaram das atividades de coleta dos dados $88(12,1 \%)$ devido a: $47(6,4 \%)$ já haviam saído das escolas no início da coleta dos dados; 40 (5,5\%) constituíram recusas, não apresentando o consentimento informado assinado pelos responsáveis e 1 escolar não foi avaliado por ser portador de deficiência física. A taxa de retorno do questionário sócio-demográfico foi de $90,8 \%$ sendo que $6,1 \%$ destas informações foram obtidas por telefone.

Participaram da avaliação do estado nutricional, 641 escolares. Destes, foram excluídos para a análise dos dados $85(13,3 \%)$ por estarem em faixas etárias não selecionadas para o estudo: 6 anos $(n=29), 11$ anos $(n=40), 12$ anos $(n=13), 13$ anos $(n=2)$ e 14 anos $(n=1)$.

A amostra final considerada na análise foi composta por 556 escolares de 7 a 10 anos de idade.

\section{Análise de heterogeneidade segundo escola}

A distribuição de escolares segundo sexo não foi semelhante em ambas as escolas, observando-se maior percentual de meninos na escola 1 $(55,3 \% ; p=0,014)$. Observou-se que, independente da escola $(p=0,076)$, $21,8 \%$ de mães são analfabetas ou tinham curso primário e $69,3 \%$ apresentam como escolaridade grau fundamental ou médio (ginasial ou colegial). Para as variáveis renda per capita e condições de moradia, os dados mostram evidência de pior situação para famílias de escolares da escola 2 ( $p<0,001$ e $p=0,001$ ) (Tabela 2 ). 
Quanto ao valor médio do escore de atividade física, os escolares não diferem segundo escola $(p=0,324)$. Observou-se que $98 \%$ dos escolares apresentam escore menor que o escore mediano da escala (Tabela 2).

Tabela 2. Distribuição de escolares segundo sexo, idade, escolaridade materna, renda per capita, condições de moradia e escore de atividade física. Duas escolas públicas de São Paulo, 2004.

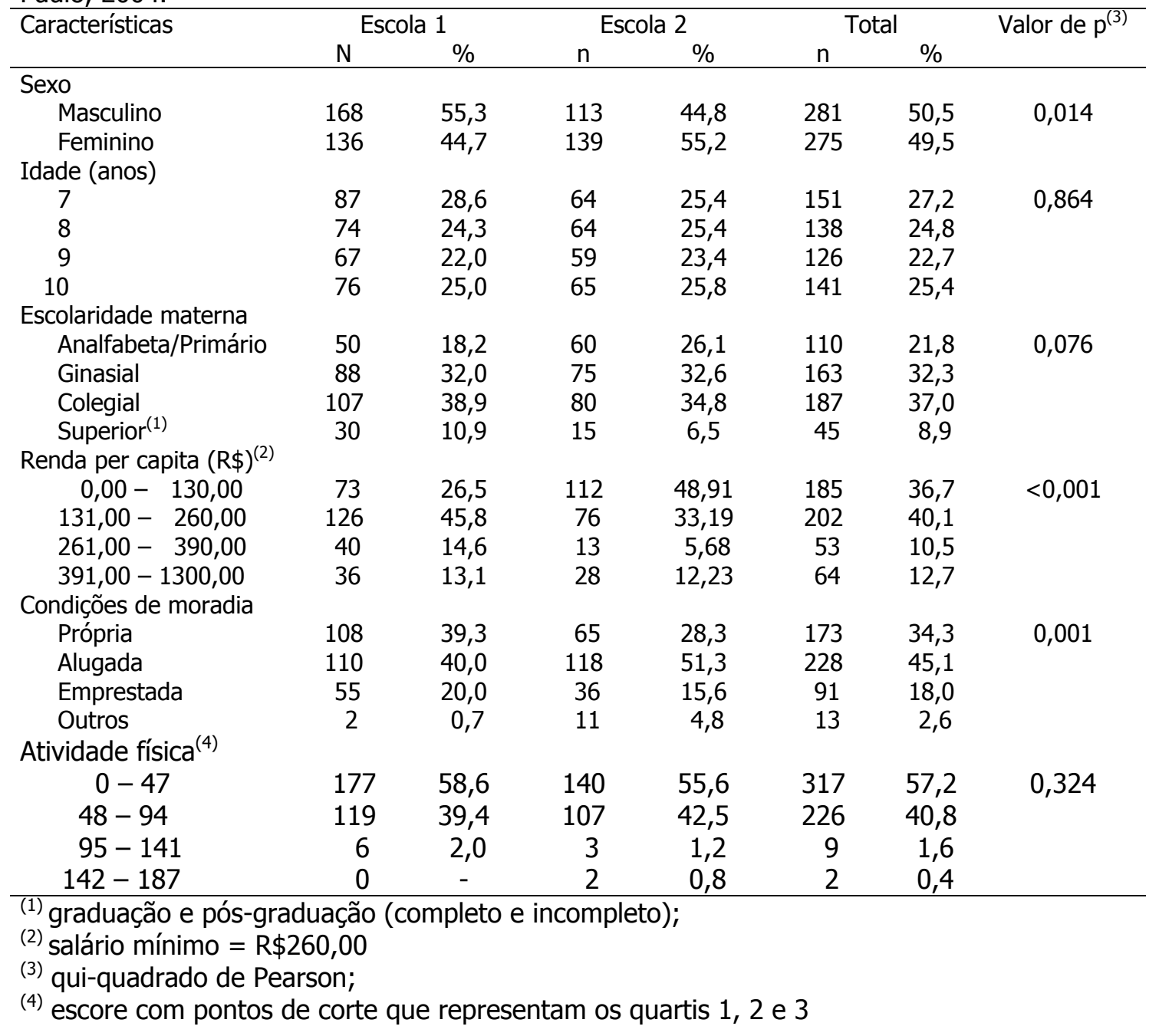

Não foi observada diferença entre as escolas quanto ao estado nutricional utilizando-se os dados de IMC classificados nas categorias baixo peso, normal, risco de sobrepeso e sobrepeso $(p=0,375)$ e para os dados de E/I $(0,951)$ (Tabela 3). Considerando-se todos os escolares e os valores do percentil de IMC, observou-se prevalência de baixo peso de 4,5\% (IC95\%: $2,9-6,6 \%$ ), de riscos de sobrepeso de $15,3 \%$ (IC95\%: $12,4-18,6 \%$ ) e de sobrepeso igual a 11,0\% (IC95\%: 8,5 - 13,9\%). A avaliação do estado 
nutricional segundo o percentil de (E/I) revelou que 2,3\% (IC95\%: 1,3 $4,0 \%)$ dos escolares apresentam déficit estatural, valor abaixo do esperado (Tabela 3).

Tabela 3. Distribuição de escolares segundo IMC, percentil de estatura/idade (E/I) e escola. Duas escolas públicas de São Paulo, 2004.

\begin{tabular}{|c|c|c|c|c|c|c|c|}
\hline \multirow[t]{2}{*}{ Avaliação nutricional } & \multicolumn{2}{|c|}{ Escola 1} & \multicolumn{2}{|c|}{ Escola 2} & \multicolumn{2}{|c|}{ Total } & \multirow[t]{2}{*}{ Valor de $\mathrm{p}^{(3)}$} \\
\hline & $\mathrm{n}$ & $\%$ & $\mathrm{n}$ & $\%$ & $\mathrm{n}$ & $\%$ & \\
\hline \multicolumn{8}{|l|}{$\operatorname{IMC}^{(1)}$} \\
\hline Baixo peso & 11 & 3,6 & 14 & 5,6 & 25 & 4,5 & 0,375 \\
\hline Normal & 214 & 70,4 & 171 & 67,9 & 385 & 69,2 & \\
\hline Risco de sobrepeso & 42 & 13,8 & 43 & 17,1 & 85 & 15,3 & \\
\hline Sobrepeso & 37 & 12,2 & 24 & 9,5 & 61 & 11,0 & \\
\hline \multicolumn{8}{|l|}{ Percentil de $E / I^{(2)}$} \\
\hline Baixa Estatura & $\begin{array}{r}7 \\
207\end{array}$ & $\begin{array}{r}2,3 \\
077\end{array}$ & 6 & $\begin{array}{r}2,4 \\
07,6\end{array}$ & $\begin{array}{r}13 \\
543\end{array}$ & $\begin{array}{r}2,3 \\
077\end{array}$ & 0,951 \\
\hline Normal & 297 & 97,7 & 246 & 97,6 & 543 & 97,7 & \\
\hline
\end{tabular}

\section{3 - Características antropométricas}

As distribuições dos escolares segundo as medidas antropométricas (peso, estatura, pregas cutâneas tricipital e da panturrilha, circunferências da cintura e do braço) são apresentadas no Anexo 12.

A tabela 4 apresenta os pesos e estaturas médias, desvio padrão e IC95\% para as médias populacionais, segundo idade e sexo. Nesta observase, pelos intervalos de confiança, sobreposição de valores segundo sexo tanto para o peso como para a estatura, sugerindo igualdade nos pesos médios e, nas estaturas médias, entre escolares do sexo masculino e do sexo feminino para cada uma das idades.

\section{Peso e estatura}

Observou-se peso com valor mínimo igual $19,0 \mathrm{~kg}$ e máximo igual a 74,0 kg para o sexo masculino e, para o sexo feminino, valores mínimo e máximo iguais a 17,8 e $87,2 \mathrm{~kg}$, respectivamente. Para a estatura, foram observados valores mínimo $117,8 \mathrm{~cm}$ e valor máximo $157,4 \mathrm{~cm}$ para o sexo 
masculino e, para o sexo feminino, valor mínimo $109,5 \mathrm{~cm}$ e valor máximo $158,1 \mathrm{~cm}$.

Considerando-se os escolares do sexo masculino e feminino como um todo, foi observado aumento no peso médio com aumento da idade, que pode ser visualizado nas curvas de freqüência acumulada segundo grupo etário (Gráfico 1). A maior diferença relativa no peso médio ocorre entre $7 \mathrm{e}$ 8 anos e entre 9 e 10 anos, com diferenças percentuais de 15,2\% e 17,7\%, respectivamente. Estes percentuais indicam diferenças de 4,0 e 5,8 kg, em média nestas idades (Tabelas 4 e 5).

Para a estatura, observou-se, também, valores médios maiores com o aumento da idade (Tabelas 4 e 5 e Gráfico 2). A diferença relativa na estatura é semelhante para cada faixa etária, variando de 3,8\% a 4,5\% representando diferença média, para cada ano cronológico, de 5,0 a 6,2 cm.

Os valores medianos de estatura $(\mathrm{cm})$ e peso $(\mathrm{kg})$ observados são pouco maiores que os valores medianos da população de referência (CDC2000), considerando-se o sexo e a idade do escolar (Gráficos 3a, 3b, 4a e 4b).

Tabela 4 - Peso médio, estatura média, desvio padrão (dp) e IC de $95 \%$ segundo sexo e idade (anos). Duas escolas públicas de São Paulo, 2004.

\begin{tabular}{|c|c|c|c|c|}
\hline \multirow[t]{2}{*}{$\operatorname{Sexo}^{(1)}$} & \multicolumn{4}{|c|}{ Idade (anos) ${ }^{(2)}$} \\
\hline & 7 & 8 & 9 & 10 \\
\hline & \multicolumn{4}{|c|}{ Peso $(\mathrm{kg})$ médio e desvio padrão (dp) (IC 95\%) } \\
\hline \multirow[t]{2}{*}{ Masculino } & $27,0(4,6)$ & $31,8(9,1)$ & $32,9(8,1)$ & $38,4(11,1)$ \\
\hline & $(25,9-28,0)$ & $(29,7-33,9)$ & $(30,8-34,9)$ & $(35,8-41,0)$ \\
\hline \multirow[t]{2}{*}{ Feminino } & $25,8(5,1)$ & $28,8(6,4)$ & $32,5(9,7)$ & $38,7(7,8)$ \\
\hline & $(24,6-27,0)$ & $(27,2-30,4)$ & $(30,1-35,0)$ & $(36,8-40,5)$ \\
\hline \multirow[t]{3}{*}{ Total } & $26,4(4,9)$ & $30,4(8,0)$ & $32,7(8,9)$ & $38,5(9,6)$ \\
\hline & $(25,6-27,2)$ & $(29,0-31,7)$ & $(31,1-34,3)$ & $(36,9-40,1)$ \\
\hline & \multicolumn{4}{|c|}{ Estatura $(\mathrm{cm})$ média e desvio padrão (dp) (IC 95\%) } \\
\hline \multirow[t]{2}{*}{ Masculino } & $126,5(4,5)$ & $132,47(6,0)$ & $137,14(6,2)$ & $141,7(7,9)$ \\
\hline & $(125,5-127,6)$ & $(131,1-133,9)$ & $(135,6-138,7)$ & $(139,8-143,6)$ \\
\hline \multirow[t]{2}{*}{ Feminino } & $124,9(5,1)$ & $130,2(5,9)$ & $135,7(7,9)$ & $143,6(6,6)$ \\
\hline & $(123,7-126,1)$ & $(128,7-131,7)$ & $(133,7-137,6)$ & $(142,0-145,1)$ \\
\hline \multirow[t]{2}{*}{ Total } & $125,7(4,9)$ & $131,4(6,1)$ & $136,4(7,1)$ & $142,6(7,3)$ \\
\hline & $(124,0-126,5)$ & $(130,4-132,4)$ & $(135,1-137,6)$ & $(141,4-143,9)$ \\
\hline
\end{tabular}

(1) Masculino $(n=281)$, Feminino $(n=275)$;

(2) 7 anos $(n=151) ; 8$ anos $(n=138) ; 9$ anos $(n=126) ; 10$ anos $(n=141)$ 
Tabela 5 - Diferença relativa (\%) e absoluta de peso e diferença segundo idade

\begin{tabular}{lrccc}
\hline Idade (anos) & \multicolumn{2}{c}{ Diferença relativa $(\%)$} & \multicolumn{2}{c}{ Diferença absoluta } \\
& Peso & Estatura & Peso $(\mathrm{kg})$ & Estatura $(\mathrm{cm})$ \\
\hline $7 / 8$ & 15,2 & 4,5 & 4,0 & 5,7 \\
$8 / 9$ & 7,6 & 3,8 & 2,3 & 5,0 \\
$9 / 10$ & 17,7 & 4,5 & 5,8 & 6,2 \\
$7 / 9$ & 21,9 & 8,5 & 5,8 & 10,7 \\
$7 / 10$ & 42,2 & 13,4 & 11,4 & 16,9 \\
\hline
\end{tabular}

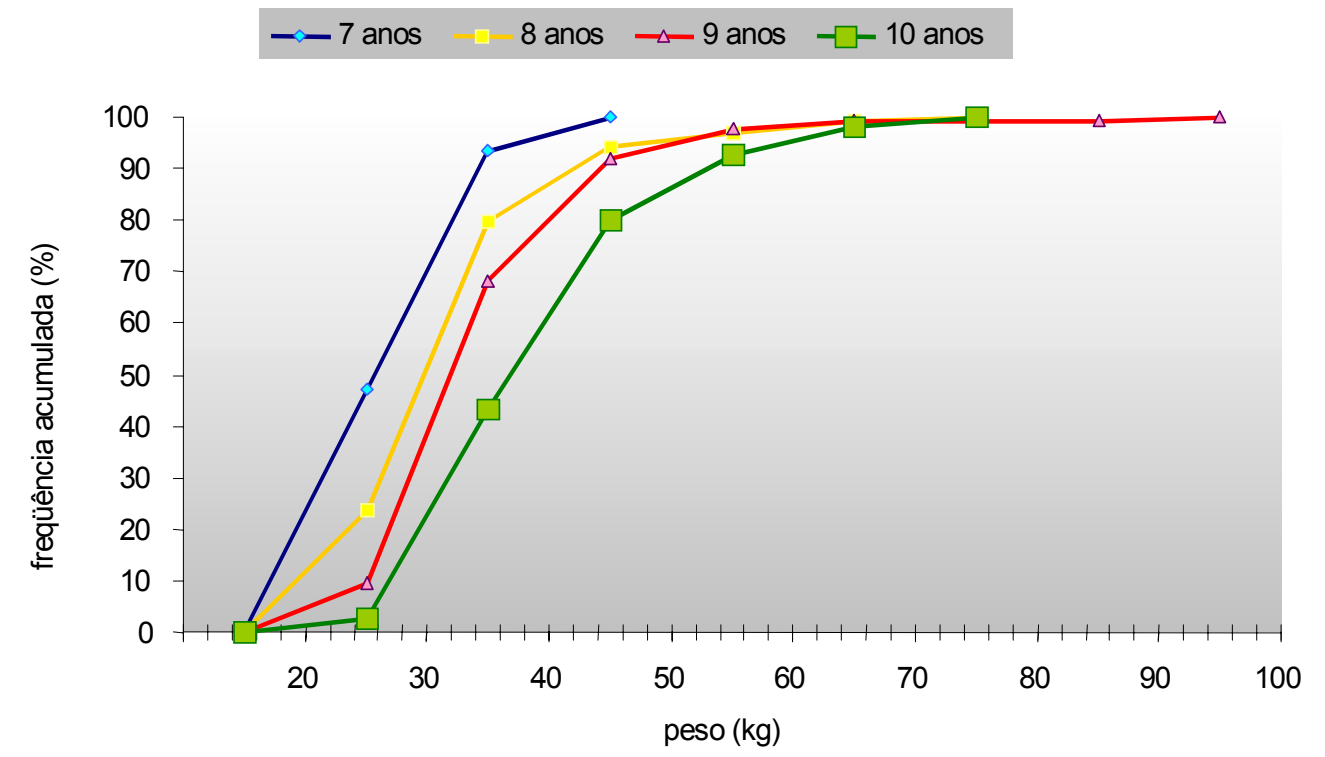

Gráfico 1- Distribuiçăo acumulada de escolares segundo peso (kg) e idade. Duas escolas públicas de São Paulo, 2004.

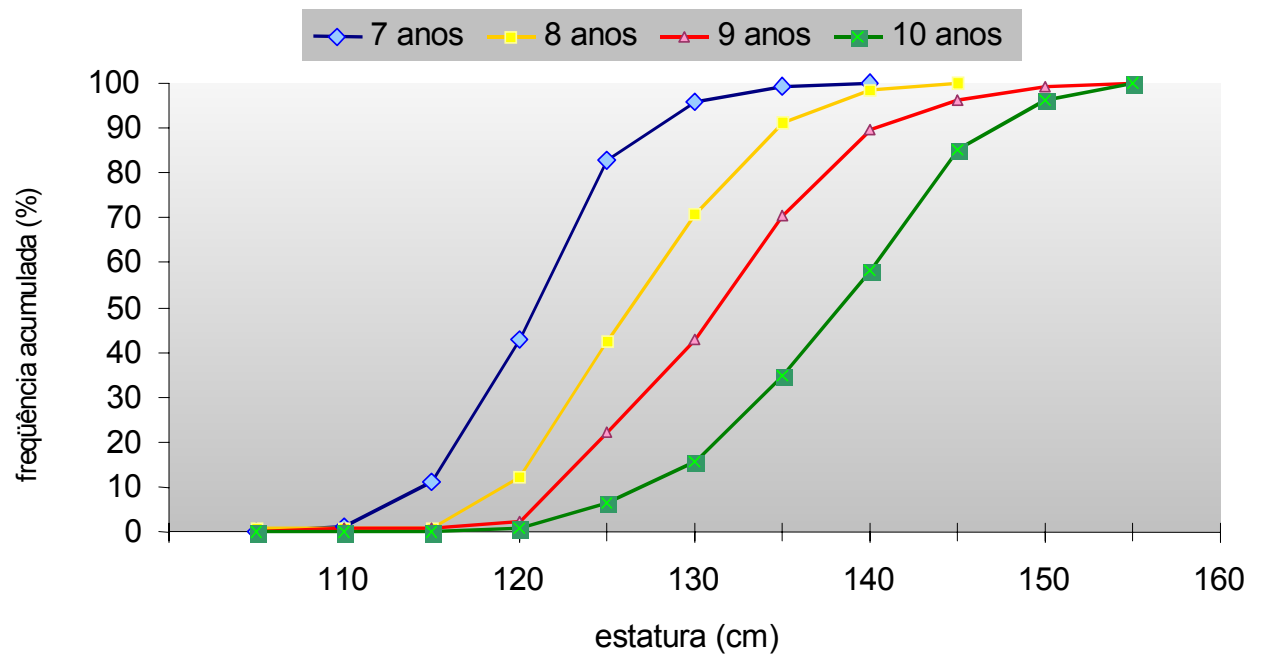

Gráfico 2- Distribuição acumulada de escolares segundo estatura (cm) e idade. Duas escolas públicas de São Paulo, 2004. 


$$
\smile \text { São Paulo } \neg \square-\text { Referência (CDC 2000) }
$$

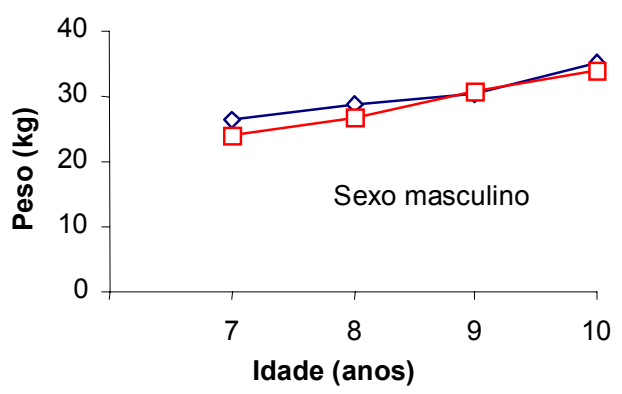

(a)
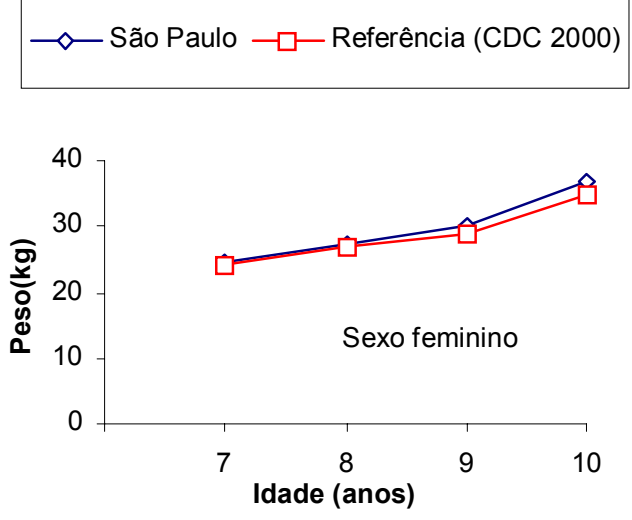

(b)

${ }^{1}$ CDC 2000

Gráficos 3a e 3b - Medianas de peso $(\mathrm{kg})$ em relação à idade de escolares de duas escolas públicas de São Paulo em 2004 e de crianças americanas ${ }^{1}$.

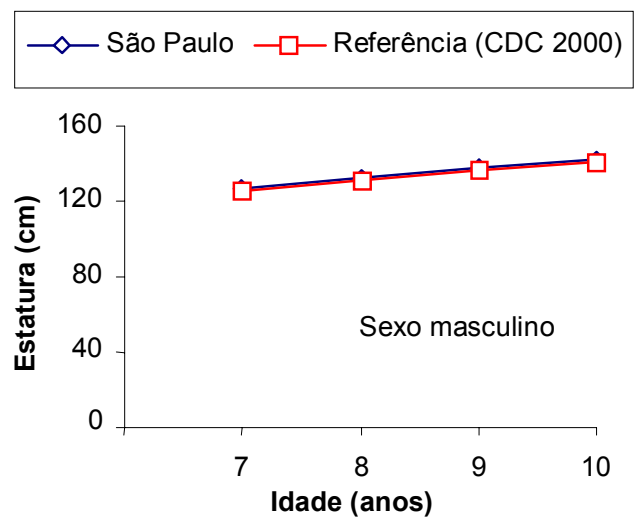

(a)

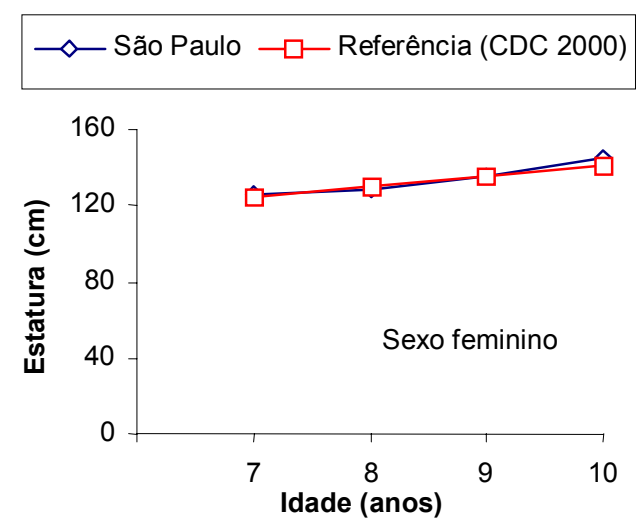

(b)

${ }^{1}$ CDC 2000

Gráficos 4a e 4b- Medianas de estatura $(\mathrm{cm})$ em relação à idade de escolares de duas escolas públicas de São Paulo em 2004 e de crianças americanas ${ }^{1}$.

\section{IMC}

O menor valor de IMC observado entre escolares do sexo masculino foi igual a $12,4 \mathrm{~kg} / \mathrm{m}^{2}$ e o maior, $32,5 \mathrm{~kg} / \mathrm{m}^{2}$. Para o sexo feminino, estes valores foram: $13,0 \mathrm{~kg} / \mathrm{m}^{2}$ e $34,9 \mathrm{~kg} / \mathrm{m}^{2}$. A comparação do IMC segundo 
sexo não revelou diferença para cada uma das idades (Tabela 6). A inexistência de diferença de valores médios de IMC é observada se comparadas as faixas etárias de 7 e 8 , de 8 e 9, de 9 e 10. Entretanto, observou-se diferença do IMC médio a partir de 9 anos, quando comparado com escolares de 7 anos (Tabelas 6 e 7; Gráfico 5). Escolares apresentam diferenças médias de $12,7 \%$ do IMC entre as idades de 7 e 9 anos e de $13,3 \%$ entre 7 e 10 anos, representando diferença média absoluta de 2,2 $\mathrm{kg} / \mathrm{m}^{2}$. Os Gráficos $6 a$ e $6 \mathrm{~b}$ apresentam os valores medianos de IMC, segundo sexo e idade, observados no presente estudo e os da população de referência americana (CDC 2000), com indicação de tendência estacionária e grande semelhança nos valores medianos e, praticamente, sobreposição para escolares do sexo feminino (Gráficos 6a e 6b).

Tabela 6 - IMC médio, desvio padrão (dp) e IC de $95 \%$ segundo sexo e idade (anos). Duas escolas públicas de São Paulo, 2004.

\begin{tabular}{|c|c|c|c|c|}
\hline \multirow[t]{2}{*}{$\operatorname{Sexo}^{(1)}$} & \multicolumn{4}{|c|}{ Idade $(\text { anos })^{(2)}$} \\
\hline & 7 & 8 & 9 & 10 \\
\hline \multirow[b]{2}{*}{ Masculino } & IMI & $\left(\mathrm{kg} / \mathrm{m}^{2}\right)$ médio e desvio & padrão (dp) (IC ؟ & \\
\hline & $\begin{array}{c}16,8(2,5) \\
(16)-174)\end{array}$ & $\begin{array}{c}17,9(4,0) \\
(170-18,9)\end{array}$ & $\begin{array}{c}17,3(3,1) \\
(165-181)\end{array}$ & $\begin{array}{r}18,9(4 \\
(179-1\end{array}$ \\
\hline Feminino & $\begin{array}{c}16,4(2,30 \\
(15,9-17,0)\end{array}$ & $\begin{array}{c}16,9(2,9) \\
(16,2-17,6)\end{array}$ & $\begin{array}{c}17,4(3,3) \\
(16,6-18,2)\end{array}$ & $\begin{array}{r}18,7(3 \\
(17,9-1\end{array}$ \\
\hline Total & $\begin{array}{c}16,6(2,4) \\
(16,2-17,0)\end{array}$ & $\begin{array}{c}17,4(3,5) \\
(16,8-18,0)\end{array}$ & $\begin{array}{c}18,7(3,2) \\
(17,9-19,5)\end{array}$ & $\begin{array}{r}18,8(3 \\
(18,2-1\end{array}$ \\
\hline \multicolumn{5}{|c|}{$\begin{array}{l}\text { (1) Masculino }(n=281) \text {, Feminino }(n=275) \text {; } \\
\text { (2) } 7 \text { anos }(n=151) ; 8 \text { anos }(n=138) ; 9 \text { anos }(n=126) ; 10 \text { anos }(n=141)\end{array}$} \\
\hline \multirow{2}{*}{\multicolumn{2}{|c|}{ Idade (anos) }} & $\frac{\text { iva }(\%) \text { e absoluta }}{\text { Diferença relativa (\%) }}$ & \multicolumn{2}{|c|}{ Diferença absoluta } \\
\hline & & $\operatorname{IMC}\left(\mathrm{kg} / \mathrm{m}^{2}\right)$ & \multicolumn{2}{|c|}{ IMC $\left(\mathrm{kg} / \mathrm{m}^{2}\right)$} \\
\hline $7 / 8$ & & 4,8 & \multicolumn{2}{|c|}{0,8} \\
\hline $7 / 9$ & & 12,7 & \multicolumn{2}{|c|}{2,1} \\
\hline $7 / 1$ & & 13,3 & \multicolumn{2}{|c|}{2,2} \\
\hline $8 / 9$ & & 7,5 & \multirow{2}{*}{\multicolumn{2}{|c|}{1,3}} \\
\hline $9 / 1$ & & 0,5 & & \\
\hline
\end{tabular}




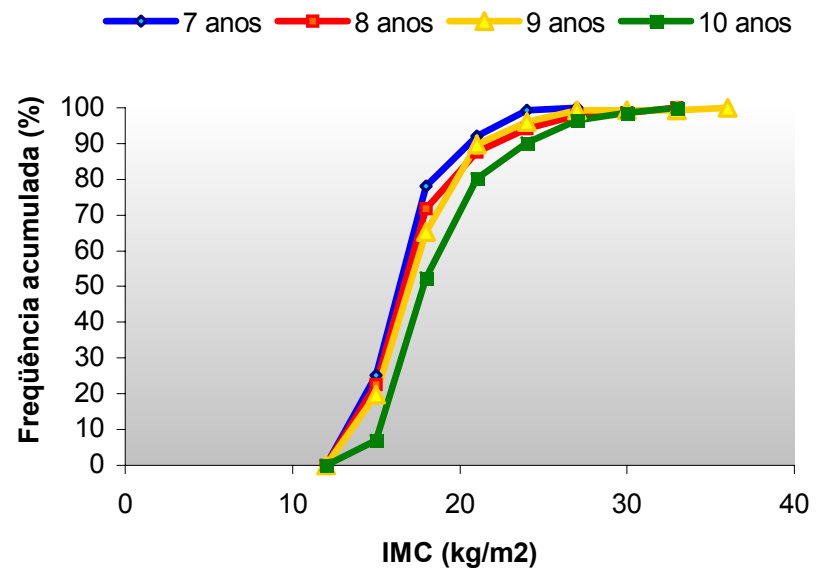

Gráfico 5 - Distribuição acumulada de escolares segundo $\operatorname{IMC}\left(\mathrm{kg} / \mathrm{m}^{2}\right)$ e idade. Duas escolas públicas de São Paulo, 2004.

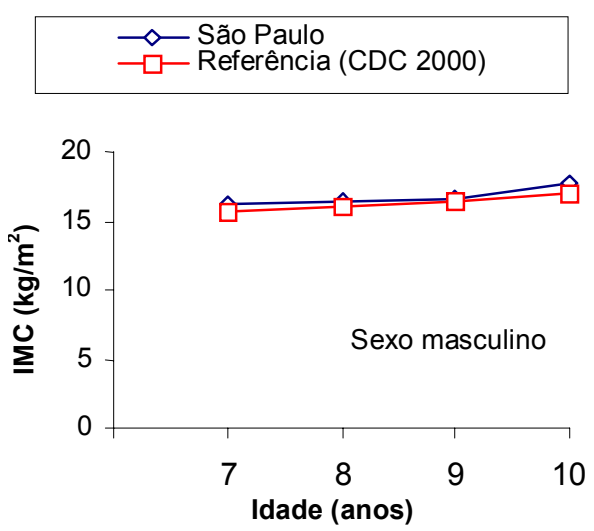

(a)

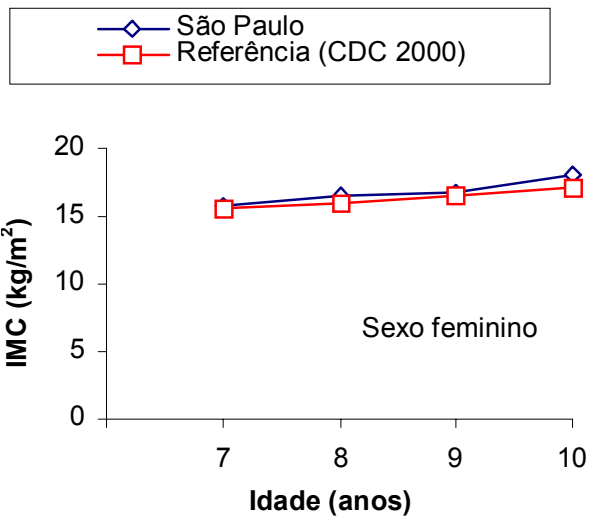

(b)

${ }^{1}$ CDC 2000

Gráficos 6a e 6b - Medianas de IMC $\left(\mathrm{kg} / \mathrm{m}^{2}\right)$ em relação à idade de escolares de duas escolas públicas de São Paulo em 2004 e de crianças americanas ${ }^{1}$.

\section{Pregas cutâneas}

Os menores valores das pregas tricipital e da panturrilha, para escolares do sexo masculino, foram $5 \mathrm{~mm}$ e $4,5 \mathrm{~mm}$ e os maiores valores foram $36,5 \mathrm{~mm}$ e $36,0 \mathrm{~mm}$, respectivamente. Para o sexo feminino estes valores foram: valor mínimo $5 \mathrm{~mm}$, tanto para prega tricipital como da panturrilha, e valores máximos $39,5 \mathrm{~mm}$ e $33,0 \mathrm{~mm}$, para cada prega cutânea, respectivamente. Pela análise dos intervalos de confiança para a média populacional das pregas cutâneas tricipital e da panturrilha para 
escolares do sexo masculino e feminino, apresentados na Tabela 8, pode-se inferir que não existe diferença entre as distribuições segundo sexo. Considerando-se, ainda, os intervalos de confiança, foi observada semelhança entre as distribuições para escolares de 7, 8 e 9 anos, com valores médios maiores para escolares de 10 anos. Estes achados são elucidados nos Gráficos 7 e 8.

Observou-se diferença relativa da prega cutânea média tricipital de $9,5 \%$ entre 7 e 8 anos e manutenção destes valores entre 8 e 9 anos. Entre 9 e 10 anos, observou-se grande diferença relativa tanto nas medidas da prega tricipital $(23,4 \%)$ como da panturrilha $(18,4 \%)$, com diferença absoluta dos valores médios de 2,6 mm (Tabela 9). Comparando-se os dados do presente estudo com os do estudo do National Health and Nutrition Examination Survey I (NHANES I), realizado nos Estados Unidos no período de 1971 a 1974, observou-se que os valores medianos de prega cutânea tricipital $(\mathrm{mm})$ dos escolares do presente estudo foram maiores que os valores medianos da população de referência para cada faixa etária, para o sexo masculino a partir de 9 anos e para o sexo feminino a partir de 8 anos (Gráficos 9a e 9b).

Tabela 8. Prega cutânea média tricipital e da panturrilha, desvio padrão (dp) e IC(95\%) segundo sexo e idade (anos). Duas escolas públicas de São Paulo.

\begin{tabular}{|c|c|c|c|c|}
\hline \multirow[t]{2}{*}{$\operatorname{Sexo}^{(1)}$} & \multicolumn{4}{|c|}{ Idade (anos) ${ }^{(2)}$} \\
\hline & 7 & 8 & 9 & 10 \\
\hline \multicolumn{5}{|c|}{ Prega cutânea tricipital (mm) médios e desvio padrão (dp) (IC 95\%) } \\
\hline \multirow[t]{2}{*}{ Masculino } & $12,0(4,0)$ & $13,5(6,1)$ & $12,5(5,6)$ & $16,7(6,7)$ \\
\hline & $(11,1-12,9)$ & $(12,1-14,9)$ & $(11,1-13,9)$ & $(15,1-18,3)$ \\
\hline \multirow[t]{2}{*}{ Feminino } & $13,2(4,1)$ & $14,1(4,5)$ & $14,9(4,8)$ & $17,2(5,9)$ \\
\hline & $(12,2-14,1)$ & $(13,0-15,2)$ & $(13,7-16,1)$ & $(15,7-18,6)$ \\
\hline Total & $\begin{array}{c}12,6(4,1) \\
(11,9-13,2)\end{array}$ & $\begin{array}{c}13,8(5,4) \\
(12,9-14,7)\end{array}$ & $\begin{array}{c}13,7(5,3) \\
(12,7-14,6)\end{array}$ & $\begin{array}{c}16,9(6,3) \\
(15,9-18,0)\end{array}$ \\
\hline \multicolumn{5}{|c|}{ Prega cutânea da panturrilha $(\mathrm{mm})$ médios e desvio padrão (dp) (IC 95\%) } \\
\hline \multirow[t]{2}{*}{ Masculino } & $11,7(4,0)$ & $13,9(6,3)$ & $13,6(5,8)$ & $16,7(6,6)$ \\
\hline & $(10,8-12,6)$ & $(12,4-15,3)$ & $(12,1-15,0)$ & $(15,1-18,3)$ \\
\hline Feminino & $13,0(4,3)$ & $13,8(5,1)$ & $14,6(4,8)$ & $16,7(5,7)$ \\
\hline \multirow{2}{*}{ Total } & $\begin{array}{c}(12,1-14,0) \\
123(42)\end{array}$ & $\begin{array}{l}(12,5-15,0) \\
13,8(5,7)\end{array}$ & $\begin{array}{c}(13,4-13,0) \\
14,1(5,3)\end{array}$ & $16,7(6,2)$ \\
\hline & $(11,7-13,0)$ & $(12,9-14,8)$ & $(13,2-15,0)$ & $(15,7-17,7)$ \\
\hline
\end{tabular}


Tabela 9 - Diferença relativa (\%) e absoluta da prega cutânea tricipital e da panturrilha de acordo com a idade

\begin{tabular}{lcccc}
\hline $\begin{array}{l}\text { Idade } \\
\text { (anos) }\end{array}$ & $\begin{array}{c}\text { Diferença relativa (\%) } \\
\text { Prega cutânea } \\
\text { tricipital }\end{array}$ & $\begin{array}{c}\text { Prega cutânea } \\
\text { da panturrilha }\end{array}$ & $\begin{array}{c}\text { Diferença absoluta (mm) } \\
\text { Prega cutânea } \\
\text { tricipital }\end{array}$ & $\begin{array}{c}\text { Prega cutânea } \\
\text { da panturrilha }\end{array}$ \\
\hline $7 / 8$ & 9,5 & 12,2 & 1,2 & 1,5 \\
$8 / 9$ & $-0,7$ & 2,17 & $-0,1$ & 0,3 \\
$9 / 10$ & 23,4 & 18,4 & 3,2 & 2,6 \\
$7 / 10$ & 34,1 & 35,8 & 4,3 & 4,4 \\
$8 / 10$ & 22,5 & 21,0 & 3,1 & 2,9 \\
\hline
\end{tabular}

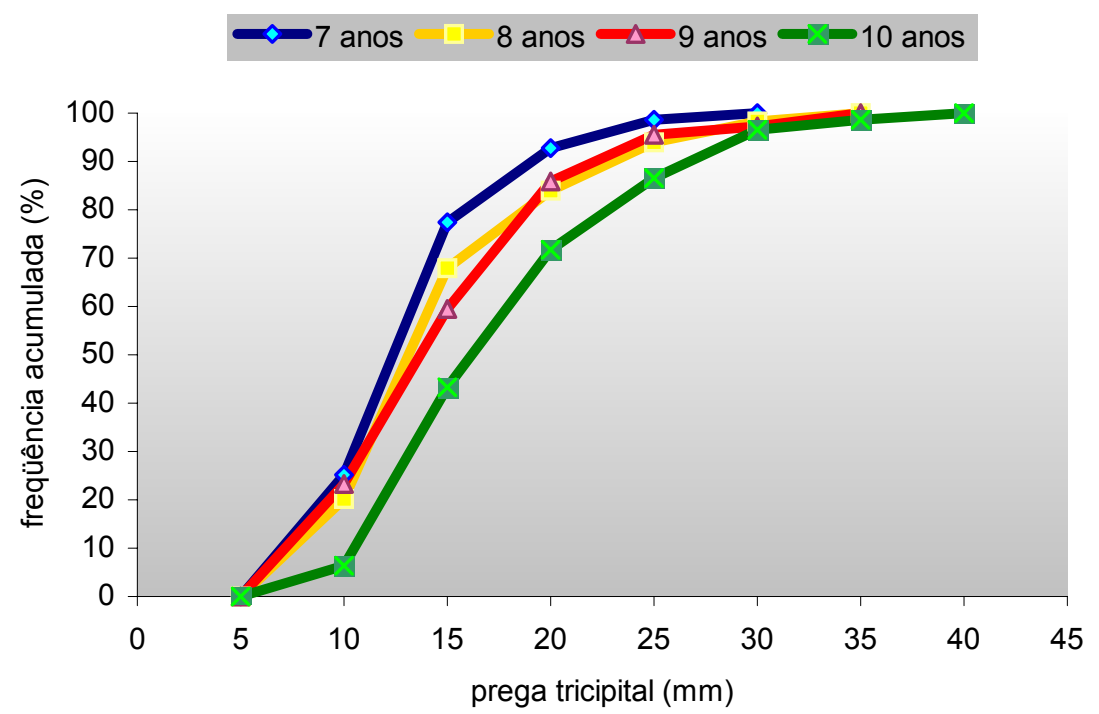

Gráfico 7 - Distribuição acumulada de escolares segundo prega cutânea tricipital (mm) e idade. Duas escolas públicas de São Paulo, 2004.

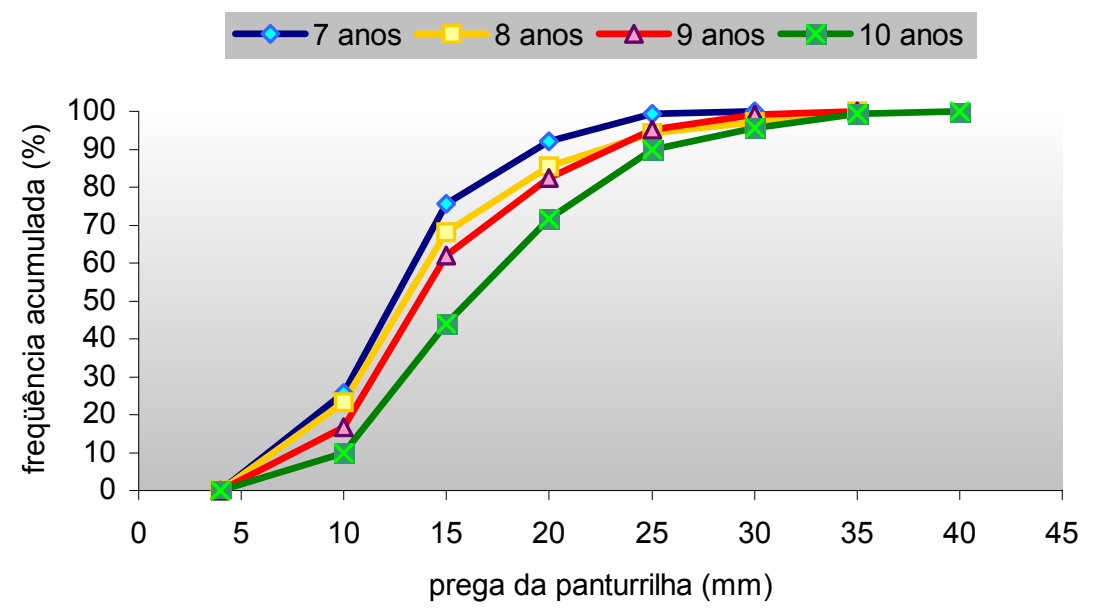

Gráfico 8 - Distribuição acumulada de escolares segundo prega cutânea da panturrilha (mm) e idade. Duas escolas públicas de São Paulo, 2004. 


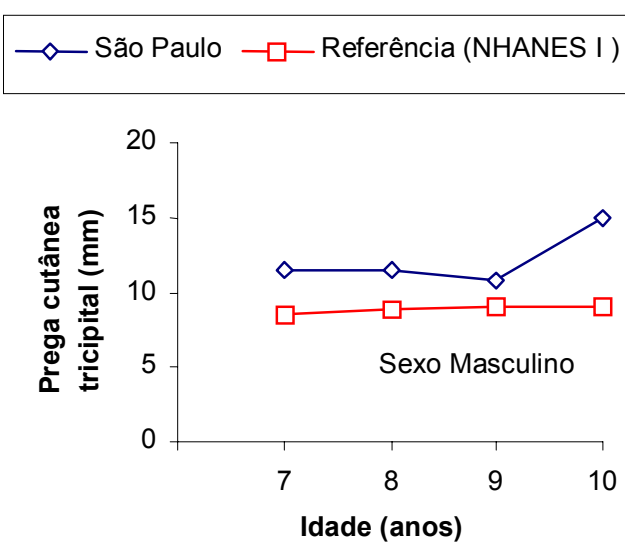

(a)

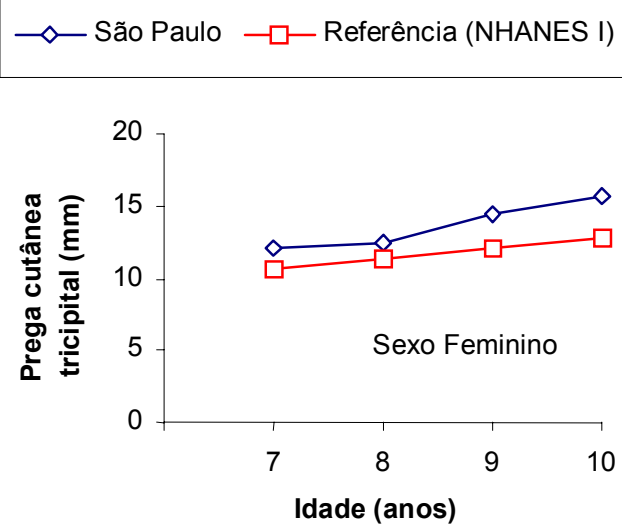

(b)

${ }^{1}$ NHANES I, 1971 - 1974

Gráficos 9a e 9b - Medianas de prega cutânea tricipital $(\mathrm{mm})$ em relação à idade de escolares de duas escolas públicas de São Paulo em 2004 e de crianças americanas ${ }^{1}$.

\section{Circunferências corporais}

Foram observados, respectivamente, valores mínimo e máximo para as circunferências do braço (CB) e da cintura (CC) iguais a 14,8 cm e 33,1 $\mathrm{cm}$ (CB, sexo masculino), 51,3 cm e 102,0 cm (CC, sexo masculino), $16,0 \mathrm{~cm}$ e 35,3 cm (CB, sexo feminino) e 48,3 cm e 106,6 cm (CC, sexo feminino). Os intervalos de confiança para a média populacional das circunferências do braço e da cintura dos escolares indicam semelhança entre os sexos em cada idade. Tanto para a circunferência braquial como para a da cintura, observase semelhança entre as idades 8 e 9 anos e, diferença entre 7 e 8 anos e entre 9 e 10 anos. A maior diferença relativa observada ocorreu entre 9 e 10 anos: $8,7 \%$ para circunferência braquial e 7,1\% para a circunferência da cintura, representando diferenças médias de $1,8 \mathrm{~cm}$ e 4,5 cm, respectivamente. (Tabelas 10 e 11; Gráficos 10 e 11).

Comparando-se os dados de circunferência mediana do braço do presente estudo com os valores medianos do estudo de FRISANCHO (1999) para cada faixa etária, observou-se semelhança entre as curvas (Gráficos $12 a$ e $12 b)$. 
Para a comparação dos valores medianos da circunferência da cintura do presente estudo com valores de referência, utilizou-se os dados de circunferência da cintura de escolares ingleses, aferidos em pesquisa realizada pela Universidade de Loughborough, em 1990 (MCCARTHY e col. 2001). Observou-se maiores valores medianos entre os escolares estudados em São Paulo (Gráficos 13a e 13b).

Tabela 10 - Circunferência média braquial e da cintura, desvio padrão (dp) e IC(95\%) segundo sexo e idade (anos). Duas escolas públicas de São Paulo.

\begin{tabular}{lcccc}
\hline & \multicolumn{4}{c}{${\text { Idade }(\text { anos })^{(2)}}$} \\
Sexo $^{(1)}$ & 7 & \multicolumn{4}{c}{8} & 9 & 10 \\
\hline \multicolumn{1}{c}{ Circunferência braquial $(\mathrm{cm})$} & valores médios e desvio padrão (dp) (IC 95\%) \\
Masculino & $19,4(2,2)$ & $20,7(3,3)$ & $20,4(3,2)$ & $22,5(3,6)$ \\
& $(18,9-19,9)$ & $(19,9-21,4)$ & $(19,6-21,3)$ & $(21,6-23,3)$ \\
Feminino & $19,2(2,1)$ & $20,13(2,6)$ & $20,8(3,1)$ & $22,5(2,8)$ \\
& $(18,7-19,7)$ & $(19,5-20,8)$ & $(20,1-21,6)$ & $(21,8-23,1)$ \\
Total & $19,3(2,2)$ & $20,4(3,0)$ & $20,6(3,2)$ & $22,4(3,2)$ \\
& $(18,9-19,6)$ & $(19,9-20,9)$ & $(20,1-21,2)$ & $(21,9-23,0)$
\end{tabular}

Circunferência da cintura $(\mathrm{cm})$ valores médios e desvio padrão (dp) (IC 95\%)

\begin{tabular}{|c|c|c|c|c|}
\hline Masculino & $\begin{array}{c}59,7(5,9) \\
(58,4-61,1)\end{array}$ & $\begin{array}{c}63,5(10,0) \\
(61,1-65,8)\end{array}$ & $\begin{array}{c}64,1(9,4) \\
(61,8-66,5)\end{array}$ & $\begin{array}{c}68,2(11,2) \\
(65,6-70,9)\end{array}$ \\
\hline Feminino & $\begin{array}{c}58,5(6,3) \\
(57,1-59,9)\end{array}$ & $\begin{array}{c}60,2(7,2) \\
(58,4-62,0)\end{array}$ & $\begin{array}{c}63,0(9,1) \\
(60,7-65,3)\end{array}$ & $\begin{array}{c}68,0(9,4) \\
(65,7-70,2)\end{array}$ \\
\hline Total & $\begin{array}{c}59,1(6,1) \\
(58,1-60,1)\end{array}$ & $\begin{array}{c}61,9(8,9) \\
(60,4-63,4)\end{array}$ & $\begin{array}{c}63,6(9,3) \\
(61,9-65,2)\end{array}$ & $\begin{array}{c}68,1(10,3) \\
(66,4-69,8)\end{array}$ \\
\hline
\end{tabular}

Tabela 11 - Diferença relativa (\%) e absoluta $(\mathrm{cm})$ da circunferência braquial e da cintura segundo idade

\begin{tabular}{lcccc}
\hline $\begin{array}{l}\text { Idade } \\
\text { (anos) }\end{array}$ & $\begin{array}{c}\text { Diferença relativa (\%) } \\
\text { Circunferência } \\
\text { braquial }\end{array}$ & $\begin{array}{c}\text { Circunferência } \\
\text { da cintura }\end{array}$ & $\begin{array}{c}\text { Diferença absoluta }(\mathrm{cm}) \\
\text { Circunferência } \\
\text { braquial }\end{array}$ & $\begin{array}{c}\text { Circunferência } \\
\text { da cintura }\end{array}$ \\
\hline $7 / 8$ & 5,7 & 2,8 & 1,1 & 2,8 \\
$8 / 9$ & 1,0 & 2,7 & 0,2 & 1,7 \\
$9 / 10$ & 8,7 & 7,1 & 1,8 & 4,5 \\
$7 / 10$ & 16,1 & 15,2 & 3,1 & 9,0 \\
$8 / 10$ & 9,8 & 10,0 & 2,0 & 6,2 \\
\hline
\end{tabular}




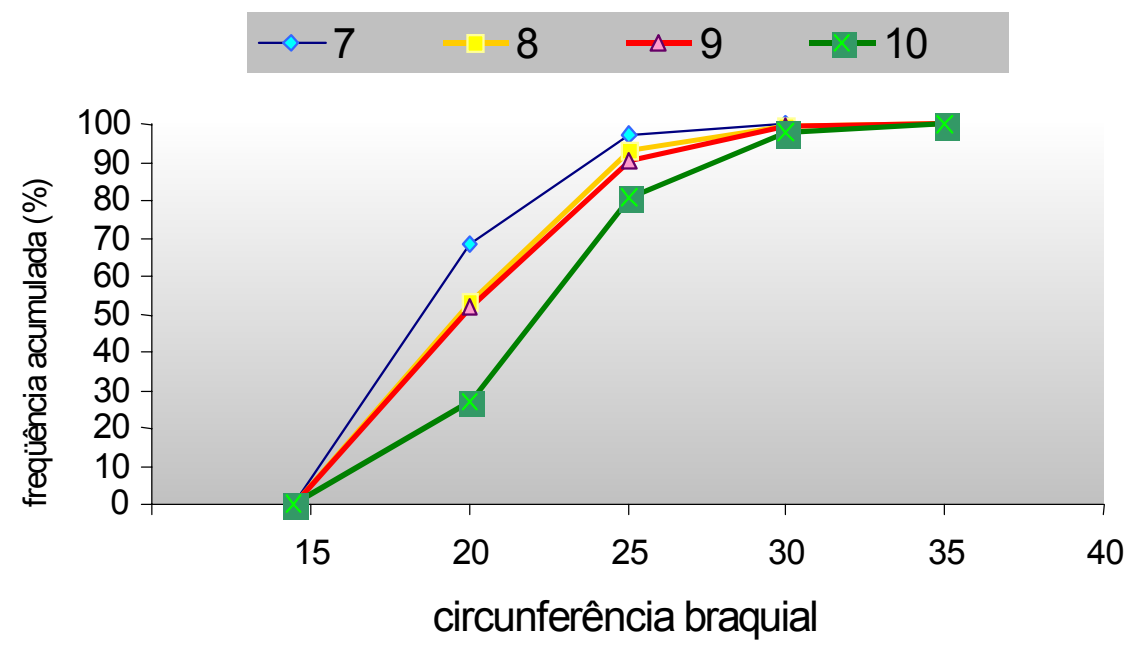

Gráfico 10 - Distribuição acumulada de escolares segundo circunferência braquial $(\mathrm{cm})$ e idade. Duas escolas públicas de São Paulo, 2004.

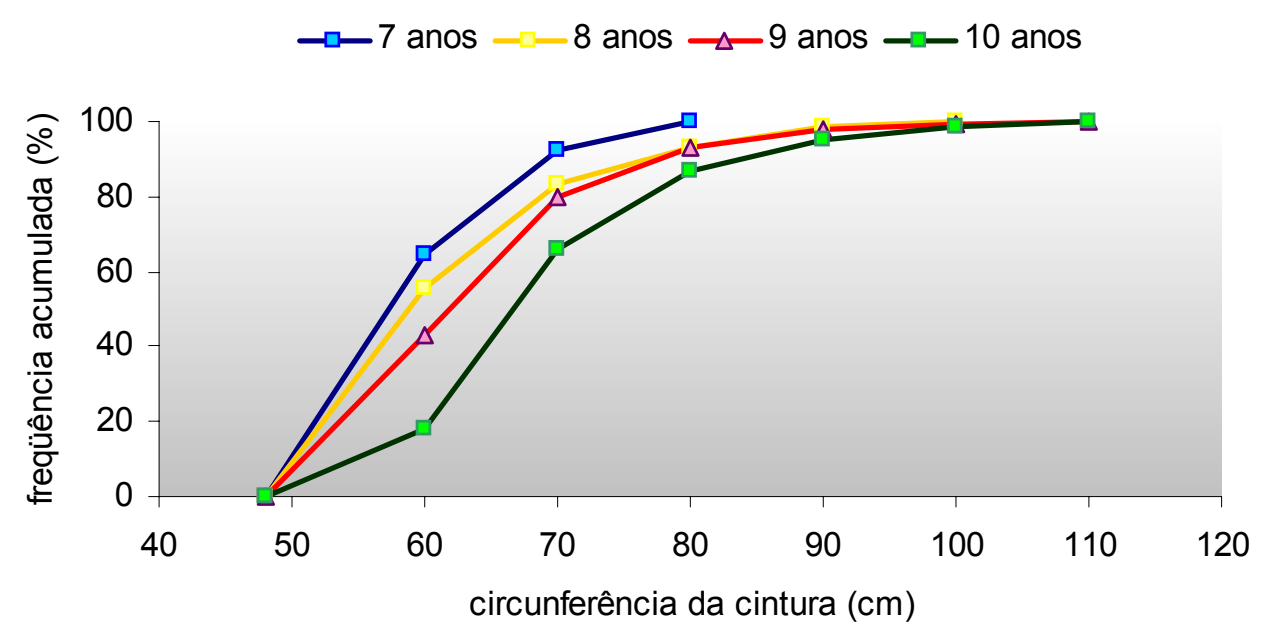

Gráfico 11 - Distribuição acumulada de escolares segundo circunferência da cintura $(\mathrm{cm})$ e idade. Duas escolas públicas de São Paulo, 2004. 


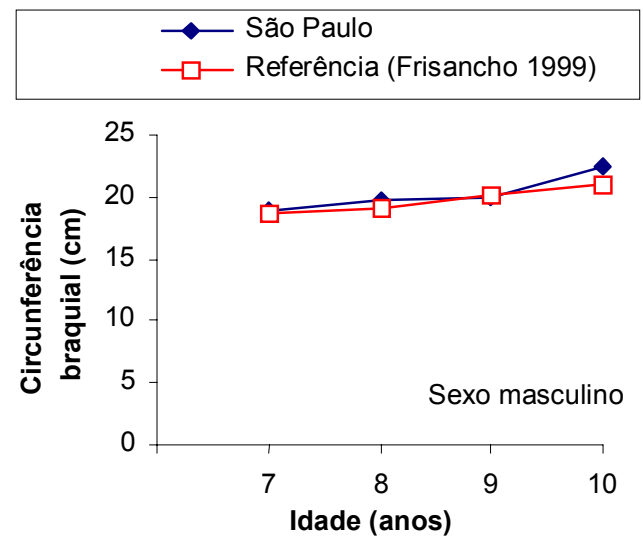

(a)

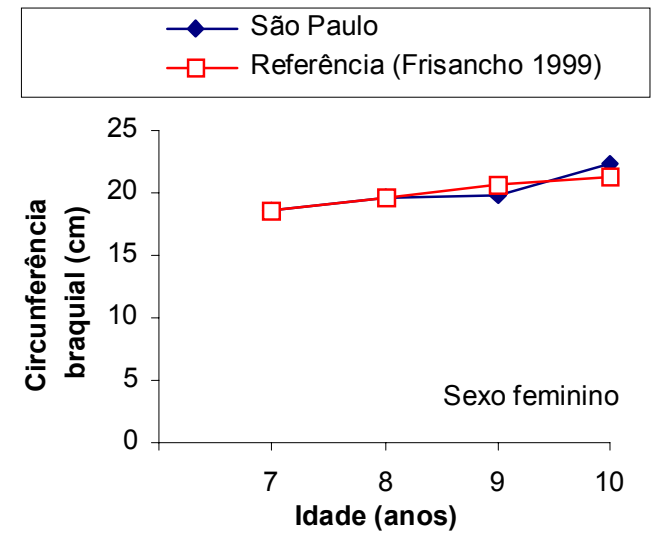

(b)

\section{${ }^{1}$ FRISANCHO 1999}

Gráfico 12a e 12b - Medianas de circunferência braquial $(\mathrm{cm})$ em relação à idade de escolares de duas escolas públicas de São Paulo em 2004 e de crianças americanas ${ }^{1}$.

$\smile$ São Paulo

$\dashv \square$ Referência (McCarthy 2001)

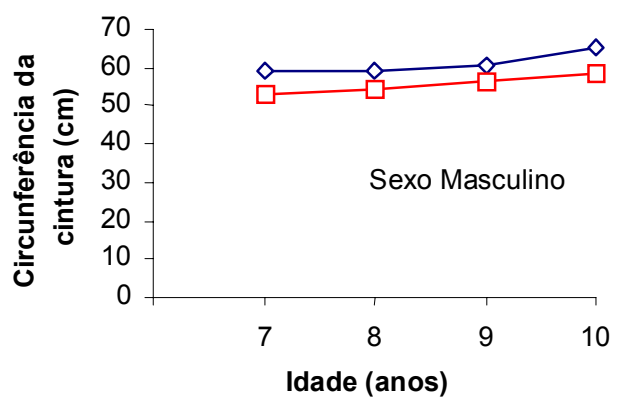

(a) $\sim$ São Paulo

$\dashv \square$ Referência (McCarthy 2001)

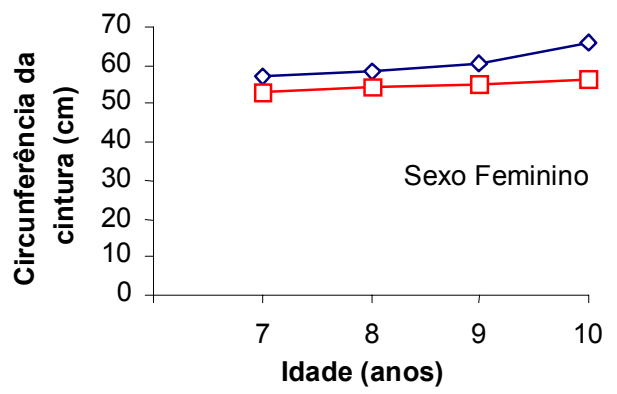

(b)

${ }^{1}$ MCCARTHY 2001

Gráfico 13a e 13b - Medianas de circunferência da cintura $(\mathrm{cm})$ em relação à idade de escolares de duas escolas públicas de São Paulo em 2004 e de crianças britânicas ${ }^{1}$. 


\section{4 - Estado Nutricional}

A avaliação do estado nutricional indicou prevalência de baixo peso igual a 4,4\% (IC95\%: 2,9-6,6\%); de risco de sobrepeso igual a $15,3 \%$ (IC95\%: $12,4-18,5 \%$ ) e de sobrepeso, $11,0 \%$ (IC 95\%: 8,5 - 13,9\%). Não foi observada diferença na classificação do estado nutricional segundo sexo $(p=0,056)$ e idade $(p=0,096)$ (Tabelas 12 e 13).

Tabela 12 - Distribuição de escolares segundo classificação do estado nutricional com base no percentil do IMC e percentil do Índice de estatura/idade segundo sexo. Duas escolas públicas de São Paulo, 2004.

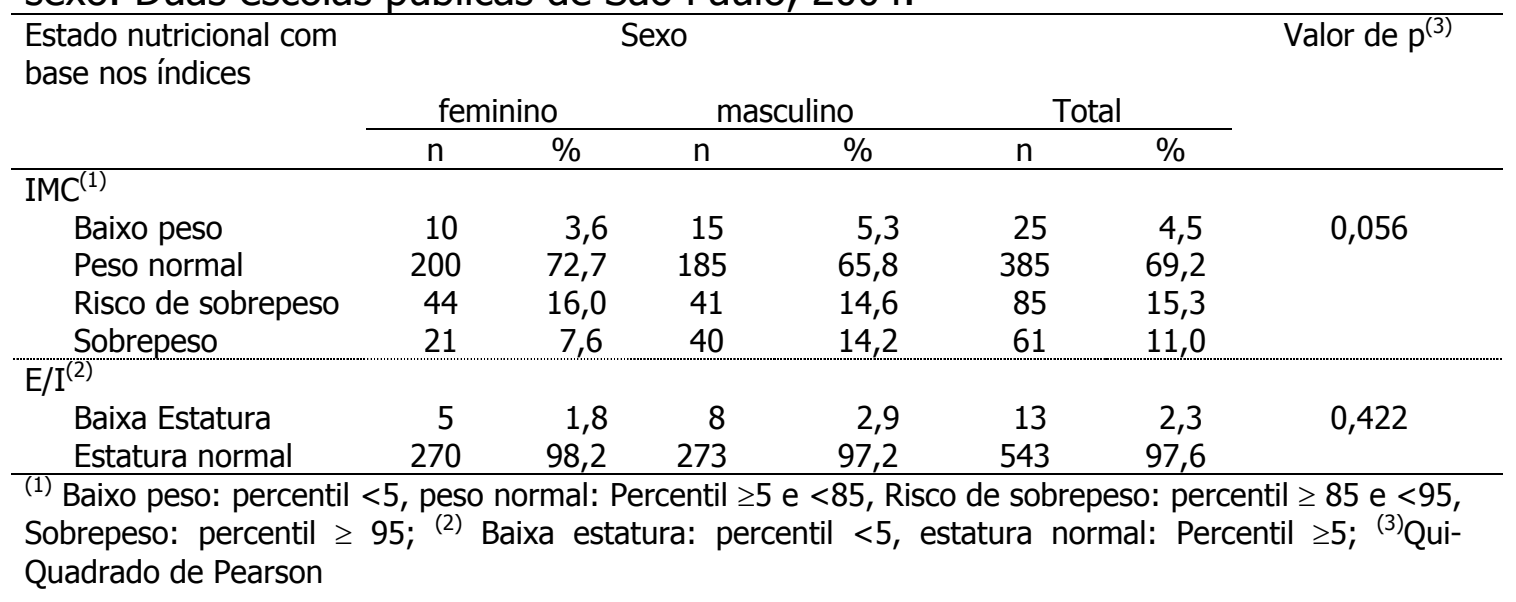

Tabela 13 - Distribuição de escolares segundo classificação do estado nutricional com base no percentil do IMC e do Índice de Estatura/idade (E/I) em relação a população de referência segundo idade (anos). Duas escolas públicas de São Paulo, 2004.

\begin{tabular}{|c|c|c|c|c|c|c|c|c|c|}
\hline \multirow{3}{*}{$\begin{array}{l}\text { Estado nutricional com } \\
\text { base nos índices }\end{array}$} & \multicolumn{8}{|c|}{ Idade (anos) } & \multirow{3}{*}{$\begin{array}{l}\text { Valor de } \\
\text { de } \mathrm{p}^{(3)}\end{array}$} \\
\hline & \multicolumn{2}{|c|}{7} & \multicolumn{2}{|c|}{8} & \multicolumn{2}{|c|}{9} & \multicolumn{2}{|c|}{10} & \\
\hline & $\mathrm{n}$ & $\%$ & $\mathrm{n}$ & $\%$ & $\mathrm{n}$ & $\%$ & $\mathrm{n}$ & $\%$ & \\
\hline \multicolumn{10}{|l|}{$\mathrm{IMC}^{(1)}$} \\
\hline Baixo peso & 6 & 4,0 & 8 & 5,8 & 8 & 6,4 & 3 & 2,1 & 0,096 \\
\hline Peso normal & 113 & 74,8 & 94 & 68,1 & 86 & 68,3 & 92 & 65,3 & \\
\hline Risco de sobrepeso & 14 & 9,3 & 18 & 13,0 & 23 & 18,3 & 30 & 21,3 & \\
\hline Sobrepeso & 18 & 11,9 & 18 & 13,0 & 9 & 7,1 & 16 & 11,4 & \\
\hline \multicolumn{10}{|l|}{ Índice $\mathrm{E} / \mathrm{I}^{(2)}$} \\
\hline Baixa estatura & 2 & 1,3 & 2 & 1,5 & 3 & 2,4 & 6 & 4,3 & 0,330 \\
\hline Estatura normal & 149 & 98,7 & 136 & 98,6 & 123 & 97,6 & 135 & 95,7 & \\
\hline
\end{tabular}


O gráfico 14 apresenta a distribuição de escolares de ambos os sexos segundo o percentil do IMC em relação à curva de referência.

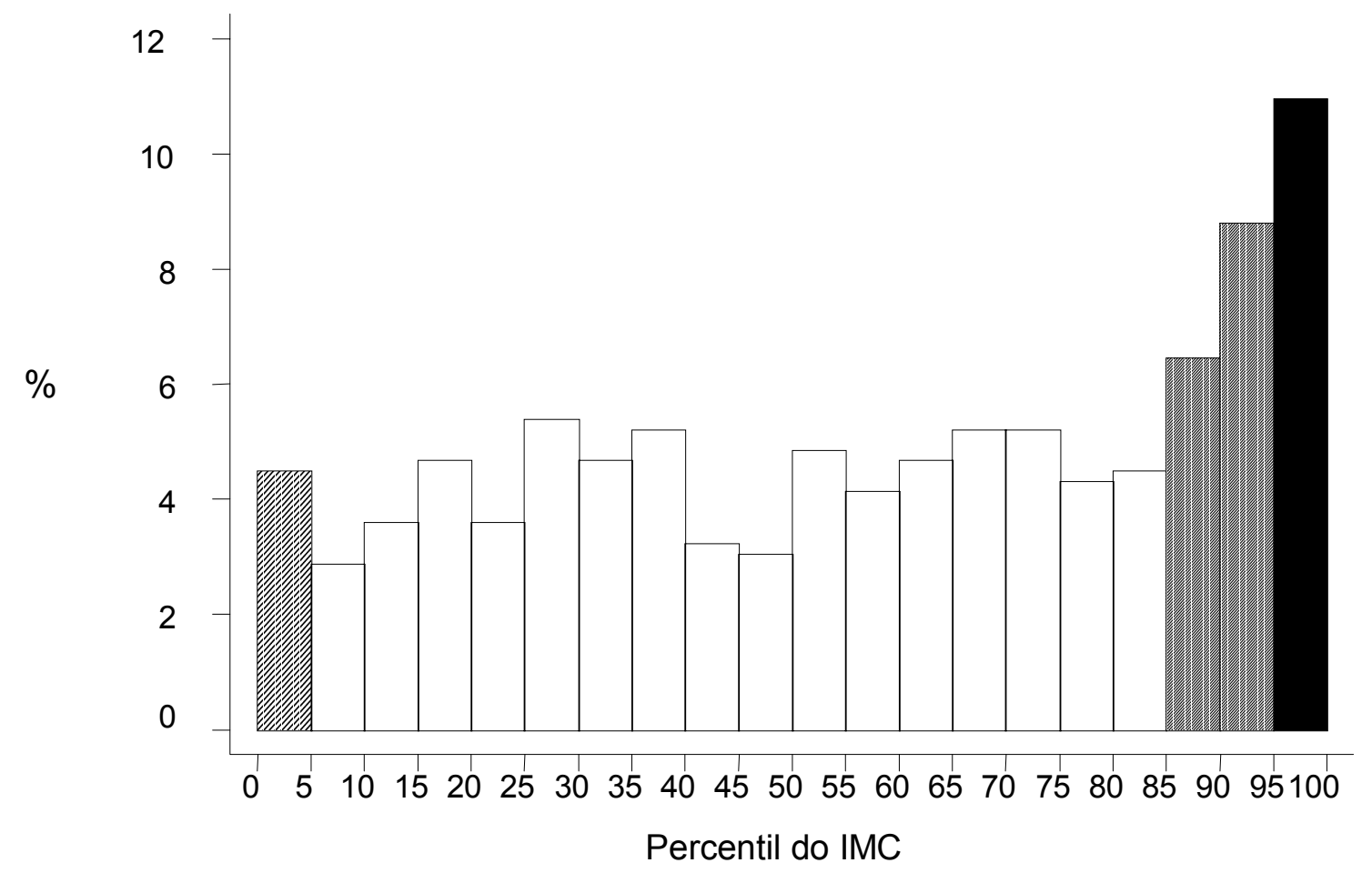

Gráfico 14 - Distribuição de escolares segundo classificação do estado nutricional com base no percentil do IMC em relação à população de referência. Duas escolas públicas de São Paulo, 2004.

O percentil do índice de Estatura/Idade em relação à curva de referência permitiu a identificação de 13 escolares classificados como tendo baixa estatura, revelando prevalência de déficit estatural de 2,3\% (IC 95\%: $1,2-4,0 \%)$.

O gráfico 15 apresenta a distribuição de escolares segundo valores do percentil de do índice de Estatura/Idade em relação à curva de referência. 


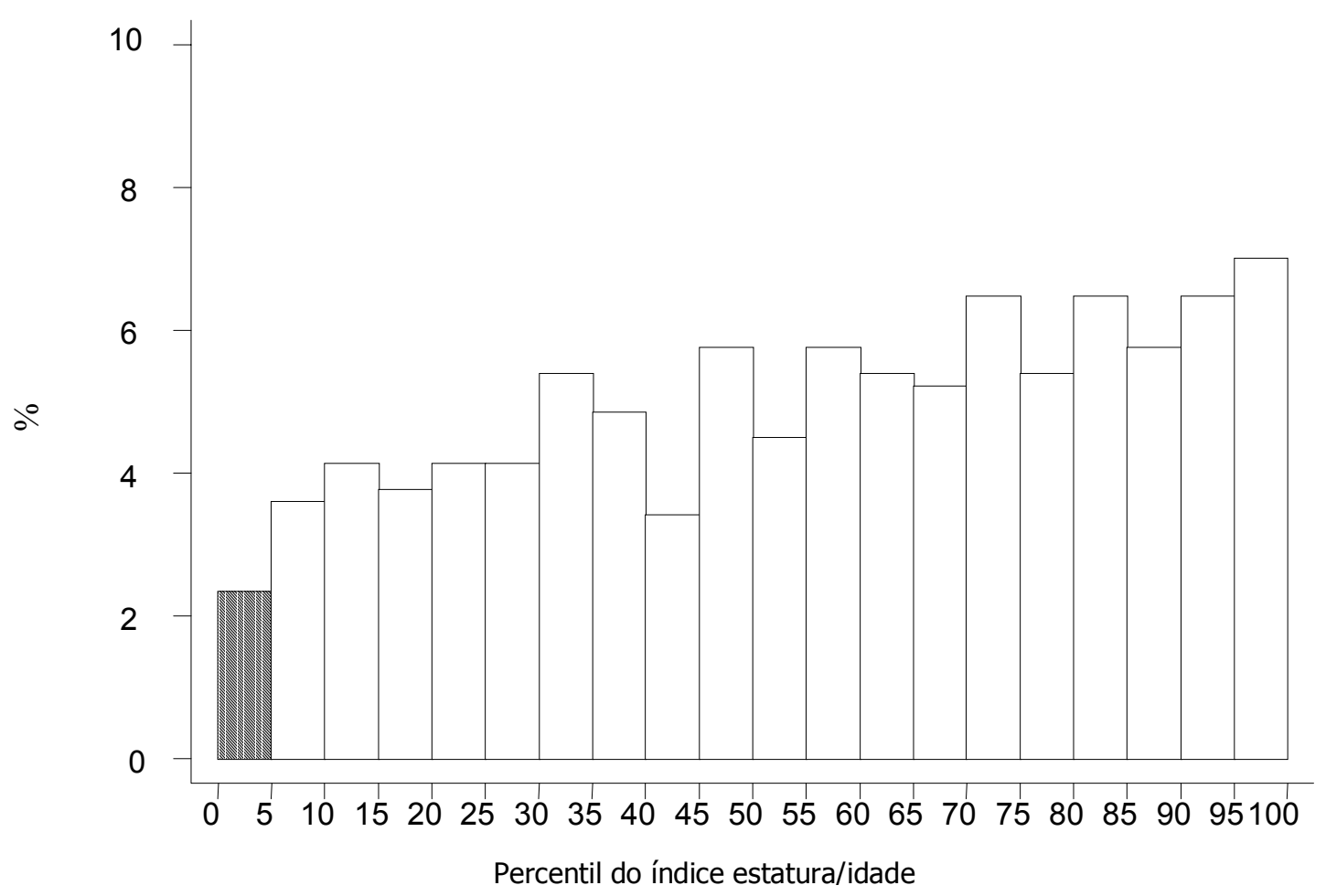

Gráfico 15 - Distribuição de escolares segundo classificação do estado nutricional com base no percentil do Índice de Estatura/idade (E/I) em relação à população de referência. Duas escolas públicas de São Paulo, 2004.

\section{5 - Composição corporal}

Os percentuais médios de gordura corporal total estimados pela BIA e pelas pregas cutâneas (tricipital e da panturrilha) variam entre $18,4 \% \mathrm{e}$ 29,7\% (Tabela 14).

Pela BIA, observou-se que escolares do sexo feminino apresentam percentuais médios de gordura maiores que os do sexo masculino para as idades de 7, 8 e 9 anos. Tanto para meninos como para meninas, não foi observada mudança nos percentuais médios de gordura total com aumento da idade. Os dados de composição corporal obtidos pela BIA, classificados em duas categorias: sem risco de doença cardiovascular e com risco de DCV, resultam em prevalência de risco de DCV igual a 42,3\% (IC95\%: 38,1 $46,5 \%)$, independente de sexo $(p=0,579)$ e idade $(p=0,642)$ (Tabelas 14,15 e 16). 
Os percentuais médios de gordura total estimados pelas pregas cutâneas parecem não diferir segundo sexo, com exceção da idade de 7 anos, onde as meninas apresentam maior percentual médio de gordura total. Segundo idade, parece não haver diferença entre os níveis médios de gordura total, com exceção dos escolares do sexo masculino com 10 anos, comparados aos de outras idades. Utilizando-se a mesma classificação de risco de DCV descrita para gordura corporal estimada pela BIA, observa-se prevalência de risco de DCV para ambos os sexos e todas as idades, igual a 20,1\% (IC95\%: 16,9 - 23,7\%). Esta prevalência é, entretanto, maior entre meninos $(p<0,001)$ com tendência de aumento com a idade $(p<0,001)$ (Tabelas 14, 15 e 16).

Tabela 14 - Percentual médio e desvio padrão $(\mathrm{dp})$ de gordura corporal total estimado pela BIA e pelas pregas cutâneas tricipital e da panturrilha e IC(95\%) segundo sexo e idade (anos). Duas escolas públicas de São Paulo, 2004.

\begin{tabular}{lcccc}
\hline Sexo $^{(1)}$ & \multicolumn{4}{c}{ Idade (anos) $)^{(2)}$} \\
\cline { 2 - 5 } Masculino & \multicolumn{4}{c}{ Valor médio e (dp) do \% gordura corporal total (BIA) } \\
& $23,3(7,1)$ & $25,2(8,9)$ & $23,4(8,1)$ & $27,1(9,0)$ \\
Feminino & $(21,7-24,9)$ & $(23,1-27,3)$ & $(21,4-25,5)$ & $(25,0-29,3)$ \\
& $29,5(6,7)$ & $29,4(7,5)$ & $28,1(7,5)$ & $29,7(8,6)$ \\
Total & $(28,0-31,0)$ & $(27,6-31,2)$ & $(26,2-29,9)$ & $(27,7-31,8)$ \\
& $26,4(7,5)$ & $27,2(8,5)$ & $25,8(8,1)$ & $28,4(8,8)$ \\
& $(25,2-27,6)$ & $(25,8-28,6)$ & $(24,4-27,2)$ & $(26,9-29,9)$ \\
& \multicolumn{4}{c}{} \\
Masculino & \multicolumn{4}{c}{ Valor médio e (dp) do \% gordura corporal total (pregas) } \\
Feminino & $18,4(5,6)$ & $21,1(8,9)$ & $20,1(8,1)$ & $25,5(9,5)$ \\
& $(17,1-19,6)$ & $(19,0-23,2)$ & $(18,1-22,2)$ & $(23,3-27,8)$ \\
Total & $21,1(5,0)$ & $22,1(5,6)$ & $23,1(5,7)$ & $25,8(6,8)$ \\
& $(19,9-22,2)$ & $(20,7-23,5)$ & $(21,6-24,5)$ & $(24,2-27,4)$ \\
& $19,7(5,5)$ & $21,5(7,5)$ & $21,6(7,1)$ & $25,7(8,2)$ \\
& $(18,8-20,6)$ & $(20,3-22,8)$ & $(20,4-22,9)$ & $(24,3-27,0)$ \\
\hline
\end{tabular}

(1) Masculino $(n=281)$, Feminino $(n=275)$;

(2) 7 anos $(n=151) ; 8$ anos $(n=138) ; 9$ anos $(n=126) ; 10$ anos $(n=141)$ 
Tabela 15 - Distribuição de escolares segundo classificação de risco de DCV, com base na gordura corporal estimado pela BIA e pelas pregas cutâneas tricipital e da panturrilha, segundo sexo. Duas escolas públicas de São Paulo, 2004.

\begin{tabular}{|c|c|c|c|c|c|c|c|}
\hline \multirow[t]{3}{*}{ Classificação de risco } & \multicolumn{4}{|c|}{ Sexo } & & & \multirow[t]{3}{*}{ Valor de $\mathrm{p}^{(3)}$} \\
\hline & \multicolumn{2}{|c|}{ Feminino } & \multicolumn{2}{|c|}{ Masculino } & \multicolumn{2}{|c|}{ Total } & \\
\hline & $n$ & $\%$ & $\mathrm{n}$ & $\%$ & $\mathrm{n}$ & $\%$ & \\
\hline \multicolumn{8}{|l|}{ BIA } \\
\hline Sem risco de $\mathrm{DCV}^{(1)}$ & 162 & 58,9 & 159 & 56,6 & 321 & 57,7 & 0,579 \\
\hline Com risco de $\mathrm{DCV}^{(2)}$ & 113 & 41,1 & 122 & 43,4 & 235 & 42,3 & \\
\hline \multicolumn{8}{|l|}{ Pregas cutâneas } \\
\hline Sem risco de $\mathrm{DCV}^{(1)}$ & 237 & 86,2 & 207 & 73,7 & 444 & 79,9 & $<0,001$ \\
\hline Com risco de $\mathrm{DCV}^{(2)}$ & 38 & 13,8 & 74 & 26,3 & 112 & 20,1 & \\
\hline
\end{tabular}

Tabela 16 - Distribuição de escolares segundo classificação de risco de DCV, com base na gordura corporal estimado pela BIA e pelas pregas cutâneas tricipital e da panturrilha, segundo idade. Duas escolas públicas de São Paulo, 2004.

\begin{tabular}{|c|c|c|c|c|c|c|c|c|c|}
\hline \multirow[t]{3}{*}{ Classificação de risco } & \multicolumn{8}{|c|}{ Idade (anos) } & \multirow{3}{*}{$\begin{array}{l}\text { Valor de } \\
\text { de } \mathrm{p}^{(3)}\end{array}$} \\
\hline & \multicolumn{2}{|c|}{7} & \multicolumn{2}{|c|}{8} & \multicolumn{2}{|c|}{9} & \multicolumn{2}{|c|}{10} & \\
\hline & $\mathrm{n}$ & $\%$ & $\mathrm{n}$ & $\%$ & $\mathrm{n}$ & $\%$ & $\mathrm{n}$ & $\%$ & \\
\hline \multicolumn{10}{|l|}{ BIA } \\
\hline Sem risco de $\mathrm{DCV}^{(1)}$ & 89 & 58,9 & 81 & 58,7 & 76 & 60,3 & 75 & 53,2 & 0,642 \\
\hline Com risco de $\mathrm{DCV}^{(2)}$ & 62 & 41,1 & 57 & 41,3 & 50 & 39,7 & 66 & 46,8 & \\
\hline \multicolumn{10}{|l|}{ Pregas cutâneas } \\
\hline Sem risco de $\mathrm{DCV}^{(1)}$ & 135 & 89,4 & 113 & 81,9 & 100 & 79,4 & 96 & 68,1 & $<0,001$ \\
\hline Com risco de $\mathrm{DCV}^{(2)}$ & 16 & 10,6 & 25 & 18,1 & 26 & 20,6 & 45 & 31,9 & \\
\hline
\end{tabular}

\section{6 - Comparação entre o percentual de gordura total estimado pela BIA e pelas pregas cutâneas tricipital e da panturrilha}

Observou-se que os percentuais de gordura total estimados pelas pregas cutâneas tricipital e da panturrilha eram menores que os estimados pela BIA, para escolares de ambos os sexos, em todas as idades; a maior diferença sendo $8,4 \%$ e a menor, $1,6 \%$. Observou-se maiores diferenças ocorrendo em idades menores (Tabela 17, Gráfico 16). 
Tabela 17 - Diferença relativa (\%) e absoluta do percentual de gordura corporal total calculado pela BIA e pelas pregas cutâneas tricipital e da panturrilha.

\begin{tabular}{lcc}
\hline & Diferença absoluta (\%): \% gordura BIA -\% gordura pregas \\
\hline Idade (anos) & Masculino & Feminino \\
\hline 7 & 4,9 & 8,4 \\
8 & 4,1 & 7,3 \\
9 & 3,3 & 5,0 \\
10 & 1,6 & 3,9 \\
\hline
\end{tabular}

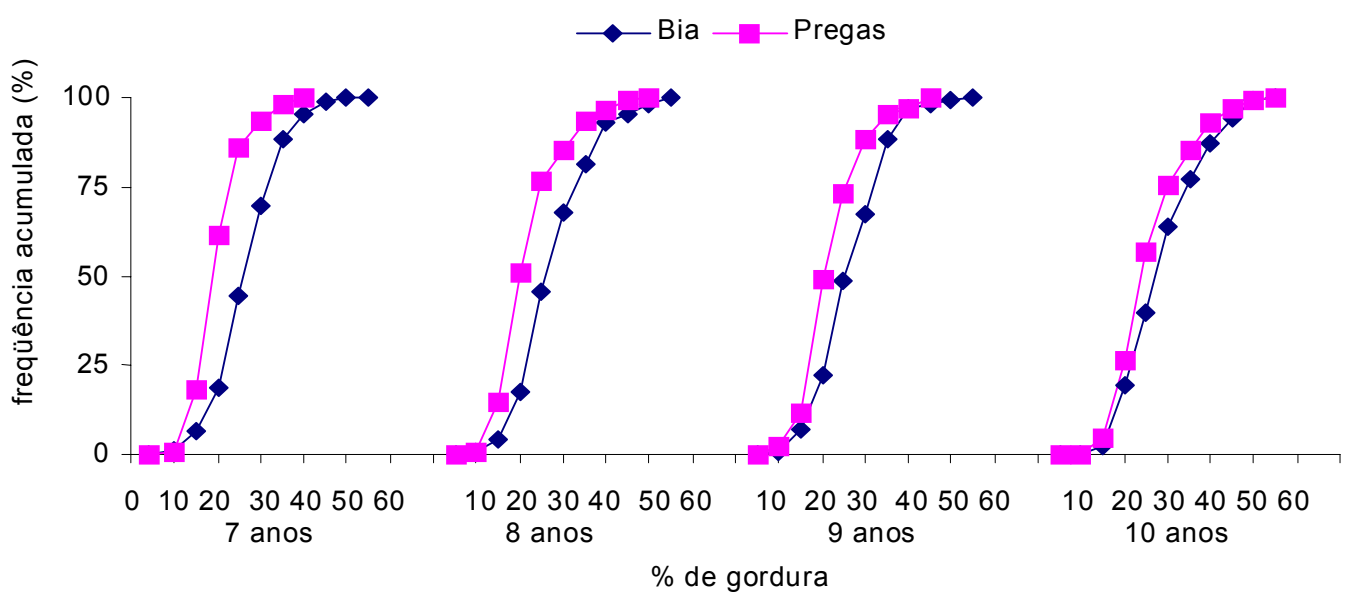

Gráfico 16 - Distribuição acumulada de escolares segundo percentual de gordura corporal total pela BIA e pelas pregas cutâneas tricipital e da panturrilha para ambos os sexos, segundo idade (anos). Duas escolas públicas de São Paulo, 2004.

Observou-se existência de correlação positiva entre os valores de percentual de gordura total estimados pelos dois métodos, tanto para escolares do sexo masculino $(n=281 ; r=0,73 ; p<0,001)$ como escolares do sexo feminino ( $n=275 ; r=0,69 ; p<0,001)$ (Gráficos 17a e 17b). 


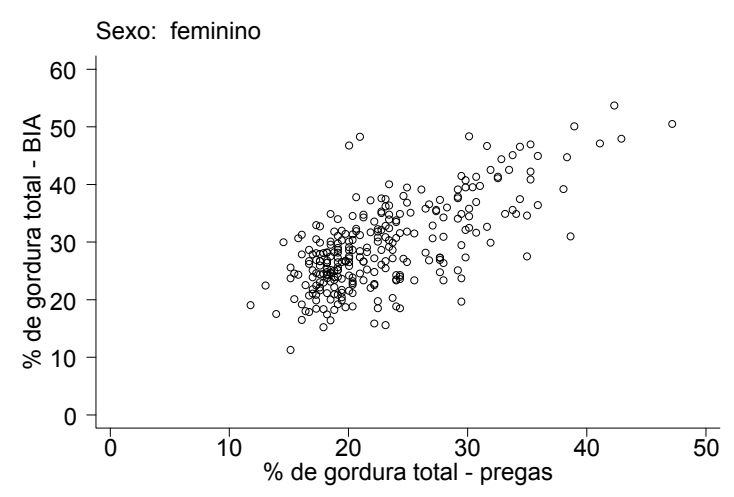

(a)

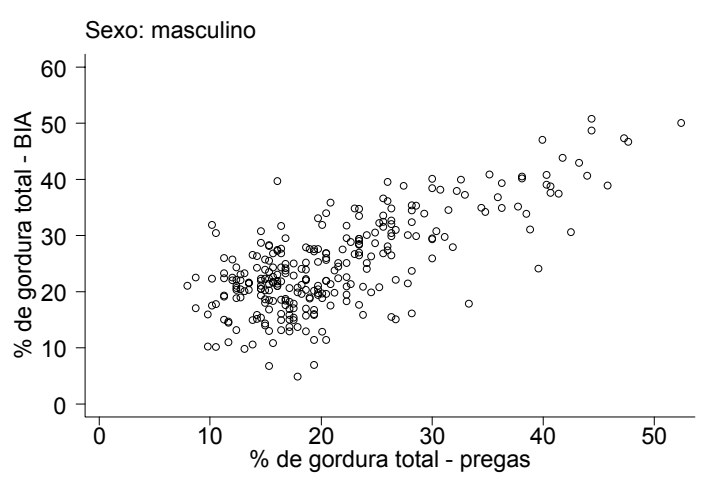

(b)

Gráficos 17a e 17b - Distribuição de escolares segundo percentual de gordura total estimado pela BIA e pelas pregas cutâneas tricipital e da panturrilha, segundo sexo. Duas escolas públicas de São Paulo, 2004.

Os Gráficos 18a e 18b apresentam a distribuição dos valores médios dos percentuais de gordura total estimados pela BIA e pelas pregas (eixo das abscissas), versus a diferença entre os valores (eixo das ordenadas), para escolares do sexo feminino (a) e do sexo masculino (b), conforme proposto por BLAND e ALTMAN (1986).

O limite de concordância observado para a diferença entre os métodos para o sexo feminino foi de $-4,6$ a $17,1 \%$ e para o sexo masculino de $-8,7$ a $15,7 \%$. Assim, o percentual de gordura total estimado pelas pregas, para todas as idades, para escolares do sexo feminino pode ser $5 \%$ abaixo ou $17 \%$ acima do percentual de gordura total estimado pela BIA e, para o sexo masculino, $9 \%$ abaixo ou $16 \%$ acima, indicando possível melhor concordância entre os métodos para o sexo feminino, se for considerado o limite inferior de concordância, entretanto, devido à magnitude do limite de concordância superior, para ambos os sexos, pode-se suspeitar de falta de concordância entre os métodos na caracterização da composição corporal (Tabela 18).

Os intervalos de confiança para os limites de concordância (inferior e superior) para cada um dos sexos indicam boa precisão da estimativa, trazendo pouca alteração na amplitude destes limites (Tabela 19).

A análise dos limites de concordância segundo idade indica, para escolares de 7 anos, que o percentual de gordura total estimado pelas pregas 
pode ser $4,2 \%$ abaixo e $17,6 \%$ acima do percentual de gordura total estimado pela BIA. Os limites inferiores do limite de concordância aumentam com a idade, entretanto, os limites superiores diminuem com a idade. Pelos intervalos de confiança das diferenças entre os valores de percentual de gordura total, observa-se aproximação destes, com o aumento da idade.

Os IC (95\%) dos LI (limite inferior) e LS (limite superior) dos limites de concordância são menores que $4 \%$, indicando boa precisão na estimativa dos limites de concordância populacionais.

Os intervalos de confiança para a diferença entre os métodos indicam menor diferença para o sexo masculino (Tabela 19) e diferenças menores com o aumento da idade.

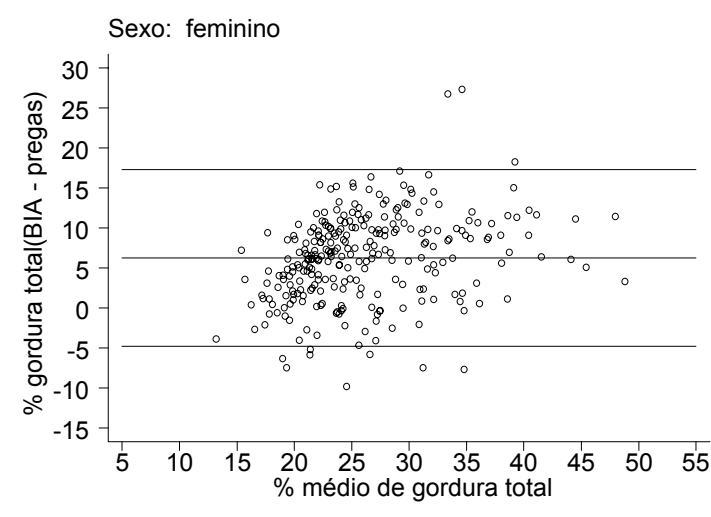

(a)

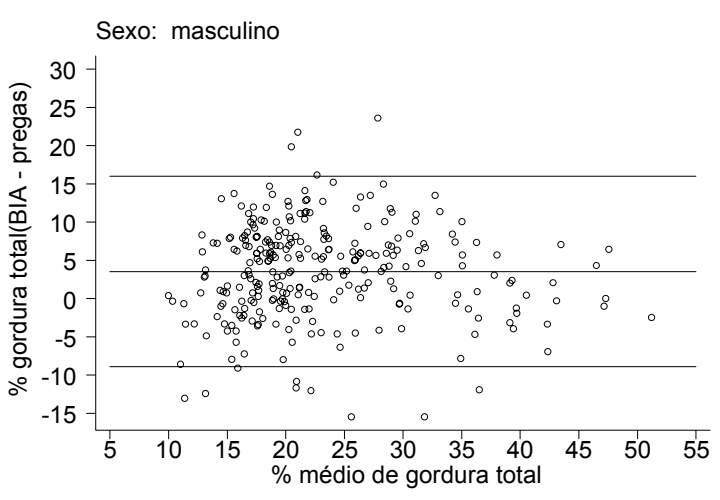

(b)

média das diferenças $=$ média $_{\text {dif }}($ fem $=6,23 \%$; masc $=3,52 \%$ ); desvio padrão das diferenças $=\mathrm{dp}_{\mathrm{dif}}(\mathrm{fem}=5,52 \%$; $\operatorname{masc}=6,22 \%)$.

Gráficos 18a e 18b - Diagrama de Bland e Altman - distribuição de escolares segundo valores médios e diferenças do percentual de gordura total estimado pela BIA e pelas pregas cutâneas tricipital e da panturrilha. Duas escolas públicas de São Paulo, 2004. 
Tabela 18 - Limites de concordância e IC (95\%) para a diferença entre percentuais de gordura total estimados pela BIA e pelas pregas cutâneas e dos limite inferior e superior dos limites de concordância, segundo idade.

\begin{tabular}{|c|c|c|c|c|c|}
\hline \multirow[t]{2}{*}{ Idade (anos) } & \multicolumn{2}{|c|}{$\begin{array}{c}\text { Limite de } \\
\text { concordância }(\%)^{(1)}\end{array}$} & \multicolumn{3}{|c|}{ IC (95\%) } \\
\hline & Inferior & Superior & $\begin{array}{c}\text { Diferença } \\
(\%)\end{array}$ & $\begin{array}{l}\text { LI do limite de } \\
\text { concordância }\end{array}$ & $\begin{array}{l}\text { LS do limite de } \\
\text { concordância }\end{array}$ \\
\hline $7(n=151)$ & $-4,2$ & 17,6 & $5,8-7,6$ & $-5,8--2,7$ & $16,0-19,1$ \\
\hline $8(n=138)$ & $-5,8$ & 17,1 & $4,7-6,6$ & $-7,5--4,1$ & $15,4-18,8$ \\
\hline $9(n=126)$ & $-7,4$ & 15,7 & $3,1-5,2$ & $-9,2--5,6$ & $13,9-17,5$ \\
\hline $10(n=141)$ & $-9,4$ & 14,9 & $1,7-3,8$ & $-11,1--7,6$ & $13,1-16,7$ \\
\hline $\begin{array}{l}\text { Geral } \\
(n=556)\end{array}$ & $-7,0$ & 16,7 & $4,4-5,4$ & $-7,9--6,1$ & $15,8-17,6$ \\
\hline
\end{tabular}

Tabela 19 - Limites de concordância e IC (95\%) para a diferença entre percentuais de gordura total estimados pela BIA e pelas pregas cutâneas e dos limite inferior e superior dos limites de concordância, segundo sexo.

\begin{tabular}{l}
$\begin{array}{l}\text { Sexo } \\
\end{array}$ \\
\cline { 2 - 5 } $\begin{array}{c}\text { Limite de } \\
\text { concordância } \\
\text { Inferior })^{(1)}\end{array}$
\end{tabular}

Observou-se existência de confiabilidade dos métodos que estimam o percentual de gordura total, com coeficientes de correlação intraclasse iguais a 0,967 (IC95\% 0,962 - 0,972); 0,954 (IC95\% 0,947 - 0,961); 0,994 (IC95\% 0,991 - 0,997) para a prega cutânea tricipital, da panturrilha e pela BIA, respectivamente (Anexo 9).

Os pontos de corte para os percentuais de gordura total estimados pela BIA e pelas pregas cutâneas que igualam (otimizam) a sensibilidade e a 
especificidade segundo sexo, calculados pelas curvas TGROC, são apresentados na Tabela 20.

Foram observados valores de ponto de corte maiores para o sexo feminino para ambos os métodos. Observa-se, ainda, valores de ponto de corte (numericamente) maiores para a BIA do que para as pregas.

Apresenta-se somente a curva TGROC para o percentual de gordura total estimado pela BIA para escolares do sexo feminino (Gráfico 19). Os demais gráficos estão apresentados no Anexo 14.

Tabela 20 - Valores de pontos de corte que igualam (otimizam) a sensibilidade e especificidade, da gordura total pela BIA e pelas pregas cutâneas, em relação ao percentil do IMC, segundo sexo. Duas escolas públicas de São Paulo, 2004.

\begin{tabular}{|c|c|c|c|c|c|}
\hline \multirow[t]{3}{*}{ Sexo } & \multirow{3}{*}{$\mathrm{n}$} & \multicolumn{4}{|c|}{ Ponto de corte do percentual de gordura corporal total (\%) } \\
\hline & & & IA & & Dregas \\
\hline & & valor & Intermediate range & valor & $\begin{array}{c}\text { Intermediate } \\
\text { range }\end{array}$ \\
\hline Masculino & 281 & 26,7 & $(23,6-28,5)$ & 22,5 & $(21,5-23,3)$ \\
\hline Feminino & 275 & 31,6 & $(29,6-33,3)$ & 24,2 & $(23,3-25,4)$ \\
\hline
\end{tabular}

Com base nos pontos de corte fornecidos pelas curvas TGROC, foram criadas variáveis dicotômicas para os dois métodos e calculados os indicadores de sensibilidade, especificidade, eficiência e Índice de Youden (Tabela 21).

Os valores de sensibilidade, especificidade, eficiência, índice de Youden e área sob a curva ROC são maiores para o percentual de gordura total estimado pelas pregas cutâneas (Tabelas 22 e Gráfico 20). 


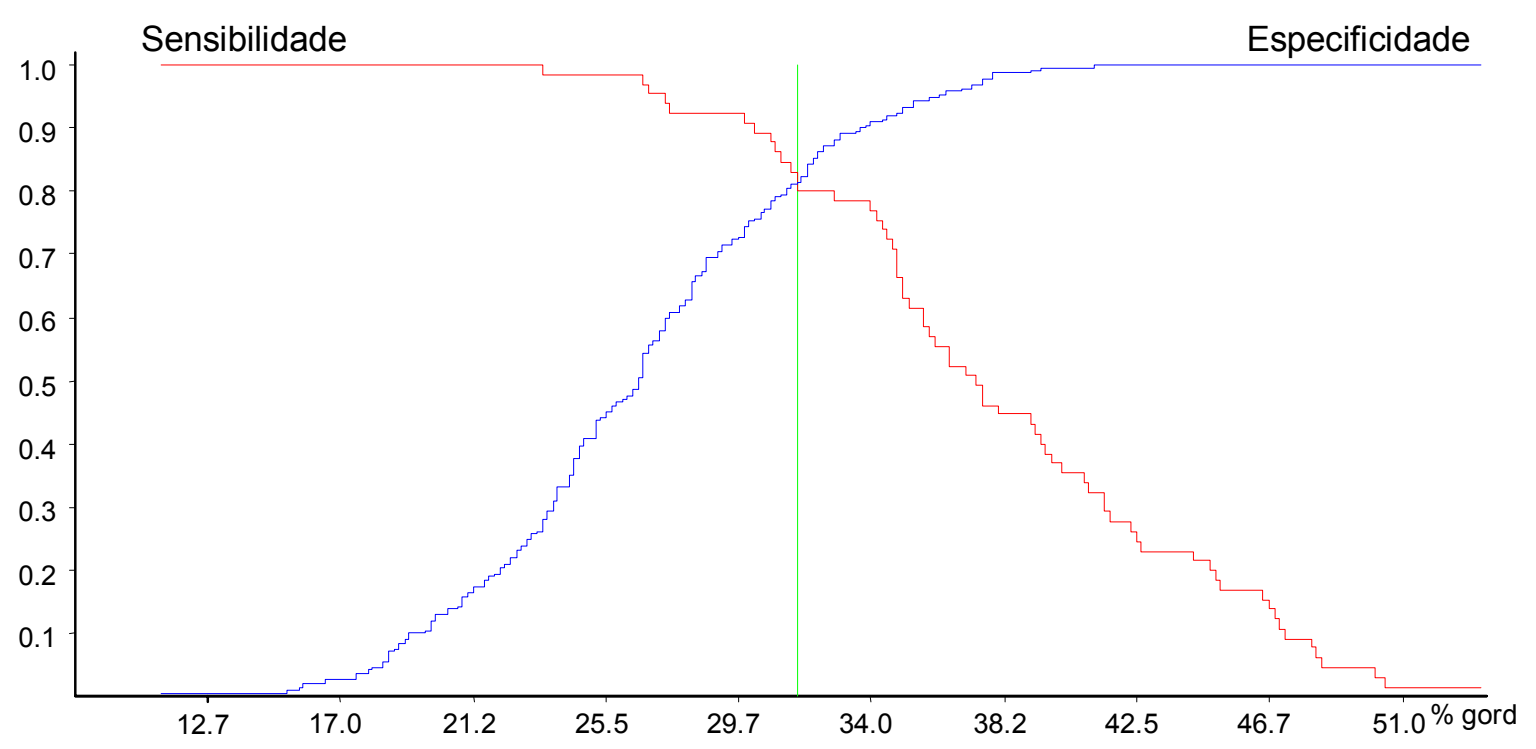

Gráfico 19 - Curva TGROC. Valores de sensibilidade e especificidade do percentual de gordura total estimado pela BIA para escolares do sexo feminino.

Tabela 21 - Distribuição de escolares segundo condição nutricional determinada pelo percentil do IMC e pelos métodos diagnóstico (BIA e pregas cutâneas), segundo sexo. Duas escolas públicas de São Paulo, 2004.

\begin{tabular}{|c|c|c|c|c|c|c|}
\hline \multirow[t]{2}{*}{ Método diagnóstico } & \multicolumn{2}{|c|}{$\begin{array}{l}\text { Não excesso de } \\
\text { peso }^{4}\end{array}$} & \multicolumn{2}{|c|}{ Excesso de peso ${ }^{4}$} & \multicolumn{2}{|c|}{ Total } \\
\hline & $\mathrm{n}$ & $\%$ & $\mathrm{n}$ & $\%$ & $\mathrm{n}$ & $\%$ \\
\hline \multicolumn{7}{|l|}{ BIA } \\
\hline \multicolumn{7}{|l|}{ Sexo feminino ${ }^{(1)}$} \\
\hline Não excesso de peso & 172 & 81,9 & 13 & 20,0 & 185 & 67,3 \\
\hline Excesso de peso & 38 & 18,1 & 52 & 80,0 & 90 & 32,7 \\
\hline Total & 210 & 100 & 65 & 100 & 275 & 100 \\
\hline \multicolumn{7}{|l|}{ Sexo masculino ${ }^{(2)}$} \\
\hline Não excesso de peso & 162 & 81,0 & 14 & 17,3 & 176 & 62,6 \\
\hline Excesso de peso & 38 & 19,0 & 67 & 82,7 & 105 & 37,4 \\
\hline Total & 200 & 100 & 81 & 100 & 281 & 100 \\
\hline \multicolumn{7}{|l|}{ Pregas cutâneas } \\
\hline \multicolumn{7}{|l|}{ Sexo feminino ${ }^{(3)}$} \\
\hline Não excesso de peso & 185 & 88,1 & 10 & 15,4 & 195 & 70,9 \\
\hline Excesso de peso & 25 & 11,9 & 55 & 84,6 & 80 & 29,1 \\
\hline Total & 210 & 100,0 & 65 & 100,0 & 275 & 100,0 \\
\hline \multicolumn{7}{|l|}{ Sexo masculino ${ }^{(4)}$} \\
\hline Não excesso de peso & 168 & 84,0 & 9 & 11,1 & 177 & 63,0 \\
\hline Excesso de peso & 32 & 16,0 & 72 & 88,9 & 104 & 37,0 \\
\hline Total & 200 & 100 & 81 & 100 & 281 & 100 \\
\hline $\begin{array}{l}\text { (1) ponto de corte: } 31,61 \% \\
\text { (3) ponto de corte: } 24,19 \% \\
\text { Cutâneas) }\end{array}$ & (BI & $\begin{array}{l}\text { pont } \\
\text { s Cutân }\end{array}$ & $\begin{array}{l}\text { orte: } \\
;(4)\end{array}$ & $\begin{array}{l}-\mathrm{ma}_{\mathrm{a}} \\
\mathrm{le} \mathrm{c}\end{array}$ & $\begin{array}{l}\text { [A) } \\
2,48 \%\end{array}$ & \\
\hline
\end{tabular}


Sexo Feminino

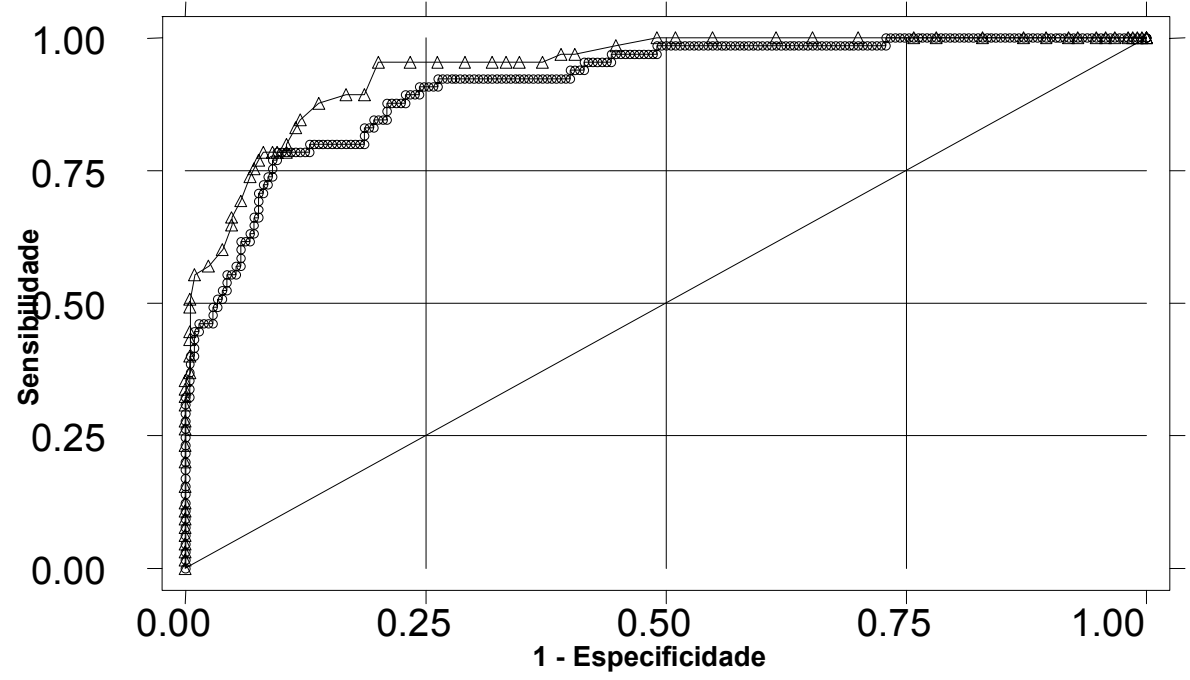

Gráfico 20 - Área da curva ROC segundo métodos para estimar percentuais de gordura total

Tabela 22 - Valores de sensibilidade (\%), especificidade (\%), eficiência e índice de Youden para o percentual de gordura total estimado pela BIA e pelas pregas cutâneas tricipital e da panturrilha, considerando-se como referência o percentil do IMC segundo sexo para escolares de 7 a 10 anos.

\begin{tabular}{lcccc}
\hline Indicadores & \multicolumn{2}{c}{ BIA } & \multicolumn{2}{c}{ Pregas cutâneas } \\
& Feminino & Masculino & Feminino & Masculino \\
\hline Sensibilidade & 80,0 & 82,7 & 84,6 & 88,9 \\
Especificidade & 81,9 & 81,0 & 88,1 & 84,0 \\
Eficiência & 81,3 & 81,6 & 87,1 & 85,8 \\
Índice de Youden & 61,9 & 63,7 & 72,7 & 72,9 \\
Área e IC(95\%) sob a curva ROC & 91,2 & 89,6 & 94,3 & 93,7 \\
\hline
\end{tabular}

\section{8 - Comparação entre a circunferência da cintura e gordura corporal total estimada pela BIA e pelas pregas cutâneas tricipital e da panturrilha}

Observa-se, pela análise da relação entre os dados de circunferência da cintura e de gordura corporal total (estimados pela BIA), indicação de existência de relação não linear entre elas. Parece não haver grande alteração de valores da circunferência da cintura, quando os valores de percentual de gordura total são abaixo de aproximadamente $24 \%$, tanto para meninos como meninas. A partir deste valor, os valores de circunferência da cintura parecem aumentar linearmente com o aumento da gordura corporal 
total. O coeficiente de correlação linear de Pearson entre as variáveis, para valores de gordura total acima de $24 \%$, é de 0,67 para o sexo feminino $(n=204 ; p<0,001)$ e de 0,75 para o sexo masculino $(n=281 ; p<0,001)$. Os Gráficos 21a e 21b descrevem a dispersão conjunta das variáveis para cada sexo. Estes gráficos, segundo idade, são apresentadas no Anexo 15.

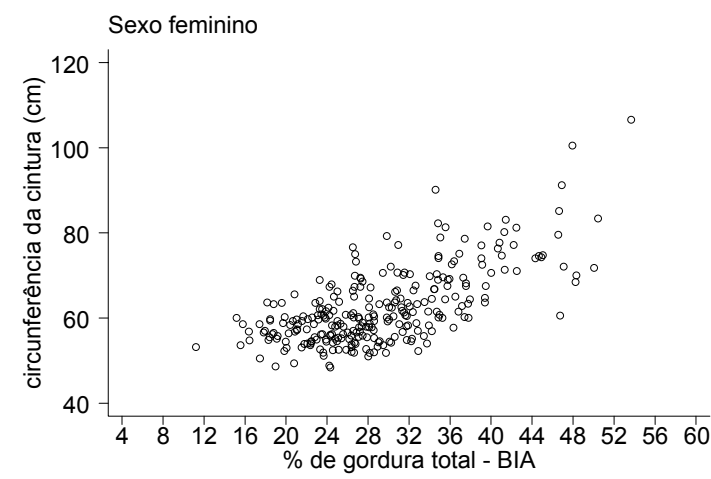

(a)

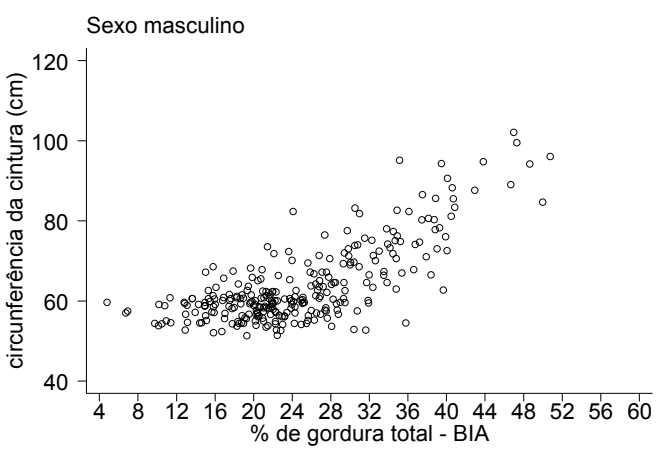

(b)

Gráfico 21a e 21b - Distribuição de escolares segundo percentual de gordura total estimado pela BIA e circunferência da cintura, segundo sexo. Duas escolas públicas de São Paulo, 2004.

Análise semelhante utilizando a gordura total estimada pelas pregas cutâneas tricipital e da panturrilha revela, diferentemente da análise anterior, existência de relação linear entre as variáveis, com correlação linear positiva tanto para escolares do sexo masculino $(n=281 ; r=0,88 ; p<0,001)$ como do sexo feminino $(n=275 ; r=0,82 ; p<0,001)$ (Gráficos 22a e 22b).

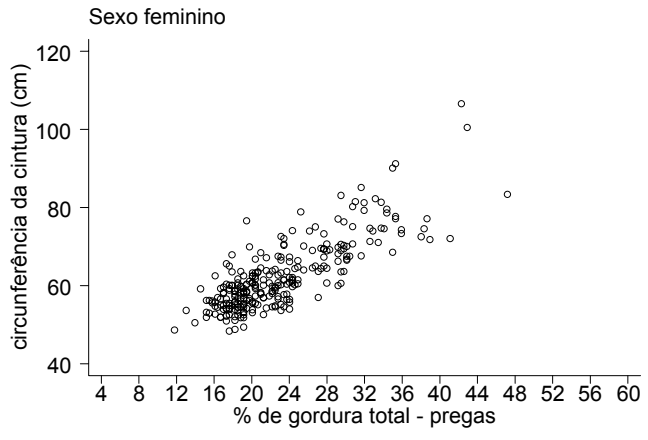

(a)

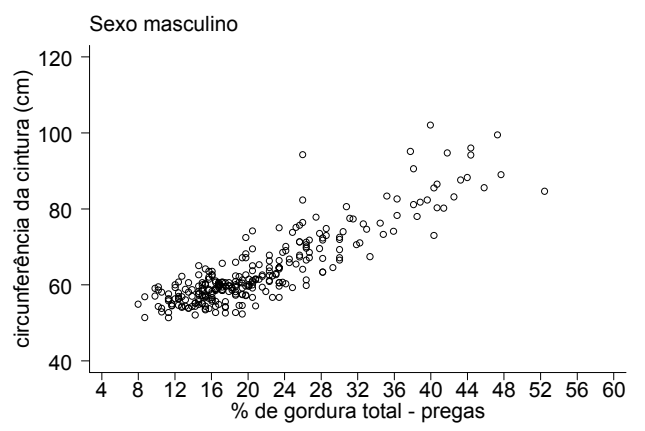

(b)

Gráficos 22a e 22b - Distribuição de escolares segundo percentual de gordura total estimado pelas pregas cutâneas tricipital e da panturrilha e circunferência da cintura, segundo sexo. Duas escolas públicas de São Paulo, 2004. 


\section{Análise de desempenho da circunferência da cintura na identificação de risco de doença cardiovascular}

Os pontos de corte estabelecidos para a circunferência da cintura (escolares do sexo masculino e feminino, separadamente), considerando-se como referência, os valores do percentual de gordura total estimados pela BIA e pelas pregas cutâneas tricipital e da panturrilha, são apresentados na tabela 23. O Quadro 3 resume os pontos de corte da gordura corporal para identificação de risco de doença cardiovascular.

Quadro 3 - Critérios de categorização para percentual de gordura total estimado pela BIA e pelas pregas cutâneas tricipital e da panturrilha (LOHMAN, 1992)

\begin{tabular}{|llc|}
\hline Sexo & Percentual de gordura total para identificação de risco de doença cardiovascular \\
Feminino & $\longrightarrow$ & $\geq 30 \%$ \\
Masculino & $\longrightarrow$ & $\geq 25 \%$ \\
\hline
\end{tabular}

Tabela 23 - Valores de pontos de corte que igualam (otimizam) a sensibilidade e especificidade, da circunferência da cintura, tomando-se como referência os percentuais de gordura total pela BIA e pelas pregas cutâneas, segundo sexo.

\begin{tabular}{|c|c|c|c|c|c|}
\hline \multirow[t]{3}{*}{ Sexo } & \multirow{3}{*}{$\mathrm{n}$} & \multicolumn{4}{|c|}{ Ponto de corte para a circunferência da cintura $(\mathrm{cm})$} \\
\hline & & & & & Pregas \\
\hline & & valor & Intermediate range & valor & Intermediate range \\
\hline $\begin{array}{l}\text { Masculino } \\
\text { Feminino }\end{array}$ & 281 & 60,63 & $(57,38-64,89)$ & 65,29 & $(65,29-65,29)$ \\
\hline
\end{tabular}

Os pontos de corte para a circunferência da cintura para escolares de 8 e 9 anos, de cada sexo, não parecem diferir daqueles estabelecidos para o grupo de 7 a 10 anos. Isto se verificou quando foi utilizado, como referência, tanto o percentual de gordura total estimado pela BIA quanto pelas pregas cutâneas tricipital e da panturrilha (resultados não apresentados).

A Tabela 24 apresenta as estatísticas para avaliação de desempenho da circunferência da cintura na identificação de risco de doenças 
cardiovasculares para escolares do sexo masculino e feminino, separadamente.

Tabela 24 - Valores de sensibilidade (\%), especificidade (\%), eficiência, índice de Youden e área sob a curva ROC para a circunferência da cintura considerando-se como referências o percentual de gordura total estimado pela BIA e pelas pregas cutâneas tricipital e da panturrilha, segundo sexo para escolares de 7 a 10 anos

Indicadores

Sensibilidade

Especificidade

Eficiência

Índice de Youden

Área e IC95\% sob a curva ROC

\section{BIA}

Feminino

0,77

0,76

0,76

0,53

0,82

$(0,77-0,87)$

Masculino

0,75

0,74

0,75

0,50

0,82

$(0,77-0,87)$ Feminino

1,00

0,63

0,68

0,63

0,96

$(0,94-0,98)$ Masculino

0,99

0,71

0,78

0,70

0,97

\section{9 - Descrição da área gordurosa do braço e comparação com o percentual de gordura total estimado pela BIA.}

Os valores observados da área gordurosa do braço variaram entre $391,6 \mathrm{~mm}^{2}$ (masculino, 7 anos) e 4717,1 mm² (feminino, 9 anos).

Não foi observada diferença entre os sexos quanto ao valor médio da AGB, para todas as idades. Observou-se, ainda, semelhança entre os grupos etários de 8 e 9 anos quanto aos valores médios da AGB. Independente do sexo, a maior diferença da área gordurosa do braço ocorreu entre as idades 9 e 10 anos, com diferença relativa (do valor mediano) de 36,6\% (Tabelas 25 e 26; Gráfico 23).

Tabela 25 - Área gordurosa do braço e IC(95\%) segundo sexo e idade (anos). Duas escolas públicas de São Paulo, 2004.

\begin{tabular}{|c|c|c|c|c|}
\hline \multirow[b]{2}{*}{$\operatorname{Sexo}^{(1)}$} & \multicolumn{4}{|c|}{ Idade(anos) $)^{(2)}$} \\
\hline & \multicolumn{4}{|c|}{ 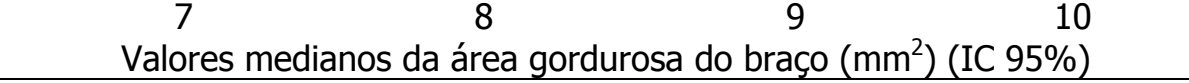 } \\
\hline Masculino & $\begin{array}{c}968,6(477,7) \\
(965,0-1169,6)\end{array}$ & $\begin{array}{c}1087,6(785,2) \\
(1124,1-1493,1)\end{array}$ & $\begin{array}{c}951,0(710,1) \\
(1028,1-1388,8)\end{array}$ & $\begin{array}{c}1520,6(917,6) \\
(1508,7-1943,1)\end{array}$ \\
\hline Feminino & $\begin{array}{c}1030,8(477,0) \\
(1042,4-1261,9)\end{array}$ & $\begin{array}{c}1080,1(544,9) \\
(1156,8-1424,8)\end{array}$ & $\begin{array}{c}1270,7(673,9) \\
(1249,9-1586,6)\end{array}$ & $\begin{array}{c}1557,4(726,5) \\
(1556,5-1902,9)\end{array}$ \\
\hline Total & $\begin{array}{c}997,6(462,9) \\
(1035,0-1183,9)\end{array}$ & $\begin{array}{c}1085,7(678,6) \\
(1185,9-1414,3)\end{array}$ & $\begin{array}{c}1135,3(697,2) \\
(1192,1-1437,9)\end{array}$ & $\begin{array}{c}1550,6(825,3) \\
(1590,4-1865,2)\end{array}$ \\
\hline
\end{tabular}


Tabela 26 - Diferença relativa (\%) e absoluta $\left(\mathrm{mm}^{2}\right)$ da área gordurosa do braço segundo idade.

\begin{tabular}{lcc}
\hline Idade (anos) & \multicolumn{2}{c}{ Área gordurosa do braço } \\
& Diferença relativa $(\%)$ & Diferença absoluta $\left(\mathrm{mm}^{2}\right)$ \\
\hline $7 / 8$ & 8,8 & 88,1 \\
$8 / 9$ & 4,6 & 49,6 \\
$9 / 10$ & 36,6 & 415,3 \\
\hline
\end{tabular}

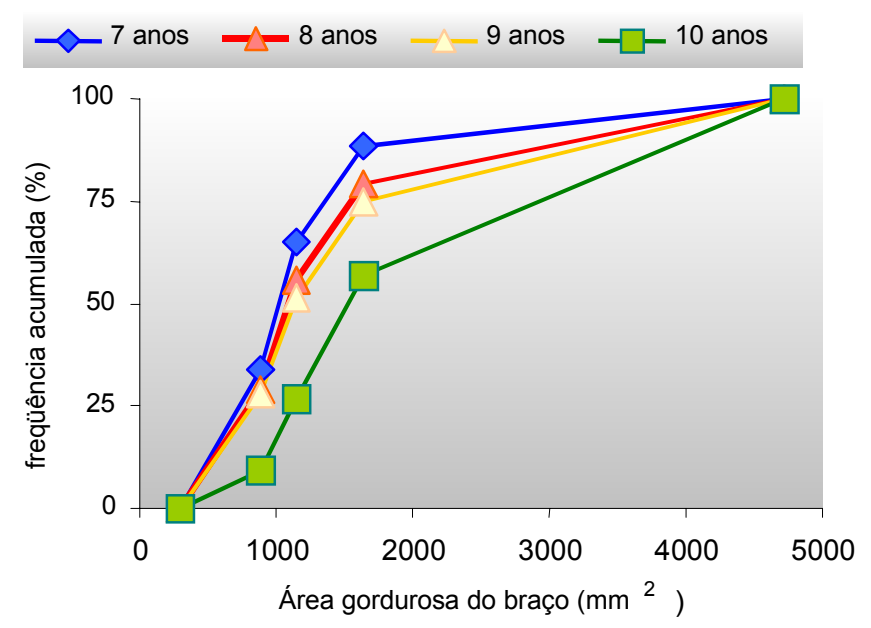

Gráfico 23 - Freqüência acumulada de escolares segundo área gordurosa do braço e idade. Duas escolas públicas de São Paulo, 2004.

Comparando-se os dados do presente estudo com os dados do FRISANCHO (1999), observou-se que os valores medianos da área gordurosa do braço $\left(\mathrm{mm}^{2}\right)$ dos escolares do presente estudo foram maiores que os valores medianos da população de referência, principalmente para o sexo masculino, com exceção da idade de 9 anos, faixa etária que apresentou valores mais próximos dos valores medianos da população de referência. Para o sexo feminino observou-se aumento dos valores medianos da área gordurosa do braço em relação a população de referência a partir de 9 anos (Gráficos 24a e 24b).

A Tabela 27 apresenta os pontos de corte estabelecidos para a área gordurosa do braço (escolares do sexo masculino e feminino, separadamente), considerando-se, como referência, os valores do percentual de gordura total estimados pela BIA (Quadro 3). 


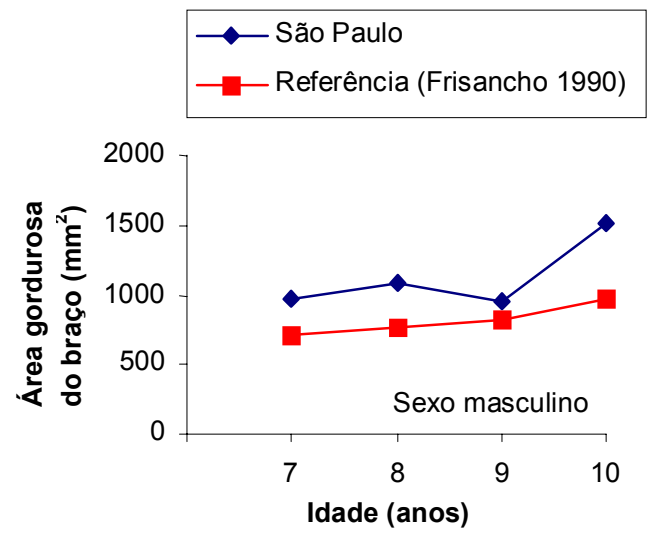

(a)

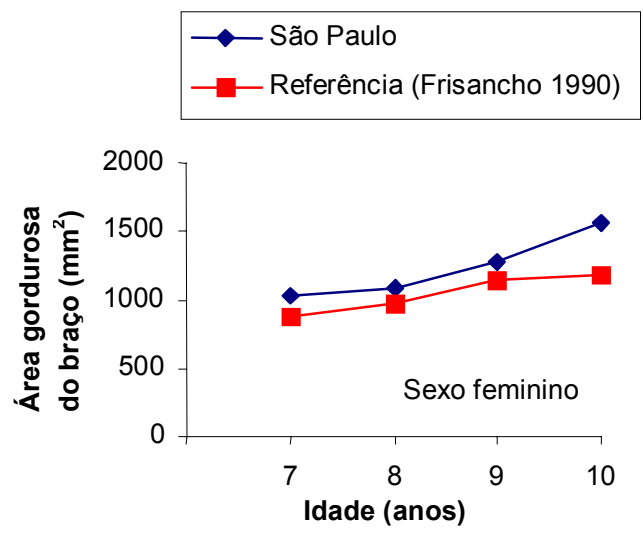

(b)

${ }^{1}$ FRISANCHO (1999)

Gráficos 24a 24b - Medianas da área gordurosa do braço $\left(\mathrm{mm}^{2}\right)$ em relação à idade de escolares de duas escolas públicas de São Paulo em 2004 e de crianças americanas ${ }^{1}$.

Tabela 27 - Valores de pontos de corte que igualam (otimizam) a sensibilidade e especificidade, da área gordurosa do braço, tomando-se como referência os percentuais de gordura total pela BIA, segundo sexo.

Sexo $\quad \mathrm{n} \quad$ Ponto de corte para a área gordurosa do braço $\left(\mathrm{mm}^{2}\right)$

\begin{tabular}{lccc} 
& & Valor & Intermediate range \\
\hline Masculino & 281 & 1150,83 & $(856,79-1461,21)$ \\
Feminino & 275 & 1260,72 & $(1018,78-1554,52)$ \\
\hline
\end{tabular}

Os pontos de corte para a área gordurosa do braço para escolares de 8 e 9 anos, de cada sexo, não parecem diferir daqueles estabelecidos para o grupo de 7 a 10 anos (resultados não apresentados).

A Tabela 28 apresenta as estatísticas para avaliação de desempenho da área gordurosa do braço na identificação de risco de doenças cardiovasculares para escolares segundo sexo.

Tabela 28 - Valores de sensibilidade (\%), especificidade (\%), eficiência, índice de Youden e área sob a curva ROC para a área gordurosa do braço considerando-se como referências 0 percentual de gordura total estimado pela BIA, segundo sexo para escolares de 7 a 10 anos Indicadores

BIA

\begin{tabular}{lcc} 
& Feminino & Masculino \\
\hline Sensibilidade & 0,74 & 0,79 \\
Especificidade & 0,75 & 0,77 \\
Eficiência & 0,75 & 0,78 \\
Índice de Youden & 0,50 & 0,56 \\
Área e IC95\% sob a curva ROC & $0,83(0,78-0,88)$ & $0,84(0,79-0,89)$ \\
\hline
\end{tabular}




\title{
4.10 - Resumo dos principais resultados
}

\section{Apresenta-se a seguir os principais resultados encontrados a título de facilitar a leitura e entendimento desta Dissertação (Quadro 4).}

\author{
Quadro 4 - Resumo dos principais resultados encontrados
}

\begin{tabular}{|c|c|}
\hline jetivo & sultados \\
\hline 1 & opulação com baixo poder aquisitivo e baixo nível de atividade física \\
\hline \multirow[t]{2}{*}{2} & $\begin{array}{l}\text { Peso: Aumento de peso com a idade (exceção para } 8 \text { a } 9 \text { anos). Não foi } \\
\text { encontrada diferença segundo sexo. } \\
\text { Estatura: Aumento da estatura com a idade. Não foi encontrada diferença } \\
\text { segundo sexo. } \\
\text { Pregas cutâneas tricipital e da panturrilha: Não foram encontradas diferenças } \\
\text { segundo sexo e idade. Médias maiores que as demais idades, para } 10 \text { anos. } \\
\text { Circunferências braquial e da cintura: Aumento dos valores médios com a idade (exceção } \\
\text { para } 8 \text { e } 9 \text { anos). Não foi encontrada diferença segundo sexo. }\end{array}$ \\
\hline & $\begin{array}{l}\text { Para todas as características, os valores medianos foram maiores, de modo geral, } \\
\text { quando comparados a outros estudos, com exceção da circunferência braquial } \\
\text { que apresentou valores semelhantes aos de Frisancho (1990). }\end{array}$ \\
\hline 3 & $\begin{array}{l}\text { Estado nutricional segundo IMC: Não foram encontradas diferenças segundo } \\
\text { idade e sexo. Prevalências de } 4,5 \% \text { de baixo peso; risco de sobrepeso } 15,3 \% \text { e } \\
\text { sobrepeso } 11,0 \% \text {. }\end{array}$ \\
\hline 4 & $\begin{array}{l}\text { Gordura corporal total estimado pela BIA e pelas pregas cutâneas: Pela BIA, valores } \\
\text { médios maiores para o sexo feminino, com exceção aos } 10 \text { anos. Não foi encontrada } \\
\text { diferença segundo idade. Valores medianos maiores comparados ao estudo de Campinas. } \\
\text { Pelas pregas: Valores médios maiores para o sexo feminino apenas para idade de } 7 \text { anos. } \\
\text { Valores médios maiores para } 10 \text { anos. }\end{array}$ \\
\hline 5 & $\begin{array}{l}\text { Comparação de métodos } \\
\text { Percentual de gordura total estimado pela BIA e pelas pregas cutâneas tricipital e da } \\
\text { panturrilha : Valores de percentual de gordura maiores quando estimado pelo método da } \\
\text { BIA. Diferenças diminuem com a idade. }\end{array}$ \\
\hline 6 & $\begin{array}{l}\text { Desempenho do percentual de gordura (estimado pela BIA e pregas) na classificação do } \\
\text { excesso de peso (método de referência - IMC): Pregas cutâneas apresentam melhor } \\
\text { desempenho - sensibilidade de } 84,6 \% \text { (meninas), } 88,9 \% \text { (meninos) e especificidade de } \\
88,1 \% \text { (meninas), } 84,0 \% \text { (meninos). Pontos de corte de } \% \text { de gordura identificados: } \\
22,5 \% \text { e } 24,2 \% \text { de para meninos e meninas, respectivamente, pelo método das pregas. }\end{array}$ \\
\hline 7 & $\begin{array}{l}\text { Circunferência da cintura e Percentual de gordura total: A circunferência da cintura e o } \\
\text { percentual de gordura pela BIA se apresentam correlacionadas de forma não linear. A } \\
\text { circunferência da cintura e o percentual de gordura estimado pelas pregas se } \\
\text { apresentam linearmente correlacionados. A circunferência da cintura apresenta bom } \\
\text { desempenho para classificação de risco de DCV (referências: BIA e pregas). Melhor } \\
\text { desempenho quando as pregas são referência. Pontos de corte para a circunferência da } \\
\text { cintura para classificar risco de DCV: } 65,3 \text { e } 67,6 \mathrm{~cm} \text { para meninos e meninas, } \\
\text { respectivamente. }\end{array}$ \\
\hline 8 & $\begin{array}{l}\text { Descrição da área gordurosa do braço: Aumento com incremento da idade (exceção } 8 \text { e } \\
9 \text { anos). Não foi encontrada diferença segundo sexo. Valores maiores, de modo geral, } \\
\text { em relação a outros estudos. }\end{array}$ \\
\hline & $\begin{array}{l}\text { Desempenho da AGB na classificação de risco de DCV (referência - BIA): pontos de corte } \\
\text { de AGB } 1150,8 \text { e } 1260,7 \mathrm{~mm}^{2} \text { para meninos e meninas, respectivamente na classificação } \\
\text { de risco de DCV. Sensibilidade de } 74 \% \text { (meninas) e } 79 \% \text { (meninos) e especificidade de } \\
75 \% \text { (meninas) e } 77 \% \text { (meninos). }\end{array}$ \\
\hline
\end{tabular}




\section{DISCUSSÃO}

\section{Aspectos metodológicos do estudo}

Os resultados obtidos, com crianças de duas escolas públicas da região sudeste do Município de São Paulo, podem estar representando escolares da rede pública daquela região apesar da inclusão destas unidades ter sido por conveniência motivada por aspectos financeiros e operacionais. Tem-se como base para tal afirmação o fato destas unidades não apresentarem nenhuma característica que as diferencie das demais da região. Assim, acredita-se que os resultados deste estudo, possam ser inferidos para escolares de 7 a 10 anos, da rede pública, daquela área geográfica.

Considerando-se que a situação nutricional é grandemente influenciada também por aspectos ambientais, acredita-se que os resultados apresentados não possam ser generalizados para qualquer área da cidade de São Paulo, a menos que esta apresente condições sociais e ambientais semelhantes à da região estudada.

Para a obtenção dos dados, seguiu-se o rigor metodológico necessário para assegurar a confiabilidade e qualidade dos dados, contribuindo para a validade interna e diminuição da variabilidade.

Para tanto foi imprescindível o treinamento dos avaliadores e padronização dos procedimentos para a coleta de dados antropométricos e de bioimpedância, teste dos instrumentos de coleta em estudo piloto, tomada de medidas em réplicas, controle de qualidade dos eletrodos para sua re-utilização, estudo da influência do horário para realização da bioimpedância e estudo de reprodutibilidade do questionário de atividade física e da realização da bioimpedância, dupla digitação e análise exploratória de dados para identificação de erros. Assim, acredita-se que os dados obtidos são de boa qualidade e refletem, com boa precisão, o estado nutricional de escolares de 7 a 10 anos de rede pública de ensino da Água Rasa. 
Para a realização do estudo, foi necessário proporcionalmente maior tempo de preparação anterior à coleta dos dados. Pode-se citar, entre os itens que requisitaram maior tempo, a entrega e recolhimento dos termos de consentimento informado, a elaboração e entrega da carta informativa sobre o estado nutricional do escolar, entrega e recolhimento do questionário sócio-demográfico. Ressalta-se que, apesar do ambiente cordial propiciado pelos diretores das unidades, a equipe trabalhou em alguns momentos com certa tensão pela possibilidade de estar criando situações desfavoráveis ao escolar que tinha que se ausentar da sala de aula por aproximadamente 20 minutos para a tomada das medidas.

A perda de 5,5\% de dados por recusa foi considerada baixa não sendo possível nenhum tipo de caracterização destas. A taxa de retorno do questionário sócio-demográfico foi alta $(90,8 \%)$, incluindo-se as informações coletas por telefone $(6,1 \%)$, refletindo 0 interesse por parte dos responsáveis na realização do estudo. De fato, a avaliação do estado nutricional dos escolares foi muito bem recebida pela equipe das escolas, pelos pais e responsáveis e pelos escolares.

\section{Caracterização da população de estudo}

Segundo dados do presente estudo, $77,8 \%$ das famílias possuem renda per capita até 1 salário mínimo e renda média do domicílio igual a $\mathrm{R} \$ 989,03$ com indicação de menor renda se comparada à da região $(R \$ 1503,34)$ segundo dados da Fundação SEADE de 2000. A proporção de famílias com renda per capita até um salário mínimo na região estudada é bastante superior à proporção de 33,8\% apresentada por MONTEIRO e CONDE (2000) para a cidade de São Paulo em 1995/96.

Os resultados de renda não são semelhantes também entre as escolas estudadas, sendo que na escola 2 estão escolares com situação econômica mais desfavorável. Apesar desta diferença, optou-se por analisar os dados conjuntamente, uma vez que o tamanho da amostra diminuiria 
consideravelmente nos grupos segundo sexo e idade e o objetivo do estudo não era identificar fatores relacionados ao estado nutricional.

Como somente $1,3 \%$ das mães informaram não possuir nenhum grau de escolaridade, optou-se por agregar estes dados aos da categoria "primeira à quarta série do ensino fundamental". O percentual $(45,9 \%)$ de mães que apresentaram nível fundamental completo (no mínimo 8 anos de escolaridade) apresentou-se inferior ao descrito por MONTEIRO e CONDE (2000) em estudo realizado na cidade de São Paulo (56,5\%), indicando possível menor nível de escolaridade das mães desta região.

Quanto à condição de moradia, 34,3\% dos escolares moram em casa própria, sendo que a escola 2 apresentou piores condições também neste aspecto. Esta variável, associada à informação obtida pela renda, indica situação social e econômica desfavorável. A maioria $(63,1 \%)$ dos escolares reside em imóveis alugados ou cedidos.

\section{Atividade física}

Encontrou-se dificuldade em identificar um questionário validado para quantificar a prática de atividade física em crianças. Optou-se por utilizar o questionário proposto por BARROS e NAHAS (2003) que, segundo os autores, permite uma aproximação do custo metabólico da intensidade das atividades explicitadas naquele instrumento.

Pelos resultados encontrados, observa-se grande concentração (98\%) de escolares com escores abaixo do valor mediano da escala proposta, que varia de 0 a 187 pontos. Não é possível afirmar se o instrumento é muito sensível ou pouco específico para identificar os escolares verdadeiramente sedentários ou verdadeiramente não sedentários. Assim, se o instrumento utilizado for válido (estiver medindo a realidade apropriadamente), então os escolares apresentam baixo nível de atividade física. Estes resultados estariam, então, em concordância com a literatura, que relata que as crianças, nas últimas décadas, tornaram-se menos ativas. Este achado pode explicar, em parte, o aumento da prevalência de sobrepeso em crianças 
observado nos últimos anos (GIUGLIANO e CARNEIRO 2004, JOHNSONDOWN e col. 1997, FAITH e col 2001, SALBE e col. 2002).

\section{Estado nutricional}

Medidas antropométricas são cada vez mais utilizadas como indicadores de crescimento, desenvolvimento e situação de saúde, especialmente em crianças, que vivenciam intenso crescimento físico que acontece até o final da puberdade (VEIGA e SIGULEM 1994).

Com o presente estudo, pôde-se melhor conhecer aspectos operacionais relacionados a métodos bastante utilizados em epidemiologia na avaliação do estado nutricional de escolares de 7 a 10 anos. Pôde-se também investigar as características intrínsecas de cada método, no que se refere à obtenção do dado e à precisão da informação obtida, e ainda a obtenção de resultados comparativos sobre estimadores de composição corporal. Como resultado, apresenta-se também a quantificação do excesso de peso neste grupo populacional, sendo este um passo importante para a realização de intervenções.

\section{Peso}

A qualidade dos dados de peso obtidos para os escolares é considerada muito boa, com alta confiabilidade e baixa variabilidade entre avaliadores. Apesar disto, a heterogeneidade existente entre os escolares, fez com que a dispersão dos pesos fosse relativamente alta, como refletido nos valores dos coeficientes de variação de Pearson segundo sexo e idade (Anexo 13), com valores entre $17,0 \%$ e $29,8 \%$. Intervalos de confiança com amplitudes (diferença entre os limites superior e inferior) relativamente grandes, no caso de peso, variando entre 1,4 e 5,2 kg têm como conseqüência uma precisão menor na estimação das características estudadas. Como as decisões estatísticas foram tomadas verificando-se a sobreposição de intervalos, nos casos onde não havia sobreposição, decidiuse pela diferença entre os parâmetros. Neste caso o problema é somente 
relacionado à precisão da estimativa. O problema reside naqueles casos onde a sobreposição dos intervalos se dá somente para uma pequena gama de valores. Pode ser que, com uma maior precisão, estes intervalos não se sobrepusessem. Assim, foi tomado cuidado na apresentação dos resultados e na discussão, não se afirmando que existe igualdade por exemplo entre o peso médio para duas idades específicas e sim que não foi identificada diferença estatística entre os pesos médios populacionais.

Ressalta-se que em estudo probabilístico realizado no Rio de Janeiro por ANJOS e col. em 1999, com amostra de 3387 escolares de 4 a 17 anos, sendo 1420 na faixa de 7 a 10 anos, foram observados coeficientes de variação de Pearson com valores entre $19,75 \%$ e $27,28 \%$. A busca por coeficientes de variação menores implicaria no aumento do tamanho da amostra, uma vez que a maior fonte de variação dos dados se encontra na heterogeneidade dos pesos dos indivíduos deste grupo populacional.

Pelos resultados do presente estudo, não foi identificada diferença nos pesos médios segundo sexo, mas parece existir aumento de peso com a idade, apesar de não ter sido encontrada diferença no peso médio para escolares de 8 e 9 anos. A grande diferença no peso pode ser observada quando se compara os extremos das idades de 7 e 10 anos: o peso médio de crianças com 10 anos é quase o dobro do peso médio de crianças de 7 anos, sendo esta diferença, em média, de 11,4 kg.

Os pesos medianos dos escolares do presente estudo, segundo sexo e faixas etárias, são maiores, de modo geral, se comparados aos valores medianos da curva do CDC 2000 e a valores obtidos em estudo realizado no Rio de Janeiro em 1999, com amostra probabilística de escolares de rede pública (ANJOS e col. 2003) e em Campinas em 2000 (COCETTI 2001) com escolares de baixa renda. Gráficos comparativos de tais estudos são apresentados no Anexo 16. A maior diferença é observada entre o presente estudo e o realizado em Campinas para meninas de 10 anos (diferença entre as medianas de 5,1 kg). É necessário ressaltar que o estudo de Campinas não apresentou caracterização sócio-demográfica detalhada, sendo possível 
a existência de diferenças entre as populações estudadas no se refere às condições sociais de vida.

Apesar das diferentes metodologias e populações de estudo das investigações citadas, a comparação entre elas sugere que além do aumento de peso com a idade, já esperado, parece haver um aumento de peso para cada idade, com o passar dos anos, ou seja, escolares, de ambos os sexos, estão ficando mais pesados. Isto pode ser observado nos gráficos apresentados no anexo 16.

\section{Estatura}

A qualidade dos dados de estatura também é considerada muito boa, com alta confiabilidade e baixa variabilidade entre avaliadores. Além disto, a tomada em duplicata dos valores assegurou maior validade das medidas. Devido a homogeneidade entre os escolares com relação à estatura, a dispersão dos dados foi pouca, resultando em baixos coeficientes de variação de Pearson segundo sexo e idade (Anexo 13); valores entre 3,6\% e 5,8\%, semelhantes aos de ANJOS e col (1999) que obtiveram valores entre 4,42\% e 5,98\%. Os intervalos de confiança apresentaram amplitudes variando entre 2,0 e 3,9 cm indicando melhor precisão na estimação, se comparada com a precisão do peso.

Para a estatura, também não foi identificada diferença (entre médias populacionais) segundo sexo nas faixas etárias de 7 a 10 anos. Segundo idade, pode-se dizer que existe diferença na estatura entre cada faixa etária. Entre as idades de 7 e 10 anos os escolares apresentam uma diferença nas estaturas médias, de 16,9 cm, com diferenças em cada faixa etária de valores aproximadamente iguais $(5,6 \mathrm{~cm} / \mathrm{ano})$, característico de crescimento linear.

As estaturas medianas de escolares, segundo sexo e faixas etárias, são maiores, de modo geral, se comparadas aos valores medianos da curva do CDC 2000 (diferença média de 1,2 cm), de estudo realizado no Rio de Janeiro em 1999 (ANJOS e col. 2003) (diferença média de 1,7 cm) e de 
estudo realizado em Campinas em 2000 (COCETTI 2001) (diferença média de 2,8 cm). Gráficos comparativos de tais estudos são apresentados no Anexo 16. A maior diferença foi observada entre o presente estudo e 0 realizado em Campinas para meninos de 8 anos (diferença entre as medianas de $5,38 \mathrm{~cm}$ ).

Apesar das diferenças metodológicas e relativas às populações de estudo das investigações citadas, a comparação entre eles sugere que além do aumento de estatura com a idade, já esperada, parece estar havendo um pequeno aumento de estatura em cada idade, com o passar dos anos. Este achado concorda com o descrito na literatura relativo à tendência secular do crescimento apontado, no Brasil, por MONTEIRO e CONDE (2000), que mencionam o aumento do crescimento de menores de 5 anos com o passar dos anos; FRANÇA JR e col. (2003) também mencionam a tendência de coortes recentes de jovens adultos apresentarem melhor crescimento em estatura.

\section{IMC}

Não foram encontradas diferenças nos valores médios de IMC segundo sexo. Como esperado, O IMC neste grupo etário, apresentou pequena variação (diferença média de $2,2 \mathrm{~kg} / \mathrm{m}^{2}$ entre 7 e 10 anos), apesar do aumento do peso e estatura, com a idade. Isto se deve ao fato do IMC ser composto pelo peso e estatura cujos aumentos se cancelam, fazendo com que o IMC permaneça constante. Isto indica que em uma avaliação de crescimento o peso e a estatura são mais indicados para descrever tal processo.

O IMC mediano dos escolares do presente estudo, segundo sexo e faixas etárias, são maiores, de modo geral, se comparados aos valores medianos da curva do CDC 2000, e de estudo realizado em Campinas em 2000 (COCETTI 2001), com diferenças médias de 0,5 e 0,65 kg/m respectivamente. Apresentam também valores medianos de IMC maiores em relação às medianas de IMC do estudo realizado no Rio de Janeiro em 1999, 
(ANJOS e col 2003) e de crianças brasileiras do PNSN de 1989 (ANJOS e col 1998), com diferenças médias de 0,7 e $1,0 \mathrm{~kg} / \mathrm{m}^{2}$ respectivamente. Gráficos comparativos de tais estudos são apresentados no Anexo 16. A maior diferença foi observada entre $o$ presente estudo e os realizados em Campinas e pelo PNSN para meninas de 10 anos (diferença entre as medianas de $1,8 \mathrm{~kg} / \mathrm{m}^{2}$ para ambos).

A comparação entre estes estudos sugere estar havendo um aumento de IMC para cada idade com o passar dos anos. Este fato pode ser explicado pelo aumento secular do peso em proporções maiores se comparado ao aumento da estatura, verificado anteriormente, fazendo com que os valores de IMC também aumentem, conforme tendência já relatada por FREEDMAN e col (1997).

No presente estudo, utilizando-se o percentil do IMC da população de referência (CDC 2000) para classificação do estado nutricional, obteve-se baixa proporção de baixo peso $(4,5 \%)$ e alta proporção de escolares com risco de sobrepeso $(15,3 \%)$ ou sobrepeso $(11,0 \%)$. A soma destas duas porcentagens revela o percentual de escolares com excesso de peso igual a $25,3 \%$. Devido aos diferentes pontos de corte, a diferentes populações de referência e de critérios de classificação utilizados na avaliação do estado nutricional, torna-se bastante difícil a comparação das prevalências de desnutrição, de risco de sobrepeso (denominado por muitos, sobrepeso) e de sobrepeso (denominado por muitos, obesidade). Não foi possível encontrar nenhum artigo brasileiro que utiliza o percentil do IMC em relação a população de referência CDC 2000 para o grupo de 7 a 10 anos. ANJOS e col. (2003) apresentam, com base na curva de referência do NCHS/1997 e escore z de Estatura para Idade e de Peso para a Estatura, estimativas de déficit de estatura para a idade e de peso para estatura para escolares de 7 a 9 anos, do Rio de Janeiro, com valores entre 1,4 e 2,3\% para meninas e 1,6 e 3,7\% para meninos. Apresentam, ainda, prevalência de sobrepeso para este grupo etário, variando entre 2,8 e 7,4\% para meninas e 6,9 e $8,1 \%$ entre meninos. Para escolares de 10 anos, os autores utilizaram o percentil 
do IMC em relação a valores da população americana (MUST 1991) encontrando prevalência de baixo peso de 7,6\% para meninas e de $8,9 \%$ para meninos e prevalência de sobrepeso (IMC para a idade >P85) de 13,7\% entre meninas e de $15,8 \%$ entre meninos.

MAYNARD e col. (2003) em estudo utilizando a população americana do NHANES III (1983-1994), para crianças de 2 a 11 anos e o percentil do IMC em relação ao CDC (2000), encontrou prevalências de risco de obesidade entre meninos e meninas iguais a $12,2 \%$ e $12,6 \%$, respectivamente, e prevalências de sobrepeso iguais a 10,3\% entre meninos e $10,4 \%$ entre meninas. ZIMMERMANN e col. (2004), utilizando a mesma estratégia de classificação de MAYNARD e col. (2003), e uma amostra representativa de crianças suíças, encontrou, no grupo etário de 7 a 10 anos, prevalências de risco de obesidade variando de $20,3 \%$ a $22,4 \%$ entre meninos e de $18,6 \%$ a $20,8 \%$ entre meninas e, prevalências de sobrepeso entre $7,65 \%$ e $8,98 \%$ para meninos e entre $3,18 \%$ e $7,63 \%$ entre meninas.

A presença de baixo peso em menor proporção que o excesso de peso indica existência de transição nutricional característica dos últimos anos com diminuição da desnutrição e aumento do excesso de peso em diferentes países do mundo. MONTEIRO e col (1995) destacam, no Brasil, o efeito, nos últimos anos, de dieta rica em gorduras (especialmente as saturadas), açúcares e alimentos industrializados, e diminuição de carboidratos complexos e fibras, e o declínio de prática de atividades físicas, no estado nutricional de brasileiros.

\section{Pregas cutâneas}

Para a obtenção de dados de pregas cutâneas confiáveis, foi necessário maior treinamento dos avaliadores e realização de padronização dos procedimentos de coleta, resultando em boa confiabilidade e baixa variabilidade entre avaliadores. A tomada da medida em duplicata assegurou maior validade das medidas. Devido a grande heterogeneidade entre os escolares no que diz respeito às medidas de pregas cutâneas tricipital e da 
panturrilha, a dispersão dos dados foi alta, com coeficientes de variação de Pearson (CV) segundo sexo e idade (Anexo 13) com valores entre $31,1 \%$ e 45,3\%. Apesar dos altos valores do CV de Pearson, os intervalos de confiança apresentaram amplitudes variando entre 1,3 e 3,2 mm, podendo indicar precisão razoável na estimação.

Não foi identificada diferença nas pregas cutâneas médias segundo sexo nas faixas etárias de 7 a 10 anos, tanto para tricipital quanto para a da panturrilha. Segundo idade, pode-se dizer que existe semelhança quanto as pregas cutâneas para escolares de 7 a 9 anos, sendo que a grande mudança nos valores médios ocorre aos 10 anos. Nesta idade, escolares apresentam prega tricipital média $4,3 \mathrm{~mm}$ maior que a prega cutânea tricipital média de escolares de 7 anos. Para a panturrilha, esta diferença é bastante semelhante $(4,4 \mathrm{~mm})$.

A prega cutânea tricipital mediana de escolares, segundo sexo e faixas etárias, são maiores, de modo geral, se comparados aos valores medianos das crianças americanas do NHANES I (1971-1974) e do estudo de FRISANCHO (1999) e de escolares de baixa renda de Campinas (COCETTI 2001). Gráficos comparativos de tais estudos são apresentados no Anexo 16. A maior diferença é observada entre o presente estudo e o realizado em Campinas para meninos de 8 anos $(4,5 \mathrm{~mm})$.

Pela comparação dos valores médios (estimativa pontual) das pregas cutâneas tricipital e da panturrilha tem-se maiores valores para tanto para escolares do sexo masculino com para o sexo feminino se comparados aos dados obtidos por FRANÇA e col (1988).

Os achados do presente estudo diferem dos de FRANÇA e col (1988) no que se refere às conclusões baseadas nos valores médios de pregas cutâneas. São apresentados, para o sexo feminino, aumentos, com a idade, nos valores médios absolutos tanto para a prega tricipital como da panturrilha, e, para o sexo masculino, estabilidade dos valores médios ou, discreto decréscimo com o decorrer da idade. 
Percebe-se que a estratégia de comparação dos valores médios segundo idade e sexo utilizando-se intervalos de confiança não é adotada por nenhum estudo identificado na discussão deste trabalho. Os artigos apresentam conclusões comparando-se somente as estimativas pontuais. Sabe-se, entretanto, que a variabilidade do dado deve ser considerada em qualquer processo de tomada de decisão, principalmente se foi feita a opção da utilização do método estatístico, para tal. Este ponto é interessante porque se os dados do presente estudo fossem analisados somente com o valor numérico dos valores médios (estimativas pontuais) as conclusões seriam semelhantes às descritas por FRANÇA e col. (1988).

\section{Circunferência braquial e da cintura}

$\mathrm{Na}$ padronização da técnica de mensuração pelos avaliadores, os dados de circunferência da cintura foram os que resultaram em maior variabilidade entre avaliadores, apesar da variabilidade intra avaliadores ser baixa, indicando boa repetibilidade. A medida de circunferência da cintura é de difícil mensuração e necessita da tomada em duplicata, como foi realizado. Para a circunferência braquial, foi necessário maior tempo de treinamento para um avaliador para diminuir a variabilidade intra avaliadores. A dispersão dos dados foi relativamente baixa, com coeficientes de variação de Pearson (CV) segundo sexo e idade (Anexo 13) variando entre $9,9 \%$ e $16,4 \%$, com intervalos de confiança apresentando amplitudes variando entre 0,7 e 1,7 cm (circunferência braquial) e 2,0 e 5,3 cm (circunferência da cintura), podendo indicar precisão razoável e baixa, respectivamente, no processo de estimação.

Não foi identificada diferença nas circunferências médias braquial e da cintura segundo sexo no grupo etário de 7 a 10 anos. Segundo idade, podese dizer que não foi encontrada diferença somente entre escolares de 8 e 9 anos; para as demais idades existe diferença. A circunferência média braquial de escolares com 10 anos é $3,1 \mathrm{~cm}$ maior do que a de escolares com 7 anos e para a circunferência média da cintura este valor é de $9 \mathrm{~cm}$. 
Os valores medianos da circunferência braquial de escolares de 7 a 10 anos, segundo sexo e faixas etárias, são semelhantes aos do estudo de FRISANCHO (1999), os valores medianos da circunferência da cintura são maiores, de modo geral, se comparados aos de crianças britânicas (MCCARTHY 2001), aos estudantes de escola pública de Florianópolis em estudo realizado em 2004 (SOAR 2004), e de escolares de Campinas (COCETTI 2001). Gráficos comparativos de tais estudos são apresentados no Anexo 16, sendo a maior diferença observada entre o presente estudo e o de MCCARTHY (2001) para meninas de 10 anos (diferença entre as medianas de $9,1 \mathrm{~cm})$.

\section{Composição corporal - percentual de gordura total e área gordurosa do braço}

A padronização da técnica de mensuração realizada pelos avaliadores e o estudo da re-utilização dos eletrodos, bem como da influência do horário para a realização da BIA associado à realização da BIA em duplicata a cada 10 escolares assegurou a qualidade do dado, com constatação de boa repetibilidade dos valores de resistência e reactância.

Para o cálculo do percentual de gordura total pela BIA, utilizou-se equações descritas na literatura segundo sexo e idade (KUSHNER 1992) e, portanto, passíveis de comparação com outros trabalhos. Para o cálculo do percentual de gordura pelas pegas cutâneas tricipital e da panturrilha, também foram utilizadas equações propostas na literatura, segundo sexo (SLAUGHTER e col. 1988). Devido à heterogeneidade entre os escolares, com relação ao percentual de gordura total, a dispersão dos dados foi alta, resultando em coeficientes de variação de Pearson segundo sexo e idade também altos (Anexo 13), variando entre $22,7 \%$ e $42,2 \%$. Os intervalos de confiança apresentaram amplitudes variando entre 2,4 e 4,3\% para BIA e 1,8 e 4,5\% para pregas cutâneas, indicando precisão razoável na estimação.

Pelos dados da BIA, as meninas apresentam percentuais de gordura corporal total mais altos que os meninos, para as idades de 7, 8 e 9 anos. A 
diferença entre o percentual médio de gordura total estimado pela BIA entre meninos e meninas parece diminuir com o aumento da idade, até desaparecer no grupo de 10 anos. Em contrapartida, se o percentual de gordura total for estimados pelas pregas cutâneas, a diferença segundo sexo só será observada entre escolares de 7 anos; para os demais, não se observa diferença entre os sexos quanto ao percentual de gordura total. Segundo idade, pode-se dizer que existe semelhança entre as faixas etárias quando o percentual de gordura é estimado pela BIA, e quando estimado pelo método das pregas cutâneas apresenta maiores valores somente para escolares de 10 anos. A diferença entre o percentual médio de gordura total pela BIA para escolares de 7 e 10 anos é de $2 \%$ e pelas pregas, $6 \%$.

Os percentuais medianos de gordura total de escolares segundo sexo e idade são maiores se comparados aos valores medianos de estudo realizado em Campinas em 2000 (COCETTI 2001). Gráficos comparativos são apresentados no Anexo 16. As maiores diferenças são observadas para meninos de 8 anos (diferença entre as medianas é de 10,9\%).

A área gordurosa do braço, calculada pelas equações propostas por FRISANCHO (1981) apresentou alta variabilidade, com coeficientes de variação de Pearson variando entre 41,4 e 60,0\% implicando em baixa precisão das estimativas. $O$ fato de ser expressa em $\mathrm{mm}^{2}$, não auxilia sua interpretação. Pela análise deste indicador não foi possível identificar diferença na área média gordurosa do braço $\left(\mathrm{mm}^{2}\right)$ segundo sexo, nas faixas etárias de 7 a 10 anos. Segundo idade, somente para os grupos etários de 8 e 9 anos não foi encontrada diferença; entre as demais idades encontrou-se diferença. A área gordurosa média do braço de escolares com 10 anos é 553 $\mathrm{mm}^{2}$ maior do que a de escolares de 7 anos, representando aumento de $55,3 \%$.

Os valores da mediana da área gordurosa do braço de escolares segundo sexo e idade são maiores, de modo geral, se comparados aos valores medianos de crianças americanas do estudo de FRISANCHO (1999) e de escolares de baixa renda de Campinas (COCETTI 2001). Gráficos 
comparativos de tais estudos são apresentados no Anexo 16. As maiores diferenças são observadas entre o presente estudo e o realizado em Campinas, para meninos de 10 anos, com diferença entre as medianas de $569,2 \mathrm{~mm}^{2}$.

\section{Comparação entre métodos}

\section{Gordura corporal total estimada pela BIA e pelas pregas cutâneas tricipital e da panturrilha}

A comparação dos métodos de estimação do percentual de gordura total pela BIA e pelas pregas cutâneas tricipital e da panturrilha foi realizada pela investigação da relação e da concordância entre os valores obtidos pelos métodos, utilizando-se a estratégia de BLAND e ALTMAN (1986). Apesar da existência de correlação linear positiva, de moderada a forte, entre as mensurações de cada método, não foi encontrada concordância entre os mesmos. Estes achados são semelhantes aos descritos por COCETTI (2001), em estudo com escolares, com identificação da existência de correlação, com força de mediana a forte, entre a gordura corporal total estimada pela BIA e pelas pregas cutâneas tricipital e subescapular, assim como baixa concordância entre os métodos utilizando-se também a estratégia de BLANDALTMAN (1986).

A existência de correlação linear entre os métodos era esperada, uma vez que ambos estimam a quantidade de gordura corporal total. A relação positiva indica que aumentos (ou diminuições) da massa gorda (estimada pelas pregas) são acompanhados por aumentos (ou diminuições) na quantidade da massa gorda estimada pela BIA. Sabe-se, entretanto, que a existência de correlação não indica necessariamente existência de concordância entre os métodos (SNEDECOR e col 1967).

No presente estudo, a falta de concordância fica bem caracterizada pela utilização dos limites de concordância propostos BLAND-ALTMAN (1986). Estes autores propõem a construção de um gráfico de dispersão de 
pontos compostos pelas diferenças e pelas médias dos valores de cada método. Se houvesse concordância, a média das diferenças estaria próxima de zero e se a mensuração (por cada método) for independente da magnitude dos valores (variabilidade constante) os pontos não teriam a dispersão alterada com o aumento da magnitude dos mesmos (expressos pelas médias). No presente estudo, a média das diferenças entre os métodos não foi próxima de zero, independente de sexo e idade, sendo 3,52\% para os meninos e $6,23 \%$ para as meninas. A variabilidade das diferenças entre os percentuais de gordura total estimados pelos dois métodos apesar de não aumentar com a magnitude dos valores, foi alta (limites de concordância iguais a $-8,7$ e $+15,7 \%$ para meninos e $-4,6$ e $17,1 \%$ para meninas). Pela construção dos limites de confiança para os limites inferior e superior de concordância, pode-se dizer que obteve-se boa precisão na estimação dos limites de concordância.

A ausência de concordância entre os métodos já havia sido identificada pela análise das freqüências acumuladas (Gráfico 16), com indicação de diminuição das discordâncias com o aumento da idade. $\mathrm{Na}$ Tabela 18, os intervalos de confiança para as diferenças entre os métodos, segundo idade, indicam ausência do valor zero e diminuição das diferenças médias, corroborando a afirmação anterior sobre a diminuição das diferenças entre os métodos com o aumento da idade. GUTIN e col. (1996) também relataram falta de concordância entre os dois métodos, concluindo que estes não podem ser utilizados indistintamente. A baixa concordância entre os métodos, segundo HAMMOND e col. (1994) não é totalmente surpreendente uma vez que a BIA essencialmente quantifica massa magra e a prega cutânea, massa gorda. Assim, segundo os autores, os dois métodos não necessariamente deveriam estar linearmente relacionados.

Os valores de gordura total, sempre maiores quando estimados pela BIA, observados no presente estudo para todas as idades, estão em concordância com outros achados na literatura: GUTIN e col.(1996), HAMMOND e col (1994) e COCETTI (2001), relatam também maior gordura 
corporal total quando utilizada a BIA em relação às pregas cutâneas. Esta ocorrência conduz ao questionamento sobre o que a BIA mede com a passagem da corrente elétrica. Pode-se suspeitar que a BIA esteja deixando de quantificar toda a massa magra existente, resultando em super estimação da massa gorda. Esta pode ser uma das explicações para a ocorrência de valores de gordura corporal superiores para a BIA, quando comparada aos estimados pelas pregas cutâneas tricipital e da panturrilha.

A falta de concordância entre os métodos também é refletida na estimação da prevalência de risco de DCV, sendo a prevalência pela BIA $(42,3 \%)$ pouco mais que o dobro da prevalência pelas pregas $(20,1 \%)$. 0 risco de DCV também se apresenta diferentemente segundo sexo e idade, dependendo do método utilizado para estimação da gordura corporal. Enquanto não existe diferença segundo sexo e idade para risco de DCV pela BIA, pelas pregas passa-se a identificar maior prevalência de risco de DCV para meninos e aumento com a idade.

\section{Desempenho dos métodos BIA e pregas cutâneas tricipital e da panturrilha na identificação de excesso de peso tomando-se como referência a classificação do estado nutricional pelo IMC}

Apesar de não existir consenso na literatura, estudos sugerem que 0 IMC pode ser um bom indicador de adiposidade em crianças (LAZARUS e col 1996, PIETROBELLI e col 1998, COCETTI 2001; MEI e col 2002, GIUGLIANO E MELO 2004). Com base nesta constatação, associado ao fato de não existir proposta de ponto de corte para gordura corporal na classificação de crianças com excesso de peso, o presente estudo investigou o desempenho de dois diferentes métodos de estimação do percentual de gordura (BIA e pregas) tomando-se como referência a classificação do estado nutricional pelo IMC.

Para a análise de desempenho e identificação dos pontos de corte para os percentuais de gordura resultantes de cada método, utilizou-se gráficos (curvas TGROC) que otimizam a sensibilidade e especificidade dos 
métodos na identificação de escolares corretamente classificados como apresentando excesso de peso (risco de sobrepeso + sobrepeso) (GREINER e GARDNER 2003). Considerou-se como de melhor desempenho o método que apresentou maior área sob a curva ROC, maior eficiência e maior índice de Youden. Com relação à área sob a curva ROC, ambos os métodos apresentam bom desempenho, entretanto, o método das pregas cutâneas tricipital e da panturrilha apresentou maior eficiência, ou seja, identificou corretamente uma proporção maior de escolares com excesso de peso, se esta condição estiver prevalente em $25 \%$ da população. O índice de Youden, que não depende da prevalência de excesso de peso, também indica o método das pregas cutâneas tricipital e da panturrilha como o de melhor desempenho.

HAMMOND e col (1994) também preferem a utilização das pregas cutâneas (tríceps, bíceps, subescapular e suprailíaca) para estimação de gordura corporal total e concluem que, pelo fato das equações para estimar este percentual pela BIA não serem totalmente desenvolvidos para uso em crianças de várias idades, deve-se dar preferência às pregas, principalmente em estudos epidemiológicos e de crescimento de crianças sadias

Identificou-se, pelas curvas TGROC, considerando-se o IMC como referência, pontos de corte para classificar excesso de peso, a partir dos resultados de gordura corporal estimados pelas pregas e pela BIA. Para as pregas, estes valores foram iguais a $22,5 \%$ para meninos e $24,2 \%$ para meninas e pela BIA, iguais a $26,7 \%$ para meninos e $31,6 \%$ para meninas. Com estes valores, pode-se identificar excesso de peso diretamente de medidas de composição corporal, sem necessidade do cálculo do IMC. Do ponto de vista operacional, a identificação de tais pontos de corte pode ser de bastante utilidade se for considerado o método que envolve as pregas cutâneas tricipital e da panturrilha. Coincidentemente, os pontos de corte identificados pela BIA são próximos aos valores de percentual de gordura utilizados para classificar risco de DCV, segundo proposto por LOHMAN (1992). 
Não foi encontrado, na revisão de literatura, nenhum artigo que utiliza o IMC como referência na análise de desempenho da BIA e pregas cutâneas tricipital e da panturrilha. ZIMMERMANN e col. (2004) utilizam o IMC como referência e avaliam o desempenho das pregas cutâneas tricipital, bicipital, subescapular e suprailíaca em crianças de 6 a 12 anos, suíças, e propõem pontos de corte segundo sexo e idade iguais a: $18,62 \% ; 20,97 \% ; 23,45 \%$ e $26,07 \%$ para meninos, nas idades de 7, 8, 9 e 10 anos, respectivamente e $21,57 \% ; 25,65 ; 27,82 \%$ e $30,08 \%$ para meninas nas referidas idades.

TAYLOR e col. (2002), utilizando como referência o IMC, mas estimando gordura corporal pela DEXA, encontraram para crianças da Nova Zelândia, de 2 a 18 anos, valores de pontos de corte iguais a 18\%; 19\% $20 \%$ e $21 \%$ para meninos de 7 a 10 anos, respectivamente e $22 \%$; $24 \%$; $26 \%$ e $28 \%$ para meninas do mesmo grupo etário.

Considerando-se os valores de ponto de corte para a gordura corporal total na identificação de excesso de peso encontrados no presente estudo: $22,5 \%$ para meninos e $24,2 \%$ para meninas, do grupo de 7 a 10 anos, podese notar semelhança entre estes e os encontrados por ZIMMERMANN e col. (2004) e TAYLOR e col. (2002), com pontos de corte menores para meninos.

\section{Comparação entre a circunferência da cintura e gordura corporal estimada pela BIA e pelas prega cutâneas tricipital e da panturrilha}

A análise exploratória da relação entre a circunferência da cintura e a gordura corporal, pelo diagrama de dispersão, sugere existência de correlação positiva não linear, com intensidade de mediana a forte quando a gordura era estimada pela BIA e, claramente linear e forte quando comparada com valores estimados pelas pregas. A existência de correlação entre a circunferência da cintura e gordura corporal em crianças e adolescentes tem sido descrita na literatura. DANIELS e col (2000) descrevem alta correlação entre a circunferência da cintura e gordura corporal estimada pela prega cutâneas subescapular, independente do sexo e grupo étnico. MAFFEIS e col. (2001) em estudo longitudinal identifica a 
circunferência da cintura, medida aos 8 anos, como o melhor preditor de sobrepeso aos 12 anos, utilizando ajuste para idade, sexo, IMC da mãe e IMC relativo da criança, aos 8 anos.

A análise de desempenho da circunferência da cintura para classificar escolares com risco de DCV tomando-se cada um dos métodos (BIA e pregas cutâneas tricipital e da panturrilha) como referência, identificou melhor desempenho se utilizadas as pregas cutâneas como referência por apresentar maior área sob a curva ROC e maior índice de Youden.

Identificou-se, assim, os pontos de corte $65,3 \mathrm{~cm}$ para meninos e 67,6 $\mathrm{cm}$ para meninas como valores que classificariam risco de DCV com sensibilidade de $100 \%$ entre meninas e $99 \%$ entre meninos e especificidade de $63 \%$ entre meninas e $71 \%$ entre meninos. Estas estatísticas, tomando-se como referência a BIA, revelam menor sensibilidade e maior especificidade indicando que pela BIA a proporção de falsos negativos seria maior, em contrapartida, a proporção de falsos positivos seria menor.

Os falsos negativos seriam os escolares verdadeiramente com risco de DCV, mas classificados pela circunferência da cintura como sem risco de DCV e os falsos positivos seriam os escolares verdadeiramente sem risco, mas classificados como de risco pela circunferência da cintura.

Se a intenção for identificar indivíduos com risco de DCV, parece razoável que o método de referência a ser escolhido deva ser as pregas, porque com este método a circunferência da cintura é mais sensível, não importando tanto o percentual de escolares erradamente classificados como de risco, pois estes, de qualquer forma, poderiam se beneficiar de qualquer intervenção nutricional ou de atividade física.

A identificação dos pontos de corte da circunferência da cintura, pelos gráficos TGROC, utilizando-se qualquer um dos métodos como referência, garante sensibilidade e especificidade com valores próximos (otimiza a distância entre especificidade e sensibilidade) e, se adotados, resultam na maior área sob a curva ROC. Se forem adotados os pontos de corte, utilizando-se a BIA como referência, seriam classificados aproximadamente 
$35 \%$ dos escolares de $7 ; 45 \%$ de $8 ; 60 \%$ de 9 e $80 \%$ de 10 anos como apresentando risco de doenças cardiovasculares e pela pelas pregas, estes valores seriam de aproximadamente $10 \%$ dos escolares de $7 ; 20 \%$ de 8 ; $25 \%$ de 9 e $40 \%$ de 10 anos, valores semelhantes aos encontrados na classificação de risco de DCV, utilizando-se os percentuais de gordura estimados pelas pregas cutâneas tricipital e da panturrilha.

Suspeita-se que os pontos de corte para circunferência da cintura poderiam superestimar a proporção de escolares com risco de DCV se fosse adotado, como referência, o método da BIA para estimar a gordura corporal total.

Devido ao reduzido número de escolares em cada idade e sexo, e considerando-se a prevalência de risco de doença cardiovascular, não foi possível identificar pontos de corte segundo sexo e idade, apesar de ter sido identificado neste estudo valores de circunferência da cintura aumentando com a idade. Seria esperada magnitude menor para ponto de corte de escolar de 7 anos se comparada a escolares de 10 anos. Entretanto, optouse por analisar juntamente todas as idades para garantir um tamanho razoável da amostra e não diminuição da precisão dos dados. Realizou-se análise comparativa dos pontos de corte, considerando-se somente o grupo de 8 e 9 anos, obtendo-se valores muito semelhantes, em números absolutos, aos encontrados para o grupo de 7 a 10 como um todo. Assim, torna-se mais confiável a utilização dos valores encontrados (para todo o grupo) somente para escolares de 8 e 9 anos.

HIGGINS e col. (2001), em estudo com crianças pré-púberes americanas, identificaram pontos de corte para a circunferência da cintura os valores $\leq 61 \mathrm{~cm}$ para identificar fator de risco normal para DCV e $\geq 71 \mathrm{~cm}$ para identificar risco adverso de DCV, utilizando a DEXA como método de referência. TAYLOR e col. (2000), também utilizando a DEXA como referência, em estudo com crianças de 3 a 19 anos, neozelandesas, propuseram pontos de corte para a circunferência da cintura para identificar altos níveis de massa gorda do tronco como fator relacionado a risco de DCV 
iguais a $62 \mathrm{~cm} ; 64,7 \mathrm{~cm} ; 67 \mathrm{~cm}$ e 69,6 cm para meninas e $62,9 \mathrm{~cm} ; 65,3 \mathrm{~cm}$; 67,7 e 70,1 cm para meninos, com 7, 8, 9 e 10 anos, respectivamente. Estes achados se assemelham aos pontos de corte do presente estudo: $65,3 \mathrm{~cm}$ para meninos e $67,6 \mathrm{~cm}$ para meninas de 8 e 9 anos.

\section{Área gordurosa do braço: descrição e comparação com a gordura total estimada pela BIA}

A investigação do desempenho da área gordurosa do braço, tomandose como referência a classificação de risco de DCV com valores de gordura corporal estimados pela BIA revelou que esta apresenta boa capacidade para identificar indivíduos com riscos de DCV, para população com prevalência de risco de doença cardiovascular semelhante a observada no presente estudo $(42,3 \%)$. Seu desempenho, entretanto, pode não ser bom se utilizado em populações sem considerar a prevalência de risco de DCV. Neste caso, o percentual de pessoas com risco de DCV corretamente identificadas cairia para $50 \%$ entre meninas e $56 \%$ entre meninos, segundo resultados obtidos pelo índice de Youden.

A comparação dos dados de área gordurosa do braço com a gordura corporal total encontrados neste estudo com os já publicados não foi possível uma vez que não se observa a sua utilização por outros investigadores, possivelmente por ser uma medida de difícil interpretação.

Do ponto de vista operacional, frente a possíveis dificuldades na realização da BIA, a utilização da circunferência braquial e da prega cutânea tricipital, elementos primários para o cálculo da área gordurosa do braço, pode se constituir em uma boa alternativa para classificar escolares de 7 a 10 anos com risco de doenças cardiovasculares.

\section{Considerações finais}

O presente estudo quantifica, em escolares de 7 a 10 anos, de escolas públicas, da região da Água Rasa, o excesso de peso e risco de doença cardiovascular utilizando medidas antropométricas e indicadores de 
composição corporal mais utilizadas em estudos epidemiológicos, bem como avalia o desempenho de métodos de avaliação do estado nutricional. A comparação dos resultados deste estudo com outros já publicados revela a existência de valores iguais ou maiores para todos os indicadores do estado nutricional e de composição corporal utilizados, evidenciando que o problema está possivelmente em ascensão. Em alguns casos identificou-se diferencial segundo sexo e idade, criando maiores possibilidades de ações preventivas mais direcionadas.

Maior acúmulo lipídico pode ser reflexo de alto consumo calórico e baixo gasto energético como conseqüência de pouca atividade física. $O$ presente trabalho caracteriza a população de estudo quanto a prática de atividade física e condições de vida com o objetivo de permitir comparações. Chama a atenção, entretanto, a o baixo nível de atividade física observado entre os escolares.

Segundo as palavras de MONTEIRO (2005), citadas em entrevista concedida à Revista Pesquisa FAPESP de maio de 2005, em resposta à discussão gerada pela publicação de resultados de pesquisa, sob sua coordenação, que evidenciou a obesidade como problema de saúde pública, "reza o censo comum que o Brasil é um país que sofre de doenças devidas à escassez, à miséria absoluta. Mas quando você examina objetivamente os dados, vê que não é bem assim. A opinião pública, infelizmente, nem sempre repousa no conhecimento científico". Utiliza-se tal pronunciamento para alertar para o fato que o excesso de peso, segundo este estudo, está presente também, em aproximadamente $25 \%$ de escolares de 7 a 10 anos, de escolas públicas, da Água Rasa, região localizada no sudeste da cidade de São Paulo. 


\section{6 - CONCLUSÕES}

A população de estudo, escolares de 7 a 10 anos apresenta características sócio-demográficas compatíveis com situação de vida desfavorável. Pela avaliação da prática de atividade física, pode-se concluir que os escolares apresentam baixos níveis de prática de exercícios físicos. Identifica-se, assim, a necessidade de programas de incentivem esta prática nesta faixa etária.

Meninos e meninas não diferem segundo peso e estatura. Como esperado, também nesta faixa etária, o peso e estatura aumentam com a idade. Pode estar havendo aumento do peso e da estatura entre escolares de gerações mais recentes.

Independente do sexo e idade a prevalência de baixo peso pode ser considerada baixa e a de excesso de peso, alta indicando deslocamento do problema nutricional de déficit para excesso de peso.

Pelo método da prega cutânea tricipital e da panturrilha, conclui-se que escolares apresentam gordura periférica em níveis médios semelhantes segundo sexo. Aumento importante na quantidade média de gordura periférica ocorre aos 10 anos.

Nesta faixa etária os escolares do sexo masculino e feminino não diferem segundo circunferências braquial e cintura. 0 mesmo se aplica para idade de 8 e 9 anos. Para os demais grupos etários, conclui-se que as medidas de circunferência da cintura e braquial aumentam com a idade.

Assim como para o peso, estatura, IMC, pregas cutâneas e circunferência da cintura, os valores de gordura total estimados pela BIA são sempre maiores que os da literatura.

De modo geral, a área gordurosa do braço aumenta com a idade e são maiores que os dados apresentados na literatura.

Os valores médios de gordura corporal estimados pela BIA, segundo sexo e idade, são sempre maiores que aqueles estimados pelas pregas cutâneas tricipital e da panturrilha. Os métodos quantificam prevalência de 
risco de doença cardiovascular em magnitudes diferentes, sendo de $42,3 \%$ para a BIA e 20,1\% pelas pregas cutâneas. Os métodos das pregas cutâneas e da BIA não devem ser utilizados indistintamente pois não apresentam resultados concordantes para estimação do percentual de gordura total.

Os desempenhos dos métodos de estimação da gordura corporal total pela BIA e pregas cutâneas tricipital e da panturrilha não são semelhantes. 0 método das pregas cutâneas tricipital e da panturrilha apresenta melhor desempenho para classificar escolares com excesso de peso (risco de sobrepeso + sobrepeso), se o IMC for considerado como o método de referência para classificação do estado nutricional. Propõem-se como pontos de corte para classificar excesso de peso os valores $22,5 \%$ para meninos e 24,2\% para meninas, utilizando-se as pregas cutâneas tricipital e da panturrilha para quantificar gordura corporal total.

A circunferência da cintura pode ser uma boa medida para avaliar gordura corporal porque é de fácil obtenção e parece não depender do sexo, mas sim da idade. Apresenta melhor desempenho na identificação de risco de doenças cardiovasculares se utilizado, como referência, o método das pregas cutâneas (tricipital e da panturrilha) para quantificar gordura corporal total. Propõem-se pontos de corte para a circunferência da cintura na identificação de risco de doença cardiovascular iguais a 65,3 cm e 67,6 cm, para escolares do sexo masculino e feminino, respectivamente, com 8 e 9 anos, com sensibilidade de aproximadamente $100 \%$ e especificidades de $63 \%$ para o sexo feminino e $71 \%$ para o sexo masculino.

A área gordurosa do braço pode se constituir, com base na análise de desempenho, uma boa alternativa para identificar escolares de 7 a 10 anos com risco de doenças cardiovasculares. 


\section{REFERÊNCIAS BIBLIOGRÁFICAS}

Abrantes MM, Lamounier JA, Colosimo EA. Prevalência de sobrepeso e obesidade em crianças e adolescentes das regiões sudeste e nordeste. J Pediatr 2002; 78(4): 335-40.

Anjos LA, Engstrom EM. Relação entre o estado nutricional materno e sobrepeso nas crianças brasileiras. Rev Saúde Pública 1996; 30(3): 233-9.

Anjos LA, Veiga GV, Castro IRR. Distribuição dos valores do índice de massa corporal da população brasileira até 25 anos. Rev Panam Salud Pública 1998; 3(3): 164-73.

Anjos LA, Castro IRR, Engstrom EM, Azevedo AMF. Crescimento e Estado Nutricional em amostra probabilística de escolares no município do Rio de Janeiro, 1999. Cad Saúde Pública 2003, 19 (supl.1): S171-S179.

Amigo $\mathrm{H}$. Bustos $\mathrm{P}$, Leone $\mathrm{C}$, Radrigán ME. Growth déficits in chilean school children. J Nutr 2001; 131: 251-54.

Amigo $\mathrm{H}$. Obesidad em el niño en America Latina: situación, criterios de diagnóstico y desafios. Cad. Saúde Pública 2003; 19 (supl. 1): S163-S170.

Balaban G, Silva GAP. Overweight and obesity prevalence in children and adolescents from a private school in Recife. J Pediatr 2001; 77(2): 96-100.

Barlow SE, Dietz WH. Obesity evaluation and treatment: Expert Committee recommendations. Pediatrics 1998; 102(3).

Barros MVG, Nahas MV. Medidas da atividade física: Teoria e aplicação em diversos grupos populacionais. Londrina: Midiograf; 2003.

Batista Filho $M$, Rissin A. A transição nutricional no Brasil: tendências regionais e temporais. Cad Saúde Pública 20 03; 19 (supl.1): S181-S191.

Benício MHD'A, Monteiro CA. Desnutrição infantil nos municípios brasileiros: risco de ocorrência. Brasília: Fundo das Nações Unidas para Infância/Núcleo de Pesquisas Epidemiológocas em Nutrição e Saúde, Universidade de São Paulo, 2000.

Bjorntorp P. Fat patterning and disease: A review. In NG Norgan (Ed.), Human body composition and fat distribution (pp. 201-209). Wageningen, Netherlands: Euronut, 1985.

Bland JM, Altman DG. Statistical methods for assessing agreement between two methods of clinical measurement. The Lancet 1986: 307-12. 
Briesofsky J. Computer Methods for Diagnostic Test (CMDT) [programa de computador] URL: http://www1.vetmed.fuberlin.de/ mgreiner/CMDT/poster.htm [2004 mar 8]

Centers for Disease Control, World Health Organization. Epi info. Epidemiologia em microcomputadores: um sistema de processamento de texto, banco de dados e estatísticas [programa de computador]. Atlanta: OPAS/WHO; 1990.

Centers fo Disease Control and Prevention and National Center for Health Statistics. 2000 CDC growth charts: United States [online] Hyaltsville; 2002], disponível em: <URL:HTTP://www.cdc.gov.br/growthcharts> [2004 dez 10].

Cocetti M. Antropometria e bioimpedância elétrica na avaliação nutricional de escolares de baixo nível socioeconômico. Campinas; 2001. [Dissertação de mestrado - Faculdade de Ciências Médicas da Universidade Estadual de Campinas/UNICAMP].

Cole TJ, Bellizzi MC, Flegal KM, Dietz WH. Establishing a standard definition for child overweight and obesity worldwide: international survey. BMJ 2000; 320: $1-6$.

Corso ACT, Buralli KO, Souza JM. Crescimento físico de escolares de Florianópolis, Santa Catarina, Brasil: um estudo caso-controle. Cad Saúde Pública 2001; 17(1): 79-87.

Daniels SR, Khoury PR, Morrison JA. The utility of body mass index as a measure of body fatness in children and adolescents: differences by race and gender. Pediatrics 1997; 99 (6): 804-7.

Daniels SR, Khoury PR, Morrison JA. Utility of different measures of body fat distribution in children and adolescents. Am J Epidemiol 2000; 152: 117984.

Dean AG, Arner TG, Sunki GG, Friedman R, Lantinga M, Sangam S, Zubieta JC, Sullivan KM, Brendel KA, Gao Z, Fontaine N, Shu M, Fuller G. Epi Info, a database and statistics program for public health professionals. Centers for Disease Control and Prevention, Atlanta, Georgia, USA, 2002.

Deurenberg P, Weststrate JA. Factors affecting bioelectrical impedance measurements in humans. Eur J Clin Nutr 1988; 42: 1017-1022. 
Deurenberg P. Limitations of the bioelectrical impedance method for the assessment of body fat in severe obesity. Am J Clin Nutr 1996; 64(suppl): 449S-52S.

Deurenberg P, Pieters JJL, Hautvast JGA. The assessment of the body fat percentage by skinfold thickness measurements in childhood and young adolescence. British Journal of Nutrition 1990; 63: 293-303.

Dietz WH. Health consequences of obesity in youth: childhood predictors of adult disease. Pediatrics 1998; 101:518-25.

Dietz WH, Robinson TN. Use of the body mass index (BMI) as a measure of overweight in children and adolescents. J pediatr 1998; 132 (2): 191-3.

Dietz WH, Bellizzi MC. Introduction: the use of body mass index to assess obesity in children Am J Clin Nutr 1999; 70: 123-5S.

Ellis $\mathrm{KJ}$, Abramis AS, Wong WW. Monitoring childhood obesity assessment of the weight/height ${ }^{2}$ index. Am J Epidemiol 1999, 150:939-46.

EMPLASA - Empresa Paulista de Planejamento Metropolitano SA. Disponível em: <URL:HTTP://www.emplasa.sp.gov.br> [10 maio 2005].

Faith MS, Berman N, Heo M, Pietrobelli A, Gallagher D, Epstein, Eiden MT, Allison DB. Effects of contingent television on physical activity and television viewing in obese children. Pediatrics 2001; 107(5): 1043-48.

Faith MS, Pietrobelli A, Nunes C, Moonseong $\mathrm{H}$, Heymsfield SB, Allison DB. Evidence for independent genetic influences on fat mass and body mass index in a pediatric twin sample. Pediatrics 1999; 104(1): 61-67.

Fleiss JL. The Design and Analysis of Clinical Experiments. United States Copyright; 1986.

Fletcher RH, Fletcher SW, Wagner EH. Epidemiologia Clínica. 2a edição. Porto Alegre: Editora Artes Médicas Sul; 1991.

Fomon SJ, Haschke F, Ziegler EE, Nelson SE. Body composition of reference children from birth to age 10 years. Am J Clin Nutr 1982; 35: 1169-1175.

França Jr I, Silva GR, Monteiro CA. Tendência secular da altura na idade adulta de crianças nascidas na cidade de São Paulo entre 1950 e 1976. Rev Saúde Pública 2003; 34 (6 Supl):102-7.

França NM, Matsudo VKR, Sessa M. Dobras cutâneas em escolares de 7 a 18 anos. Rev Bras Cienc Mov 1988; 2(4): 7-16. 
Freedman DS, Srinivasan SR, Harcha DW, Weber LS, Berenson GS. Relation of body fat patterning to lipid and lipoprotein concentrations in children and adolescents: the Bogalusa Heart Study. An J Clin Nutr 1989; 50: 930-9.

Freedman DS, Srinivasan SR, Valdez RA, Williamson DF, Berenson GS. Secular increases in relative weight and adiposity among children over two decades: The Bogalusa Heart Study. Pediatrics 1997; 99(3): 420-6.

Frisancho AR. Anthropometric standards for the assessment of growth and nutritional status. University of Michigan, 1999.

Frisancho AR. Triceps skin fold and upper arm muscle size norms for assessment of nutritional status. Am J Clin Nutr 1974; 27: 1052-58.

Frisancho AR. New norms of upper limb fat and muscle areas for assessment of nutritional status. Am J Clin Nutr 1981; 34: 2540-45.

Fundação SEADE (fundação sistema estadual de análise de dados). Índice de vulnerabilidade social. Disponível em URL:http://www.seade.gov.br [10 maio 2005]

Giugliano R, Carneiro EC. Fatores associados à obesidade em escolares. Jornal de Pediatria 2004; 80(1): 17-22.

Giugliano R, Melo ALP. Diagnóstico de sobrepeso e obesidade em escolares: utilização do índice de massa corporal segundo padrão internacional. Jornal de Pediatria 2004; 80(2): 129-34.

Greiner M, Gardner I. Princípios e métodos avançados em avaliação de testes diagnósticos. São Paulo; 2003. [Apostila do curso de difusão Faculdade de Saúde Pública da USP]

Gross R, Lima FD. The relationship between selected anthropometric and socio-economic data in schoolchildren from diferent social strata in Rio de Janeiro, Brazil. Rev Saúde Pública 1990; 24(1): 11-9.

Gurney JM, Jelliffe DB. Anthropometric in the differential diagnosis of protein-calorie malnutrition. J Trop Pediat 1972; 18: 1.

Gurney JM, Jelliffe DB. Arm anthropometric in nutritional assessment: nomogram for rapid calculation of muscle circumference and cross-sectional muscle and fat areas. Am J Clin Nutr 1973; 26: 912-15.

Gutin B, Litaker M, Islam S, Manos T, Smith C, Treiber F. Body-composition measurement in 9-11-y-old children by dual-energy X-ray absorptiometry, 
skinfold-thickness measurements, and bioimpedance analysis. Am J Clin Nutr 1996; 63: 287-92.

Hamill PVV, Drizd TA, Johnson CL, Reed RB, Roche AF, Moore WM. Physical growth: National Center for Health Statistics percentiles. Am J Clin Nutr 1979; 32: 607-29.

Hammer LD, Kraemer HC, Wilson DM, Ritter PL, Dornbusch SM. Standardized percentile curves of body-mass index for children and adolescents. AJDC 1991; 145: 259-63.

Hammond J, Rona RJ, Chinn S. Estimation in community survey of total body fat of children using bioelectrical impedance or skinfold thickness measurements. Eur J Clin Nutr 1994. 48, 164-71.

Heyward VH, Stolarczyk LM. Avaliação da composição corporal aplicada. Barueri: Editora Manole; 2000.

Higgins PB, Gower BA, Hunter GR, Goran MI. Definig health-related obesity in prepuberal children. Obesity Research 2001; 9: 233-9.

Hill JO, Trowbridge FL. Childhood obesity: future directions and research priorities. Pediatrics 1998; 101: 570-74.

Jellife DB. The assessment of the nutritional status of the community. World health Organ. Monograf Ser no53. Geneva, 1966.

Johnson-Down L, O' Loughlin J, Koski KG, Gray-Donald K. High prevalence of obesity in low income and multiethnic schoolchildren: A diet and physical activity assessment. J Nutr 1997; 127: 2310-15.

Khaled MA, McCutcheon MJ, Reddy S, Pearman PL, Hunter GR, Weinsier RL. Electrical impedance in assessing human body composition: the BIA method. Am J Clin Nutr $1988 ; 47: 789-92$.

Kotler DP, Burastero S, Wang J, Pierson Júnior RN. Prediction of body cell mass, fat-free mass, and total body water with bioelectrical impedance analysis: effects of race, sex and disease. Am J Clin Nutr 1996;64 (suppl): 489S-97S.

Kushner RF, Schoeller DA, Fjeld CR, Danford L. Is the impedance index $\left(\mathrm{ht}^{2} / \mathrm{R}\right)$ significant in prediction total body water? Am J Clin Nutr 1992; 56: 835-9. 
Lazarus R, Baur L, Webb K, Blyth F. Body mass index in screening for adiposity in children and adolescents: systematic evaluation using receiver operating characteristic curves. Am J Clin Nutr 1996; 63: 500-6.

Lei DLM, Chaves SP, Lerner BR, Arruda SC, Stefanini MLR. Estudo em escolares de Barueri (SP): estatura, rendimento escolar e suplementação alimentar: Rev Nutr. PUCCAMP 1993; 6(1): 29-51.

Lohman TG. Advances in body composition assessment. Champaign, IL: Human Kinetics, 1992.

Lukaski HC. Methods for assessment of human body composition: traditional and new. Am J Clin Nutr 1987; 46: 537-56.

Lukaski HC. Biological indexes considered in the derivation of the bioelectrical impedance analysis. Am J Clin Nutr 1996; 64 (suppl): 397S-404S.

Maffeis C, Grezzani A, Pietrobelli A, Provera S, Tato L. Does waist circumference predict fat gain in children Int J Obesity 2001; 25: 978-83.

Malina RM, Katzmarzyk PT. Validity of the body mass index as an indicator of the risk and presence of overweight in adolescents. Am J Clin Nutr 1999, 70 (suppl):131S-136S.

Mângia CMF. Índices primários de bioimpedância corporal: resistência e reactância em crianças. São Paulo; 2000. [Dissertação de mestrado - Escola Paulista de Medicina da Universidade Federal de São Paulo/UNIFESP].

Martins C. Protocolo de procedimento nutricionais in: Riella MC, Martins C. Nutrição e o rim. Rio de Janeiro: Ed Guanabara; 2001

Maynard LM, Wisemandle W, Roche AF, Chumlea WC, Guo SS, Siervogel RM. Childhood Body Composition in relation to Body Mass Index. Pediatrics 2001; 107 (2): 344-50.

Maynard LM, Galuska DA, Blanck HM, Serdula MK. Maternal perceptions of weight status of children. Pediatrics 2003; 111(5): 1226-1231.

McCarthy HD, Jarrett KV, Crawley HF. The development of waist circumference percentiles in British children aged 5.0-16.9 y. European Journal of Clinical Nutrition 2001; 55: 902-7.

Mei Z, Grummer-Strawn LM, Onís M, Yip R. El desarrollo de valores de referencia para el perímetro braquial según la estatura y su comparación con 
otros indicadores utilizados para el tamizaje del estado nutricional. Rev Panam Salud Pública 1998; 4(3): 187-95.

Mei Z, Grummer-Strawn LM, Pietrobelli A, Goulding A, Goran M, Dietz WH. Validity of body mass index compared with other body-composition screening indexes for the assessment of body fatness in children and adolescents. Am J Clin Nutr 2002; 75: 978-85.

Mello ED. O que significa a avaliação do estado nutricional. Jornal de Pediatria 2002; 78(5): 357-358.

Monteiro CA, Reis IM, Benício MHD'a Estudo antropométrico-nutricional de pré escolares de áreas de baixa renda do estado de São Paulo, Brasil. Rev Saúde Pública 1984; 18: 1-18.

Monteiro CA, Lenise M, Souza ALM, Popkin BM. Da desnutrição para a obesidade: a transição nutricional no Brasil: in Monteiro CA - Velhos e novos males da saúde no Brasil: a evolução do país e de suas doenças. São Paulo: Hucitec/Nupens/USP; 1995, p.247-255.

Monteiro CA, Conde WL, Popkin BM. A tendência secular da obesidade segundo estratos sociais: Nordeste e Sudeste do Brasil, 1975-1989-1997. Arquivos Brasileiros de Endocrinologia e Metabologia 1999; 43: 186194.

Monteiro CA, Conde WL. Tendência secular da desnutrição e da obesidade na infância na cidade de São Paulo (1974-1996). Rev Saúde Pública 2000; 34(6 Supl): 52-61.

Monteiro CA. Da privação ao excesso de comida. Revista Ciência e Tecnologia no Brasil - Pesquisa Fapesp, no 111, maio 2005, p.12-17.

Monteiro POA, Victora CG, Barros FC, Tomasi E. Diagnóstico de sobrepeso em adolescentes: estudo do desempenho de diferentes critérios para o índice de massa corporal. Rev Saúde Pública 2000; 34(5): 506-13.

Must A, Dallal GE, Dietz WH. Reference data for obesity: $85^{\text {th }}$ and $95^{\text {th }}$ percentile of body mass index $\left(\mathrm{wt} / \mathrm{ht}^{2}\right)$ and triceps skinfold thickness. Am J Clin Nutr 1991; 53: 839-46.

National Institutes of Health [NIH]. Health implications of obesity: National Institutes of Health consensus development statement. Annals of Internal Medicine 1985; 103: 1073-77.

Ogden CL, Kuczmarski RJ, Flegal KM, Mei Z, Guo S, Wei R, Grummer-Strawn $L M$, Curtin LR, Roche AF, Jonson CL. Center for disease control and 
prevention 2000 growth charts for the United States: Improvements to the 1977 National Center for Health Statistics Version. Pediatrics 2002; 109(1): 45-60.

Pietrobelli A, Faith MS, Allison DB, Gallagher D, Chuimell G, Heymsfield SB et al. Body mass index as a measure of adiposity among children and adolescents: a validation study. J Peditr 1998; 132-204-10.

Poskitt E. Defining childhood obesity: the relative body mass index (BMI). Acta Pediatr 1995, 84: 961-963.

Prata PR. The epidemiologic transition in Brazil. Cad Saúde Pública 1992; 8(2): $168-75$.

Rolland-Cachera MF, Sempé M, Guilloud-Bataille M, Patois E, PéquignotGuggenbuhl, Fautrad V. Adiposity indices in children. Am J Clin Nutr 1982; 34: $178-84$.

Rolland-Cachera MF, Deheeger M, Bellisle F, Sempé M, Guilloud-Bataille M, Patois E. Adiposity rebound in children: a simple indicator for predicting obesity. Am J Clin Nutr 1984 ;39: 129-35.

Salbe AD, Weyer C, Lindsay RS, Ravussin E, Tataranni PA. Assessing risk factors for obesity between childhood and Adolescence: I. Birth Weight, Childhood adiposity, parental obesity, insulin and leptin. Pediatrics 2002; 110(2): 299-306.

Salbe AD, Weyer C, Harper I, Lindsay RS, Ravussin E, Tataranni PA. Assessing risk factors for obesity between childhood and Adolescence: II. Energy metabolism and Physical Activity. Pediatrics 2002; 110(2): 307-14.

SAS/STAT 8.0 [programa de computador]. Gary, North Carolina: SAS Institute Inc; 1999.

Sawaya AL, Roberts S. Stunting and future risk of obesity: principal physiological mechanisms. Cad. Saúde Pública 2003; 19(Sup.1): S21-S28.

Schaefer F, Georgi M, Wühl E, Schärer K. Body mass index and percentage fat mass in healthy German schoolchildren and adolescents. Int J Obes 1998; 22: 461-9.

Schell B, Gross R. The reliability of bioelectrical impedance measurements in the assessment of body composition in health adults. Nutrition Reports International 1987; 36(2): 449-59. 
Schroeder DG, Martorell R. Fatness and body mass index from birth to young adulthood in a rural Guatemalan population. Am J Clin Nutr 1999; 70 (supl): 137S-44S.

SEADE - Fundação Sistema Estadual de Análise de Dados. Disponível em: <URL:HTTP://www.seade.gov.br> [2005 mai 10].

Sigulem DM, Devincenzi MU, Lessa AC. Diagnóstico do estado nutricional da criança e do adolescente. Jornal de pediatria 2000; 76(supl.3): 275-84.

Slaughter MH, Lohman TG, Boileau RA, Horswill CA, Stillman RJ, Van Loan MD et al. Skinfold equations for estimation of body fatness in children and youth. Human Biology 1988; 60(5): 709-723.

Snedecor GW, Cochran WG. Statistical Methods. Sixth edition. Iowa/USA: The Iowa State university press; 1967.

Soar C, Vasconcelos FAG, Assis MAA. A relação cintura quadril e o perímetro da cintura associados ao índice de massa corporal em estudo com escolares. Cad Saúde Pública 2004; 20(6): 1609-16.

Soares NT. Um novo referencial antropométrico de crescimento: significados e implicações. Rev. Nutr. 2003; 16(1): 93-104.

Sotelo YOM, Colugnati FAB, Taddei JAAC. Prevalência de sobrepeso e obesidade entre escolares da rede pública segundo três critérios de diagnóstico antropométrico. Cad. Saúde Pública 2004; 20(1): 233-240.

Stata Corporation. Statistical software for professionals/STATA [programa de computador]. Versão 7. Texas: College Station; 2002.

Stettler N, Zemel BS, Kumanyika S, Stallings VA. Infant weight gain and childhood overweight status in a multicenter, cohort study. Pediatrics 2002; 109(2): 194-99.

Tanasescu M, Ferris AM, Himmelgreen DA, Rodrigues N, Perez-Escamilla R. Biobehavioral factors are associated with obesity in Puerto Rican children. J Nutr 2000; 130: 1734-1742

Taylor RW, Jones IE, Williams SM, Goulding A. Evaluation of waist circumference, waist-to-hip ratio, and the conicity index as screening tools for high trunk fat mass, as measured by dual-energy X-ray absorptiometry, in children aged 3-19 y. Am J Clin Nutr 2000; 72: 490-5.

Taylor RW, Jones IE, Williams SM, Goulding A. Body fat percentages measured by dual-energy $\mathrm{X}$-ray absorptiometry corresponding to recently 
recommended body mass index cutoffs for overweight and obesity in children and adolescents aged 3-18 y. Am J Clin Nutr 2002; 76: 1416-21.

Troiano RP, Flegal KM. Overweight children and adolescents: description, epidemiology, and demographics. Pediatrics 1998; 101 (3): 497-504.

Veiga GV, Sigulem DM. Avaliação da composição corporal através de medidas antropométricas, de adolescentes obesas e eutróficas de dois níveis sócio-econômicos. J Pediatr 1994; 70(4):206-14.

Veiga GV, Dias PC, Anjos LA. A comparison of distribution curve of body mass index from Brazil and the United States for assessing overweight and obesity in Brasilian adolescents. Rev. Panam Salud Publica 2001; 10(2): 79-85.

Wang Y. Is obesity associated with early sexual maturation? A comparison of the association in American boys versus girls. Pediatrics 2002; 110(5): 9039.

Willet W. Monographs of epidemiology and biostatístics. New York: Oxford University Press; 1990, pp. 231-44.

World Health Organization/WHO. Use and interpretation of anthropometric indicators of nutritional status. Bulletin of the World Health Organization 1986; 64(6): 929-941.

World Health Organization Physical Status: The use and interpretation of anthropometry. Technical Report Series 854. Geneva: WHO; 1995.

Zambon MP, Zanolli ML, Marmo DB, Magna LA, Guimarey LM, Morcillo AM. Correlação entre o índice de massa corporal e a prega cutânea tricipital em crianças da cidade de Paulínea, São Paulo, SP. Rev.Assoc. Med. Bras. 2003; 49(2): 137-40.

Zeferino AMB, Barros Filho AA, Bettiol H, Barbieri MA. Acompanhamento do crescimento. Jornal de Pediatria 2003;79 (supl1): S23-S32.

Zimmermann MB, Gübeli C, Piintener C, Molinari L. Overweight and obesity in 6-12 year old children in Switzerland. Swiss Med Wkly 2004;134:523-28. 
Termo autorização das escolas para realização da pesquisa

Termo de consentimento informado dirigido às Diretoras das Escolas

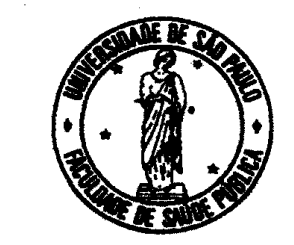

\author{
UNIVERSIDADE DE SÃO PAULO \\ FACULDADE DE SAÚDE PÚBLICA \\ DEPARTAMENTO DE NUTRIÇÃO \\ Av.Dr.Arnaldo, 715 - CEP: 01246-90 - São Paulo. \\ Fone: 3066 - 7736/7705 / 7762/7771 \\ Fone/Fax: (011) 3062-6748
}

OF. HNT. $119 / 03$.

À Sra. Diretora da Escola:

Venho por meio desta, solicitar de V.Sa. para a coleta de dados de alunos matriculados nesta Escola, para a realização da pesquisa "Avaliação nutricional de escolares de 7 a 10 anos de idade, matriculados em duas Escolas Públicas no Município de São Paulo" com período de duração de 24 meses. Serão realizadas mensurações antropométricas em 8 ou 9 ocasiões diferentes durante este período de 2 anos. Também serão feitas perguntas sobre prática de exercícios físicos. Gostaria de informá-la que esta pesquisa também fará parte do Curso de Mestrado em Saúde Pública da área de Nutrição da Faculdade de Saúde Pública da Universidade de São Paulo FSP/USP.

Os dados serão coletados por Claudia Regina Koga (número USP 2929062; RG 280930264) e por Denise Pimentel Bergamaschi (Professora do Departamento de Epidemiologia da FSP/USP, número USP 408752, RG 1053522); será solicitado aos pais ou responsáveis a assinatura de um pedido de autorização para a participação dos escolares. A pesquisa não envolverá riscos à saúde dos alunos.

Nos comprometemos a informar os pais dos alunos que apresentarem qualquer evidência de possuir estado nutricional fora do normal, bem como fornecer orientações nutricionais nestes casos. Solicitamos também acesso às notas bimestrais e freqüência de comparecimento mensal dos alunos de 1 a 4 série do ensino fundamental. A Escola terá acesso aos dados e resultados da pesquisa tão logo estiverem disponíveis.

Atenciosamente,

$\overline{\text { Profa Doutora Denise Pimentel Bergamaschi. }}$

\title{
TERMO DE CONSENTIMENTO
}

Eu, —

da pesquisa "Avaliação nutricional de escolares de 7 a 10 anos de idade, matriculados em duas Escolas Públicas no Município de São Paulo".

Assinatura:

São Paulo, de 
Termo de consentimento informado preenchido pelos pais ou responsáveis

Termo de consentimento informado dirigido aos pais ou responsáveis pelo escolar

$\mathrm{Eu}$, (nome) responsável

por

declaro que livremente autorizo a participação da criança na pesquisa "Avaliação Nutricional de escolares de 7 a 10 anos de idade", sob responsabilidade da Profa Denise Pimentel Bergamaschi, da Faculdade de Saúde Pública/USP, cujo objetivo é avaliar o estado nutricional.

Serão realizados os seguintes procedimentos com a criança, na própria Escola, gratuitamente, durante o horário das aulas:

$\checkmark$ Medição do peso, altura, circunferência da cintura, quadril e do braço, prega cutânea do braço e \% de gordura;

$\checkmark$ Aplicação de questionário (para a criança e família) para colher dados sobre características demográficas (sexo, idade, escolaridade, entre outros) e de prática de atividade física.

As tomadas das medidas antropométricas serão feitas com os cuidados necessários, ficando garantida a ausência de riscos à integridade física, mental ou moral da criança. No caso de identificar que a criança está com o peso/altura abaixo ou acima do normal, a equipe de pesquisadores irá informar os responsáveis. Garantimos o anonimato da criança e de toda a família.

Qualquer dúvida será esclarecida pela equipe responsável, sendo em qualquer momento do estudo, é possível anular este termo de consentimento, sem qualquer constrangimento ou prejuízo para o responsável ou para a criança.

Data: de de 2004.

Concordo com os dizeres deste consentimento e autorizo a participação da criança no estudo,

Assinatura do responsável

Dúvidas ou informações, procurar: Denise Pimentel Bergamaschi, Faculdade de Saúde Pública da Universidade de São Paulo - Av. Dr. Arnaldo, 715. São Paulo/SP. Tel (011) 3066-7744/7724 ou Cláudia Regina Koga, Rua Tocandira, 79. Tel (011) 69653362. 
Carta de retorno dirigida aos responsáveis pelo escolar para informar os dados antropométricos.

\section{Aluno:}

Série:

Prezado Sr(a),

Estivemos na escola de seu (sua) filho(a),

no dia, ________ e realizamos a tomada de medidas antropométricas obtendo os seguintes resultados:

Peso $(\mathrm{kg})$ :

Altura $(\mathrm{cm})$ :

Circunferência do braço $(\mathrm{cm})$ :

Circunferência da cintura $(\mathrm{cm})$ :

Prega cutânea tricipital $(\mathrm{mm})$ referente a dobra da região posterior do braço:

Prega cutânea da panturrilha $(\mathrm{mm})$ referente a região lateral da barriga da perna:

Realizamos também a bioimpedância que consiste em quantificar a quantidade de água no corpo e, indiretamente, calcular o percentual de gordura corporal. Este valor para seu (sua) filho(a) foi igual a _ \%.

Para a avaliação do estado nutricional de seu(sua) filho(a) calculamos o Índice de Massa Corporal (IMC) utilizando o peso e a altura. O IMC de seu(sua) filho(filha) foi

\section{Estado Nutricional:}

Com base no valor do IMC, existe indicação que seu (sua) filho (a) está com indicando situação nutricional

Esclarecemos que esta faixa etária é importante para construção de hábitos alimentares saudáveis. As características físicas sofrem muitas mudanças principalmente entre 8 e 16 anos. Assim, é importante acompanhar o desenvolvimento de seu filho, promover hábitos alimentares saudáveis e incentivar a prática de exercícios físicos.

Estamos enviando pelo seu(sua) filho(a) algumas perguntas que necessitamos para concluir nosso estudo. Pedimos a gentileza de respondê-las e devolver o documento pela criança.

Estaremos na Escola em data a ser definida para tirar as dúvidas. Estaremos também desenvolvendo ações educativas com as crianças.

Obrigada por ter permitido a participação de seu(sua) filho(a) em nosso estudo.

Atenciosamente, 


\section{Anexo 4}

Procedimentos padronizados para mensuração de variáveis antropométricas

\section{Quadro A4.1 - Procedimentos para mensuração de variáveis antropométricas}

\begin{tabular}{|c|c|}
\hline Características & Procedimentos \\
\hline Peso* & $\begin{array}{l}\text { O indivíduo a ser medido não deve usar calçado e roupas pesadas. Deve-se } \\
\text { mantê-lo no centro da balança com o corpo na posição vertical. }\end{array}$ \\
\hline Estatura* & $\begin{array}{l}\text { O indivíduo a ser medido deve estar descalço, vestindo roupas leves para que } \\
\text { a posição do corpo possa ser visto. Para o posicionamento da cabeça, a linha } \\
\text { da visão deve estar perpendicular ao corpo. A cabeça, costa, quadril e } \\
\text { calcanhar devem estar encostados em uma superfície vertical. Antes da } \\
\text { realização pede-se ao indivíduo para inspirar, fazendo-se com que fique numa } \\
\text { posição mais ereta. }\end{array}$ \\
\hline $\begin{array}{l}\text { Prega cutânea } \\
\text { tricipital* }\end{array}$ & $\begin{array}{l}\text { O indivíduo a ser medido deve estar na posição vertical. A medida é feita no } \\
\text { ponto médio entre o processo acrômio e o olécrano (para marcar o ponto } \\
\text { médio, o braço deve estar posicionado a } 90 \text { graus). Fazer a mensuração na } \\
\text { parte posterior do braço, posicionando-o na vertical. O calibrador deve estar } \\
\text { na mão direita do avaliador e com a mão esquerda, deve-se pinçar a prega } 1 \\
\mathrm{~cm} \text { acima do nível marcado. O calibrador deve estar perpendicular ao braço do } \\
\text { avaliado. }\end{array}$ \\
\hline $\begin{array}{l}\text { Prega cutânea da } \\
\text { panturrilha** }\end{array}$ & $\begin{array}{l}\text { O indivíduo a ser medido deve estar com joelho e quadril flexionados a } 90 \\
\text { graus; a prega é pinçada ao nível da circunferência máxima da panturrilha, no } \\
\text { aspecto medial. }\end{array}$ \\
\hline $\begin{array}{l}\text { Circunferência } \\
\text { braquial * }\end{array}$ & $\begin{array}{l}\text { O indivíduo a ser medido deve estar na posição vertical. A medida é feita no } \\
\text { ponto médio entre o processo acrômio e o olécrano (para marcar o ponto } \\
\text { médio, o braço deve estar posicionado a } 90 \text { graus). Deve-se fazer a } \\
\text { mensuração com a pressão suficiente para que a fita métrica esteja } \\
\text { totalmente aderida ao corpo no local referido, sem que fique muito frouxa ou } \\
\text { apertada demais. Para isso o braço deve estar na vertical. }\end{array}$ \\
\hline $\begin{array}{l}\text { Circunferência da } \\
\text { cintura* }\end{array}$ & $\begin{array}{l}\text { O indivíduo a ser medido deve estar na vertical, a medida é feita no ponto } \\
\text { médio entre a margem inferior da última costela e a crista ilíaca no plano } \\
\text { horizontal. Deve-se fazer a mensuração com a pressão suficiente para que a } \\
\text { fita métrica esteja totalmente aderida ao corpo no local referido, sem que } \\
\text { fique muito frouxa ou apertada demais. A circunferência é medida no final de } \\
\text { uma expiração normal. }\end{array}$ \\
\hline
\end{tabular}

*WHO (1995)

**HEYWARD e STOLARCZYK (2000) 


\section{Anexo 5}

Instrumento para coleta de dados antropométricos e de bioimpedância*

\section{Avaliação antropométrica (medida 1)}

$$
\text { Entrevistador }
$$

Peso (kg) medida 1

Altura $(\mathrm{cm})$ medida 1

Circunferência da cintura (cm) medida 1

Comprimento do braço $(\mathrm{cm})$ medida 1

Circunferência do braço $(\mathrm{cm})$ medida 1

Prega tricipital (mm): medida 1

Prega da panturrilha (mm): medida 1

Bioimpedância: Resistência: medida 1

Reactância: medida 1:

\section{Avaliação antropométrica (medida 2)}

Entrevistador

Data : $\perp_{\text {dia }} \underset{\text { mês }}{2004}$ ano

Altura $(\mathrm{cm})$ medida 2

Comprimento do braço $(\mathrm{cm})$ medida 2

Prega tricipital (mm): medida 2
Circunferência da cintura (cm) medida 2

Circunferência do braço $(\mathrm{cm})$ medida 2

Prega da panturrilha (mm): medida 2

* Obs: As avaliações antropométricas 1 e 2 eram grampeadas separadamente não permitindo que os valores já registrados na primeira avaliação fossem vistos durante o registro da segunda tomada das medidas. 


\section{Anexo 6}

Resultados da qualidade dos dados durante o estudo

São apresentados alguns valores de dois avaliadores (avaliador 3 - 5 escolares; avaliador $4-8$ escolares).

Tabela A6.1 - Valores da primeira e segunda medidas da resistência $(\Omega)$ segundo avaliador

\begin{tabular}{|c|c|c|c|c|c|}
\hline \multirow[t]{2}{*}{ Escolar } & \multicolumn{2}{|c|}{ Avaliador 3} & \multirow[t]{2}{*}{ Escolar } & \multicolumn{2}{|c|}{ Avaliador 4} \\
\hline & Medida 1 & Medida 2 & & Medida 1 & Medida 2 \\
\hline 1 & 636 & 630 & 6 & 578 & 574 \\
\hline 2 & 651 & 655 & 7 & 652 & 647 \\
\hline 3 & 680 & 686 & 8 & 691 & 684 \\
\hline 4 & 690 & 695 & 9 & 709 & 706 \\
\hline 5 & 701 & 696 & 10 & 759 & 758 \\
\hline & & & 11 & 806 & 810 \\
\hline & & & 12 & 810 & 810 \\
\hline & & & 13 & 825 & 818 \\
\hline
\end{tabular}

A Tabela A6.1 apresenta os valores dos coeficientes de correlação intraclasse e IC(95\%) para o estudo da variabilidade intra-avaliador, para as medidas de resistência, reactância e escore de atividade física.

Tabela A6.1 - Coeficientes de correlação intraclasse e IC(95\%) segundo avaliador e medidas de resistência, reactância e escore de atividade física.

\begin{tabular}{lcccc}
\hline & $\begin{array}{c}\text { Avaliador } 1 \\
(\mathrm{n}=35)\end{array}$ & $\begin{array}{c}\text { Avaliador } 2 \\
(\mathrm{n}=13)\end{array}$ & $\begin{array}{c}\text { Avaliador } 3 \\
(\mathrm{n}=6)\end{array}$ & $\begin{array}{c}\text { Avaliador 4 } \\
(\mathrm{n}=8)\end{array}$ \\
\hline Resistência & 0,993 & 0,992 & 0,993 & 0,999 \\
& $0,989-0,998$ & $0,983-1,001$ & $0,981-1,005$ & $0,997-1,001$ \\
Reactância & 0,975 & 0,962 & 0,967 & 0,987 \\
& $0,958-0,991$ & $0,921-1,003$ & $0,911-1,022$ & $0,969-1,005$ \\
Escore de & 0,925 & 0,865 & 0,988 & 0,989 \\
atividade física & $0,877-0,973$ & $0,726-1,005$ & $0,967-1,008$ & $0,973-1,005$ \\
\hline
\end{tabular}




\section{ANEXO 7}

Questionário de atividade física (Barros e Nahas, 2003)

Página 1

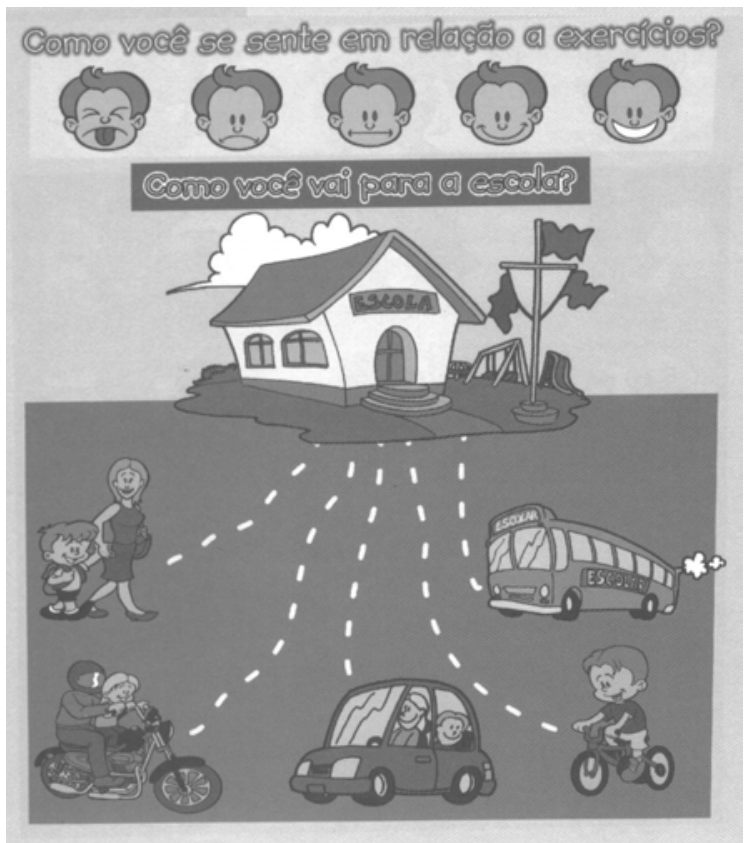

Página 2

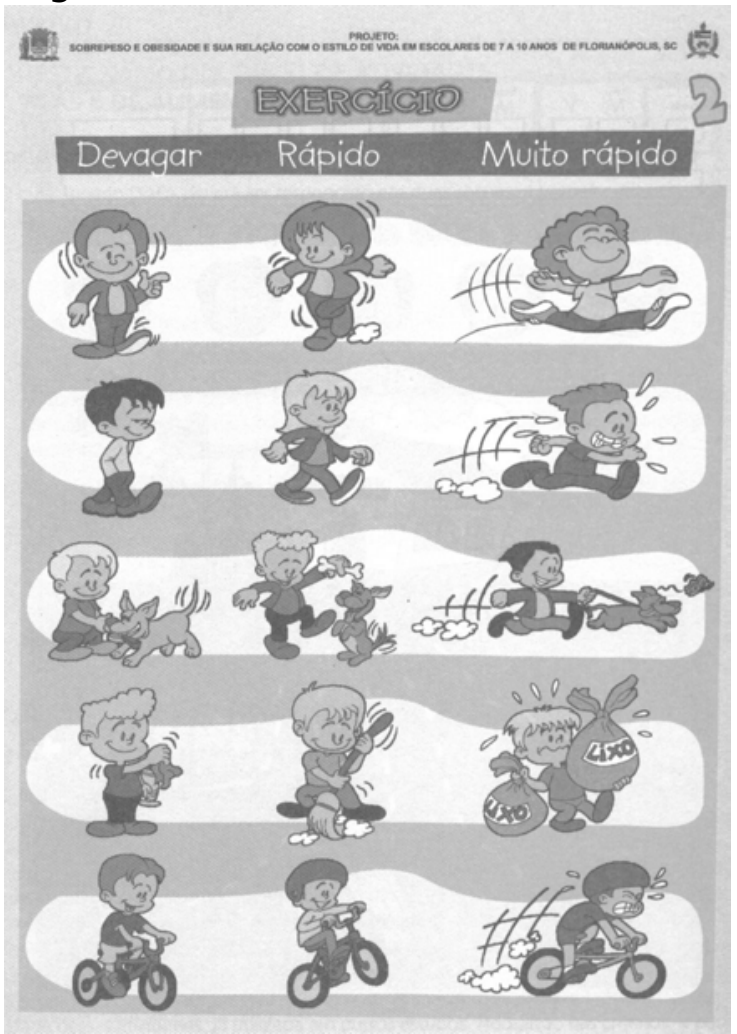

Página 3

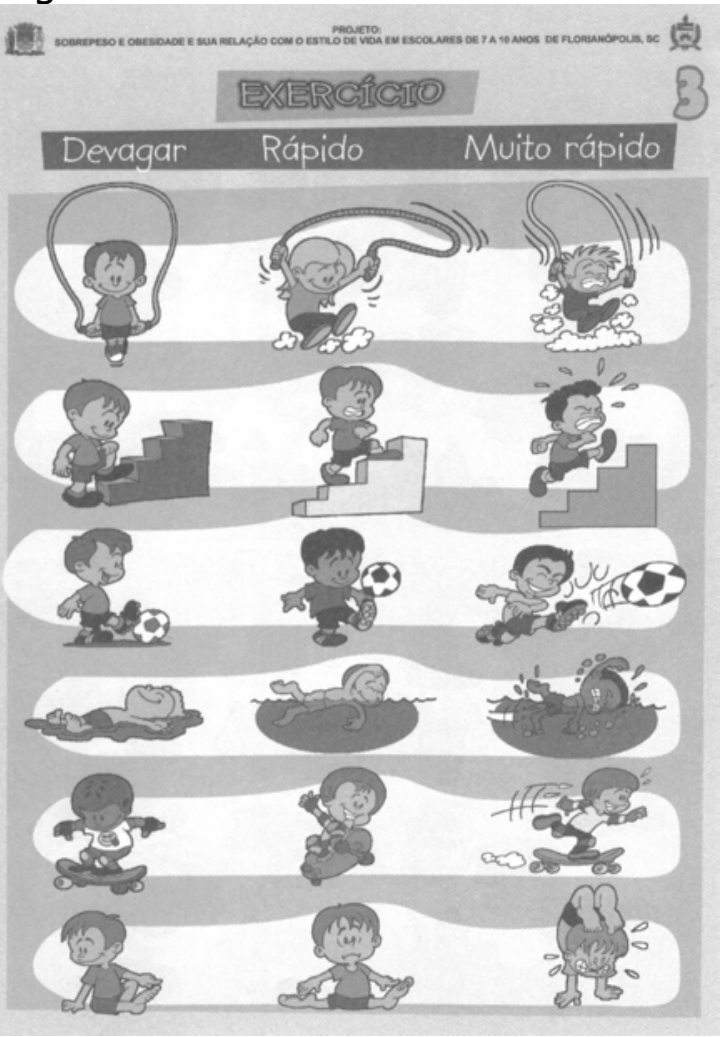




\section{ANEXO 8}

\section{Questionário sócio-demográfico - preenchido pelos responsáveis.}

Estudante:

série:

Prezados pais,

Já realizamos a tomada das medidas antropométricas de seu(sua) filho(a) e, para finalizarmos a coleta dos dados solicitamos o preenchimento deste formulário, respondendo às perguntas que seguem e, posterior envio para a professora de seu(sua) filho(a).

1. Assinale a alternativa que indica o nível de escolaridade da mãe do aluno(a)

$\begin{aligned} \text { Não alfabetizada } & \\ 1^{\mathrm{a}} \text { a } 4^{\mathrm{a}} \text { série do ensino fundamental (antigo curso primário) } & \\ 5^{\mathrm{a}} \text { a } 8^{\mathrm{a}} \text { série do ensino fundamental (antigo curso ginasial) } & \\ 1^{\mathrm{a}} \text { a } 3^{\mathrm{a}} \text { série do ensino médio (antigo curso colegial) } & \\ \text { Curso superior incompleto (Faculdade incompleta) } & \\ \text { Curso superior completo (Faculdade completa) } & \\ \text { Curso de pós-graduação } & \end{aligned}$

2. A renda familiar, somando todas pessoas que contribuem para as despesas da família, é de:

Menos de 260,00 (menos de 1 salário mínimo)

260,00 até 780,00 reais (entre 1 e 3 salários mínimos)

780,01 até 1300,00 reais (mais de 3 e até 5 salários mínimos)

1300,01 até 2600,00 reais (mais de 5 e até 10 salários mínimos)

2600,01 até 5200,00 reais (mais de 10 e até 20 salários mínimos)

Mais de 5200,00 reais (mais de 20 salários mínimos)

3. Quantas pessoas vivem com esta renda familiar?

pessoas

4. Quantos quartos tem na casa?

quartos

5. Quantas pessoas moram na casa?

pessoas

6. Mora em imóvel (casa ou apartamento)

\begin{tabular}{r|r|} 
Próprio & \\
Alugado & \\
Emprestado ou cedido & \\
Abrigo ou orfanato & \\
Outro &
\end{tabular}

6. Tem telefone (comum ou celular)?

$$
\text { Sim }
$$

7. Podemos telefonar caso surja alguma dúvida?

Sim

8. Por favor, forneça seu nome e telefone

Nome:

Telefone:

Em caso de dúvida, telefone para Denise Pimentel Bergamaschi, tel: 30667744 ou 30667724 ou para Claudia Regina Koga tel: 69653362.

Muito Obrigada! 


\section{Anexo 9}

Padronização dos procedimentos para a tomada das medidas: peso $(\mathrm{kg})$, altura $(\mathrm{cm})$, pregas cutâneas tricipital e da panturrilha $(\mathrm{mm})$, circunferências da cintura e do braço $(\mathrm{cm})$, resistência e reactância $(\Omega)$.

\section{Padronização para realização da mensuração da peso $(\mathrm{kg})$, altura $(\mathrm{cm})$, prega cutânea tricipital $(\mathbf{m m})$, circunferências da cintura e do braço $(\mathrm{cm})$ \\ A padronização dos procedimentos para a mensuração do peso $(\mathrm{kg})$, da altura $(\mathrm{cm})$,} da prega cutânea tricipital e das circunferências da cintura e do braço $(\mathrm{cm})$ foi realizada em 10/12/2003, com 16 escolares de ambos os sexos e participação de 4 avaliadores.

A variabilidade intra-avaliadores foi estimada pelo coeficiente de correlação

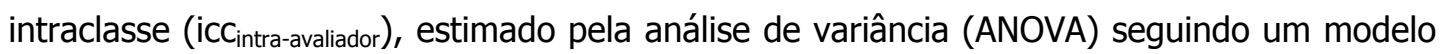
com um fator aleatório (escolares) e intervalos de confiança de $95 \%$ para o coeficiente de correlação intraclasse populacional. Para a investigação de concordância entre avaliadores foram consideradas as primeiras medidas de cada característica, tomadas pelos avaliadores e utilizado o coeficiente de correlação intraclasse (iccentre-avaliadores) estimado pela ANOVA a partir de um modelo de efeitos aleatórios com dois fatores (avaliador e escolar). As fórmulas e modelos utilizados são apresentados a seguir.

\section{$\underline{\text { Coeficiente de correlação intraclasse, para variabilidade intra-avaliador }}$}

Foi utilizado o coeficiente de correlação intraclasse, $\rho_{\text {intra-avaliador }}=\frac{\sigma_{\mathrm{T}}^{2}}{\sigma_{\mathrm{T}}^{2}+\sigma_{\mathrm{e}}^{2}}$; onde $\sigma_{T}^{2}$ e $\sigma_{e}^{2}$ representam a variabilidade dos "verdadeiros valores" e do erro experimental, respectivamente, construído com base no modelo linear $Y=T+e$; onde $Y$ representa o valor observado da característica de interesse, para um indivíduo; $T$ é o valor médio de réplicas hipotéticas realizadas para este indivíduo ( $T$ possui média ${ }^{\mu}$ e variância $\sigma_{T}^{2}$ ); sendo que e representa o erro da medida para esta observação ( $e$ possui média 0 e variância $\sigma_{e}^{2}$ ). Com base nas pressuposições de independência dos erros e entre as distribuições do erro $e$ de $T$, tem-se que a variabilidade total pode ser escrita como a soma das variabilidades de $T$ e $e: \sigma_{Y}^{2}=\sigma_{T}^{2}+\sigma_{e}^{2}$ (FLEISS 1986).

Utilizou-se como estimador de $\rho_{\text {intra-avaliador }}$ o coeficiente:

$$
\text { icc }_{\text {intra-avaliador }}=\frac{\text { QMEntre }- \text { QMDentro }}{\text { QMEntre }+\left(\mathrm{k}_{0}-1\right) \text { QMDentro }} \text {, }
$$


estimado pela ANOVA, com um fator aleatório (escolar). QMEntre e QMDentro representam os quadrados médios entre (escolar) e dentro (escolar), e $\mathrm{k}_{0}=\left[\mathrm{N}-\sum_{\mathrm{i}=1}^{\mathrm{n}} \frac{\mathrm{n}_{\mathrm{i}}^{2}}{\mathrm{~N}}\right] /(\mathrm{n}-1)$ é utilizado quando o número de réplicas não é igual para todos os indivíduos. $\mathrm{N}$ representa o número total de observações; $n_{i}$ representa o número de réplicas para o escolar $i$ e $n$ representa o número de escolares.

Para 0 intervalo de confiança de $\rho_{\text {intra-avaliador }}$ utilizou-se a fórmula: $P\left(\frac{L_{i}}{1+L_{i}} \leq \rho_{\text {int ra-avaliador }} \leq \frac{L_{s}}{1+L_{s}}\right)=1-\alpha$, onde $\left\{\begin{array}{l}L_{i}=\frac{1}{n}\left(\frac{Q M A}{Q M R} \frac{1}{F_{2}}-1\right) \\ L_{s}=\frac{1}{n}\left(\frac{Q M A}{Q M R} \frac{1}{F_{1}}-1\right)\end{array}\right.$ $\mathrm{F}_{2}=\mathrm{F}_{\mathrm{n}-1, \mathrm{~N}-\mathrm{n}, 1-\alpha / 2}$, e $\mathrm{F}_{1}=\mathrm{F}_{\mathrm{n}-1, \mathrm{~N}-\mathrm{n}, \alpha / 2}$, obtidos na tabela da distribuição $F$, para os graus de liberdade e nível de significância $\alpha$ especificados.

\section{Coeficiente de correlação intraclasse, para variabilidade entre-avaliadores}

Neste caso tem-se que $\sigma_{\mathrm{Y}}^{2}=\sigma_{\mathrm{T}}^{2}+\sigma_{\mathrm{r}}^{2}+\sigma_{\mathrm{e}}^{2}$, que inclui a fonte de variação para avaliador $\left(\sigma_{\mathrm{r}}^{2}\right)$. Utilizou-se o estimador $\operatorname{icc}_{\text {entre-avaliador }}=\frac{\sigma_{\mathrm{T}}^{2}}{\sigma_{\mathrm{T}}^{2}+\sigma_{\mathrm{r}}^{2}+\sigma_{\mathrm{e}}^{2}}$, estimado, pela ANOVA por icc $_{\text {ente-avalaadores }}=\frac{n(\text { QMEscolar }- \text { QMErro })}{n \text { QMEscolar }+ \text { k.QMAvaliador }+(n k-n-k) \text { QMErro }}$, onde QMEscolar, QMErro e QMAvaliador representam os quadrados médios de escolar, Erro e Avaliador, respectivamente; $n$ é o número de escolares $(n=16)$ e $k$, o número de avaliadores $(k=4)$.

Para cálculo do Intervalo de confiança utilizou-se a fórmula

$$
\begin{aligned}
& \rho_{\text {entre-avaliadores }}>\frac{\mathrm{n}\left(\mathrm{QMescolar}-\mathrm{F}_{\mathrm{N}-1, \mathrm{v}^{*}, \alpha} \cdot \mathrm{QMErro}\right)}{\mathrm{n} \cdot \mathrm{QMEscolar}+\mathrm{F}_{\mathrm{n}-1, \mathrm{v}^{*}, \alpha}[\mathrm{k} \cdot \mathrm{QMAvaliador}+(\mathrm{nk}-\mathrm{n}-\mathrm{k}) \mathrm{QMErro}]} \\
& \text { sendo } \mathrm{v}^{*}=\frac{(\mathrm{n}-1)(\mathrm{k}-1)\left(\mathrm{kicc}_{\text {entre-aval }} \mathrm{F}+\mathrm{n}\left[1+(\mathrm{k}-1) \text { icc }_{\text {entre-aval }}\right]-\mathrm{kicc}_{\text {entre-aval }}\right)^{2}}{(\mathrm{n}-1) \mathrm{k}^{2} \mathrm{icc}_{\text {entre-aval }} \mathrm{F}^{2}+\left(\mathrm{n}\left[1+(\mathrm{k}-1) \mathrm{icc}_{\text {entre-aval }}\right]-\mathrm{kicc}_{\text {entre-aval }}\right)^{2}}
\end{aligned}
$$

Apresenta-se somente os valores observados pelos avaliadores, para as medidas de prega cutânea tricipital (Tabela A9.1) e os valores dos coeficientes de correlação intraclasse e IC(95\%), para as medidas antropométricas (Tabela A9.2). 
Tabela A9.1 - Valores da primeira e segunda medidas da prega cutânea tricipital (mm) segundo avaliador

\begin{tabular}{|c|c|c|c|c|c|c|c|c|}
\hline \multirow[t]{2}{*}{ Escolar } & \multicolumn{2}{|c|}{ Avaliador 1} & \multicolumn{2}{|c|}{ Avaliador 2} & \multicolumn{2}{|c|}{ Avaliador 3} & \multicolumn{2}{|c|}{ Avaliador 4} \\
\hline & Medida 1 & Medida 2 & Medida 1 & Medida 2 & Medida 1 & Medida 2 & Medida 1 & Medida 2 \\
\hline 1 & 12 & 12 & 13 & 13 & 16 & 19 & 13 & 13 \\
\hline 2 & 16 & 15 & 11 & 11 & 22 & 21 & 16 & 18 \\
\hline 3 & 8 & 9 & 9 & 9 & 23 & 21 & 8 & 9 \\
\hline 4 & 13 & 13 & 15 & 15 & 16 & 16 & 14 & 14 \\
\hline 5 & 11 & 11 & 13 & 14 & 17 & 14 & 12 & 12 \\
\hline 6 & 12 & 12 & 14 & 14 & 22 & 22 & 14 & 13 \\
\hline 7 & 16 & 14 & 17 & 17 & 19 & 18 & 17 & 17 \\
\hline 8 & 11 & 10 & 11 & 11 & 18 & 18 & 11 & 11 \\
\hline 9 & 11 & 11 & 12 & 12 & 19 & 17 & 12 & 14 \\
\hline 10 & 17 & 18 & 20 & 20 & 21 & 21 & 18 & 18 \\
\hline 11 & 14 & 11 & 13 & 13 & 20 & 19 & 13 & 13 \\
\hline 12 & 6 & 6 & 7 & 7 & 15 & 14 & 6 & 8 \\
\hline 13 & 6 & 6 & 6 & 6 & 18 & 21 & 7 & 6 \\
\hline 14 & 7 & 17 & 9 & 9 & 18 & 19 & 7 & 8 \\
\hline 15 & 11 & 12 & 9 & 9 & 17 & 21 & 10 & 11 \\
\hline \multirow[t]{2}{*}{16} & 13 & 13 & 12 & 12 & 20 & 21 & 11 & 11 \\
\hline & \multicolumn{2}{|c|}{ Variação intra-avaliador } & \multicolumn{2}{|c|}{ Variação intra-avaliador } & \multicolumn{2}{|c|}{ Variação intra-avaliador } & \multicolumn{2}{|c|}{ Variação intra-avaliado } \\
\hline
\end{tabular}

Tabela A9.2 Valores do coeficiente de correlação intraclasse (icc), intervalo de confiança de 95\% (IC) segundo avaliador e característica antropométrica

\begin{tabular}{|c|c|c|c|c|c|c|}
\hline Avaliador & Estatística & Peso (kg) & Altura $(\mathrm{cm})$ & $\begin{array}{l}\text { Circunferência da } \\
\text { cintura }(\mathrm{cm})\end{array}$ & $\begin{array}{l}\text { Circunferência do } \\
\text { braço }(\mathrm{cm})\end{array}$ & $\begin{array}{l}\text { Prega cutânea } \\
\text { tricipital (mm) }\end{array}$ \\
\hline 1 & $\begin{array}{l}\text { ICC }_{\text {intra-avaliador }} \\
\text { IC }(95 \%)\end{array}$ & $\begin{array}{c}0,999 \\
0,998-1,000\end{array}$ & $\begin{array}{c}0,999 \\
0,998-1,000\end{array}$ & $\begin{array}{c}0,907 \\
0,819-0,995\end{array}$ & $\begin{array}{c}0,512 \\
0,144-0,879\end{array}$ & $\begin{array}{c}0,672 \\
0,399-0,945\end{array}$ \\
\hline 2 & $\begin{array}{l}\text { ICC }_{\text {intra-avaliador }} \\
\text { IC }(95 \%)\end{array}$ & $\begin{array}{c}0,9998 \\
0,9996-1,000\end{array}$ & $\begin{array}{c}0,9998 \\
0,9996-1,000\end{array}$ & $\begin{array}{c}0,998 \\
0,996-1,000\end{array}$ & $\begin{array}{c}0,996 \\
0,991-1,000\end{array}$ & $\begin{array}{c}0,998 \\
0,995-1,000\end{array}$ \\
\hline 3 & $\begin{array}{l}\text { ICC } \text { intra-avaliador } \\
\text { IC }(95 \%)\end{array}$ & $\begin{array}{c}0,999 \\
0,9986-1,000\end{array}$ & $\begin{array}{c}0,999 \\
0,998-1,000\end{array}$ & $\begin{array}{c}0,865 \\
0,740-0,991\end{array}$ & $\begin{array}{c}0,991 \\
0,982-0,999\end{array}$ & $\begin{array}{c}0,704 \\
0,453-0,955\end{array}$ \\
\hline 4 & $\begin{array}{l}\text { ICC }_{\text {intra-avaliador }} \\
\text { IC }(95 \%)\end{array}$ & $\begin{array}{c}0,999 \\
0,998-1,000\end{array}$ & $\begin{array}{c}0,997 \\
0,994-1,000\end{array}$ & $\begin{array}{c}0,931 \\
0,865-0,997\end{array}$ & $\begin{array}{c}0,988 \\
0,975-0,999\end{array}$ & $\begin{array}{c}0,958 \\
0,918-0,999\end{array}$ \\
\hline & $\begin{array}{l}\text { ICC entre-avaliador } \\
\text { IC }(95 \%)\end{array}$ & $\begin{array}{c}0,992 \\
>0,999\end{array}$ & $\begin{array}{c}0,998 \\
>0,998\end{array}$ & $\begin{array}{r}0,258 \\
>0,271\end{array}$ & $\begin{array}{c}0,848 \\
>0,820\end{array}$ & $\begin{array}{c}0,268 \\
>0,218\end{array}$ \\
\hline
\end{tabular}

A comparação intra-avaliador indicou necessidade de mais treinamento para 0 avaliador 1 principalmente para mensuração da circunferência do braço e da prega cutânea tricipital, para as quais apresentou baixa precisão entre as duas mensurações. Os demais avaliadores foram considerados aptos para a realização das mensurações com exceção do avaliador 3, na tomada da prega tricipital. Apesar dos avaliadores terem participado do mesmo treinamento prévio, seus desempenhos foram diferentes na mensuração da prega cutânea tricipital e circunferências da cintura e do braço. Comparando-se os valores, nota-se baixa concordância entre avaliadores para a circunferência da cintura e para a prega cutânea tricipital. Para a primeira medida, observou-se que o avaliador 2 apresentou valores, em duas ocasiões, bem acima dos demais avaliadores e para a medida da prega tricipital, o avaliador 3 obteve, em um número razoável de medições, valores maiores que os demais avaliadores (Tabela A9.1). 


\section{Padronização de procedimentos para realização da mensuração da prega cutânea da panturrilha e da bioimpedância (BIA)}

Esta padronização foi realizada em 26/05/2004, com a participação de 16 crianças (9 e 10 anos) e 2 avaliadores.

Utilizou-se para o estudo da variabilidade entre avaliadores, o coeficiente de correlação intraclasse estimado com base em um modelo de efeitos fixos (avaliador):

$$
\mathrm{icc}_{\text {entre-avaliadores }}=\frac{\mathrm{n}(\text { QMEscolar }- \text { QMErro })}{\mathrm{nQMEscolar}+(\mathrm{k}-1) \text { QMAvaliador }+(\mathrm{n}-1)(\mathrm{k}-1) \text { QMErro }}
$$

(FLEISS 1986).

Para a BIA, o estudo de concordância foi feito com base nas mensurações da resistência $(\Omega)$ e da reactância $(\Omega)$. Observou-se boa concordância tanto intra como entre avaliadores com coeficientes de correlação intraclasse variando de 0,88 a 0,98.

Para a mensuração da prega cutânea da panturrilha observou-se boa concordância intra e entre os avaliadores com coeficientes de correlação intraclasse variando de 0,96 a 0,98. Apresenta-se na tabela A9.3 os dados coletados de prega cutânea da panturrilha, segundo avaliador.

Tabela A9.3 - Valores de prega cutânea da panturrilha $(\mathrm{mm})$ segundo avaliador.

\begin{tabular}{|c|c|c|c|c|c|c|c|c|c|}
\hline \multirow[b]{2}{*}{ Criança } & \multicolumn{2}{|c|}{ Avaliador 1} & \multicolumn{2}{|c|}{ Avaliador 2} & \multicolumn{3}{|c|}{ Avaliador 1} & \multicolumn{2}{|c|}{ Avaliador 2} \\
\hline & Medida 1 & Medida 2 & Medida 1 & Medida 2 & Criança & Medida 1 & Medida 2 & Medida 1 & Medida 2 \\
\hline 1 & 6 & 5 & 5 & 4 & 9 & 6 & 6 & 6 & 6 \\
\hline 2 & 25 & 24 & 25 & 26 & 10 & 10 & 10 & 12 & 13 \\
\hline 3 & 18 & 19 & 20 & 18 & 11 & 5 & 5 & 5 & 5 \\
\hline 4 & 11 & 9 & 12 & 10 & 12 & 7 & 7 & 7 & 7 \\
\hline 5 & 10 & 8 & 10 & 9 & 13 & 10 & 10 & 10 & 11 \\
\hline 6 & 15 & 16 & 19 & 17 & 14 & 11 & 10 & 11 & 11 \\
\hline 7 & 17 & 16 & 19 & 18 & 15 & 16 & 15 & 18 & 20 \\
\hline 8 & 14 & 12 & 12 & 13 & 16 & 9 & 9 & 9 & 9 \\
\hline
\end{tabular}




\section{ANEXO 10}

Escore de atividade física: padronização de procedimentos na aplicação do questionário e estudo de confiabilidade do escore de atividade física (BARROS e NAHAS 2003)

\section{Padronização de procedimentos na aplicação do questionário}

Para investigar a variabilidade entre avaliadores, na aplicação do questionário de atividade física, dois avaliadores aplicaram o questionário em 16 crianças de 9 a 10 anos de idade, sendo que cada escolar respondeu o mesmo duas vezes, uma para cada avaliador. Entre cada aplicação, realizou-se a tomada de medidas antropométricas.

Utilizou-se o coeficiente de correlação intraclasse estimado pela ANOVA, com dois fatores: escolar (aleatório) e avaliador (fixo), obtendo-se icc igual a 0,995. Os valores dos escores são apresentados na Tabela A10.1

Tabela A10.1 - Escores de atividade física de escolares de 9 e 10 anos, segundo avaliador.

\begin{tabular}{cccccc}
\hline Escolar & Avaliador 1 & Avaliador 2 & Escolar & Avaliador 1 & Avaliador 2 \\
\hline 1 & 38 & 38 & 9 & 71 & 67 \\
2 & 27 & 27 & 10 & 10 & 10 \\
3 & 45 & 47 & 11 & 33 & 30 \\
4 & 50 & 50 & 12 & 75 & 75 \\
5 & 18 & 18 & 13 & 54 & 54 \\
6 & 50 & 50 & 14 & 27 & 27 \\
7 & 42 & 40 & 15 & 23 & 18 \\
8 & 50 & 50 & 16 & 32 & 32 \\
\hline
\end{tabular}




\section{Aspectos metodológicos na realização da BIA}

\section{Estudo do horário da realização da BIA: medições antes e após o recreio escolar}

Realizou-se a BIA antes e após o intervalo que ocorria entre as 9:30 e 10 horas, em uma amostra aleatória de escolares de 9 e 10 anos, obtendo-se valores de resistência e reactância (Tabela A11.1). Participou da tomada das medidas somente um avaliador.

Para análise estatística utilizou-se a média das duas medidas realizadas antes e após o recreio e o teste de médias para amostras dependentes, t de "Student" (pareado). Não foi observada evidência de diferença entre os valores médios antes e após o intervalo, para a reactância $(p=0,524)$ e para a resistência $(p=0,180)$.

Tabela A11.1 Valores de resistência $(\Omega)$ e reactância $(\Omega)$ segundo momento em relação ao intervalo escolar.

\begin{tabular}{lcccccccc}
\hline & \multicolumn{3}{c}{ Antes do recreio escolar } & \multicolumn{3}{c}{ Após o recreio escolar } \\
\cline { 2 - 8 } Criança & \multicolumn{2}{c}{ Medida1 } & \multicolumn{2}{c}{ Medida2 } & \multicolumn{2}{c}{ Medida1 } & \multicolumn{2}{c}{ Medida2 } \\
\hline 1 & $\mathrm{R}$ & $\mathrm{XC}$ & $\mathrm{R}$ & $\mathrm{Xc}$ & $\mathrm{R}$ & $\mathrm{Xc}$ & $\mathrm{R}$ & $\mathrm{Xc}$ \\
2 & 727 & 64 & 729 & 64 & 728 & 67 & 731 & 65 \\
3 & 645 & 59 & 647 & 60 & 680 & 63 & 679 & 64 \\
4 & 842 & 73 & 838 & 74 & 826 & 75 & 825 & 76 \\
5 & 647 & 61 & 645 & 59 & 662 & 60 & 663 & 59 \\
6 & 594 & 64 & 595 & 64 & 595 & 64 & 598 & 62 \\
7 & 724 & 73 & 723 & 74 & 715 & 72 & 717 & 72 \\
8 & 520 & 62 & 522 & 63 & 540 & 65 & 540 & 65 \\
9 & 748 & 77 & 745 & 74 & 664 & 78 & 661 & 79 \\
10 & 779 & 78 & 779 & 80 & 772 & 76 & 773 & 79 \\
11 & 659 & 68 & 658 & 68 & 690 & 75 & 691 & 77 \\
12 & 733 & 76 & 733 & 76 & 712 & 76 & 713 & 74 \\
13 & 799 & 84 & 796 & 83 & 682 & 81 & 680 & 80 \\
14 & 593 & 58 & 593 & 58 & 576 & 57 & 576 & 57 \\
15 & 835 & 81 & 835 & 82 & 789 & 79 & 787 & 80 \\
16 & 713 & 64 & 713 & 65 & 693 & 64 & 695 & 63 \\
\hline R & 764 & 71 & 762 & 72 & 765 & 71 & 768 & 69 \\
\hline
\end{tabular}

\section{Influência do uso repetido de eletrodos, nos resultados da bioimpedância elétrica}

Foram realizadas, em duplicata, mensurações pela BIA com eletrodos novos e utilizados 1 , 2 e 3 vezes, em amostra de 16 escolares, com a tomada das medidas por um único avaliador. Os dados para resistência $(\Omega)$ são apresentados na Tabela A11.2.

Utilizou-se para a análise de concordância, o coeficiente de correlação intraclasse estimado pela ANOVA com modelo de dois fatores: escolar (aleatório) e número de utilizações do eletrodo (fixo). 
São apresentado os valores observados, na Tabela A11.2.

Tabela A11.2 - Valores de resistência $(\Omega)$ na realização da BIA, segundo número de utilizações de eletrodos

\begin{tabular}{lcccccccc}
\hline Escolar & \multicolumn{2}{c}{ Eletrodo 1 } & \multicolumn{2}{c}{ Eletrodo 2 } & \multicolumn{2}{c}{ Eletrodo 3 } & \multicolumn{2}{c}{ Eletrodo 4 } \\
& Medida 1 & Medida 2 & Medida 1 & Medida 2 & Medida 1 & Medida 2 & Medida 1 & Medida 2 \\
\hline 1 & 756 & 756 & 758 & 759 & 761 & 760 & 760 & 763 \\
2 & 648 & 646 & 647 & 647 & 645 & 645 & 645 & 645 \\
3 & 804 & 803 & 803 & 803 & 805 & 809 & 809 & 810 \\
4 & 635 & 636 & 635 & 635 & 634 & 634 & 636 & 636 \\
5 & 594 & 593 & 592 & 592 & 593 & 594 & 596 & 595 \\
6 & 678 & 678 & 680 & 681 & 678 & 677 & 677 & 678 \\
7 & 507 & 505 & 503 & 504 & 506 & 505 & 506 & 507 \\
8 & 670 & 669 & 669 & 668 & 667 & 667 & 670 & 671 \\
9 & 765 & 766 & 764 & 764 & 767 & 770 & 769 & 769 \\
10 & 687 & 688 & 689 & 687 & 687 & 687 & 688 & 689 \\
11 & 737 & 737 & 737 & 736 & 733 & 734 & 736 & 735 \\
12 & 707 & 707 & 707 & 704 & 702 & 705 & 703 & 707 \\
13 & 612 & 612 & 611 & 611 & 612 & 613 & 612 & 612 \\
14 & 773 & 772 & 773 & 768 & 768 & 769 & 768 & 770 \\
15 & 718 & 716 & 718 & 718 & 719 & 718 & 719 & 721 \\
16 & 794 & 795 & 795 & 794 & 797 & 796 & 798 \\
\hline
\end{tabular}

Eletrodo 1 - novo; primeira utilização; Eletrodo 2 - segunda utilização;

Eletrodo 3 - terceira utilização; Eletrodo 4 - quarta utilização

As medidas de resistência e reactância com eletrodos não usados, e usados uma, duas e três vezes apresentaram alta concordância com icc igual a 0,999 indicando que a reutilização dos eletrodos não interferiu no resultado final das medidas. 


\section{Apresentação dos dados antropométricos e de composição corporal}

Tabela A12.1 - Distribuição do percentual (\%) de escolares segundo peso (kg), sexo e idade.

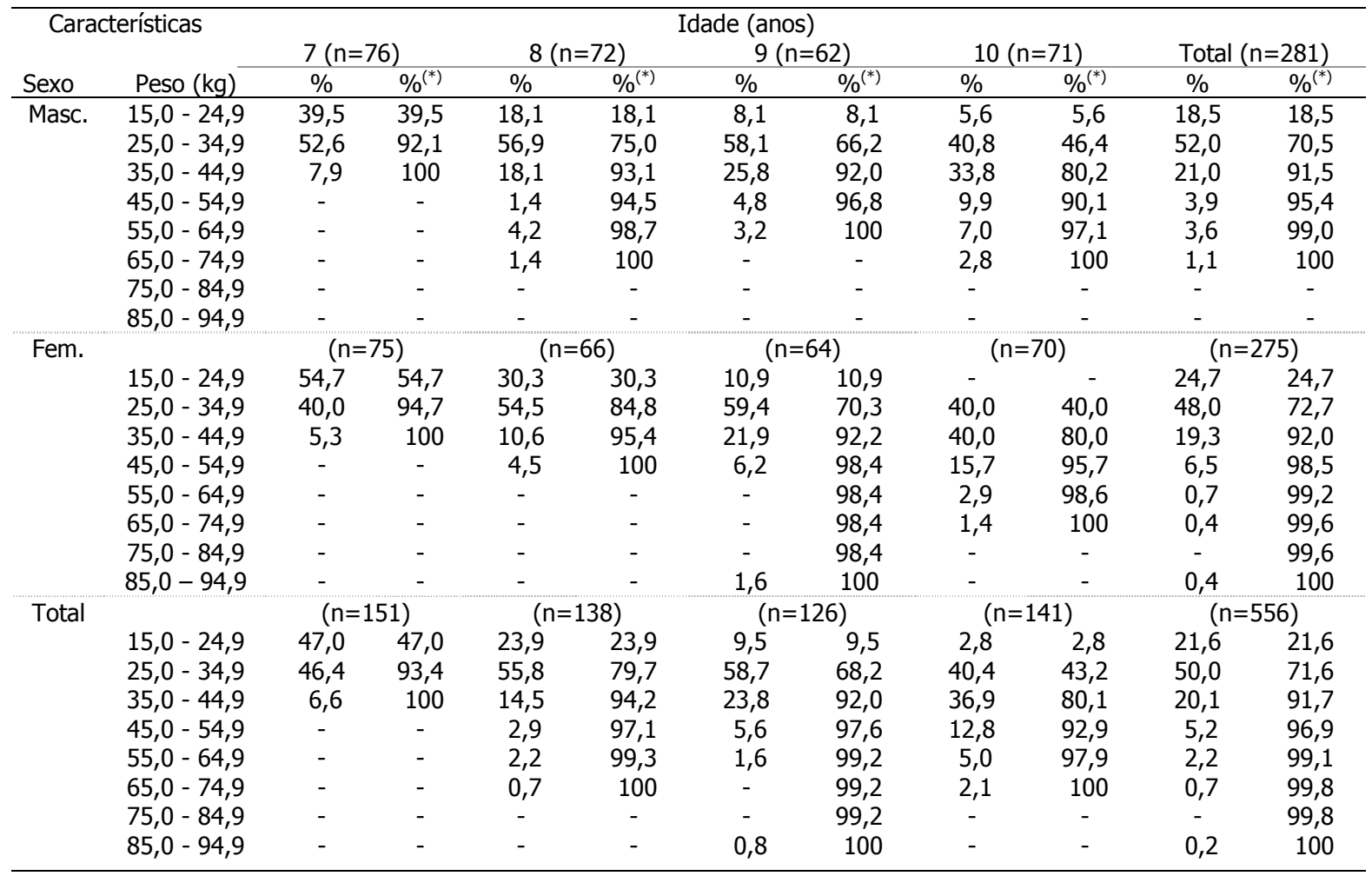

(*) percentual acumulado 
Tabela A12.2 - Distribuição do percentual (\%) de escolares segundo estatura (cm), sexo e idade.

\begin{tabular}{|c|c|c|c|c|c|c|c|c|c|c|c|}
\hline \multirow{2}{*}{\multicolumn{2}{|c|}{ Características }} & \multicolumn{9}{|c|}{ Idade (anos) } & \\
\hline & & \multicolumn{2}{|c|}{$7(n=76)$} & \multicolumn{2}{|c|}{$8(n=72)$} & \multicolumn{2}{|c|}{$9(n=62)$} & \multicolumn{2}{|c|}{$10(n=71)$} & \multicolumn{2}{|c|}{ Total $(n=281)$} \\
\hline Sexo & Estatura (cm) & $\%$ & $\%^{(*)}$ & $\%$ & $\%^{(*)}$ & $\%$ & $\%^{(*)}$ & $\%$ & $\%^{(*)}$ & $\%$ & $\%^{(*)}$ \\
\hline \multirow[t]{9}{*}{ Masc. } & $115,0-119,9$ & 3,9 & 3,9 & - & - & - & - & - & - & 1,1 & 1,1 \\
\hline & $120,0-124,9$ & 34,2 & 38,1 & 11,1 & 11,1 & 1,6 & 1,6 & 1,4 & 1,4 & 12,8 & 13,9 \\
\hline & $125,0-129,9$ & 42,1 & 80,2 & 19,4 & 30,5 & 14,5 & 16,1 & 8,4 & 9,8 & 21,7 & 35,6 \\
\hline & $130,0-134,9$ & 15,8 & 96,0 & 36,1 & 66,6 & 21,0 & 37,1 & 8,4 & 18,2 & 20,2 & 55,8 \\
\hline & $135,0-139,9$ & 2,6 & 98,6 & 20,8 & 87,4 & 32,3 & 69,4 & 21,1 & 39,3 & 18,5 & 74,3 \\
\hline & $140,0-144,9$ & 1,3 & 100 & 11,1 & 98,5 & 19,3 & 88,7 & 23,9 & 63,2 & 13,5 & 87,8 \\
\hline & $145,0-149,9$ & - & - & 1,4 & 100 & 8,1 & 96,8 & 22,5 & 85,7 & 7,8 & 95,6 \\
\hline & $150,0-154,9$ & - & - & - & - & 3,2 & 100 & 11,3 & 97,0 & 3,6 & 99,2 \\
\hline & $155,0-159,9$ & - & - & - & - & - & - & 2,8 & 100 & 0,7 & 100 \\
\hline \multirow[t]{12}{*}{ Fem. } & & \multicolumn{2}{|c|}{$(n=75)$} & \multicolumn{2}{|c|}{$(n=66)$} & \multicolumn{2}{|c|}{$(n=64)$} & \multicolumn{2}{|c|}{$(n=70)$} & \multicolumn{2}{|c|}{$(n=275)$} \\
\hline & $105,0-109,9$ & - & - & 1,5 & 1,5 & - & - & - & - & 0,4 & 0,4 \\
\hline & $110,0-114,9$ & 2,7 & 2,7 & - & 1,5 & 1,6 & 1,6 & - & - & 1,1 & 1,5 \\
\hline & $115,0-119,9$ & 16,0 & 18,7 & - & 1,5 & - & 1,6 & - & - & 4,4 & 5,9 \\
\hline & $120,0-124,9$ & 29,3 & 48,0 & 12,1 & 13,6 & 1,6 & 3,2 & - & - & 11,3 & 17,2 \\
\hline & $125,0-129,9$ & 37,3 & 85,3 & 42,4 & 56,0 & 25,0 & 28,2 & 2,9 & 2,9 & 26,9 & 44,1 \\
\hline & $130,0-134,9$ & 10,7 & 96,0 & 19,7 & 75,7 & 20,3 & 48,5 & 10,0 & 12,9 & 14,9 & 59,0 \\
\hline & $135,0-139,9$ & 4,0 & 100 & 19,7 & 95,4 & 23,4 & 71,9 & 17,1 & 30,0 & 15,6 & 74,6 \\
\hline & $140,0-144,9$ & - & - & 3,0 & 98,4 & 18,7 & 90,6 & 22,9 & 52,9 & 10,9 & 85,5 \\
\hline & $145,0-149,9$ & - & - & 1,5 & 100 & 4,7 & 95,3 & 31,4 & 84,3 & 9,4 & 94,9 \\
\hline & $150,0-154,9$ & - & - & - & - & 3,1 & 98,4 & 11,4 & 95,7 & 3,6 & 98,5 \\
\hline & $155,0-159,9$ & - & - & - & - & 1,6 & 100 & 4,3 & 100 & 1,4 & 100 \\
\hline \multirow[t]{12}{*}{ Total } & & \multicolumn{2}{|c|}{$(n=151)$} & \multicolumn{2}{|c|}{$(n=138)$} & \multicolumn{2}{|c|}{$(n=126)$} & \multicolumn{2}{|c|}{$(n=141)$} & \multicolumn{2}{|c|}{$(n=556)$} \\
\hline & $105,0-109,9$ & - & - & 0,7 & 0,7 & - & - & - & - & 0,2 & 0,2 \\
\hline & $110,0-114,9$ & 1,3 & 1,3 & - & 0,7 & 0,8 & 0,8 & - & - & 0,5 & 0,7 \\
\hline & $115,0-119,9$ & 9,9 & 11,2 & - & 0,7 & - & 0,8 & - & - & 2,7 & 3,4 \\
\hline & $120,0-124,9$ & 31,8 & 43,0 & 11,6 & 12,3 & 1,6 & 2,4 & 0,7 & 0,7 & 12,0 & 15,4 \\
\hline & $125,0-129,9$ & 39,7 & 82,7 & 30,4 & 42,7 & 19,8 & 22,2 & 5,7 & 6,4 & 24,3 & 39,7 \\
\hline & $130,0-134,9$ & 13,2 & 95,9 & 28,3 & 71,0 & 20,6 & 42,8 & 9,2 & 15,6 & 17,6 & 57,3 \\
\hline & $135,0-139,9$ & 3,3 & 99,2 & 20,3 & 91,3 & 27,8 & 70,6 & 19,1 & 34,7 & 17,1 & 74,4 \\
\hline & $140,0-144,9$ & 0,7 & 100 & 7,3 & 98,6 & 19,0 & 89,6 & 23,4 & 58,1 & 12,2 & 86,6 \\
\hline & $145,0-149,9$ & - & - & 1,4 & 100 & 6,4 & 96,0 & 26,9 & 85,0 & 8,6 & 95,2 \\
\hline & $150,0-154,9$ & - & - & - & - & 3,2 & 99,2 & 11,3 & 96,3 & 3,6 & 98,8 \\
\hline & $155,0-159,9$ & - & - & - & - & 0,8 & 100 & 3,5 & 100 & 1,1 & 100 \\
\hline
\end{tabular}

$(*)$ percentual acumulado 
Tabela A12.3 - Distribuição do percentual (\%) de escolares segundo prega cutânea tricipital (PCT) (mm), sexo e idade.

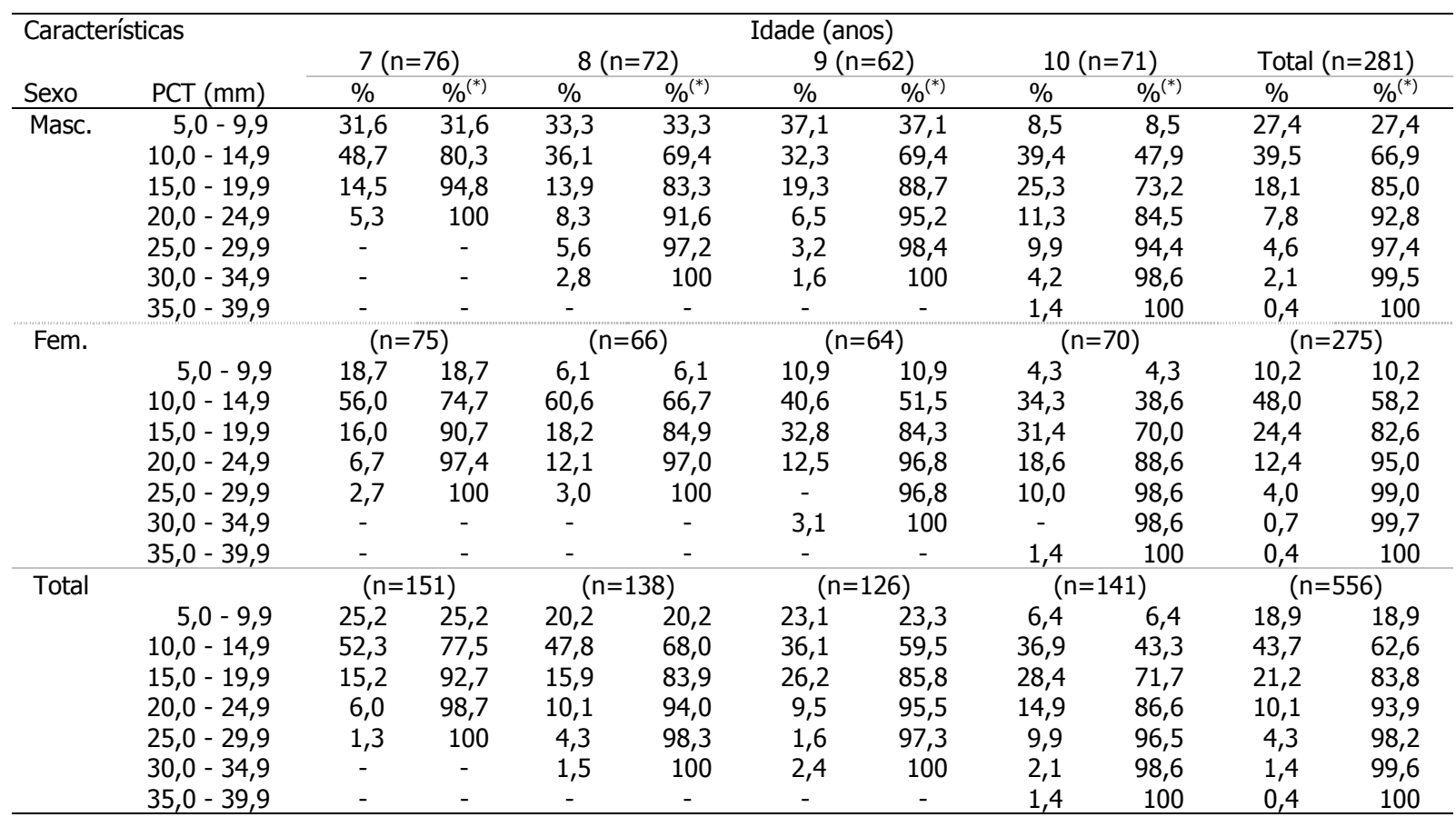

$(*)$ percentual acumulado

Tabela A12.4 - Distribuição do percentual (\%) de escolares segundo prega cutânea da panturrilha (PCP) (mm), sexo e idade.

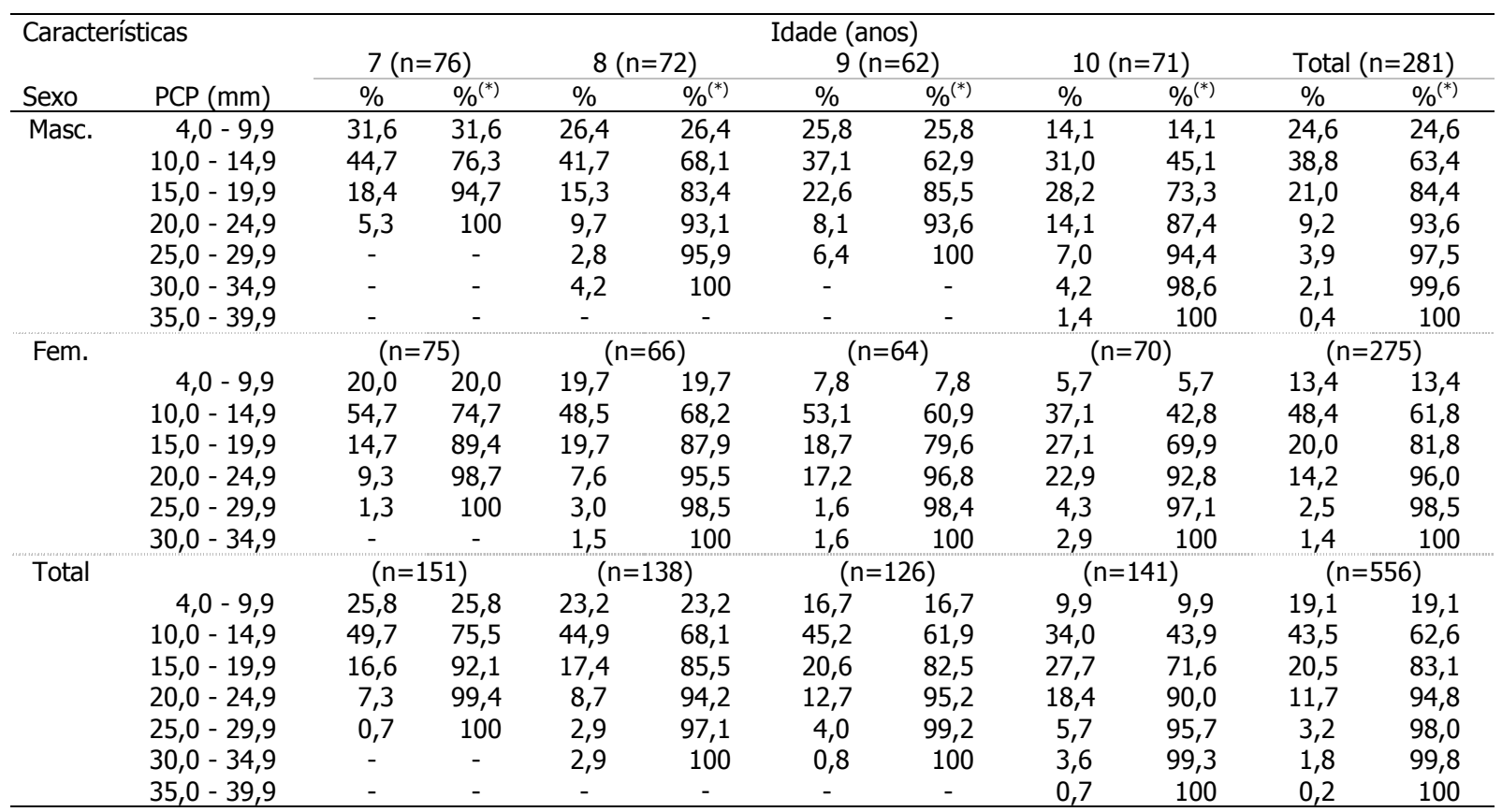

$(*)$ percentual acumulado 
Tabela A12.5 - Distribuição do percentual (\%) de escolares segundo circunferência braquial $(\mathrm{CB})(\mathrm{cm})$, sexo e idade.

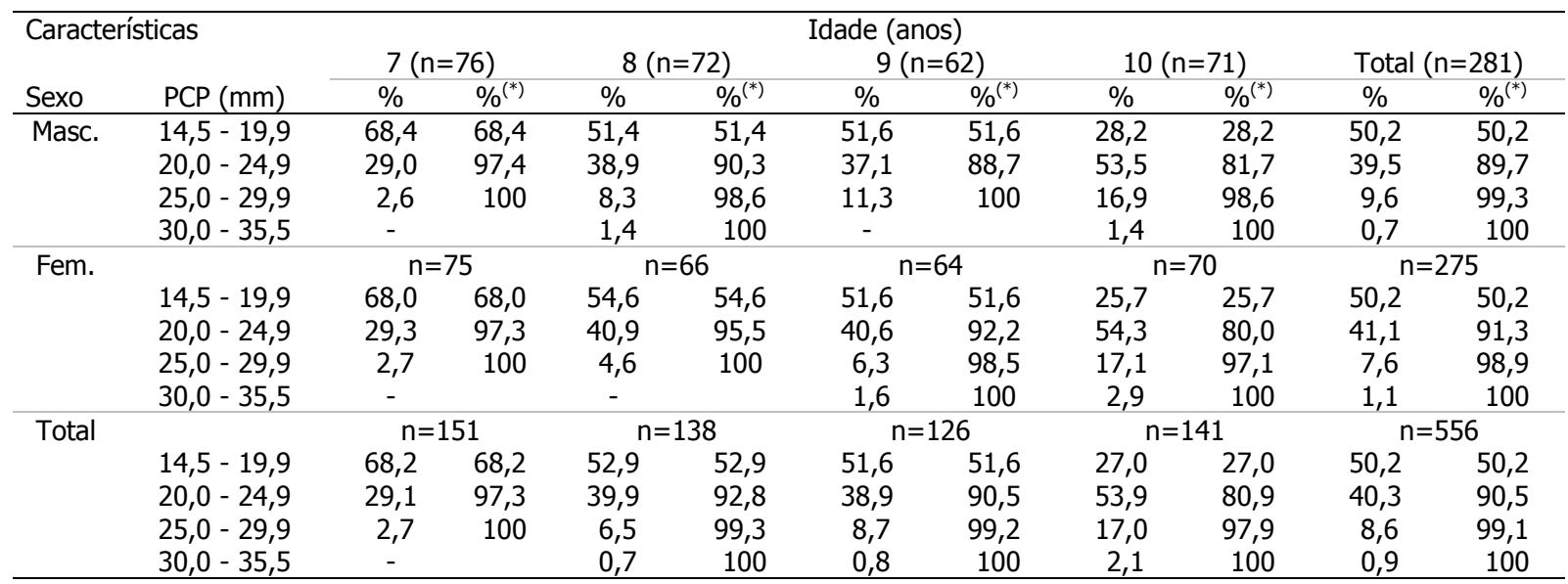

$(*)$ percentual acumulado

Tabela A12.6 - Distribuição do percentual (\%) de escolares segundo circunferência da cintura $(C C)(\mathrm{cm})$, sexo e idade.

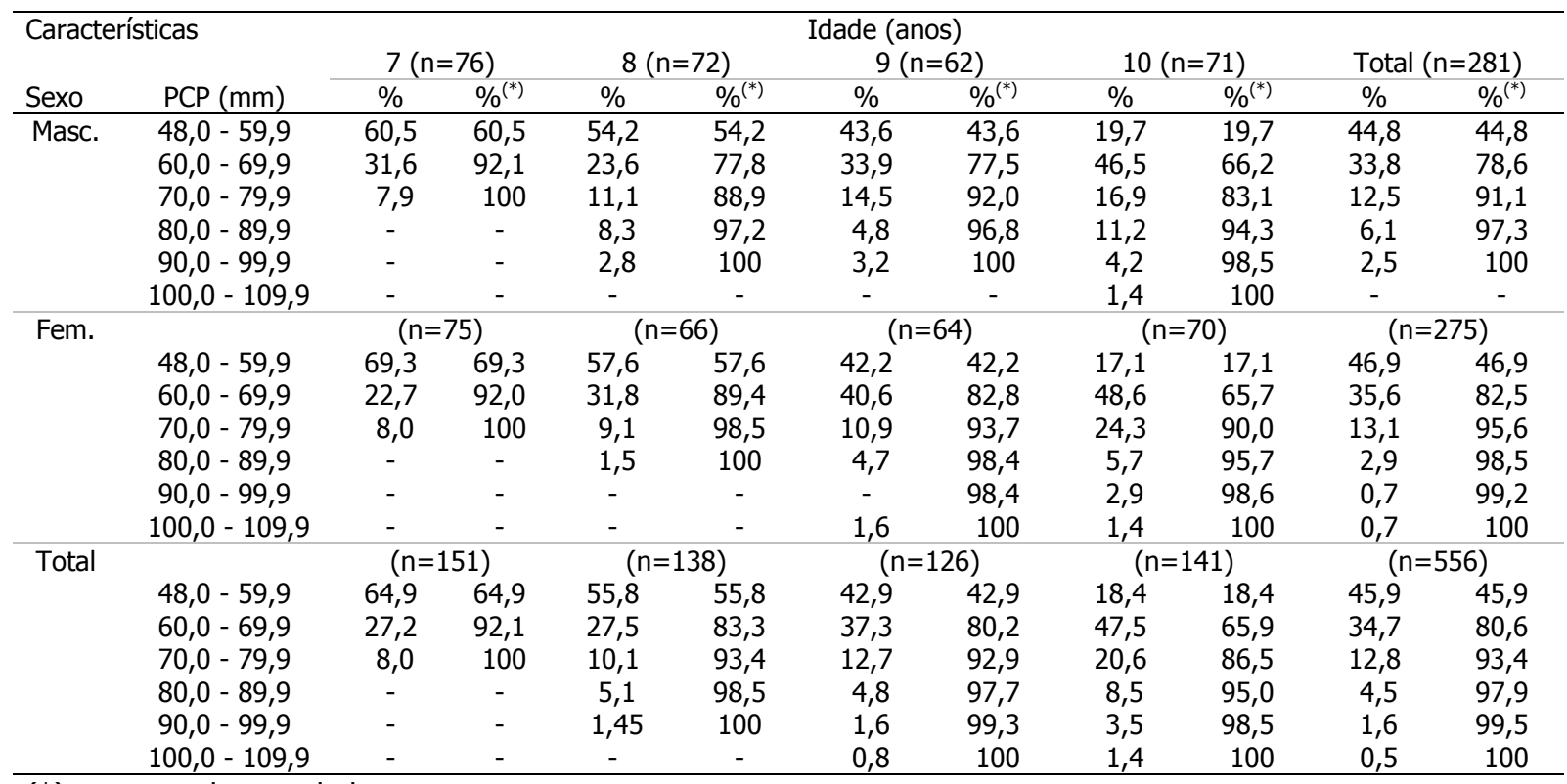

(*) percentual acumulado 
Tabela A12.7 - Distribuição do percentual (\%) de escolares segundo percentual de gordura (\%) estimado pela BIA, sexo e idade.

\begin{tabular}{|c|c|c|c|c|c|c|c|c|c|c|c|}
\hline \multirow{2}{*}{\multicolumn{2}{|c|}{ Características }} & \multicolumn{9}{|c|}{ Idade (anos) } & \\
\hline & & \multicolumn{2}{|c|}{$7(n=76)$} & \multicolumn{2}{|c|}{$8(n=72)$} & \multicolumn{2}{|c|}{$9(n=62)$} & \multicolumn{2}{|c|}{$10(n=71)$} & \multicolumn{2}{|c|}{ Total $(n=281)$} \\
\hline Sexo & $\%$ de gordura & $\%$ & $\%{ }^{(*)}$ & $\%$ & $\%{ }^{(*)}$ & $\%$ & $\%^{(*)}$ & $\%$ & $\%^{(*)}$ & $\%$ & $\%^{(*)}$ \\
\hline \multirow[t]{10}{*}{ Masc. } & $4,0-9,9$ & 2,6 & 2,6 & 1,4 & 1,4 & 1,6 & 1,6 & 0,0 & 0,0 & 1,4 & 1,4 \\
\hline & $10,0-14,9$ & 10,5 & 13,2 & 6,9 & 8,3 & 11,3 & 12,9 & 4,2 & 4,2 & 8,2 & 9,6 \\
\hline & $15,0-19,9$ & 18,4 & 31,6 & 18,1 & 26,4 & 21,0 & 33,9 & 19,7 & 24,0 & 19,2 & 28,8 \\
\hline & $20,0-24,9$ & 30,3 & 61,8 & 31,9 & 58,3 & 25,8 & 59,7 & 22,5 & 46,5 & 27,8 & 56,6 \\
\hline & $25,0-29,9$ & 21,1 & 82,9 & 18,1 & 76,4 & 14,5 & 74,2 & 21,1 & 67,6 & 18,9 & 75,5 \\
\hline & $30,0-34,9$ & 10,5 & 93,4 & 8,3 & 84,7 & 17,7 & 91,9 & 12,7 & 80,3 & 12,1 & 87,6 \\
\hline & $35,0-39,9$ & 5,3 & 98,7 & 8,3 & 93,1 & 6,5 & 98,4 & 9,9 & 90,2 & 7,5 & 95,1 \\
\hline & $40,0-44,9$ & 1,3 & 100 & 2,8 & 95,8 & 1,6 & 100 & 5,6 & 95,8 & 2,8 & 97,9 \\
\hline & $45,0-49,9$ & - & - & 2,8 & 98,6 & - & - & 4,2 & 100 & 1,8 & 99,7 \\
\hline & $50,0-55,0$ & - & - & 1,4 & 100 & - & - & - & - & 0,4 & 100 \\
\hline \multirow[t]{10}{*}{ Fem. } & & \multicolumn{2}{|c|}{$(n=75)$} & \multicolumn{2}{|c|}{$(n=66)$} & \multicolumn{2}{|c|}{$(n=64)$} & \multicolumn{2}{|c|}{$(n=70)$} & \multicolumn{2}{|c|}{$(n=275)$} \\
\hline & $10,0-14,9$ & - & - & - & - & 1,6 & 1,6 & - & - & 0,4 & 0,4 \\
\hline & $15,0-19,9$ & 5,3 & 5,3 & 7,6 & 7,6 & 9,4 & 10,9 & 14,3 & 14,3 & 9,1 & 9,5 \\
\hline & $20,0-24,9$ & 21,3 & 26,7 & 24,2 & 31,8 & 26,6 & 37,5 & 18,6 & 32,9 & 22,5 & 32,0 \\
\hline & $25,0-29,9$ & 29,3 & 56,0 & 27,3 & 59,1 & 23,4 & 60,9 & 27,1 & 60,0 & 26,9 & 58,9 \\
\hline & $30,0-34,9$ & 26,7 & 82,7 & 18,2 & 77,3 & 23,4 & 84,4 & 14,3 & 74,3 & 20,7 & 79,6 \\
\hline & $35,0-39,9$ & 9,3 & 92,0 & 15,2 & 92,4 & 10,9 & 95,3 & 10,0 & 84,3 & 11,3 & 90,9 \\
\hline & $40,0-44,9$ & 5,3 & 97,3 & 3,0 & 95,5 & 1,6 & 96,9 & 8,6 & 92,9 & 4,7 & 95,6 \\
\hline & $45,0-49,9$ & 2,7 & 100 & 3,0 & 98,5 & 1,6 & 98,4 & 5,7 & 98,6 & 3,3 & 98,9 \\
\hline & $50,0-55,0$ & - & - & 1,5 & 100 & 1,6 & 100 & 1,4 & 100 & 1,1 & 100 \\
\hline \multirow[t]{11}{*}{ Total } & & \multicolumn{2}{|c|}{$(n=151)$} & \multicolumn{2}{|c|}{$(n=138)$} & \multicolumn{2}{|c|}{$(n=126)$} & \multicolumn{2}{|c|}{$(n=141)$} & \multicolumn{2}{|c|}{$(n=556)$} \\
\hline & $4,0-9,9$ & 1,3 & 1,3 & 0,7 & 0,7 & 0,8 & 0,8 & 0,0 & 0,0 & 0,7 & 0,7 \\
\hline & $10,0-14,9$ & 5,3 & 6,6 & 3,6 & 4,3 & 6,4 & 7,1 & 2,1 & 2,1 & 4,3 & 5,0 \\
\hline & $15,0-19,9$ & 11,9 & 18,5 & 13,0 & 17,4 & 15,1 & 22,2 & 17,0 & 19,2 & 14,2 & 19,2 \\
\hline & $20,0-24,9$ & 25,8 & 44,4 & 28,3 & 45,6 & 26,2 & 48,4 & 20,6 & 39,7 & 25,2 & 44,4 \\
\hline & $25,0-29,9$ & 25,2 & 69,5 & 22,5 & 68,1 & 19,1 & 67,5 & 24,1 & 63,8 & 22,8 & 67,2 \\
\hline & $30,0-34,9$ & 18,5 & 88,1 & 13,0 & 81,1 & 20,6 & 88,1 & 13,5 & 77,3 & 16,4 & 83,6 \\
\hline & $35,0-39,9$ & 7,3 & 95,4 & 11,6 & 92,7 & 8,7 & 96,8 & 9,9 & 87,2 & 9,3 & 92,9 \\
\hline & $40,0-44,9$ & 3,3 & 98,7 & 2,9 & 95,6 & 1,6 & 98,4 & 7,1 & 94,3 & 3,8 & 96,7 \\
\hline & $45,0-49,9$ & 1,3 & 100 & 2,9 & 98,5 & 0,8 & 99,2 & 5,0 & 99,3 & 2,5 & 99,2 \\
\hline & $50,0-55,0$ & - & - & 1,5 & 100 & 0,8 & 100 & 0,7 & 100 & 0,7 & 100 \\
\hline
\end{tabular}

$\left(^{*}\right)$ percentual acumulado 
Tabela A12.8 - Distribuição do percentual (\%) de escolares segundo percentual de gordura (\%) estimado pelas pregas cutâneas tricipital e da panturrilha, sexo e idade.

\begin{tabular}{|c|c|c|c|c|c|c|c|c|c|c|c|}
\hline \multirow{2}{*}{\multicolumn{2}{|c|}{ Características }} & \multicolumn{9}{|c|}{ Idade (anos) } & \\
\hline & & \multicolumn{2}{|c|}{$7(n=76)$} & \multicolumn{2}{|c|}{$8(n=72)$} & \multicolumn{2}{|c|}{$9(n=62)$} & \multicolumn{2}{|c|}{$10(n=71)$} & \multicolumn{2}{|c|}{ Total $(n=281)$} \\
\hline Sexo & $\%$ de gordura & $\%$ & $\%^{(*)}$ & $\%$ & $\%{ }^{(*)}$ & $\%$ & $\%{ }^{(*)}$ & $\%$ & $\%^{(*)}$ & $\%$ & $\%^{(*)}$ \\
\hline \multirow[t]{10}{*}{ Masc. } & $4,0-9,9$ & 1,3 & 1,3 & 1,4 & 1,4 & 4,8 & 4,8 & - & - & 1,8 & 1,8 \\
\hline & $10,0-14,9$ & 30,3 & 31,6 & 25,0 & 26,4 & 19,4 & 24,2 & 9,9 & 9,9 & 21,3 & 23,1 \\
\hline & $15,0-19,9$ & 40,8 & 72,4 & 31,9 & 58,3 & 37,1 & 61,3 & 18,3 & 28,2 & 32,0 & 55,1 \\
\hline & $20,0-24,9$ & 13,2 & 85,5 & 18,1 & 76,4 & 11,3 & 72,6 & 31,0 & 59,2 & 18,5 & 73,6 \\
\hline & $25,0-29,9$ & 7,9 & 93,4 & 6,9 & 83,3 & 17,7 & 90,3 & 14,1 & 73,2 & 11,4 & 85,0 \\
\hline & $30,0-34,9$ & 5,3 & 98,7 & 6,9 & 90,3 & 3,2 & 93,6 & 7,0 & 80,3 & 5,7 & 90,7 \\
\hline & $35,0-39,9$ & 1,3 & 100 & 2,8 & 93,1 & 3,2 & 96,8 & 8,5 & 88,7 & 3,9 & 94,6 \\
\hline & $40,0-44,9$ & - & - & 5,6 & 98,6 & 3,2 & 100 & 7,0 & 95,8 & 3,9 & 98,5 \\
\hline & $45,0-49,9$ & - & - & 1,4 & 100 & - & - & 2,8 & 98,6 & 1,1 & 99,6 \\
\hline & $50,0-55,0$ & - & - & - & - & - & - & 1,4 & 100 & 0,4 & 100 \\
\hline \multirow[t]{9}{*}{ Fem. } & & \multicolumn{2}{|c|}{$(n=75)$} & \multicolumn{2}{|c|}{$(n=66)$} & \multicolumn{2}{|c|}{$(n=64)$} & \multicolumn{2}{|c|}{$(n=70)$} & \multicolumn{2}{|c|}{$(n=275)$} \\
\hline & $10,0-14,9$ & 4,0 & 4,0 & 1,5 & 1,5 & - & - & - & - & 1,4 & 1,4 \\
\hline & $15,0-19,9$ & 46,7 & 50,7 & 40,9 & 42,4 & 37,5 & 37,5 & 24,3 & 24,3 & 37,5 & 38,9 \\
\hline & $20,0-24,9$ & 36,0 & 86,7 & 34,9 & 77,3 & 35,9 & 73,4 & 30,0 & 54,3 & 34,2 & 73,1 \\
\hline & $25,0-29,9$ & 6,7 & 93,3 & 10,6 & 87,9 & 12,5 & 85,9 & 22,9 & 77,2 & 13,1 & 86,2 \\
\hline & $30,0-34,9$ & 4,0 & 97,3 & 9,1 & 97,0 & 10,9 & 96,9 & 12,9 & 90,0 & 9,1 & 95,3 \\
\hline & $35,0-39,9$ & 2,7 & 100 & 3,0 & 100 & - & 96,9 & 7,1 & 97,2 & 3,3 & 98,6 \\
\hline & $40,0-44,9$ & - & - & - & - & 3,1 & 100 & 1,4 & 98,6 & 1,1 & 99,7 \\
\hline & $45,0-49,9$ & - & - & - & - & - & - & 1,4 & 100 & 0,4 & 100 \\
\hline \multirow[t]{11}{*}{ Total } & & \multicolumn{2}{|c|}{$(n=151)$} & \multicolumn{2}{|c|}{$(n=138)$} & \multicolumn{2}{|c|}{$(n=126)$} & \multicolumn{2}{|c|}{$(n=141)$} & \multicolumn{2}{|c|}{$(n=556)$} \\
\hline & $4,0-9,9$ & 0,7 & 0,7 & 0,7 & 0,7 & 2,4 & 2,4 & - & - & 0,9 & 0,9 \\
\hline & $10,0-14,9$ & 17,2 & 17,9 & 13,8 & 14,5 & 9,5 & 11,9 & 5,0 & 5,0 & 11,5 & 12,4 \\
\hline & $15,0-19,9$ & 43,7 & 61,6 & 36,2 & 50,7 & 37,3 & 49,2 & 21,3 & 26,2 & 34,7 & 47,1 \\
\hline & $20,0-24,9$ & 24,5 & 86,1 & 26,1 & 76,8 & 23,8 & 73,0 & 30,5 & 56,7 & 26,2 & 73,3 \\
\hline & $25,0-29,9$ & 7,3 & 93,4 & 8,7 & 85,5 & 15,1 & 88,1 & 18,4 & 75,2 & 12,2 & 85,5 \\
\hline & $30,0-34,9$ & 4,6 & 98,0 & 8,0 & 93,5 & 7,1 & 95,2 & 9,9 & 85,1 & 7,4 & 92,9 \\
\hline & $35,0-39,9$ & 2,0 & 100 & 2,9 & 96,4 & 1,6 & 96,8 & 7,8 & 92,9 & 3,6 & 96,5 \\
\hline & $40,0-44,9$ & - & - & 2,9 & 99,3 & 3,2 & 100 & 4,3 & 97,2 & 2,5 & 99,0 \\
\hline & $45,0-49,9$ & - & - & 0,7 & 100 & - & - & 2,1 & 99,3 & 0,7 & 99,7 \\
\hline & $50,0-55,0$ & - & - & - & - & - & - & 0,7 & 100 & 0,2 & 100 \\
\hline
\end{tabular}

$\left(^{*}\right)$ percentual acumulado 
Tabela A12.9 - Distribuição do percentual (\%) de escolares segundo área gordurosa do braço $(A G B)\left(\mathrm{mm}^{3}\right)$, sexo e idade.

\begin{tabular}{|c|c|c|c|c|c|c|c|c|c|c|c|}
\hline \multirow{2}{*}{\multicolumn{2}{|c|}{ Características }} & \multirow{2}{*}{\multicolumn{2}{|c|}{$7(n=76)$}} & \multicolumn{4}{|c|}{ Idade (anos) } & \multirow{2}{*}{\multicolumn{2}{|c|}{$10(n=71)$}} & \multirow{2}{*}{\multicolumn{2}{|c|}{ Total $(n=281)$}} \\
\hline & & & & & & & & & & & \\
\hline Sexo & $(\mathrm{AGB})\left(\mathrm{mm}^{3}\right)$ & $\%$ & $\%^{(*)}$ & $\%$ & $\%^{(*)}$ & $\%$ & $\%^{(*)}$ & $\%$ & $\%(*)$ & $\%$ & $\%^{(*)}$ \\
\hline \multirow[t]{4}{*}{ Masc. } & $300,0-882,9$ & 38,2 & 38,2 & 36,1 & 36,1 & 41,9 & 41,9 & 12,7 & 12,7 & 32,03 & 32,0 \\
\hline & $883,0-1147,9$ & 28,9 & 67,1 & 18,1 & 54,2 & 17,7 & 59,6 & 16,9 & 29,6 & 20,64 & 52,7 \\
\hline & $1148,0-1642,9$ & 22,4 & 89,5 & 25,0 & 79,2 & 17,7 & 77,3 & 29,6 & 59,2 & 23,84 & 76,5 \\
\hline & $1643,0-4718,9$ & 10,5 & 100 & 20,8 & 100 & 22,6 & 100 & 40,8 & 100 & 23,49 & 100 \\
\hline \multirow[t]{5}{*}{ Fem. } & & \multicolumn{2}{|c|}{$(n=75)$} & \multicolumn{2}{|c|}{$(n=66)$} & \multicolumn{2}{|c|}{$(n=64)$} & \multicolumn{2}{|c|}{$(n=70)$} & \multicolumn{2}{|c|}{$(n=275)$} \\
\hline & $300,0-882,9$ & 29,3 & 29,3 & 21,2 & 21,2 & 14,1 & 14,1 & 5,7 & 5,7 & 17,82 & 17,8 \\
\hline & $883,0-1147,9$ & 33,3 & 62,6 & 36,4 & 57,6 & 29,7 & 43,8 & 18,6 & 24,3 & 29,45 & 47,3 \\
\hline & $1148,0-1642,9$ & 25,3 & 87,9 & 21,2 & 78,8 & 28,1 & 71,9 & 30,0 & 54,3 & 26,18 & 73,4 \\
\hline & $1643,0-4718,9$ & 12,0 & 100 & 21,2 & 100 & 28,1 & 100 & 45,7 & 100 & 26,55 & 100 \\
\hline \multirow[t]{5}{*}{ Total } & & \multicolumn{2}{|c|}{$(n=151)$} & \multicolumn{2}{|c|}{$(n=138)$} & \multicolumn{2}{|c|}{$(n=126)$} & \multicolumn{2}{|c|}{$(n=141)$} & \multicolumn{2}{|c|}{$(n=556)$} \\
\hline & $300,0-882,9$ & 33,8 & 33,8 & 29,0 & 29,0 & 27,8 & 27,8 & 9,2 & 9,2 & 25,0 & 25,0 \\
\hline & $883,0-1147,9$ & 31,1 & 64,9 & 26,8 & 55,8 & 23,8 & 51,6 & 17,7 & 26,9 & 25,0 & 50,0 \\
\hline & $148,0-1642,9$ & 23,8 & 88,7 & 23,2 & 79,0 & 23,0 & 74,6 & 29,8 & 56,7 & 25,0 & 75,0 \\
\hline & $1643,0-4718,9$ & 11,3 & 100 & 21,0 & 100 & 25,4 & 100 & 43,3 & 100 & 25,0 & 100 \\
\hline
\end{tabular}

(*) percentual acumulado 
Tabela A13.1 - Variabilidade (CV\%) de peso $(\mathrm{kg})$ e estatura $(\mathrm{cm})$ segundo sexo e idade (anos)

\begin{tabular}{|c|c|c|c|c|}
\hline \multirow[t]{2}{*}{$\operatorname{Sexo}^{(1)}$} & \multicolumn{4}{|c|}{ Idade (anos) $)^{(2)}$} \\
\hline & 7 & 8 & 9 & 10 \\
\hline & \multicolumn{4}{|c|}{ Peso $(\mathrm{kg})$} \\
\hline Masculino & 17,0 & 28,6 & 24,6 & 28,9 \\
\hline Feminino & 19,8 & 22,2 & 29,8 & 20,2 \\
\hline \multirow[t]{2}{*}{ Total } & 18,6 & 26,3 & 27,2 & 24,9 \\
\hline & \multicolumn{4}{|c|}{ Estatura $(\mathrm{cm})$} \\
\hline Masculino & 3,6 & 4,5 & 4,5 & 5,6 \\
\hline Feminino & 4,1 & 4,5 & 5,8 & 4,6 \\
\hline Total & 3,9 & 4,6 & 5,2 & 5,1 \\
\hline
\end{tabular}

Tabela A13.2 - Variabilidade (CV\%) das pregas cutâneas tricipital e da panturrilha $(\mathrm{mm})$ segundo sexo e idade (anos)

\begin{tabular}{|c|c|c|c|c|}
\hline \multirow[t]{2}{*}{$\operatorname{Sexo}^{(1)}$} & \multicolumn{4}{|c|}{ Idade $(a n o s)^{(2)}$} \\
\hline & 7 & 8 & 9 & 10 \\
\hline & \multicolumn{4}{|c|}{ Prega cutânea tricipital $(\mathrm{mm})$} \\
\hline Masculino & 33,3 & 45,2 & 44,8 & 40,1 \\
\hline Feminino & 31,1 & 32,1 & 32,2 & 34,5 \\
\hline \multirow{2}{*}{ Total } & 32,5 & 39,1 & 38,7 & 37,3 \\
\hline & \multicolumn{4}{|c|}{ Prega cutânea da panturrilha $(\mathrm{mm})$} \\
\hline Masculino & 34,2 & 45,3 & 42,6 & 39,5 \\
\hline Feminino & 33,1 & 37,0 & 32,9 & 34,1 \\
\hline Total & 34,1 & 41,3 & 37,6 & 37,1 \\
\hline
\end{tabular}

Tabela A13.3 - Variabilidade (CV\%) das circunferências braquial e da cintura $(\mathrm{cm})$ segundo sexo e idade (anos)

\begin{tabular}{|c|c|c|c|c|}
\hline \multirow[t]{2}{*}{$\operatorname{Sexo}^{(1)}$} & \multicolumn{4}{|c|}{ Idade (anos) $)^{(2)}$} \\
\hline & 7 & 8 & 9 & 10 \\
\hline & \multicolumn{4}{|c|}{ Circunferência braquial $(\mathrm{cm})$} \\
\hline Masculino & 11,3 & 15,9 & 15,7 & 16,1 \\
\hline Feminino & 10,9 & 12,9 & 14,9 & 12,5 \\
\hline \multirow[t]{2}{*}{ Total } & 11,4 & 14,7 & 15,5 & 14,3 \\
\hline & \multicolumn{4}{|c|}{ Circunferência da cintura $(\mathrm{cm})$} \\
\hline Masculino & 9,9 & 15,7 & 14,7 & 16,4 \\
\hline Feminino & 10,8 & 12,0 & 14,4 & 13,8 \\
\hline Total & 10.3 & 144 & 14.6 & 15.1 \\
\hline
\end{tabular}


Tabela A13.4 - Variabilidade (CV\%) do percentual de gordura total estimado pela BIA e pelas pregas cutâneas segundo sexo e idade (anos)

\begin{tabular}{|c|c|c|c|c|}
\hline \multirow[t]{2}{*}{$\operatorname{Sexo}^{(1)}$} & \multicolumn{4}{|c|}{ Idade (anos) $)^{(2)}$} \\
\hline & 7 & 8 & 9 & 10 \\
\hline & \multicolumn{4}{|c|}{$\%$ de gordura total estimado pela BIA } \\
\hline Masculino & 30,5 & 35,3 & 34,6 & 33,2 \\
\hline Feminino & 22,7 & 25,5 & 26,7 & 29,0 \\
\hline \multirow[t]{2}{*}{ Total } & 28,4 & 31,3 & 31,4 & 31,3 \\
\hline & \multicolumn{4}{|c|}{$\%$ de gordura total estimado pelas pregas } \\
\hline Masculino & 30,4 & 42,2 & 39,8 & 37,1 \\
\hline Feminino & 23,7 & 25,3 & 24,7 & 26,4 \\
\hline Total & 27,9 & 34,7 & 32,9 & 31,9 \\
\hline
\end{tabular}

Tabela A13.5 - Variabilidade (CV\%) da área gordurosa do braço $\left(\mathrm{mm}^{2}\right)$ segundo sexo e idade (anos)

\begin{tabular}{lcccc}
\hline Sexo $^{(1)}$ & \multicolumn{4}{c}{${\text { Idade }(\text { anos })^{(2)}}^{(2)}$} \\
\cline { 2 - 5 } & 7 & 8 & 9 & 10 \\
\hline \multirow{3}{*}{ Masculino } & 41,9 & Área gordurosa do braço $\left(\mathrm{mm}^{2}\right)$ \\
Feminino & 41,4 & 60,0 & 58,8 & 53,2 \\
Total & 41,7 & 42,2 & 47,5 & 42,0 \\
(1) Masculino $(\mathrm{n}=281)$, Feminino $(\mathrm{n}=275) ;{ }^{(2)} 7$ anos $(\mathrm{n}=151) ; 8$ anos $(\mathrm{n}=138) ; 9$ anos $(\mathrm{n}=126) ; 10$ \\
anos (n=141) $) ; \mathrm{CV} \%=$ =coeficiente de variação de Pearson.
\end{tabular}




\section{ANEXO 14}

Curvas TGROC - Valores de pontos de corte do percentual de gordura que otimizam a sensibilidade e especificidade para identificar excesso de peso.

Sexo feminino

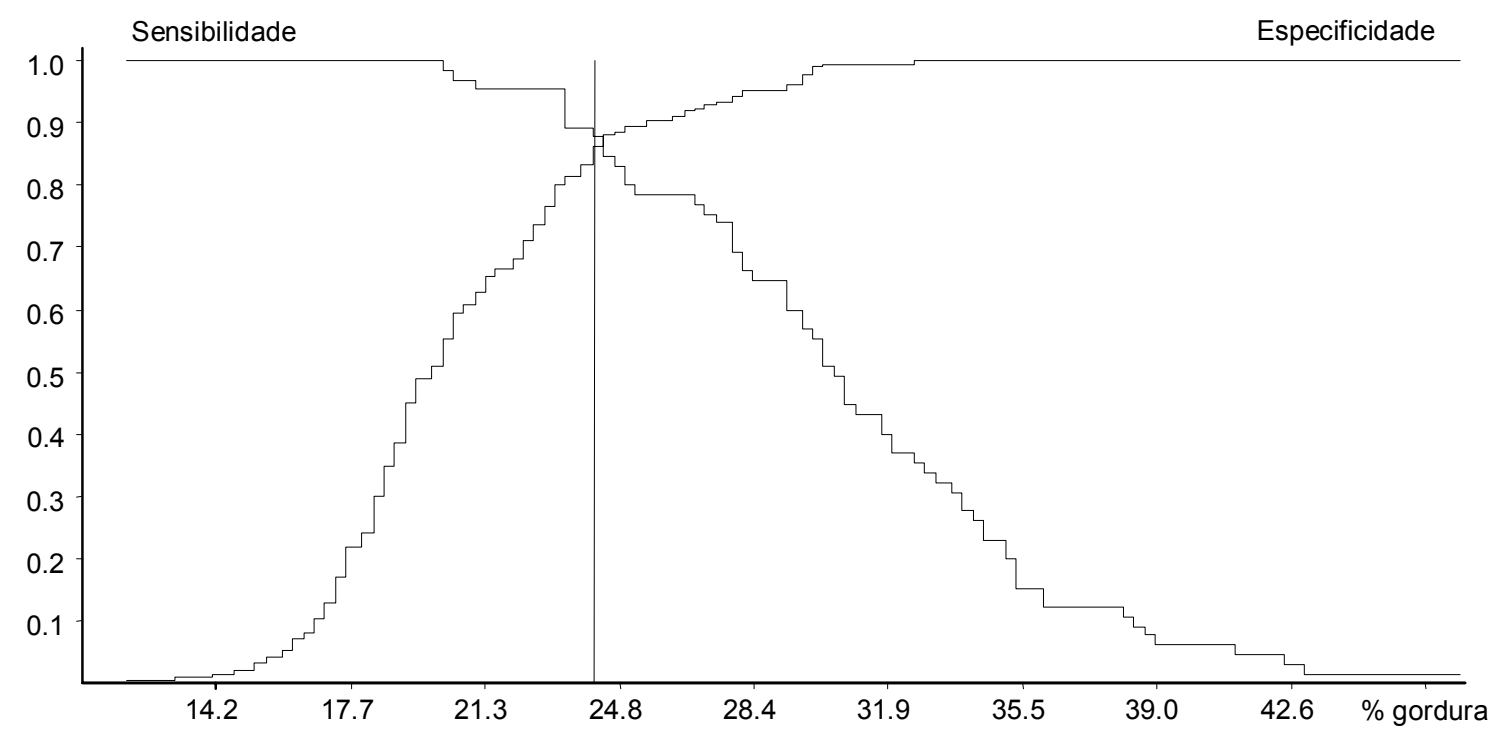

Gráfico A14.1 - Curva TgROC - Valores de sensibilidade e especificidade do percentual de gordura total estimado pelas pregas cutâneas para escolares do sexo feminino.

Sexo masculino

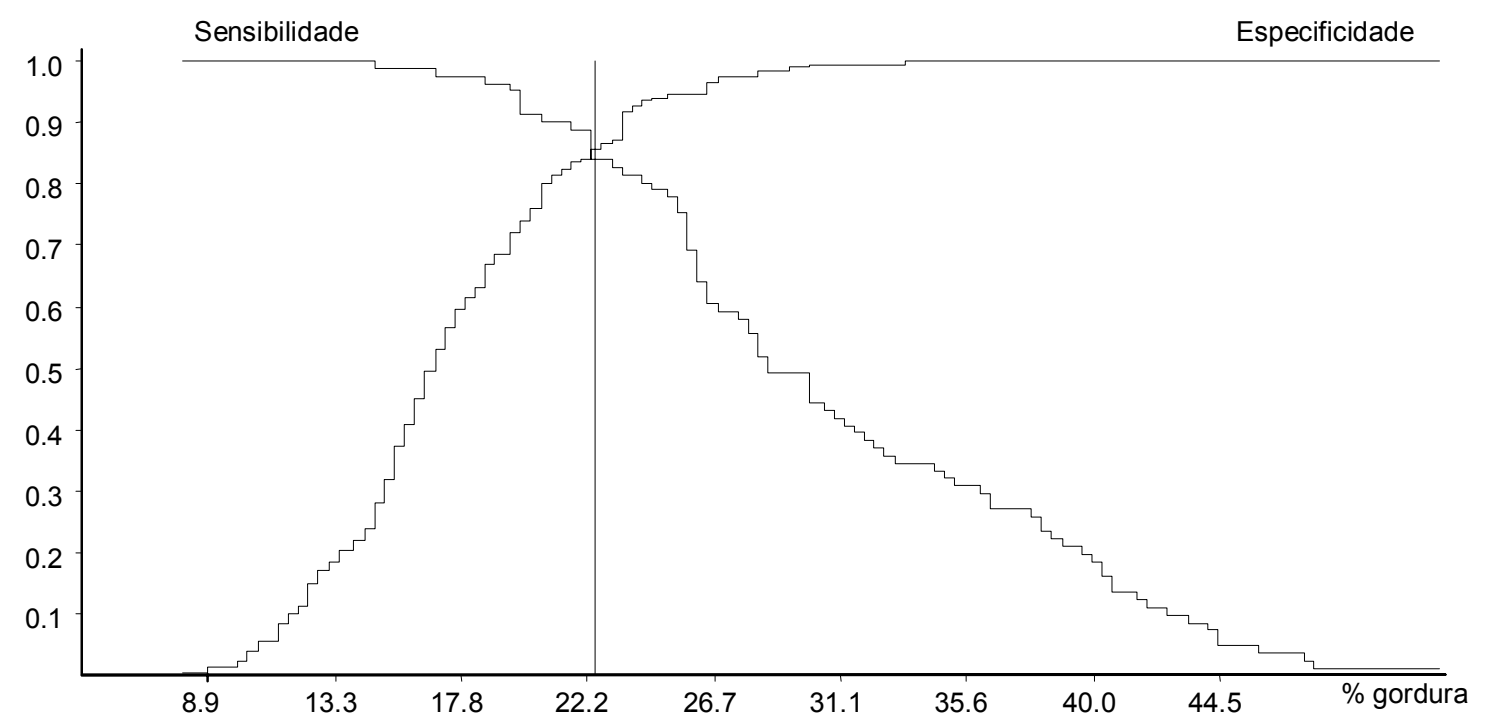

Gráfico A14.2 - Curva TgROC - Valores de sensibilidade e especificidade do percentual de gordura total estimado pelas pregas cutâneas para escolares do sexo masculino. 


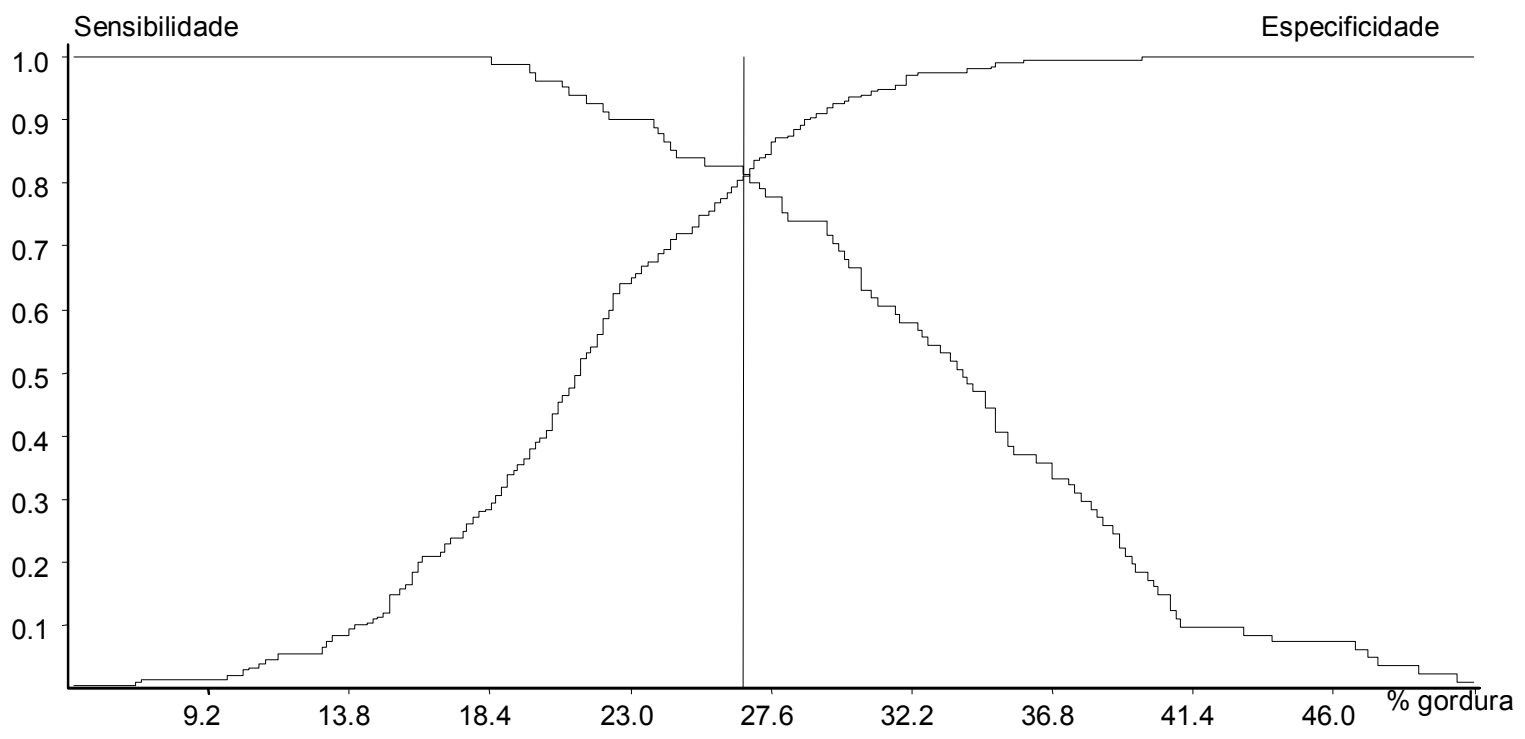

Gráfico A14.3 - Curva TgROC - Valores de sensibilidade e especificidade do percentual de gordura total estimado pela BIA para escolares do sexo masculino. 


\section{ANEXO 15}

Diagramas de dispersão entre a circunferência da cintura e percentual de gordura total estimado pela BIA e pelas pregas cutâneas.

\section{7 anos}

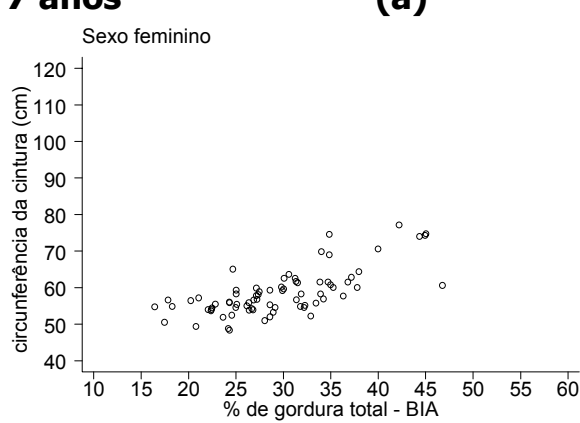

\section{8 anos}

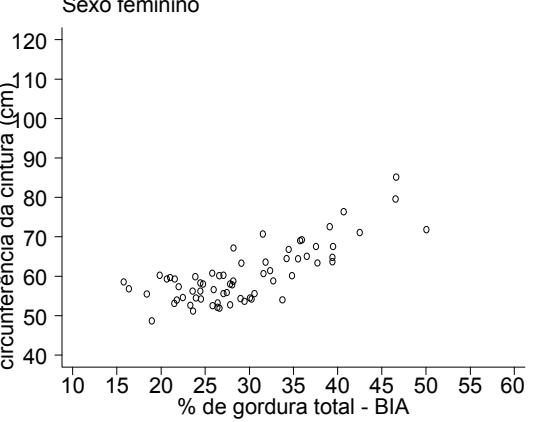

\section{9 anos}

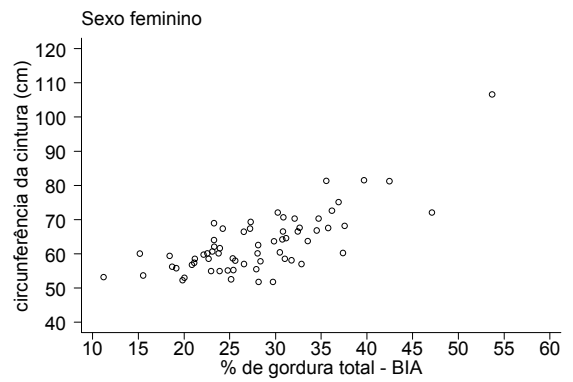

10 anos

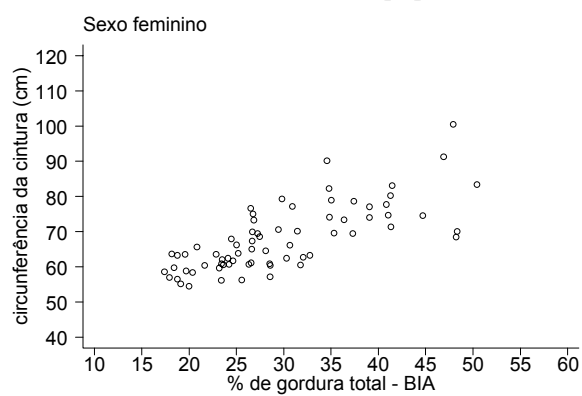

(b)

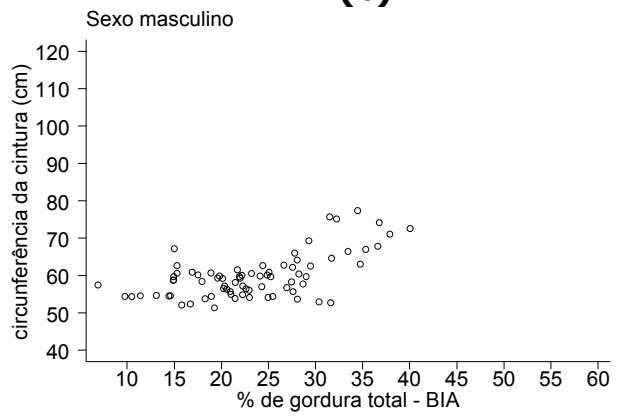

(b)

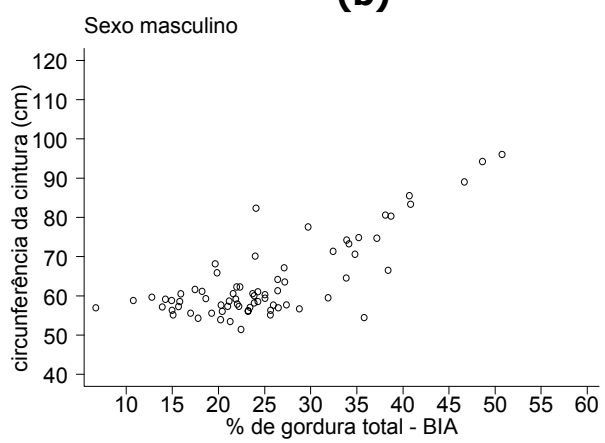

(b)

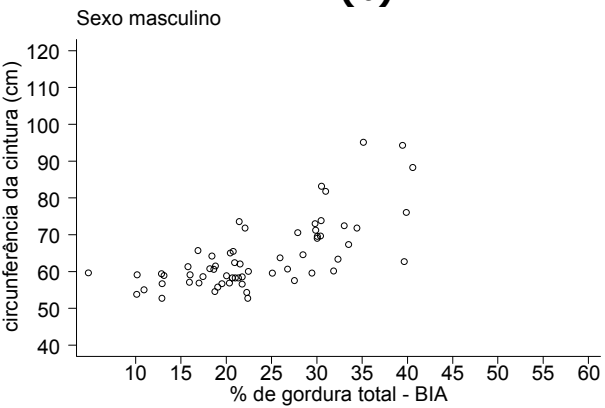

(b)

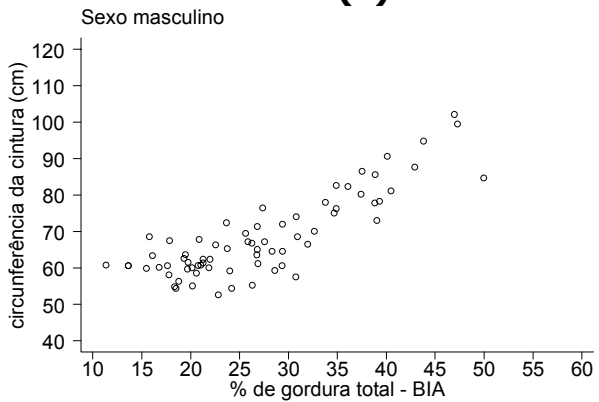

Gráficos A15a - Distribuição de escolares segundo o percentual de gordura corporal total estimado pelo BIA e circunferência da cintura. Faixas etárias, sexo feminino (a) e masculino (b). 
7 anos

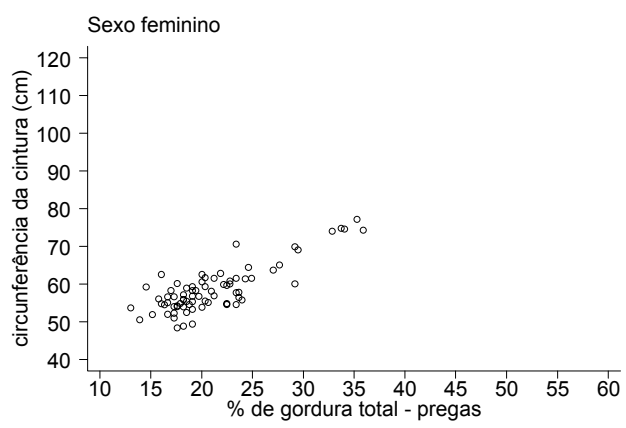

8 anos

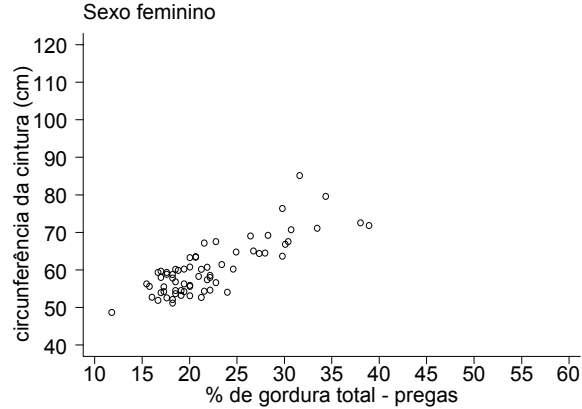

9 anos

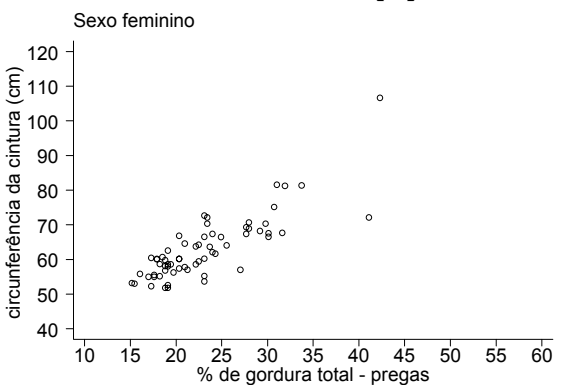

10 anos

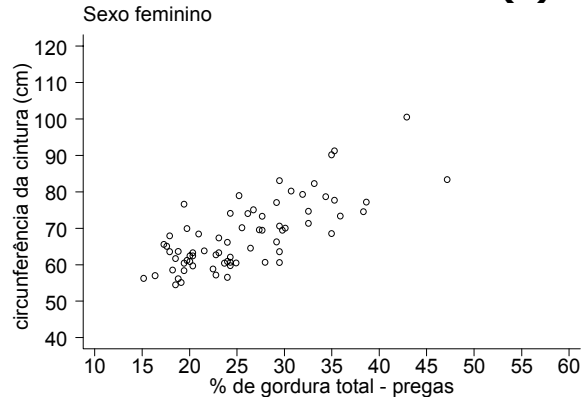

(b)

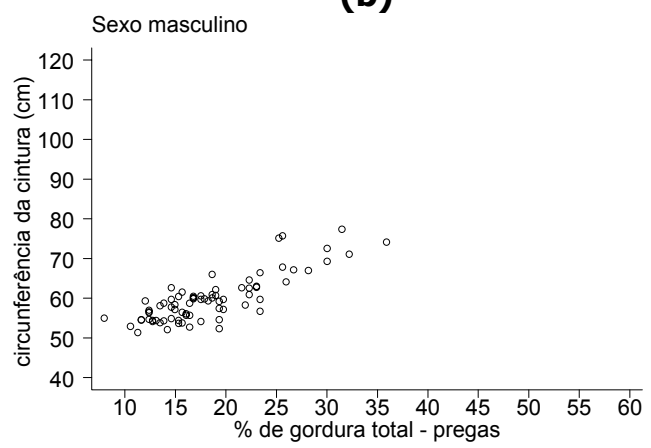

(b)

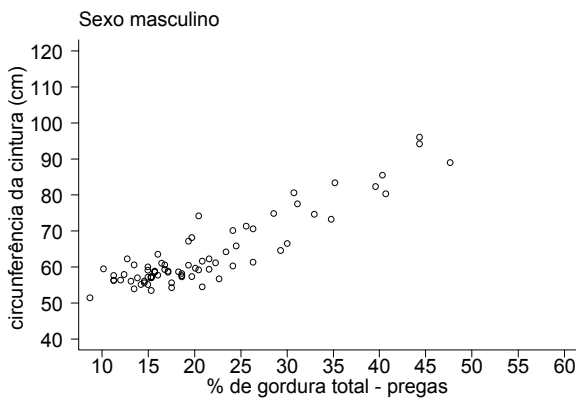

(b)

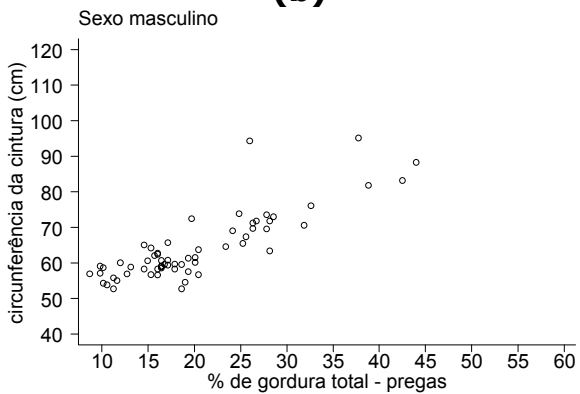

(b)

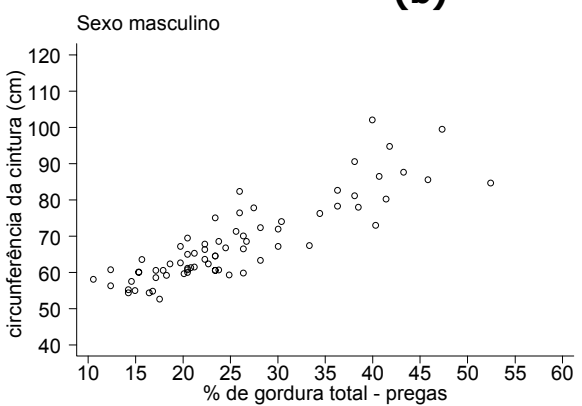

Gráficos A15b - Distribuição de escolares segundo o percentual de gordura corporal total estimado pelas pregas cutâneas e circunferência da cintura. Faixas etárias, sexo feminino (a) e masculino (b). 


\section{ANEXO 16}

Comparação de valores medianos de peso $(\mathrm{kg})$ com valores medianos de outras populações de referência.

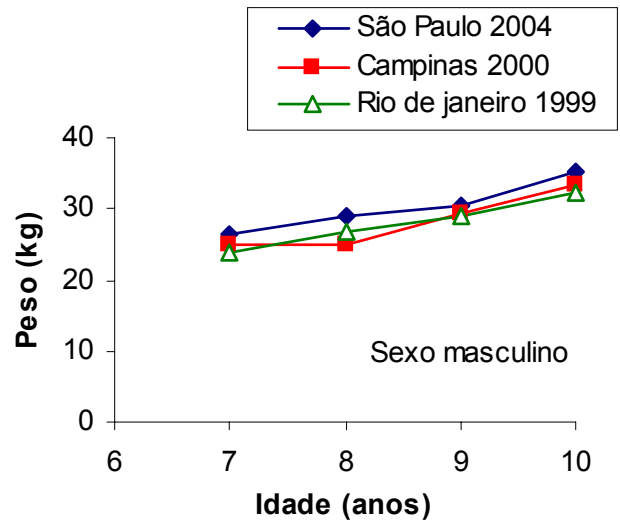

(a)

${ }^{(1)}$ (Anjos e col 2003); (2) (Cocetti 2001)

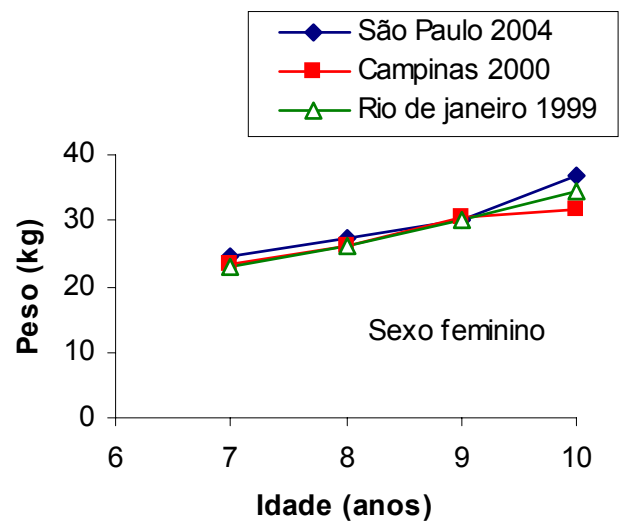

(b)

Gráficos A16.1a e A16.1b - Medianas do peso $(\mathrm{kg})$ em relação à idade de escolares de duas escolas públicas de São Paulo em 2004, de escolares da rede pública do Rio de Janeiro em $1999^{(1)}$ e de escolares de Campinas de baixa renda em $2000^{(2)}$.

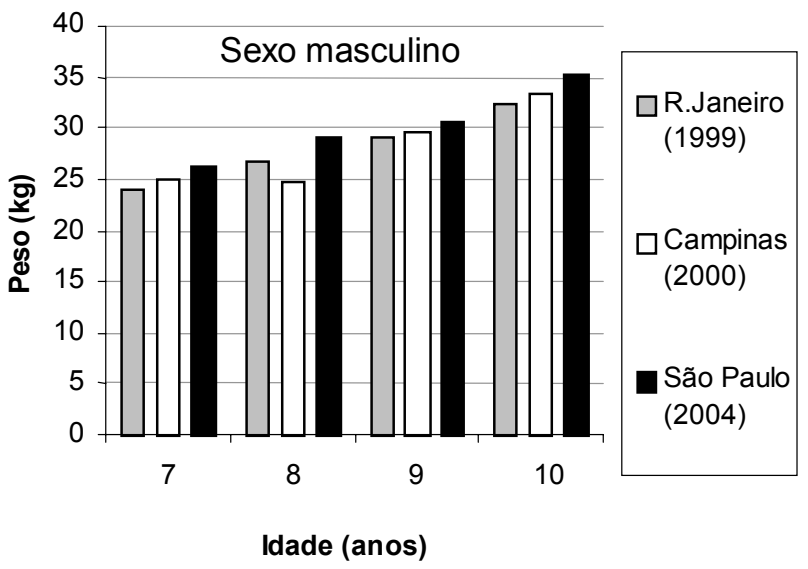

(a)

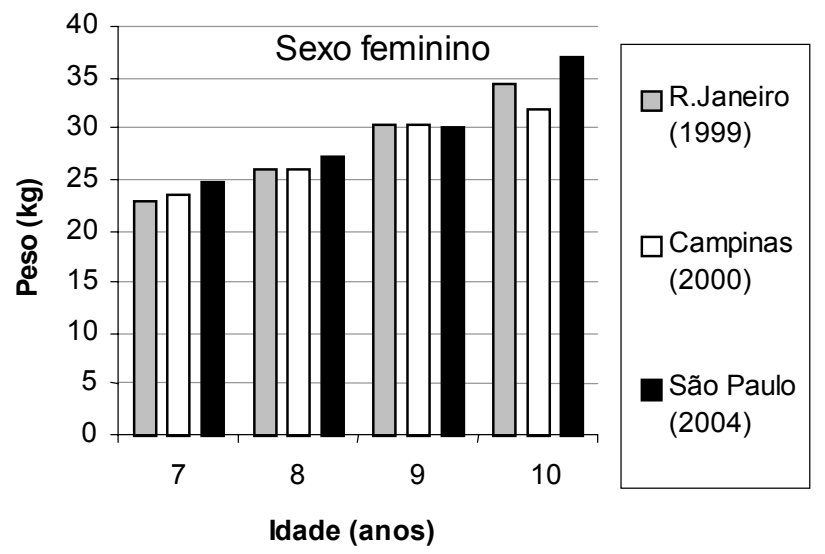

(b)

${ }^{\text {(1) }}$ (Anjos e col 2003); ${ }^{(2)}$ (Cocetti 2001)

Gráficos A16.2a e A16.2b - Tendência temporal dos valores das medianas do peso $(\mathrm{kg})$ em relação à idade de escolares de duas escolas públicas de São Paulo em 2004, de escolares da rede pública do Rio de Janeiro em $1999^{(1)}$ e de escolares de Campinas de baixa renda em $2000^{(2)}$. 
Comparação de valores medianos de estatura $(\mathrm{cm})$ com valores medianos de outras populações de referência.

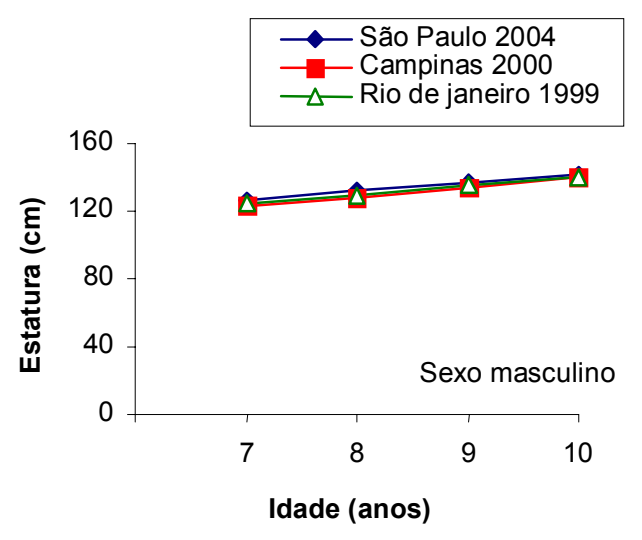

(a)

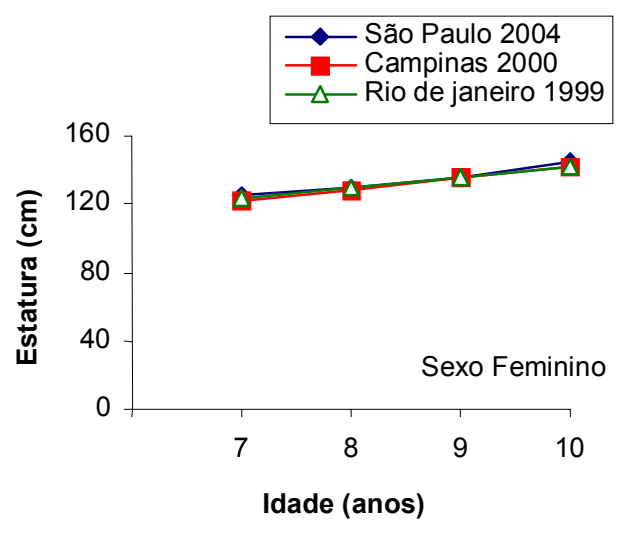

(b)

(1) (Anjos e col 2003); ${ }^{(2)}$ (Cocetti 2001)

Gráficos A16.3a e A16.3b - Medianas de estatura $(\mathrm{cm})$ em relação à idade de escolares de duas escolas públicas de São Paulo em 2004, de escolares da rede pública do Rio de Janeiro em $1999^{(1)}$ e de escolares de Campinas de baixa renda em $2000^{(2)}$.

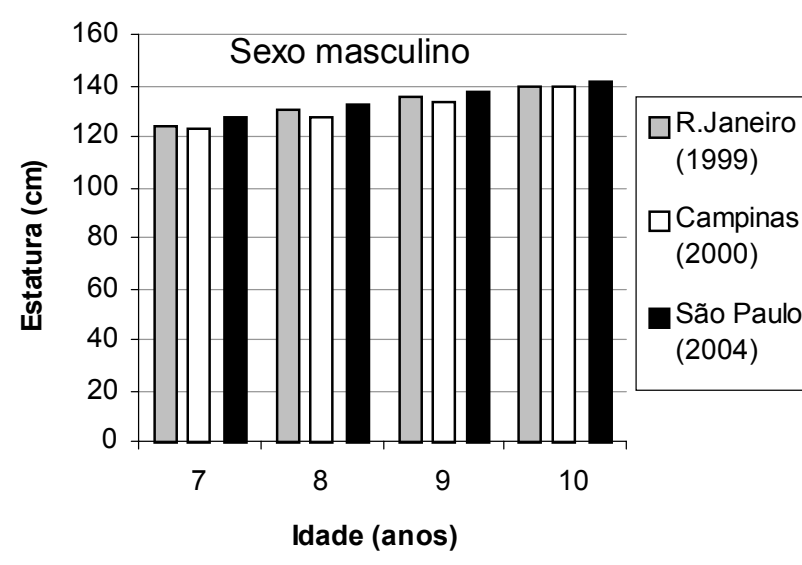

(a)

(1) (Anjos e col 2003); (2) (Cocetti 2001)

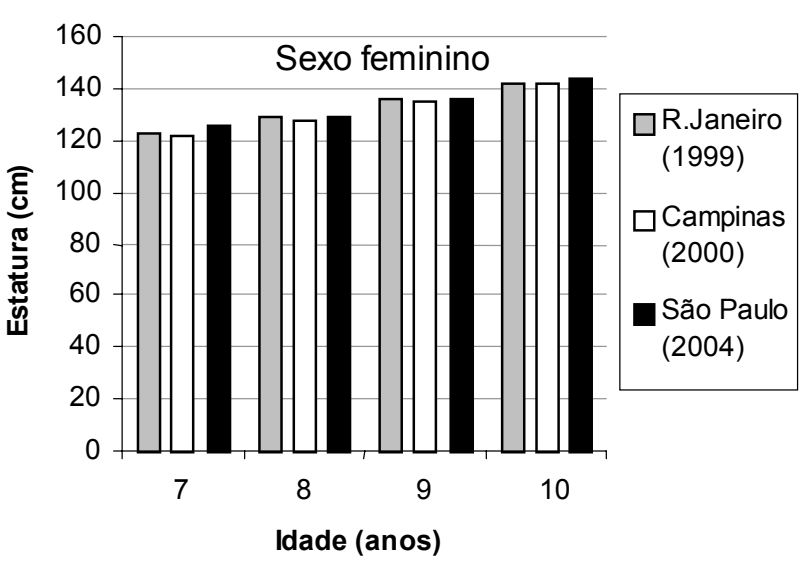

(b)

Gráficos A16.4a e A16.4b - Tendência temporal dos valores das medianas da estatura $(\mathrm{cm})$ em relação à idade de escolares de duas escolas públicas de São Paulo em 2004, de escolares da rede pública do Rio de Janeiro em $1999^{(1)}$ e de escolares de Campinas de baixa renda em $2000^{(2)}$. 
Comparação de valores medianos de IMC $\left(\mathrm{kg} / \mathrm{m}^{2}\right)$ com valores medianos de outras populações de referência.

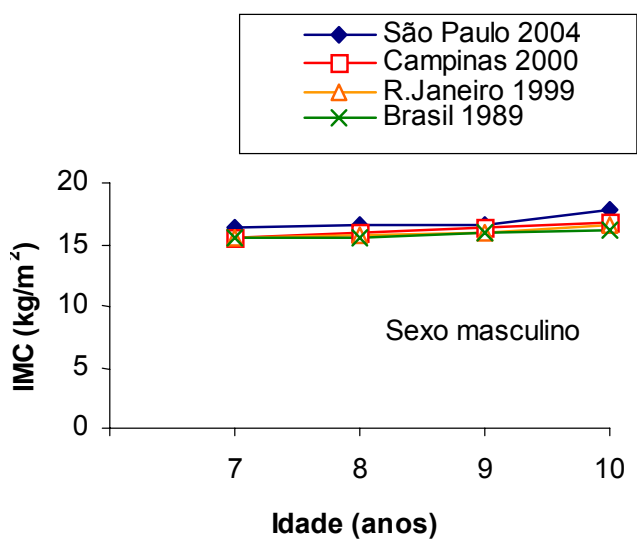

(a)

${ }^{(1)}$ (Anjos e col 2003); ${ }^{(2)}$ (Cocetti 2001); (3) (Anjos e col 1998)
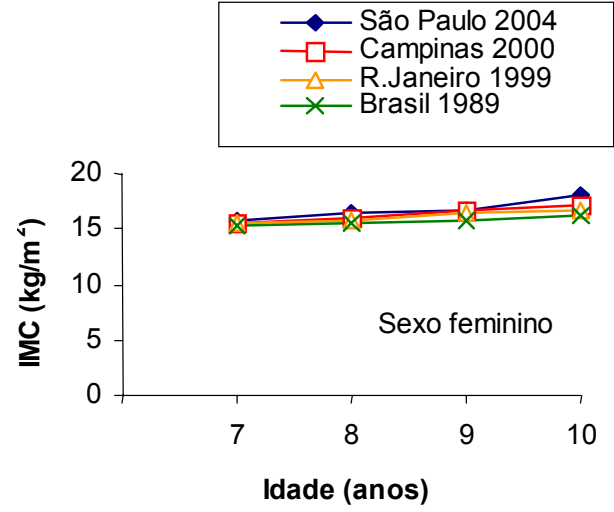

(b)

Gráficos A16.5a e A16.5b - Medianas de $\mathrm{IMC}\left(\mathrm{kg} / \mathrm{m}^{2}\right)$ em relação à idade de escolares de duas escolas públicas de São Paulo em 2004, de escolares da rede pública do Rio de Janeiro em $1999^{(1)}$, de escolares de Campinas de baixa renda em $2000^{(2)}$ e de crianças brasileiras do PNSN de $1989^{(3)}$.

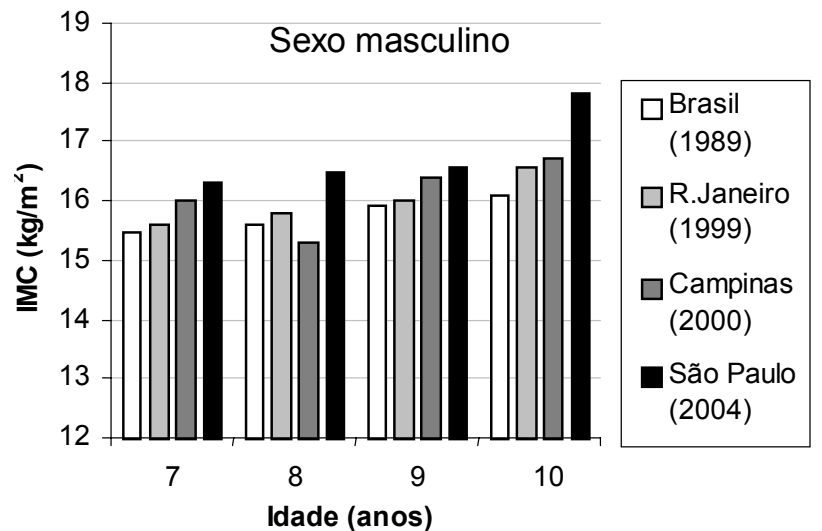

(a)

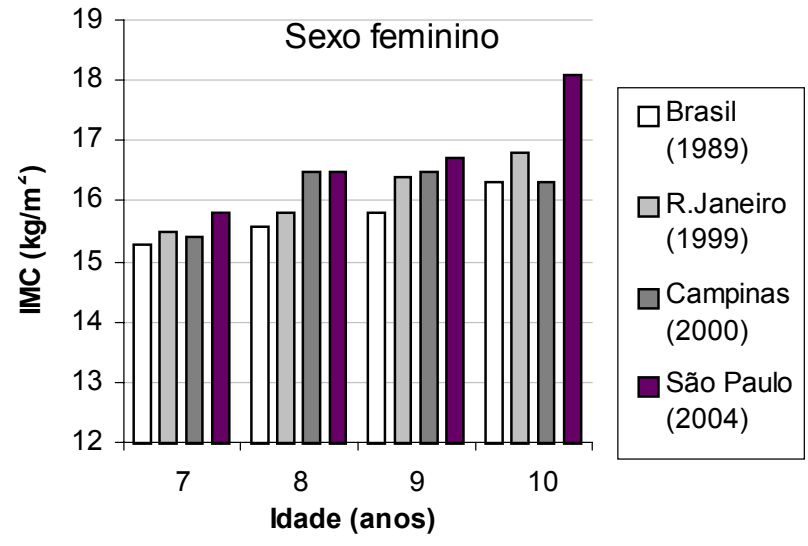

(b)

${ }^{(1)}$ (Anjos e col 2003); (2) (Cocetti 2001); (3) (Anjos e col 1998)

Gráficos A16.6a e A16.6b - Tendência temporal dos valores das medianas do IMC $\left(\mathrm{kg} / \mathrm{m}^{2}\right)$ em relação à idade de escolares de duas escolas públicas de São Paulo em 2004, de escolares da rede pública do Rio de Janeiro em $1999^{(1)}$, de escolares de Campinas de baixa renda em $2000^{(2)}$ e de crianças brasileiras do PNSN de $1989^{(3)}$. 
Comparação de valores medianos de prega cutânea tricipital (mm) com valores medianos de outras populações de referência.

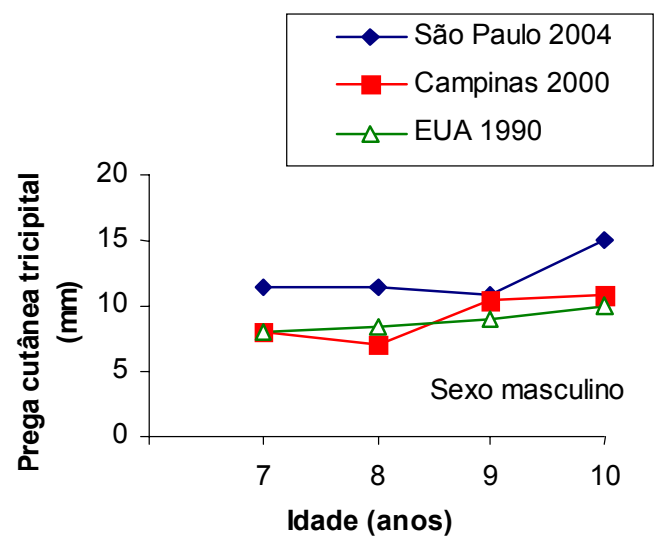

(a)

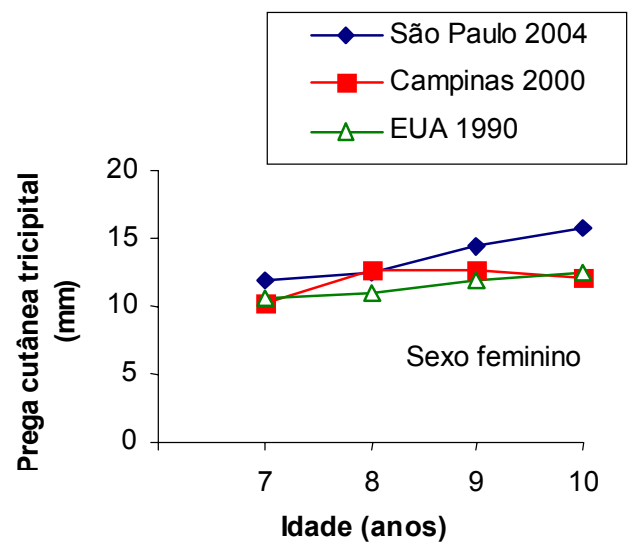

(b)

${ }^{(1)}$ (Cocetti 2001); ${ }^{(2)}$ (Frisancho 1999)

Gráficos A16.7a e A16.7b - Medianas de prega cutânea tricipital $(\mathrm{mm})$ em relação à idade de escolares de duas escolas públicas de São Paulo em 2004, de escolares de Campinas de baixa renda em $2000^{(1)}$ e de crianças americanas do estudo de Frisancho ${ }^{(2)}$.

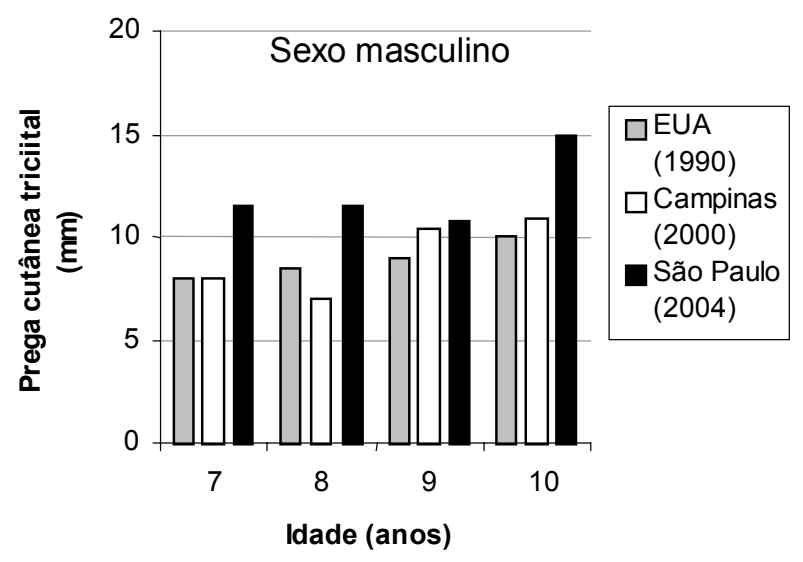

(a)

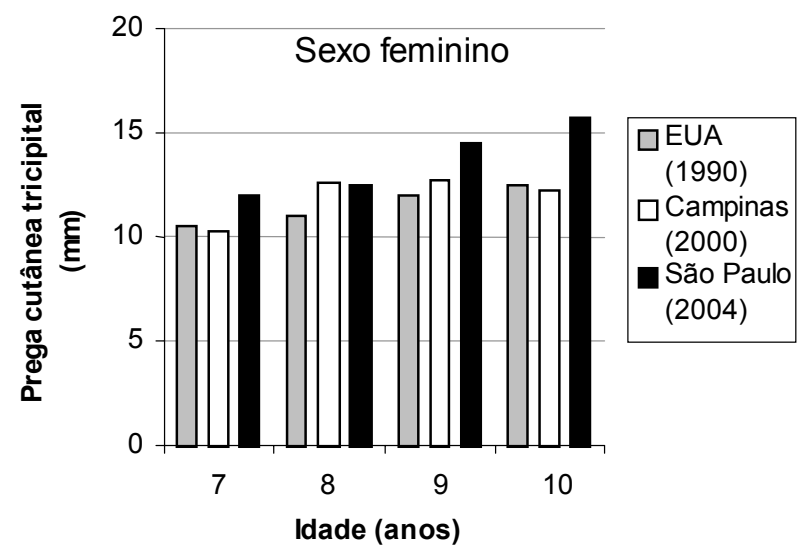

(b)

${ }^{(1)}$ (Cocetti 2001); ${ }^{(2)}$ (Frisancho 1999)

Gráficos A16.8a e A16.8b - Tendência temporal dos valores das medianas da prega cutânea tricipital $(\mathrm{mm})$ em relação à idade de escolares de duas escolas públicas de São Paulo em 2004, de escolares de Campinas de baixa renda em $2000^{(1)}$ e de crianças americanas do estudo de Frisancho ${ }^{(2)}$. 
Comparação de valores medianos da circunferência da cintura $(\mathrm{cm})$ com valores medianos de outras populações de referência.

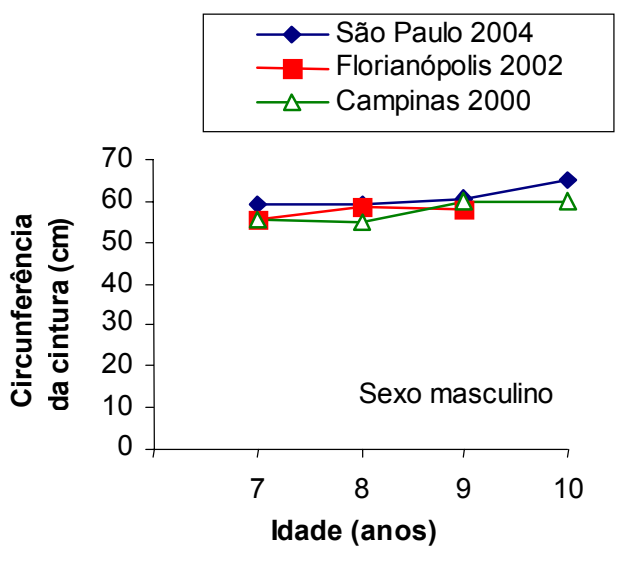

(a)

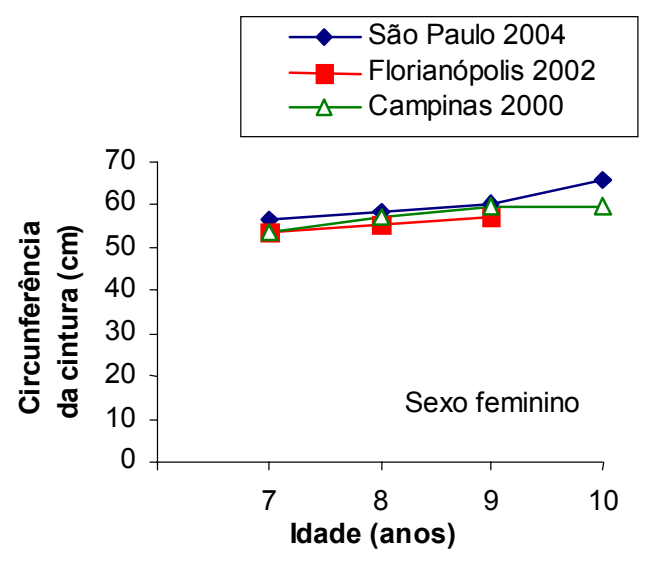

(b)

(1) (Cocetti 2001); (2) (Soar e col 2004)

Gráficos A16.9a e A16.9b - Medianas da circunferência da cintura (cm) em relação à idade de escolares de duas escolas públicas de São Paulo em 2004, de escolares de Campinas de baixa renda em $2000^{(1)}$ e de escolares de uma escola estadual de Florianópolis em $2002^{(2)}$.

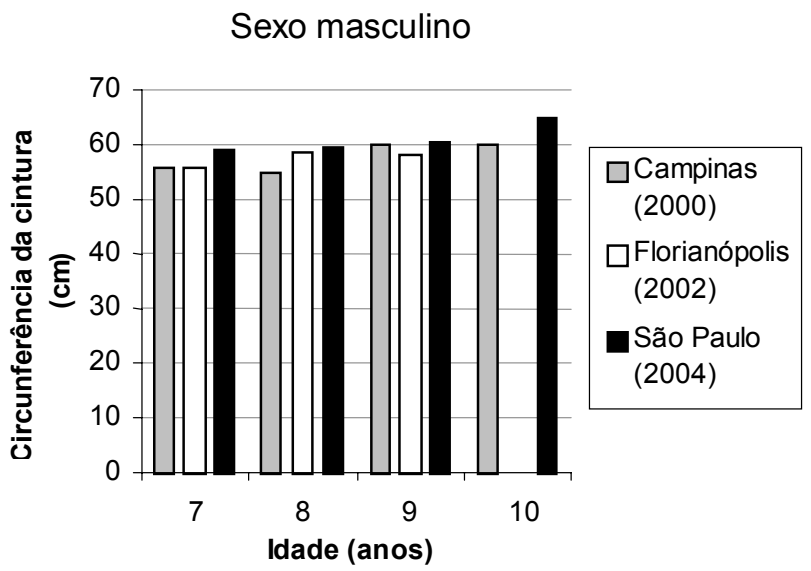

(a)
Sexo feminino

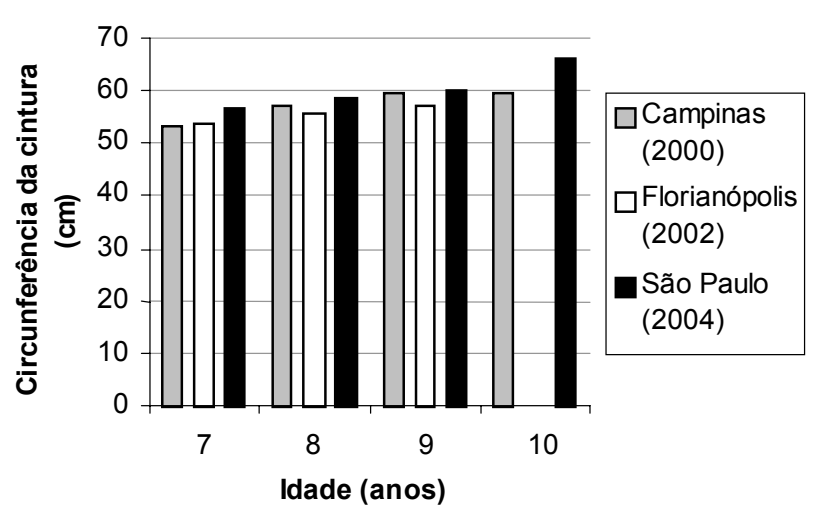

(b)

(1) (Cocetti 2001); (2) (Soar e col 2004)

Gráficos A16.10a e A16.10b - Tendência temporal dos valores das medianas da circunferência da cintura $(\mathrm{cm})$ em relação à idade de escolares de duas escolas públicas de São Paulo em 2004, de escolares de Campinas de baixa renda em $2000^{(1)}$ e de escolares de uma escola estadual de Florianópolis em $2002^{(2)}$. 
Comparação de valores medianos da área gordurosa do braço $\left(\mathrm{mm}^{2}\right)$ com valores medianos de outras populações de referência.

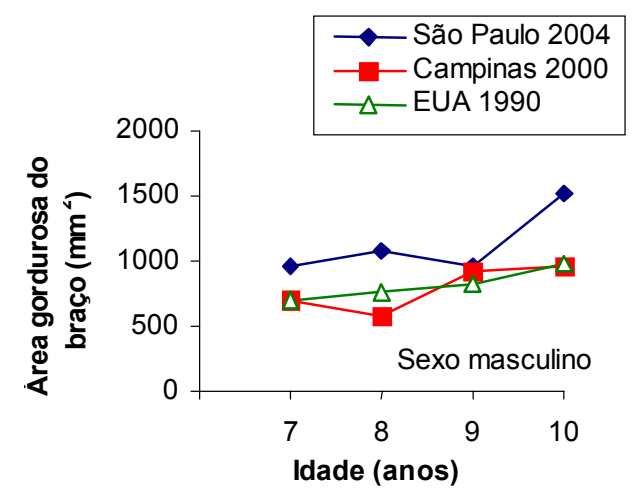

(a)

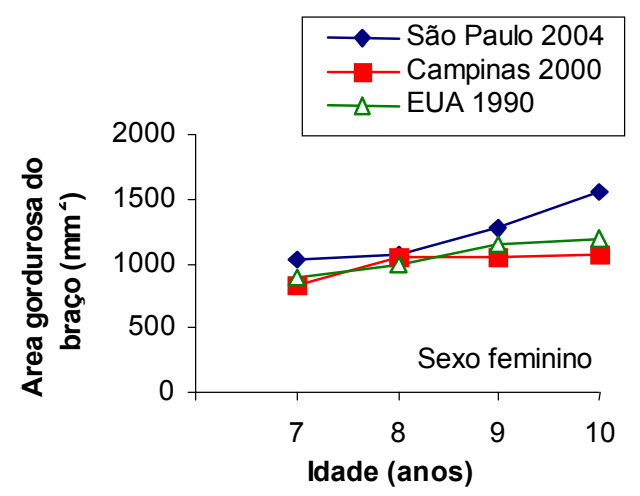

(b)

${ }^{(1)}\left(\right.$ Cocetti 2001); ${ }^{(2)}$ (Frisancho 1999)

Gráficos A16.11a e A16.11b - Medianas da área gordurosa do braço $\left(\mathrm{mm}^{2}\right)$ em relação à idade de escolares de duas escolas públicas de São Paulo em 2004, de escolares de Campinas de baixa renda em $2000^{(1)}$ e de crianças americanas do estudo de Frisancho ${ }^{(2)}$.

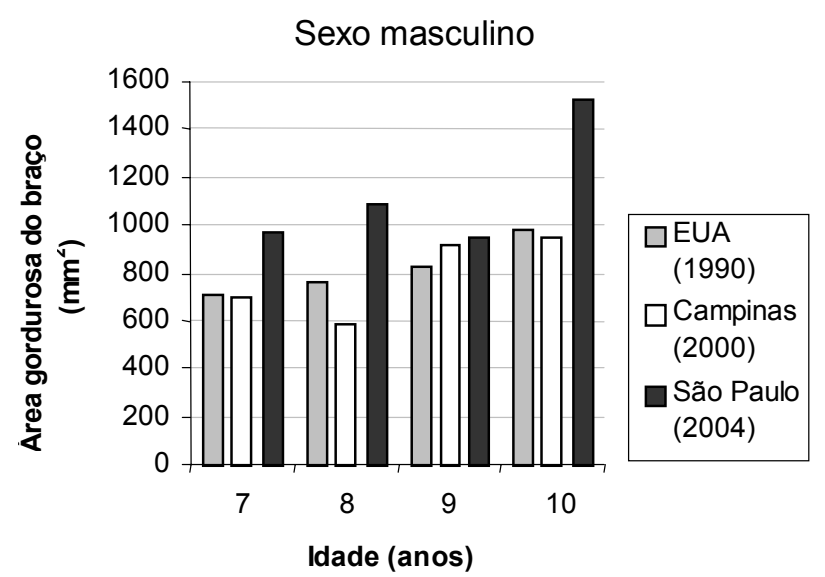

(a)

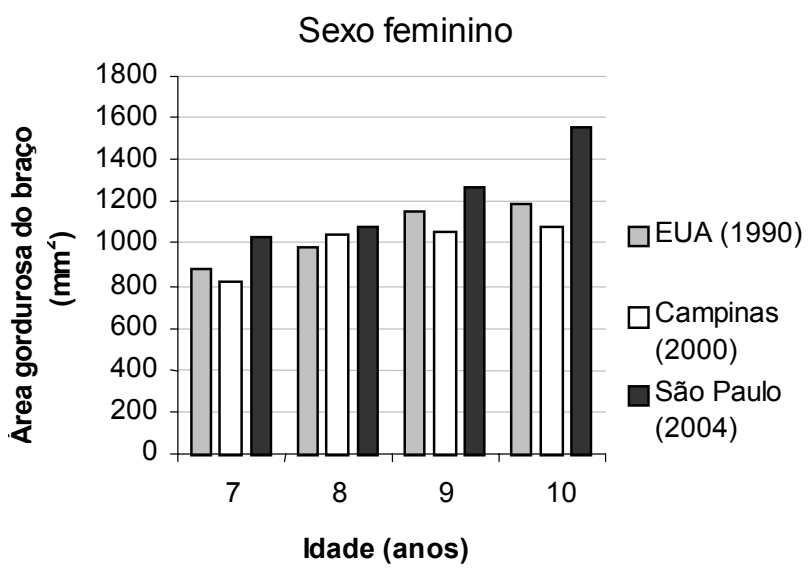

(b)

${ }^{(1)}$ (Cocetti 2001); (2) (Frisancho 1999)

Gráficos A16.12a e A16.12b - Tendência temporal dos valores das medianas da área gordurosa do braço $\left(\mathrm{mm}^{2}\right)$ em relação à idade de escolares de duas escolas públicas de São Paulo em 2004, de escolares de Campinas de baixa renda em $2000^{(1)}$ e de crianças americanas do estudo de Frisancho ${ }^{(2)}$. 
Comparação de valores medianos do percentual de gordura corporal total com valores medianos de outra população de referência.

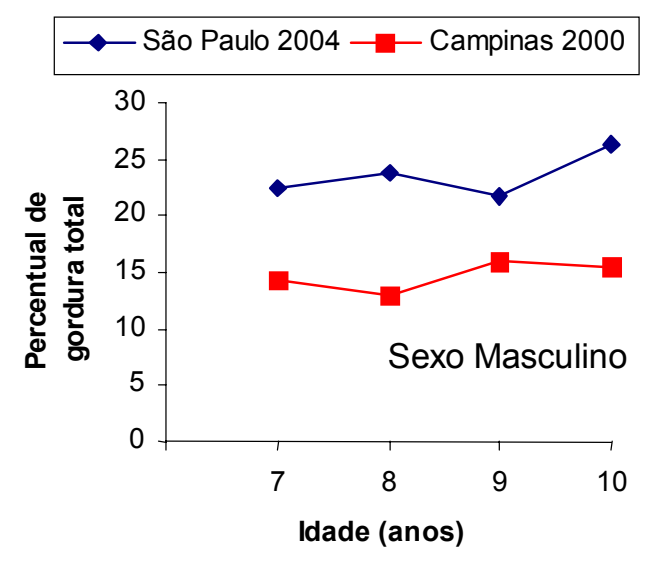

(a)

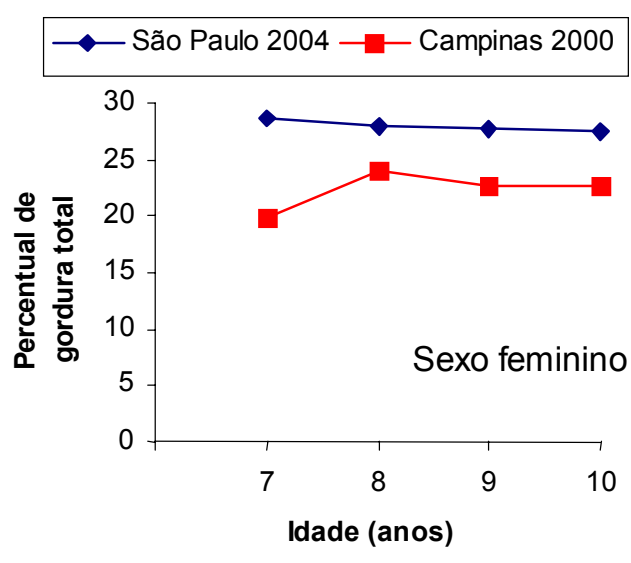

(b)

${ }^{(1)}($ Cocetti 2001)

Gráficos A16.13a e A16.13b - Medianas do percentual de gordura total em relação à idade de escolares de duas escolas públicas de São Paulo em 2004 e de escolares de Campinas de baixa renda em $2000^{(1)}$.

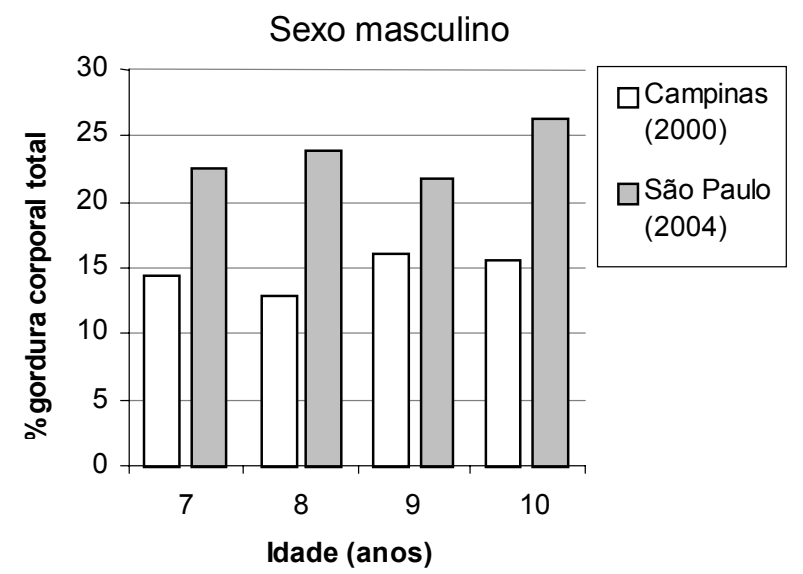

(a)

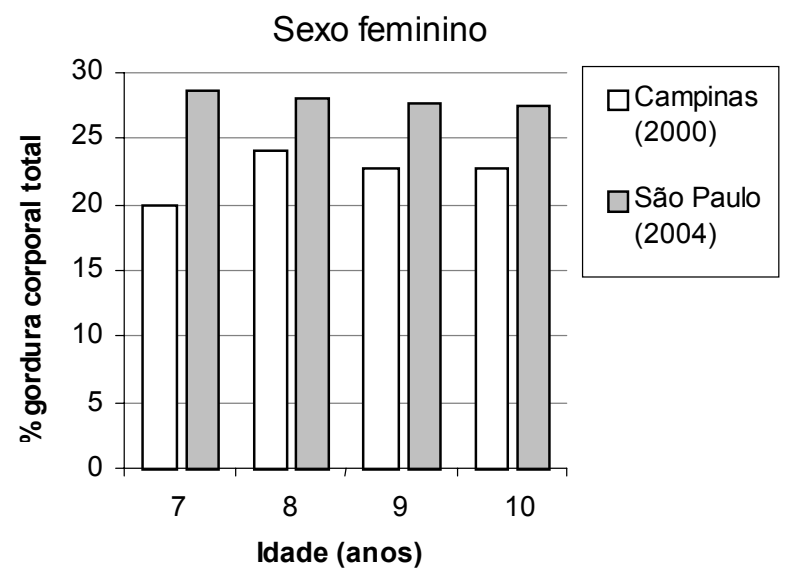

(b)

${ }^{(1)}($ Cocetti 2001)

Gráficos A16.14a e A16.14b - Tendência temporal dos valores das medianas do percentual de gordura corporal total em relação à idade de escolares de duas escolas públicas de São Paulo em 2004 e de escolares de Campinas de baixa renda em $2000^{(1)}$. 